\title{
The chicken embryo as a model for ductus arteriosus developmental developmental biology
}

Citation for published version (APA):

Ågren, P. A. E. (2010). The chicken embryo as a model for ductus arteriosus developmental developmental biology. [Doctoral Thesis, Maastricht University]. Maastricht University. https://doi.org/10.26481/dis.20100325pa

Document status and date:

Published: 01/01/2010

DOI:

10.26481/dis.20100325pa

Document Version:

Publisher's PDF, also known as Version of record

\section{Please check the document version of this publication:}

- A submitted manuscript is the version of the article upon submission and before peer-review. There can be important differences between the submitted version and the official published version of record.

People interested in the research are advised to contact the author for the final version of the publication, or visit the DOI to the publisher's website.

- The final author version and the galley proof are versions of the publication after peer review.

- The final published version features the final layout of the paper including the volume, issue and page numbers.

Link to publication

\footnotetext{
General rights rights.

- You may freely distribute the URL identifying the publication in the public portal. please follow below link for the End User Agreement:

www.umlib.nl/taverne-license

Take down policy

If you believe that this document breaches copyright please contact us at:

repository@maastrichtuniversity.nl

providing details and we will investigate your claim.
}

Copyright and moral rights for the publications made accessible in the public portal are retained by the authors and/or other copyright owners and it is a condition of accessing publications that users recognise and abide by the legal requirements associated with these

- Users may download and print one copy of any publication from the public portal for the purpose of private study or research.

- You may not further distribute the material or use it for any profit-making activity or commercial gain

If the publication is distributed under the terms of Article $25 \mathrm{fa}$ of the Dutch Copyright Act, indicated by the "Taverne" license above, 


\section{THE CHICKEN EMBRYO AS A MODEL FOR DUCTUS ARTERIOSUS DEVELOPMENTAL BIOLOGY}

Pia Anna Elisabet Ågren 
ISBN/EAN: 978-90-9025162-2 


\section{THE CHICKEN EMBRYO AS A MODEL FOR DUCTUS ARTERIOSUS DEVELOPMENTAL BIOLOGY}

\section{PROEFSCHRIFT}

ter verkrijging van de graad van doctor

aan de Universiteit Maastricht, op gezag van de Rector Magnificus, prof. mr. G.P.M.F. Mols,

volgens het besluit van het College van Decanen, in het openbaar te verdedigen op donderdag 25 maart 2010 om 14.00 uur

door

Pia Anna Elisabet Ågren

Geboren op 8 augustus 1979

te Gårdsby, Sweden 


\section{Promotores}

Prof.dr. C.E. Blanco

Prof.dr. L. Zimmermann

\section{Co-promotores}

Dr. E. Villamor

Dr. A.L. Cogolludo-Torralba (Universidad Complutense, Madrid)

\section{Beoordelingscommissie}

Prof.dr. J.G. Nijhuis (voorzitter)

Prof.dr. F. van Bel (Wilhelmina Kinderziekenhuis Utrecht)

Prof.dr. H.A.J. Struijker Boudier

Prof.dr. M. Post

Prof.dr. J. Vazquez-Jimenez (Universitätsklinikum Aachen) 


\section{Table of contents}

Abbreviations

Chapter 1

INTRODUCTION

Chapter 2

ONTOGENY OF CHICKEN DUCTUS ARTERIOSUS RESPONSE TO OXYGEN AND VASOCONSTRICTORS

Chapter 3

DEVELOPMENTAL CHANGES IN ENDOTHELIUM-DEPENDENT

RELAXATION OF THE CHICKEN DUCTUS ARTERIOSUS

\section{Chapter 4}

DEVELOPMENTAL CHANGES IN THE EFFECTS OF

PROSTAGLANDIN E $E_{2}$ IN THE CHICKEN DUCTUS ARTERIOSUS

\section{Chapter 5}

RESPONSE OF CHICKEN DUCTUS ARTERIOSUS TO HYPERCARBIC AND NORMOCARBIC ACIDOSIS

\section{Chapter 6}

MORPHOLOGICAL AND FUNCTIONAL ALTERATIONS OF THE DUCTUS ARTERIOSUS IN A CHICKEN MODEL OF HYPOXIA-INDUCED FETAL GROWTH RETARDATION

\section{Chapter 7}

DISCUSSION

\section{Chapter 8}

SAMENVATTING

SUMMARY

ACKNOWLEDGEMENTS 


\section{Abbreviations}

4-AP, 4-aminopyridine

AA, arachidonic acid

$\mathrm{AC}$, adenylate cyclase

ACh, acetylcholine

ATP, adenosine-5'-triphosphate

BK, bradykinin

$\mathrm{BK}_{\mathrm{Ca}}$, large conductance $\mathrm{Ca}^{2+}$ activated $\mathrm{K}^{+}$channel

$\mathrm{Ca}^{2+}$, calcium

$\left[\mathrm{Ca}^{2+}\right]_{\mathrm{i}}$, intracellular $\mathrm{Ca}^{2+}$ concentration

CaM, calmodulin

CAM, chorioallatoic membrane

cAMP, cyclic adenosine-3', 5'-monophosphate

cGMP, cyclic guanosine-3', 5'-monophosphate

ChTx, charybdotoxin

$\mathrm{CO}$, carbon monoxide

$\mathrm{CO}_{2}$, carbon dioxide

COX, cyclooxygenase, two forms COX-1 and COX-2

DA, ductus arteriosus

DAF-2DA, 4,5-diaminoflourescein diacetate

DAF-2T, DAF-2 triazole (flouresecent product used to detect NO)

DAG, diacylglycerol

DASMC, ductus arteriosus smooth muscle cell

DMSO, dimethyl sulfoxide

DNTB, dithionitrobenzoic acid (oxidizing agent)

DTT, ditiotreitol (reducing agent)

ECE, endothelin-converting enzyme

EDHF, endothelium-derived hyperpolarizing factor

EDRF, endothelium derived relaxant factors

eNOS, endothelial nitric oxide synthase

$\mathrm{E}_{\max }$, calculated maximal response

ET-1, endothelin-1

$\mathrm{ET}_{\mathrm{A}}$, endothelin receptor type $\mathrm{A}$

$\mathrm{ET}_{\mathrm{B}}$, endothelin receptor type $\mathrm{B}$ 
ETC, electron transport chain

$\mathrm{G}_{\mathrm{i}}$, inhibitory $\mathrm{G}$ protein that inhibits cAMP production

$\mathrm{G}_{\mathrm{q}}, \mathrm{G}$ protein that enhance intracellular $\mathrm{Ca}^{2+}$ levels

$\mathrm{G}_{\mathrm{s}}$, stimulatory $\mathrm{G}$ protein that stimulates cAMP production

$\mathrm{H}_{2} \mathrm{O}_{2}$, hydrogen peroxide

$\mathrm{HO}$, Heme oxygenase, two forms HO-1 and HO-2

$\mathrm{I}_{\mathrm{K}}, \mathrm{K}^{+}$current

$\mathrm{IK}_{\mathrm{Ca}}$, intermediate conductance $\mathrm{Ca}^{2+}$ activated $\mathrm{K}^{+}$channel

iNOS, inducible nitric oxide synthase

$\mathrm{IP}_{3}$, inositol 1,4,5-triphosphate

IUGR, intrauterine growth restriction

$\mathrm{K}^{+}$, potassium

$\mathrm{K}_{\mathrm{ATP}}$, ATP sensitive $\mathrm{K}^{+}$channels

$\mathrm{K}_{\mathrm{Ca}}, \mathrm{Ca}^{2+}$-activated $\mathrm{K}^{+}$channels

KRB, Krebs-Ringer bicarbonate

$\mathrm{K}_{\mathrm{V}}$, voltage gated $\mathrm{K}^{+}$channels

L-NAME, $\mathrm{N}^{\omega}$-Nitro-L-arginine methyl ester (NOS inhibitor)

$\mathrm{M}$, muscarinic receptor

MAT, maximal active tension

MLC, myosin light chain

MLCK, myosin light chain kinase

MLCP, myosin light chain phosphatase

$\mathrm{N}_{2}$, nitrogen

$\mathrm{NADPH}$, reduced form of nicotinamide adenine dinucleotide phosphate

NE, norepinephrine

nNOS, neuronal nitric oxide synthase

$\mathrm{NO}$, nitric oxide

NOS, nitric oxide synthase

$\mathrm{O}_{2}$, oxygen

ODQ, 1H-[1,2,4]oxidiazolo[4,3a]quinoxalin-1-one (sGC inhibitor)

PA, pulmonary artery

$\mathrm{PaCO}_{2}$, partial pressure of $\mathrm{CO}_{2}$ in blood

$\mathrm{PCO}_{2}$, partial pressure of $\mathrm{CO}_{2}$

$\mathrm{pD}_{2}$, sensitivity 
PDA, patent ductus arteriosus

PDE, phosphodiesterase

PG, prostaglandin

$\mathrm{PGI}_{2}$, prostacyclin

Phe, phenylephrine

$\mathrm{PIP}_{2}$, phosphatidylinositol 4,5- biphosphate

PKA, protein kinase A, a cAMP-dependent protein kinase

$\mathrm{PKC}$, protein kinase $\mathrm{C}$

PKG, protein kinase G, a cGMP-dependent protein kinase

PLC, phospholipase C

$\mathrm{PO}_{2}$, partial oxygen pressure

ROCK-1, Rho-associated coiled-coil containing protein kinase 1

ROK, Rho kinase

ROS, reactive oxygen species

$\mathrm{SD}$, standard deviation

SE, standard error

SEM, standard error of mean

SERCA, sarco-endoplasmatic reticulum $\mathrm{Ca}^{2+}$-ATPase

sGC, soluble guanylate cyclase

$\mathrm{SK}_{\mathrm{Ca}}$, small conductance $\mathrm{Ca}^{2+}$ activated $\mathrm{K}^{+}$channel

$\mathrm{SM}$, smooth muscle

SMC, smooth muscle cells

SNP, sodium nitroprusside

SOC, store operated $\mathrm{Ca}^{2+}$ channels

TEA, tetraethylammonium

$\mathrm{TP}$, thromboxane receptor

Txs, thromboxanes

VEGF, vascular endothelium growth factor

VSM, vascular smooth muscle 


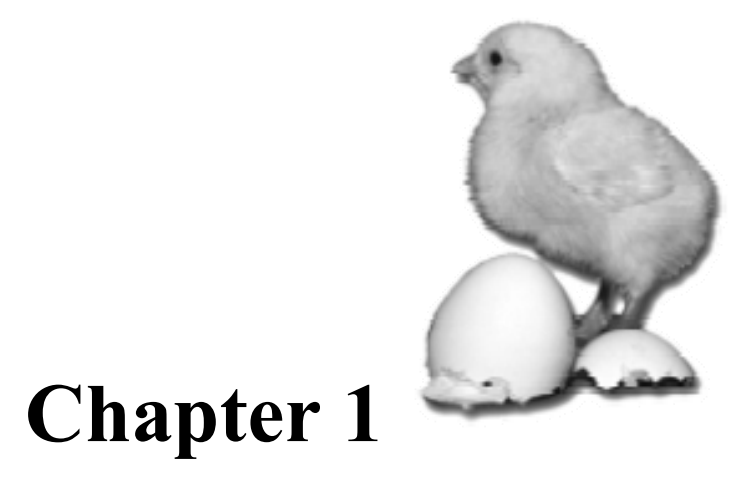

INTRODUCTION 


\section{General introduction}

\section{Foetal circulation and transition to extrauterine life}

The foetus is an aquatic organism, obtaining oxygen $\left(\mathrm{O}_{2}\right)$ and nutrients from the placenta, whereas the newborn and adult is terrestrial, obtaining $\mathrm{O}_{2}$ through the lungs (Bergwerff et al. 1999). To accommodate the different site of $\mathrm{O}_{2}$ uptake, the foetal circulation is unique in several ways (Teitel and Cassidy 2001; Blackburn 2003): shunts are present in the venous system (ductus venosus), in the heart (foramen ovale) and in the arterial system (ductus arteriosus, DA). The presence of these foetal shunts allows the circulation to be reasonably effective at distributing $\mathrm{O}_{2}$ and nutrients (Teitel and Cassidy 2001). However, the presence of these shunts also allows for mixing of oxygenated and deoxygenated blood. During fetal life the pulmonary circuit exists as a high-resistance-low flow system while the systemic circuit has lowresistance, due to presence of the placenta (Teitel and Cassidy 2001; Blackburn 2003).

As the blood returns from the placenta via the umbilical vein, it passes either into the portal system of the liver or is shunted past the liver via the ductus venosus. In the human fetus the amount of blood passing through the ductus venosus is $30 \%$ at mid gestation and reduced to $20 \%$ after 30 weeks of gestation (Kiserud 2005). The ductus venosus is connected with the inferior vena cava above the liver, where the highly oxygenated blood from the umbilical vein joins the blood returning from the lower part of the body. The blood returning from the umbilical vein has a higher kinetic energy and stays in a stream separated along the left dorsal wall of the inferior vena cava (Blackburn 2003). Around 50-60\% of this highly oxygenated blood is then shunted through the foramen ovale to the left atrium, where it is mixed with the minimal blood flow returning from the lungs, and it continues into the left ventricle (Blackburn 2003). Upon contraction of the heart, this blood is ejected into the ascending aorta to feed the heart and brain (Figure 1).

The blood returning from the lower part of the body in the inferior vena cava is mixed with blood returning from the upper body via the superior vena cava in the right atrium (Teitel and Cassidy 2001; Blackburn 2003). This blood flow is directed downward across the tricuspid valve and into the right ventricle. Upon contraction it is ejected into the pulmonary artery (PA), where the high pulmonary vascular resistance prevents more than $10-12 \%$ to enter the pulmonary bed and the majority of this blood is shunted across the DA into the descending aorta (Blackburn 2003). 


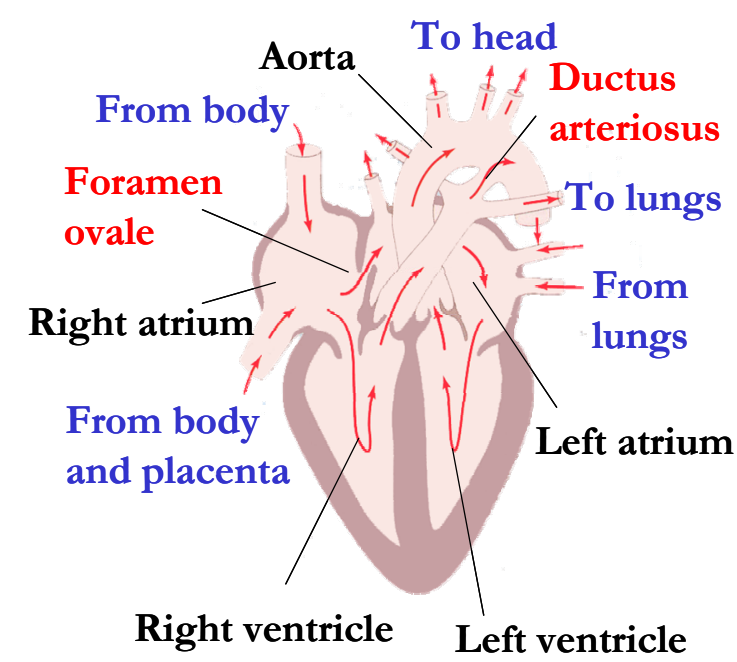

Figure 1. Blood flow through human fetal heart. Specific fetal fetures are the foramen ovale and the ductus arteriosus, which accommodates the different oxygen uptake site of the fetus.

The changeover from foetal to neonatal circulation is directly linked with the development and function of the pulmonary vasculature and changes in pulmonary vascular resistance (Reynolds 1953; Smith 1998; Teitel and Cassidy 2001; Herrera et al. 2004; Thebaud et al. 2004). At delivery, the low-resistance placental circulation is removed, leading to an increase in systemic vascular resistance. The initiation of air breathing leads to the expansion of the lungs, an increase in alveolar $\mathrm{O}_{2}$ concentration, and vasodilation of the pulmonary bed (Teitel and Cassidy 2001). As vasodilatation occurs, pulmonary vascular resistance falls rapidly, by almost $80 \%$, resulting in a dramatic increase in pulmonary blood flow (Teitel and Cassidy 2001). The decrease in inferior vena cava return, due to the cessation of umbilical blood flow, leads to a functional closure of the ductus venosus within minutes after birth, and together with the increased blood return from the lungs, augments pressure in the heart leading to foramen ovale closure (Reynolds 1953; Teitel and Cassidy 2001). At birth, the simultaneous pulmonary vasodilatation and loss of the low-tension umbilico-placental circulation increases the pressure in the systemic circuit, while there is a decrease in the pulmonary circuit, leading to a reversed blood flow over the DA (Smith 1998). Thereby, the DA is exposed to arterial blood, with high $\mathrm{O}_{2}$ tension (Smith 1998). Closure of the normal DA is believed to occur in two steps: (1) a functional closure due to constriction of the medial muscle layer that usually occurs within the first hours after birth and (2) an anatomic closure that involves infolding of the 
endothelium and disruption of the subintimal layers, which is usually completed by the second week of life (Clyman et al. 1983).

\section{Clinical relevance of the DA}

\subsection{Patency of the DA in the premature infant}

In contrast with the full term DA, the premature DA is less likely to constrict after birth. Therefore, preterm neonates, and more particularly those with gestational age $<30 \mathrm{wk}$, and birth weight $<1500 \mathrm{~g}$, are at increased risk of having a persistent patent (P) DA beyond 96 hours postnatally and absence of remodelling (Clyman 2006; Koch et al. 2006). This may result in a left-to-right shunt and hyperperfusion of the pulmonary vascular bed, often resulting in decreased lung compliance, increased need for mechanical ventilation, and altered postnatal nutrition and growth. Thus, a PDA may adversely affect morbidity and mortality in an already high-risk population (Bancalari et al. 2005; Clyman 2006; Koch et al. 2006). In preterm infants, PDA induces a higher risk of adverse outcomes such as chronic lung disease (Rojas et al. 1995), pulmonary hemorrhage (Kluckow et al. 1999), renal hypoperfusion (Hammerman 1995) and decreased glomerular filtration rate, necrotizing enterocolitis (Cotton et al. 1978), and if not managed, may lead to death (Cotton et al. 1978).

The incidence of PDA is inversely related to gestational age, such that it affects up to $60 \%$ of infants less than 28 weeks gestation (Gersony et al. 1983; Van Overmeire and Chemtob 2005). The ineffective ductal closure in preterm infants is partially explained by decreased sensitivity to $\mathrm{O}_{2}$, diminished responsiveness to prostaglandin (PG) withdrawal at birth, increased levels of PGs, nitric oxide (NO) and other vasodilatory stimuli, and immaturity of the structural apparatus necessary for the constriction and obliteration of the ductus lumen (Hammerman 1995; Smith 1998; Kajino et al. 2000; Kajino et al. 2001; Van Overmeire and Chemtob 2005; Reese 2006). The premature DA has a much smaller intrinsic tone, and together with the increased sensitivity to vasodilators, it might not be able to remain constricted during the remodelling process, which might explain why extremely premature infants have a high rate of reopening (Kajino et al. 2001).

The increased number of surviving preterm infants has led to a higher number of infants requiring medical or surgical intervention for PDA. Standard therapies include fluid restriction and use of cyclooxygenase (COX) inhibitors such as indomethacin or ibuprofen (Van Overmeire and Chemtob 2005; Malviya et al. 2008). 
Surgical ligation is used when medical treatment fails or is contraindicated (Mosalli and Alfaleh 2008). There is no consensus as to what is the best time of treatment and the optimal management strategy among this high-risk vulnerable population (Mosalli and Alfaleh 2008). In addition, there has been considerable debate about the benefits and risks of surgical ligation for PDA on subsequent neurodevelopmental outcome. Surgery in the neonatal period is associated with a systemic inflammatory response; in addition the use of sedative and/or anaesthetic drugs may adversely impact the immature brain (Doyle 2001).

\subsection{Persistent DA in term infants}

In contrast to premature infants, in whom PDA generally is due to developmental immaturity, patent ductus in term infants likely results from a significant structural abnormality. Persistence of the DA has been defined as continued patency in term newborns older than 3 months (Benson and Cowan 2002). There are several reasons for a persistent ductus: 1) Failure of the normal constriction due to structural or biochemical abnormalities. 2) Alternatively, the contractile apparatus might be completely normal, but the stimulus, $\mathrm{O}_{2}$, may be lacking or ineffective. 3) Relaxant mediators could also prevent closure. In the majority of cases, no clear cause is identifiable, and both genetic and environmental factors may be involved (Benson and Cowan 2002).

\subsection{Congenital heart diseases}

There are several congenital heart diseases that, as a consequence of the defect, require a patent ductus for survival. The role of the ductus can either be to maintain adequate pulmonary blood flow, to maintain adequate systemic flow or to improve mixing of systemic and pulmonary circulations (Knight 2001). The behaviour of the ductus in the immediate postnatal period may be crucial if the heart is congenitally malformed. When either the pulmonary or the systemic circulation is entirely supplied through the ductus, survival itself depends on the behaviour of the DA. The DA that closes despite an obligatory need to remain patent has been named "the suicidal duct" (Benson and Cowan 2002). If the DA is necessary for pulmonary blood flow, the patients never experience the normal postnatal rise in blood oxygenation. Closure of the DA usually occurs, however it is frequently delayed, but without medical and/or surgical intervention, this can only lead to death (Benson and Cowan 2002). On the 
other hand, if the DA is necessary for systemic blood flow, heart failure predominates, which become rapidly more severe as the DA close.

\subsection{Premature in utero closure}

Contraction of the DA, with or without fetal heart failure, is a recognized side effect of administration of COX inhibitors to the mother. This can lead to serious fetal and neonatal complications including pulmonary hypertension, necrotizing enterocolitis and intraventricular hemorrhage. Constriction of the DA causes an ischemic insult of the vessel wall, making the vessel less responsive to $\mathrm{PGE}_{2}, \mathrm{O}_{2}$ and indomethacin (Clyman et al. 1983). Thus a DA that has closed once but reopened again, is more reluctant to close again. Exposure to indomethacin increases the thickness of the avascular zone (i.e., the zone without vasa vasorum), associated with a decline in distensability and maximal contractile capability due to smooth muscle cells (SMC) loss and migration (Clyman et al. 2001). The excessive avascular zone thickness causes a decrease in intravavascular blood flow, leading to hypoxia of the vessel wall, which in turn makes the DA less responsive to $\mathrm{O}_{2}$ and remaining patent after birth (Goldbarg et al. 2002).

\section{The mammalian DA}

Significant progress in our understanding of the DA physiology and pathophysiology has been achieved with the use of animal models, including the sheep, the rabbit, the mouse, the rat or primates (Sutendra and Michelakis 2007). In this section of the chapter, the embryology and the process of patency and closure of the mammalian DA are analyzed. In section III, the vasoactive mediators and signalling pathways involved in DA patency and closure are reviewed.

\section{Embryology}

During early fetal development, six arterial arches link the aortic sac with the paired dorsal aortas, although all six arches are never present simultaneously (Benson and Cowan 2002). In humans, the DA develops from the dorsal portion of the left sixth arch. The sixth arch is associated early on with the developing lung buds, which initially are supplied by a plexus of capillaries that develops from the arterial sac and later connects to the dorsal aorta. 
In normal cardiovascular development, the proximal portion of the sixth pair of embryonic aortic arches persists as the proximal branch PAs, and the distal portion of the left sixth arch persists as the DA, connecting the left PA with the left dorsal aorta (Schneider and Moore 2006). Normally, the distal right sixth aortic arch loses its connection to the dorsal aorta and degenerates. In humans this transformation is complete by 8 weeks of fetal life (Schneider and Moore 2006).

\section{Foetal patency}

\subsection{Foetal patency of the $D A$}

Ductal patency in utero is an active state, dependent on the balance between dilating and constricting forces. The ductus normally has a high level of intrinsic tone during foetal life (Kajino et al. 2001), but the factors that promote ductus constriction in the foetus have yet to be identified (Clyman 2006). The factors that oppose ductus constriction are better understood. The elevated vascular pressure within the ductus lumen, due to the constricted pulmonary bed, plays an important role in opposing ductus constriction (Clyman et al. 1989). Circulating and locally produced PGs as well as NO appear to be the major factors (Coceani et al. 1994 (lamb); Smith 1998; Takizawa et al. 1999 (rat); Kajino et al. 2000; Seidner et al. 2001 (baboon)). Several studies have shown developmental changes in the roles of PG and NO in different mammalian species (see section III: 3.2 and 5).

\section{Closure of the DA}

\subsection{Functional closure}

Closure of the DA occurs in two steps, functional closure, due to vasoconstriction, which precedes anatomical closure, due to remodelling. This closure occurs within days and is crucial for the neonatal transition to an air-breathing organism (Smith 1998). In full-term newborn humans, the DA closes $24-48 \mathrm{~h}$ after delivery. The simultaneous change in pulmonary vascular resistance and the loss of the placental blood flow at birth, leads to a reversed blood flow over the DA (Smith 1998). After birth, the DA is exposed to arterial blood, $\mathrm{O}_{2}$ tension rises rapidly, which leads to constriction (Smith 1998).

At birth, the major source of $\mathrm{PGE}_{2}$, the placenta, is lost, and the increased blood flow in the lungs reduces the amount of free circulating $\mathrm{PGE}_{2}$, since the lung is the most important site for breakdown of PGs (Bouayad et al. 2001). During the first 
hour after birth the amount of $\mathrm{PGE}_{2}$ decreases by around tenfold and within the first three hours it is reduced by around twenty fold in foetal lambs (Clyman et al. 1980). This loss of free circulating $\mathrm{PGE}_{2}$ has been postulated to be fundamental to the closure of the DA.

\subsection{Anatomical closure}

The lumen is first occluded in the narrowest part, that is, in the proximal (pulmonary) part of the DA, between opposed intimal cushions (Silver et al. 1981). Necrosis of the inner DA wall, due to anoxia, is the first definitive morphological evidence of sustained muscular contraction to appear (Silver et al. 1981). Based on studies in baboons it was shown that regions of the DA where the lumen was most constricted were associated with moderate/intense hypoxia; vascular endothelium growth factor (VEGF) expression was increased in the hypoxic muscle media; and luminal endothelial cells were proliferating (Clyman et al. 1999a). Cells in the most hypoxic regions of the DA wall were undergoing DNA fragmentation.

The immature foetus has an increased glycolytic capacity, which may enable it to tolerate episodes of hypoxia and nutrient shortage, thus making it more resistant to postnatal cell death and permanent closure (Levin et al. 2005). In premature baboon DA no evidence of moderate/intense hypoxia, no cell death, or VEGF expression was found, events that all occurred in the term foetus (Clyman et al. 1999a). The preterm DA must completely obliterate luminal blood flow to develop the same degree of hypoxia as the term DA (Levin et al. 2006) and the preterm is capable of undergoing anatomic remodelling if it can produce the same degree of intense hypoxia that is observed at term (Seidner et al. 2001).

Waleh et al (2005) explain that the inflammatory response following postnatal DA constriction may be necessary for ductus remodelling. Monocytes/ macrophages and, to a lesser extent, T-lymphocytes adhere to the DA lumen after postnatal constriction in baboon. The same inflammatory and remodelling changes are seen whether or not the DA close spontaneously, close following PG inhibition, or close after combined PG and NO inhibition. These changes are seen only in areas of the DA that are tightly constricted (Waleh et al. 2005). 
Table 1. Summary of the literature concerning closure and remodelling of the ductus

arteriosus.

\begin{tabular}{|c|c|c|c|}
\hline Reference & Species/ Age & Experiments/Results & Comments \\
\hline $\begin{array}{l}\text { (Eldridge et } \\
\text { al. 1954) }\end{array}$ & $\begin{array}{l}\text { Human/ } \\
\text { Neonates } 1-118 \mathrm{~h}\end{array}$ & $\begin{array}{l}\text { Blood oxygenation from the right foot and hand were compared, and up to } \\
72 \text { hours after birth, the saturation was significantly lower in the foot, } \\
\text { indicating the presence of a veno-arterial shunt through the open DA. }\end{array}$ & \\
\hline $\begin{array}{l}\text { (Silver et } \\
\text { al. 1981) }\end{array}$ & Human & $\begin{array}{l}\text { An elastic network in the media of the SM was observed. Maturation of the } \\
\text { contractile apparatus was also evident. Closure begins in the pulmonary half, } \\
\text { between closely opposed intimal cushions. The vessel is probably too large } \\
\text { to be closed merely by the contraction of circularly arranged muscles. } \\
\text { Longitudinal muscles are present to shorten the DA. Necrosis of the inner } \\
\text { DA wall, due to anoxia, is the first definite morphological evidence of } \\
\text { sustained muscular contraction to appear, while central ischemic } \\
\text { degeneration or necrosis is a result of strong sustained DA contraction. }\end{array}$ & $\begin{array}{l}\text { The lumen is firstly } \\
\text { occluded in the } \\
\text { narrowest part, that is, in } \\
\text { the proximal } \\
\text { (pulmonary) part of the } \\
\text { DA, between opposed } \\
\text { intimal cushions. }\end{array}$ \\
\hline $\begin{array}{l}\text { (Tomita et } \\
\text { al. 1996) }\end{array}$ & $\begin{array}{l}\text { Human/ (1-66 } \\
\text { mo) }\end{array}$ & $\begin{array}{l}\text { The vascular (V) SM of the PDA remains capable of constriction beyond } \\
\text { infancy, at least at the pulmonary end. In some cases of PDA, } \\
\text { catecholamines induce late closure. }\end{array}$ & \\
\hline $\begin{array}{l}\text { (Clyman et } \\
\text { al. 1999a) }\end{array}$ & $\begin{array}{l}\text { Baboon/ } 125 \text { and } \\
175 \mathrm{~d}(\mathrm{t} 185 \mathrm{~d})\end{array}$ & $\begin{array}{l}\text { In full term, the DA was functionally closed on Doppler examination by } 24 \mathrm{~h} \text {. } \\
\text { Constriction was associated with moderate/intense hypoxia, increased VEGF } \\
\text { and proliferating luminal endothelial cells. In the most hypoxic regions DNA } \\
\text { fragmentation occurred. In contrast, in the premature, only } 29 \% \text { had closed } \\
\text { their DA before } 6 \mathrm{~d} \text {. None had evidence of moderate/intense hypoxia; no cell } \\
\text { death, VEGF expression, endothelial proliferation nor neoimtima formation } \\
\text { was found by day } 6 \text {. }\end{array}$ & $\begin{array}{l}\text { DA constriction is } \\
\text { associated with hypoxia, } \\
\text { cell death, VEGF } \\
\text { expression etc, but not } \\
\text { in the premature. }\end{array}$ \\
\hline $\begin{array}{l}\text { (Clyman et } \\
\text { al. 2001) }\end{array}$ & Lamb/ 127-131d & $\begin{array}{l}\text { Infusion of indomethacin in utero increased VEGF and endothelial NO } \\
\text { synthase (eNOS) expression, neoimtima formation, and muscle media cell } \\
\text { death. Inhibition of NO production produces significantly greater contraction } \\
\text { in the moderately constricted DA than in the control. A marked degree of } \\
\text { DA constriction in utero, increases the avascular zone thickness due to tissue } \\
\text { compaction (caused by circumferential and longitudinal muscle constriction), } \\
\text { associated with SMC loss and migration into the neointima, leading to a } \\
\text { significant decline in distensability and maximal contractile capability. }\end{array}$ & $\begin{array}{l}\text { Exposure to indo- } \\
\text { methacin in utero } \\
\text { increases avascular zone } \\
\text { thickness, associated } \\
\text { with a decline in } \\
\text { distensability and } \\
\text { maximal contractile } \\
\text { capability, due to SMC } \\
\text { loss and migration. } \\
\end{array}$ \\
\hline $\begin{array}{l}\text { (Seidner et } \\
\text { al. 2001) }\end{array}$ & $\begin{array}{l}\text { Baboon/ } 125 \text { and } \\
\text { term } 185 \mathrm{~d}\end{array}$ & $\begin{array}{l}\text { Combined NOS and COX inhibition produced much greater degree of } \\
\text { constriction in vivo than indomethacin alone. The effects of indomethacin } \\
\text { wanes with increasing postnatal age. After delivery eNOS-expressing vasa } \\
\text { vasorum invade the outer media, which does not express COX-1 or -2. Thus } \\
\text { NOS inhibition could become useful. The preterm DA is capable of } \\
\text { undergoing anatomic remodeling if it can produce the same degree of intense } \\
\text { hypoxia that is observed at term. }\end{array}$ & $\begin{array}{l}\text { The preterm DA is } \\
\text { capable of undergoing } \\
\text { anatomic remodeling if } \\
\text { it can produce the same } \\
\text { degree of intense } \\
\text { hypoxia that is observed } \\
\text { at term. }\end{array}$ \\
\hline $\begin{array}{l}\text { (Clyman et } \\
\text { al. 2002) }\end{array}$ & Baboon/ 125d & $\begin{array}{l}\text { Indomethacin and L-NNA (NOS inhibitor) produce constriction of the } \\
\text { preterm DA and VEGF expression, which corresponds exactly with the } \\
\text { distribution and intensity of hypoxia. VEGF may play an essential role in } \\
\text { vasa vasorum ingrowth and SM expansion of the neointima. }\end{array}$ & $\begin{array}{l}\text { VEGF is an important } \\
\text { mediator of the } \\
\text { anatomic remodeling. }\end{array}$ \\
\hline $\begin{array}{l}\text { (Goldbarg } \\
\text { et al. 2002) }\end{array}$ & Lamb/ 131-135d & $\begin{array}{l}\text { Exposure to indomethacin produced nuclear fragmentation and cell death in } \\
\text { SMCs, directly related to the degree of DA constriction, and it occurs even at } \\
\text { moderate degrees of constriction. It decreases vasa vasorum blood flow and } \\
\text { increases wall thickness, thereby increasing the avascular zone thickness. } \\
\text { These changes in cell viability lead to a significant decline in distensibility } \\
\text { and contractile capacity, which explain why after indomethacin exposure in } \\
\text { utero the DA remains patent and refuse to close. }\end{array}$ & $\begin{array}{l}\text { Exposure of } \\
\text { indomethacin in utero, } \\
\text { decrease responsiveness } \\
\text { to, among others, } \mathrm{O}_{2} \text { and } \\
\text { the DA remains patent } \\
\text { after birth. }\end{array}$ \\
\hline $\begin{array}{l}\text { (Levin et } \\
\text { al. 2005) }\end{array}$ & $\begin{array}{l}\text { Lamb/ 101-107 } \\
\text { and 138-144d }\end{array}$ & $\begin{array}{l}\text { After birth the DA develops adenosine triphosphate (ATP), glucose and } \\
\text { glycogen depletion in addition to hypoxia. Cell death correlates best with } \\
\text { ATP depletion and is most marked when both glucose and } \mathrm{O}_{2} \text { are severely } \\
\text { depleted. Under hypoxic conditions, the immature DA is more capable of } \\
\text { preserving its ATP supply as a result of increased glucose availability, } \\
\text { glycogen stores and glucose utilization. The increased glycolytic capacity of } \\
\text { the immature DA may enable it to tolerate episodes of hypoxia and nutrient } \\
\text { shortage, making it more resistant to developing postnatal cell death and } \\
\text { permanent closure. }\end{array}$ & $\begin{array}{l}\text { The immature fetus can } \\
\text { tolerate episodes of } \\
\text { hypoxia and nutrient } \\
\text { shortage due to the } \\
\text { increased glycolytic } \\
\text { capacity, making it more } \\
\text { resistant to permanent } \\
\text { closure. }\end{array}$ \\
\hline $\begin{array}{l}\text { (Waleh et } \\
\text { al. 2005) }\end{array}$ & \begin{tabular}{|l|} 
Baboon/ 125 and \\
$175 \mathrm{~d}$ \\
\end{tabular} & $\begin{array}{l}\text { Similarities in gene expression between artherosclerotic- and DA - } \\
\text { remodeling were found. Monocytes/macrophages and, to a lesser extent, T- } \\
\text { lymphocytes adhere to the lumen. The same inflammatory and remodelling } \\
\text { changes are seen whether or not the DA close spontaneously, close following } \\
\text { PG inhibition or close after combined PG and NO inhibition. These changes } \\
\text { are seen only in areas of the DA that are tightly constricted. }\end{array}$ & $\begin{array}{l}\text { The inflammatory } \\
\text { response following } \\
\text { postnatal DA } \\
\text { constriction may be } \\
\text { necessary for ductus } \\
\text { remodeling. }\end{array}$ \\
\hline $\begin{array}{l}\text { (Levin et } \\
\text { al. 2006) }\end{array}$ & \begin{tabular}{|l|} 
Baboon/ 123-127 \\
and $175 \mathrm{~d}$
\end{tabular} & $\begin{array}{l}\mathrm{O}_{2} \text {, glucose, glycogene and ATP depletion, and subsequent cell death in the } \\
\text { muscle media occur even before complete loss of luminal blood flow in full } \\
\text { term, while constriction of the preterm DA in vivo is associated with } \mathrm{O}_{2}, \\
\text { glucose and ATP depletion. The preterm DA must completely obliterate } \\
\text { luminal flow to develop the same degree of hypoxia, glucose depletion and } \\
\text { cell death as found in the full-term DA. }\end{array}$ & $\begin{array}{l}\text { The preterm DA must } \\
\text { completely obliterate } \\
\text { luminal blood flow to } \\
\text { develop the same degree } \\
\text { of hypoxia as the term } \\
\text { DA. }\end{array}$ \\
\hline
\end{tabular}




\subsection{Vasa vasorum and DA closure}

The presence of vasa vasorum in the muscle media depends on the thickness of the arterial wall (Clyman et al. 2001). If the vessel is thicker than $0.5 \mathrm{~mm}$, the maximal diffusion distance, there is a need for a vasa vasorum to provide the muscle media with $\mathrm{O}_{2}$ and nutrients (Kajino et al. 2002). The muscle media of most vessels has a region, adjacent to the lumen, which lacks vasa vasorum (Wolinsky and Glagov 1967; Goldbarg et al. 2002). This avascular zone depends on diffusion from both the lumen and vasa vasorum to meet its $\mathrm{O}_{2}$ needs and is therefore particularly vulnerable to changes in $\mathrm{O}_{2}$ supply (Clyman et al. 1999a).

In the human foetus, before week 28 , luminal blood flow is sufficient to meet the $\mathrm{O}_{2}$ demands of the thin-walled ductus, while after the $28^{\text {th }}$ week of gestation, vasa vasorum usually enter the ductus wall (Clarke 1965; Goldbarg et al. 2002). The vasa vasorum provide the DA with a unique mechanism for controlling the maximal diffusion distance across its wall. By elimination of vasa vasorum blood flow to the outer muscle media, in the newborn DA, the entire thickness of the muscle media turns into an avascular zone, creating a diffusion distance that is approximately 3 times the maximally tolerated diffusion distance (Kajino et al. 2002; Levin et al. 2005). As a result, profound hypoxia $(<0.2 \%)$ develops even before luminal blood flow is eliminated (Jurrus and Weiss 1977; Clyman et al. 1999a; Kajino et al. 2000; Goldbarg et al. 2002; Kajino et al. 2002). In contrast, the extremely preterm DA has no vasa vasorum, and with a reduction of luminal flow to the same degree as that found at term, the preterm DA wall thickness is only reduced to $0.67 \mathrm{~mm}$ (Clyman et al. 1999a). This diffusion distance is insufficient to produce the profound degree of hypoxia needed for vessel remodelling and only mild to moderate hypoxia (2.0 - 0.7\% tissue $\mathrm{O}_{2}$ concentration) after postnatal constriction in vivo is developed (Clyman et al. 1999a; Kajino et al. 2000). Without a drop in tissue $\mathrm{O}_{2}$ concentration to $<0.4 \%$, ductus remodelling does not occur. The mild to moderate degrees of hypoxia in the preterm do not inhibit PG and NO production, whereas they do lead to loss of $\mathrm{O}_{2}$ induced tension (Clyman et al. 1999a; Kajino et al. 2000). In the full-term newborn DA, severe $\mathrm{O}_{2}$, glucose, glycogen and ATP depletion, cell death and tissue remodelling occur even before there is complete loss of luminal blood flow. The preterm ductus has to completely obstruct luminal blood flow before it develops the 
same degree of in vivo hypoxia, glucose depletion, and cell death as found in the fullterm newborn ductus (Levin et al. 2006).

\section{Vasoactive mediators and signalling pathways involved in DA patency and closure}

\section{Regulation of vascular tone, role of smooth muscle and endothelium, differential maturation of smooth muscle in the DA}

\subsection{Regulation of vascular tone}

Vascular tone is regulated by a balance between constricting and relaxing forces. The primary signal responsible for activation of SM contractile proteins is calcium $\left(\mathrm{Ca}^{2+}\right)$. Thus, an increase in intracellular $\mathrm{Ca}^{2+}\left(\left[\mathrm{Ca}^{2+}\right]_{\mathrm{i}}\right)$ leads to contraction, while a decrease leads to relaxation (Carvajal et al. 2000; Ratz et al. 2005). Cytosolic $\mathrm{Ca}^{2+}$ is increased through $\mathrm{Ca}^{2+}$ release from intracellular stores (sarcoplasmic reticulum, SR) as well as entry from the extracellular space through $\mathrm{Ca}^{2+}$ channels. The changes in $\left[\mathrm{Ca}^{2+}\right]_{\mathrm{i}}$ lead to a different degree of phosphorylation of the myosin light chain (MLC) kinase (MLCK). Thus, an increase in $\left[\mathrm{Ca}^{2+}\right]_{\mathrm{i}}$ activates the $\mathrm{Ca}^{2+} /$ calmodulin (CaM)-dependent MLCK which triggers a reversible phosphorylation at $\operatorname{Ser}^{19}$ of the MLC facilitating the cross-bridge formation between actin and myosin filaments and contraction (Somlyo and Somlyo 2003). However, $\mathrm{Ca}^{2+}$ does not directly activate SM motor proteins (Ratz 2004). On the other hand, there is a $\mathrm{Ca}^{2+}$-independent mechanism, the MLC phosphatase (MLCP), which dephosphorylates the MLC and counteracts the contraction (Somlyo and Somlyo 2003; Kitazawa et al. 2004).

The MLCK mechanisms involves the membrane bound enzyme, phospholipase C (PLC, Katzung 1995; Macrez-Lepretre et al. 1997; Kitazawa et al. 2004), which hydrolyses a component of the plasma membrane called phosphatidylinositol 4,5- biphosphate ( $\mathrm{PIP}_{2}$, Figure 2). Two second messengers are formed, diacylglycerol (DAG) and inositol 1,4,5-triphosphate ( $\left.\mathrm{IP}_{3}\right)$. DAG, being positioned in the plasma membrane, activates the phospholipid- and $\mathrm{Ca}^{2+}$-sensitive protein kinase C (PKC, Katzung 1995), which, in turn, stimulates $\mathrm{Ca}^{2+}$ influx through voltage dependent $\mathrm{Ca}^{2+}$ channels (Macrez-Lepretre et al. 1997). $\mathrm{IP}_{3}$, the other messenger, is water-soluble and diffuses through the cytoplasm, where it triggers release of $\mathrm{Ca}^{2+}$ from the SR. 
The MLCP mechanism involves an increase or a decrease in SM tension at a constant $\mathrm{Ca}^{2+}$ concentration, which are correspondingly referred to as $\mathrm{Ca}^{2+}$ sensitization and desensitization of the SM (Somlyo and Somlyo 2003; Kitazawa et al. 2004; Ratz et al. 2005). $\mathrm{Ca}^{2+}$ sensitization/desensitization is an important component of the constrictor/relaxant response of many agonists and may involve a number of different mechanisms. The RhoA and Rho kinase (ROK) pathway is believed to be the most important modulator of $\mathrm{Ca}^{2+}$ sensitivity in $\mathrm{SM}$, and a large number of vasoconstrictor agonists act by activating this pathway (Somlyo and Somlyo 2003). A schematic drawing over vascular responses and actions of different agonists used in this Thesis is depicted in Figure 4, on p. 39.

\subsection{The role of the Endothelium}

Endothelial cells control the tone of the underlying vascular smooth muscle (VSM) cells by releasing various relaxing and contracting factors (Furchgott and Vanhoutte 1989). The main vasoconstrictors are endothelin-1 (ET-1) and thromboxane $\mathrm{A}_{2}$ $\left(\mathrm{TxA}_{2}\right)$, while at least three endothelium derived relaxant factors (EDRF) have been found. These include NO, PGs (mainly prostacyclin, $\mathrm{PGI}_{2}$ ) and a yet unidentified factor called endothelium-derived hyperpolarizing factor (EDHF, Takizawa et al. 1999; Tare et al. 2000; Kamper et al. 2002; Sendao Oliveira and Bendhack 2004). NO is produced by a family of enzymes called NOS (Arnal et al. 1999), while PGs are synthesized by COX (Bos et al. 2004, see section III: 3 and 5). Endotheliumdependent agonists such as acetylcholine (ACh) and bradykinin (BK), in addition to physical vascular stimuli such as shear stress, stimulate endothelial cells to release NO, PGs and EDHF (Scotland et al. 2005). The contribution of each of these factors to endothelium-dependent vasodilatation varies across vascular beds and also with the

physiological or pharmacological stimuli used to stimulate the endothelium (Arnal et al. 1999; Tare et al. 2000). 


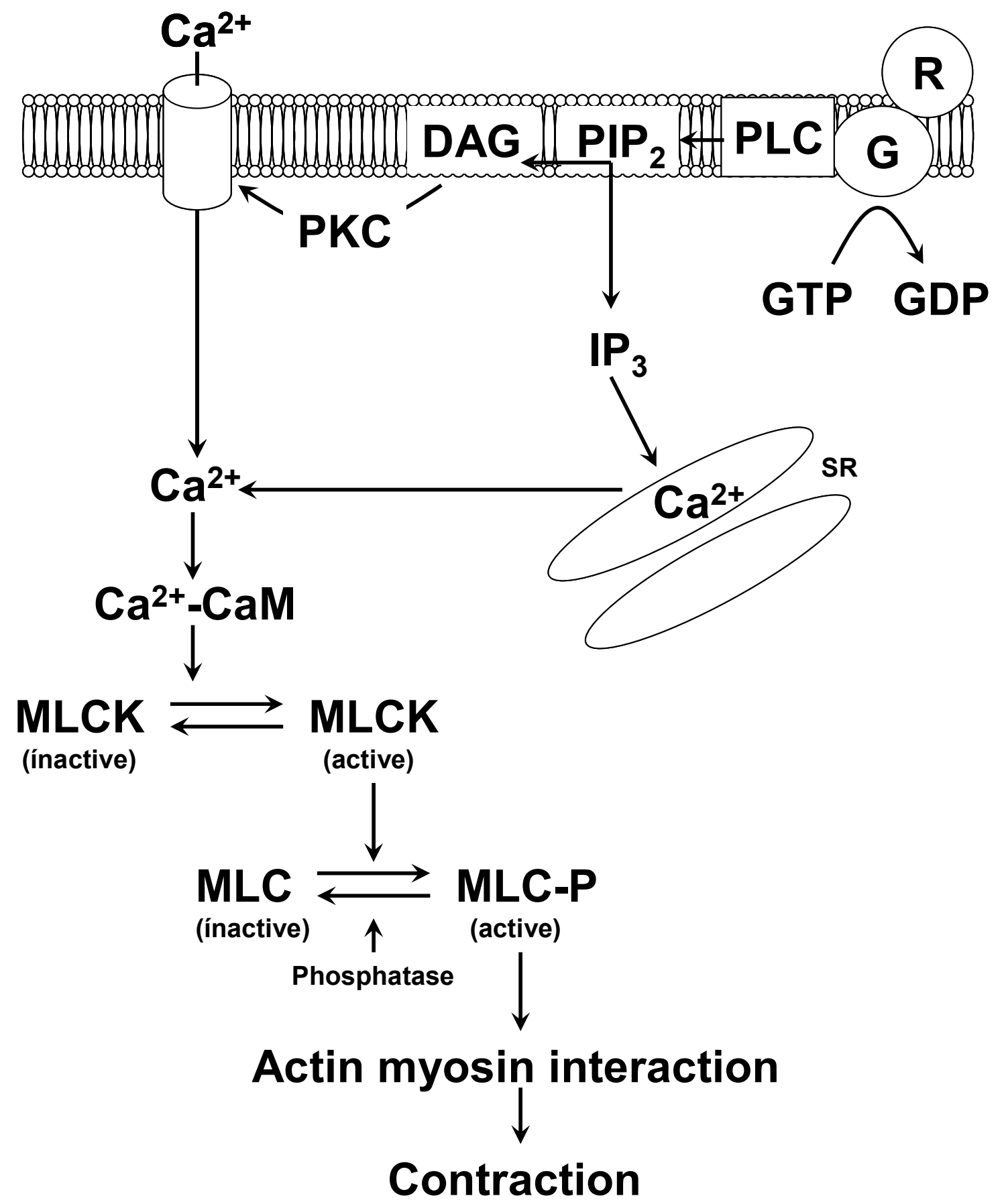

Figure 2. Schematic picture of the pathway of contraction. R, G protein coupled receptor; G, G protein. For further explanation see section III: 1.1. 


\section{Vasoactive factors}

\subsection{Oxygen}

The inflation of the lungs at birth produces a rapid increase in alveolar $\mathrm{O}_{2}$ tension, leading to DA constriction and at the same time relaxes PAs and decreases pulmonary vascular resistance (Waypa and Schumacker 2005). The importance of $\mathrm{O}_{2}$ in initiating closure of the DA is underlined by the occurrence of six times as many cases of PDA in babies born at high altitude (Alzamora-Castro et al. 1960).

\subsection{Control of patency}

The relatively low $\mathrm{O}_{2}$ tension to which the fetal DA is exposed helps maintain patency (Smith 1998). At mean tissue $\mathrm{O}_{2}$ concentration between 0.2 and $0.4 \%$, endogenous PGs and NO play a significant role in regulating DA tone because they inhibit $>60 \%$ of the active tension developed by the vessel (Kajino et al. 2000). As tissue $\mathrm{O}_{2}$ concentration increases above $0.4 \%$, the vasoconstrictor effects of $\mathrm{O}_{2}$ outweigh the inhibitory effects of PGs and NO (Kajino et al. 2000). Below $0.2 \%$ tissue $\mathrm{O}_{2}$ concentration, neither COX nor NOS inhibition had any effect on the tone of the DA, suggesting that both PG and NO production are inhibited by hypoxia (Kajino et al. 2000).

\subsection{Control of closure}

That $\mathrm{O}_{2}$ is important in the closure of the DA is well known, however the mechanism by which $\mathrm{O}_{2}$ produces contraction is less clear. There are four main theories about the actual way that $\mathrm{O}_{2}$ causes contraction (Smith 1998). None of the models fit all of the experimental observations and it is therefore likely that there is more than one $\mathrm{O}_{2}$ sensor. Furthermore $\mathrm{O}_{2}$ tension has a modulatory role on other vasoactive systems, and therefore the contractility of locally released vasoactive agents varies with alterations in $\mathrm{O}_{2}$ tension (Smith and McGrath 1993). It was early shown that $\mathrm{O}_{2}$ was acting directly on the SM of the DA, and that the contractions to $\mathrm{O}_{2}$ were not due to innervation (Born et al. 1956).

\subsubsection{The cytochrome $a_{3}$ hypothesis}

The cytochrome $a_{3}$ hypothesis is based on experiments performed by Fay et al (1971; 1972). They observed that cyanide and several other inhibitors of oxidative phosphorylation inhibited $\mathrm{O}_{2}$-induced contraction (Fay 1971; Fay and Jobsis 1972) 
and postulated that cytochrome $\mathrm{a}_{3}$ was the $\mathrm{O}_{2}$ sensor and that the contractile effect of $\mathrm{O}_{2}$ was related to ATP levels in ductal SM (Fay and Jobsis 1972). Cyanide has been shown to affect VSM contraction by several mechanisms, among them affecting several potassium $\left(\mathrm{K}^{+}\right)$channels (Smith 1998). Thus, although cyanide affects the $\mathrm{O}_{2-}$ induced contraction, the mechanism of action remains unclear.

\subsubsection{Arachidonate hypothesis}

An attractive hypothesis, given that dilation of the ductus in utero is mediated by an arachidonic acid (AA) metabolite $\left(\mathrm{PGE}_{2}\right)$, is that an $\mathrm{AA}$ metabolite also might mediate $\mathrm{O}_{2}$-induced contraction of the vessel with a shift in AA metabolism occurring at birth (Smith 1998).

\subsubsection{Endothelin/cytochrome $P_{450}$ hypothesis}

Coceani et al. $(1991 ; 1992 ; 2000 ; 2002)$ suggested that cytochrome $\mathrm{P}_{450}$ acts as $\mathrm{O}_{2}$ sensor and that its interaction with $\mathrm{O}_{2}$ might increase ET-1 production by the ductal endothelial cells, resulting in contraction. There is a large body of evidence obtained from studies on lamb DA, mostly from a single laboratory, which supports the cytochrome $\mathrm{P}_{450} / \mathrm{ET}-1$ hypothesis (Coceani et al. 1994). However, the actual role of ET-1 as a mediator of ductus constriction at birth is debated. Coceani et al (1999) showed that $\mathrm{ET}_{\mathrm{A}}$ receptor knockout foetal mice displayed a markedly reduced $\mathrm{O}_{2}$ induced constriction compared to wild type. Blockade of endothelin release in lamb (Coceani et al. 1992) and rat (Shen et al. 2002) reduce $\mathrm{O}_{2}$-induced contraction by half, while in rabbit the reduction is about one fifth (Shen et al. 2002). Thus, there is a species-dependent difference in the degree of contribution of endothelin to the $\mathrm{O}_{2}$ induced contraction.

\subsubsection{Membrane depolarization}

The nowadays main theory about $\mathrm{O}_{2}$ sensing and action is through membrane depolarization. Vascular $\mathrm{O}_{2}$ sensing systems consists of a sensor, the function of which is altered by changes in partial oxygen pressure $\left(\mathrm{PO}_{2}\right)$, a mediator, produced by this sensor, and an effector, which alters vascular tone in response to the mediator (Archer and Michelakis 2002). Many aspects of the $\mathrm{O}_{2}$ sensor-effector pathway are conserved among $\mathrm{O}_{2}$-sensitive mammalian tissues, the PAs, the DA, the adrenomedullary cells, the neuroepithelial body, and the carotid body. In each tissue, 
$\mathrm{K}^{+}$channels have been implicated in the effector mechanism (Archer et al 2000), whereas the $\mathrm{O}_{2}$ sensor has been proposed to involve a change in redox state, as determined by mitochondria or NADPH oxidase. Attention has focused on the mitochondria because electron transport chain (ETC) inhibitors mimic hypoxia, constricting the PAs and activating the carotid body (Michelakis et al. 2002). The mitochondria respond to changes in $\mathrm{PO}_{2}$ by altering their respiration and production of ROS (Archer et al. 1993; Duchen 1999). This changes the cellular redox potential and alters the function of many second messenger systems, and $\mathrm{O}_{2}$-sensitive $\mathrm{K}^{+}$ channels in the membrane (Michelakis et al. 2002).

Several studies have suggested that changes in $\mathrm{O}_{2}$ tension are signalled by changes in redox status and that $\mathrm{O}_{2}$-induced contraction of the DA is, at least partly, induced by membrane depolarization, which then results in entry of $\mathrm{Ca}^{2+}$ through $\mathrm{L}$ type voltage-gated $\mathrm{Ca}^{2+}$ channels (Roulet and Coburn 1981; Nakanishi et al. 1993; Tristani-Firouzi et al. 1996; Smith 1998; Weir et al. 2005). Roulet and Coburn (1981) first demonstrated that $\mathrm{O}_{2}$-induced DA constriction is associated with membrane depolarization. Nakanishi et al. (1993) hypothesized that, in the rabbit DA, membrane depolarization is related to $\mathrm{O}_{2}$ - induced closure of an ATP sensitive $\mathrm{K}^{+}\left(\mathrm{K}_{\text {ATP }}\right)$ channel. In contrast, Tristani-Firouzi et al. (1996) suggested that a voltage gated $\mathrm{K}^{+}$ $\left(\mathrm{K}_{\mathrm{V}}\right)$ channel was responsible for $\mathrm{O}_{2}$-induced membrane depolarization of rabbit DA.

A patch clamp study of SMCs from the rabbit ductus showed that the $\mathrm{K}^{+}$ channels controlling membrane potential change from the $\mathrm{O}_{2}$-insensitive $\mathrm{Ca}^{2+}$ activated $\left(\mathrm{K}_{\mathrm{Ca}}\right)$ channels to the $\mathrm{O}_{2}$-sensitive $\mathrm{K}_{\mathrm{V}}$ channels with advancing gestational age (Reeve et al. 1997). This suggests that the fundamental pathway involved in $\mathrm{O}_{2}$ induced contraction changes with advancing gestational age. Moreover, ex vivo transfer of the gene for $\mathrm{K}_{\mathrm{V} 1.5}$ or $\mathrm{K}_{\mathrm{V} 2.1}$ partially restores constriction to $\mathrm{O}_{2}$ in the preterm rabbit DA (Thebaud et al. 2002). Accordingly, regulation by a mitochondrial redox sensor of $\mathrm{K}_{\mathrm{V}}$ channels in human DASMCs has been demonstrated by Michelakis et al. (2000; 2002).

In human DA it was shown that $\mathrm{K}_{\mathrm{V}}$ channels are the effectors of $\mathrm{O}_{2}$ constriction (Michelakis et al. 2002). Inhibiting these channels, either by 4aminopyridine (4-AP) or $\mathrm{O}_{2}$ leads to vasoconstriction. Although the $\mathrm{K}_{\mathrm{V}}$ channel in both PAs and DA respond in opposite fashion when faced with similar $\mathrm{O}_{2}$ tensions, the $\mathrm{K}_{\mathrm{V}}$ channel antagonist, 4-AP, constricts both the PAs and the DA, suggesting that the $\mathrm{O}_{2}$ sensor mechanism is proximal to the channel (Tristani-Firouzi et al. 1996). It 
was also shown that the proximal mitochondrial ETC serves as the $\mathrm{O}_{2}$ sensor (Michelakis et al. 2002). Inhibition of complex I or III inhibits $\mathrm{O}_{2}$ constriction. The mediator linking the sensor and effector in the human DA appears to be a ROS, in this case hydrogen peroxide $\left(\mathrm{H}_{2} \mathrm{O}_{2}\right.$, Figure 3). Michelakis et al (2002) proposed that the increase in $\mathrm{H}_{2} \mathrm{O}_{2}$ levels that occurs with normoxia at the time of birth inhibits the $\mathrm{K}_{\mathrm{V}}$ current in the SMCs of the DA, causing depolarization and vasoconstriction. Although the $\mathrm{K}^{+}$channel effector mechanism is widely conserved among $\mathrm{O}_{2}$ sensitive tissues, the type of $\mathrm{K}^{+}$channel and downstream response to channel inhibition may vary among species, between tissues, and with maturation (Archer et al. 2000).

On the other hand it has been shown that ET-1 can have an inhibitory action on $\mathrm{K}^{+}$channels (Salter and Kozlowski 1998; Salter et al. 1998; Shimoda et al. 1998; Coceani et al. 1999). Therefore, $\mathrm{O}_{2}$ may, either directly or mediated by ET-1 or some other factor, cause membrane depolarization of the SMC, and increase $\left[\mathrm{Ca}^{2+}\right]_{\mathrm{i}}$ through the increase of $\mathrm{Ca}^{2+}$ influx, or the induction of $\mathrm{Ca}^{2+}$ release from intracellular store sites, and finally cause DA contraction.

\subsubsection{Rho-kinase and store operated calcium (SOC) channels.}

A third phase (Figure 3) in the closure of the DA has been suggested to occur after the initial electrical phase $\left(\mathrm{K}_{\mathrm{V}}\right.$ channel inhibition, membrane depolarization, and activation of the L-type, voltage-gated $\mathrm{Ca}^{2+}$-channel) and mediator phase (increased endothelin synthesis); $\mathrm{a} \mathrm{Ca}^{2+}$-sensitization phase (through activation of $\mathrm{ROK}$, Kajimoto et al. 2007). Hong et al. (2006), found a significant normoxic contraction that occurred after blocking of $\mathrm{K}_{\mathrm{V}}$ channels with 4-AP, due to $\mathrm{Ca}^{2+}$ entry through SOC channels and increased $\mathrm{Ca}^{2+}$-sensitization. $50 \%$ of the normoxic tension of sheep DA, may be due to increased $\mathrm{Ca}^{2+}$-sensitization (Clyman et al. 2007). Both ROK and tyrosine kinase appear to play a significant role in maintaining active tension (Clyman et al. 2007). Kajimoto et al. (2007), found that ROK activation was necessary for sustained $\mathrm{O}_{2}$ constriction and that $\mathrm{Ca}^{2+}$-sensitization accounts for approximately one third of $\mathrm{O}_{2}$ constriction. They also showed that with prolonged exposure to $\mathrm{O}_{2}$, the ROK pathway increases its contribution to DA constriction (Kajimoto et al. 2007). Furthermore, increased expression of key components of the Rho-pathway was found in DASMC and vasa vasorum (Kajimoto et al. 2007). Finally they also showed that activation as well as increased expression occurred via an $\mathrm{O}_{2}$-dependent increase in mitochondrial ROS production in human and rabbit DA (Kajimoto et al. 2007). In 
preterm DAs, immaturity of mitochondrial ROS generation is associated with reduced and delayed $\mathrm{O}_{2}$ constriction and lack of $\mathrm{PO}_{2}$-dependent upregulation of Rho-kinase expression (Kajimoto et al. 2007). Inhibition of Rho-kinases (with Y-27632 or fasudil) ablated the normoxic contraction of the DA regardless of whether they were given before normoxic contraction or during contraction (Hong et al. 2006).

The preterm DA generates smaller tensions than the mature DA under both normoxic and hypoxic conditions, even after endogenous PG and NO production have been inhibited (Clyman et al. 2007). Hong et al. (2006) and Kajimoto et al. (2007), suggested (in rabbit and human DA) that alterations in $\mathrm{Ca}^{2+}$-sensitization may contribute to the increase in DA tension that occurs with advancing gestation, while Clyman et al. (2007), found that the major factor responsible is the way that the immature DA processes extracellular $\mathrm{Ca}^{2+}$. The mature DA has an increased expression of L-type $\mathrm{Ca}^{2+}$ channels (Clyman et al. 2007).

Table 2. Summary of literature concering the effect of oxygen on the DA.

\begin{tabular}{|c|c|c|c|}
\hline Reference & Species/ Age & Experiments/Results & Comments \\
\hline (Born et al. 1956) & Lamb & $\begin{array}{l}\text { Increased arterial } \mathrm{O}_{2} \text { saturation, suggested to act directly on the SMC, } \\
\text { causes DA constriction. Inflation of the lungs with } \mathrm{N}_{2} \text {, with the } \\
\text { placental circulation intact, did not constrict the DA. In contrast, } \\
\text { asphyxia, through under-ventilation causes DA constriction, probably } \\
\text { through release of catecholamines. After long exposure to high } \mathrm{O}_{2} \text {, } \\
\text { fully reversed constriction is not seen at the return to fetal } \mathrm{O}_{2} \\
\text { saturation. }\end{array}$ & $\begin{array}{l}\mathrm{O}_{2} \text { causes constriction of } \\
\text { the } \mathrm{DA} \text {, and after some } \\
\text { time with high } \mathrm{O}_{2} \text {, the } \\
\text { vessel will not return to a } \\
\text { fully dilated state. }\end{array}$ \\
\hline $\begin{array}{l}\text { (McMurphy et al. } \\
\text { 1972) }\end{array}$ & Lamb/ 90-150d & $\begin{array}{l}\text { Higher } \mathrm{PO}_{2} \text { levels are needed for constriction in younger fetuses. } \\
\text { Maximal constriction is higher in older fetuses. } \mathrm{BK} \text { and } \mathrm{ACh} \\
\text { augmented the constriction over different levels of } \mathrm{PO}_{2} \text {. Following } \\
\text { exposure to } \mathrm{BK} \text { or ACh, the DA of younger fetuses responded to a } \\
\text { lower } \mathrm{PO}_{2} \text { than before. }\end{array}$ & $\begin{array}{l}\text { Threshold } \mathrm{PO}_{2} \text { decreases } \\
\text { and maximal } \\
\text { constriction increases } \\
\text { with age. }\end{array}$ \\
\hline $\begin{array}{l}\text { (Knight et al. } \\
\text { 1973) }\end{array}$ & Dog/ Near-term & $\begin{array}{l}\text { The DA constricted in response to high } \mathrm{PO}_{2} \text {, while hypoxia relaxed the } \\
\text { DA. After repeated challenges with } \mathrm{O}_{2} \text {, the DA became refractory to } \mathrm{O}_{2} \\
\text { but not to ACh or norepinephrine (NE). Ducti from PDA-related } \\
\text { fetuses tended to be more widely patent, and responded less to } \mathrm{O}_{2} \text {. }\end{array}$ & \\
\hline $\begin{array}{l}\text { (Noel and Cassin } \\
\text { 1976) }\end{array}$ & $\begin{array}{l}\text { Guinea pigs/ } \\
\text { 40d-term (60d) }\end{array}$ & $\begin{array}{l}\text { Response to } \mathrm{O}_{2} \text { matures with age. In near-term and term, } \mathrm{O}_{2} \text { induce } \\
\text { similar contractions as excess } \mathrm{K}^{+} . \mathrm{K}^{+} \text {-induced contractions did not } \\
\text { differ between preterm and term. Over high }(95 \%) \mathrm{O}_{2} \text {-induced } \\
\text { contraction, BK and ACh caused an augmentation, while neither } \\
\text { epinephrine nor NE did. }\end{array}$ & \\
\hline
\end{tabular}




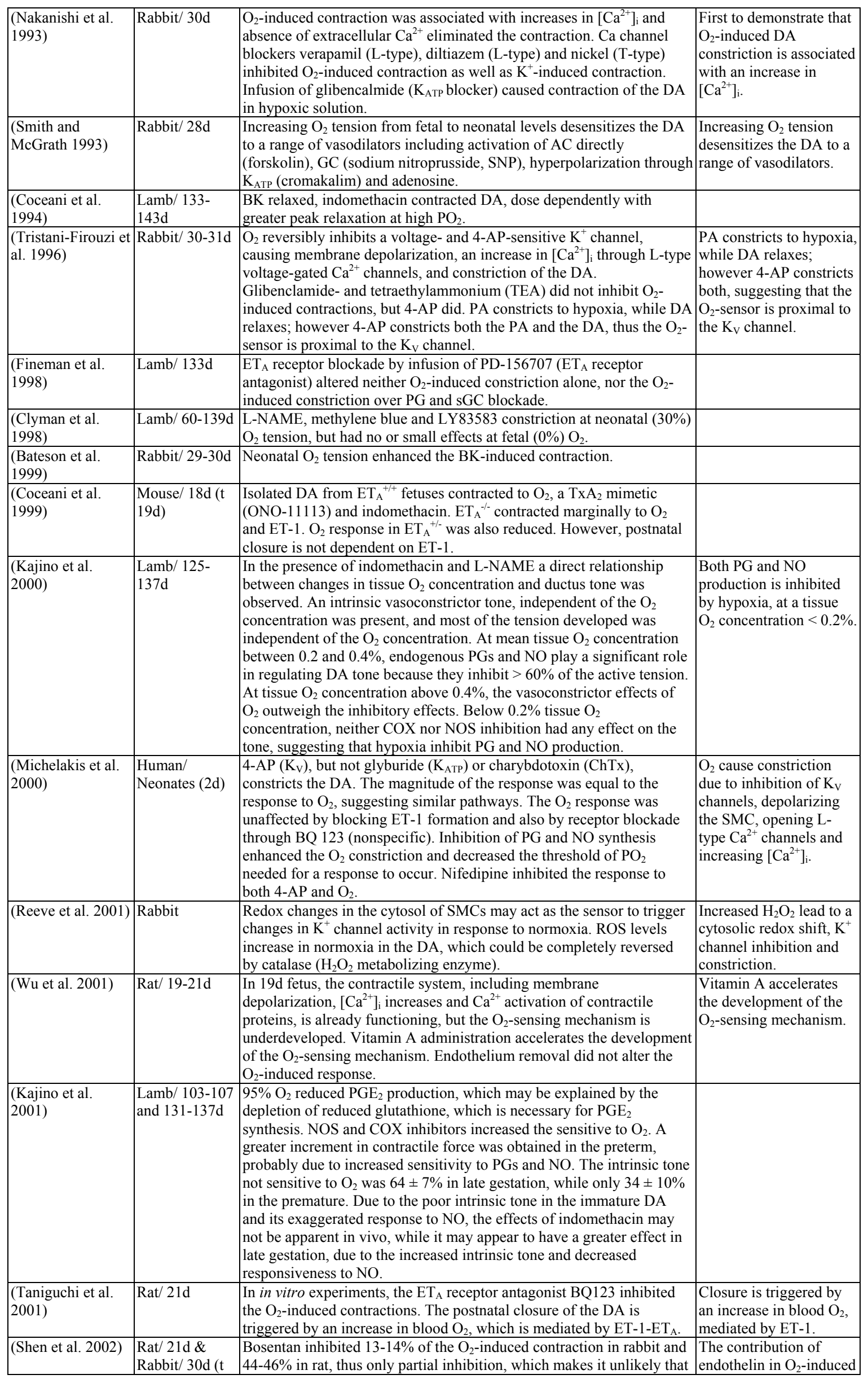




\begin{tabular}{|c|c|c|c|}
\hline & 31d) & $\begin{array}{l}\text { endothelin is the sole mediator } \mathrm{O}_{2} \text {-induced contraction. In the rabbit, } \\
\text { endothelin is present in both endothelium and VSM, but it is only } \\
\text { released from the endothelium in response to } \mathrm{O}_{2} \text {. }\end{array}$ & $\begin{array}{l}\text { contractions differs } \\
\text { between species. }\end{array}$ \\
\hline $\begin{array}{l}\text { (Michelakis et al. } \\
\text { 2002) }\end{array}$ & $\begin{array}{l}\text { Human/ } \\
\text { Neonates }\end{array}$ & $\begin{array}{l}\mathrm{K}_{\mathrm{V}} \text { channels are the effectors of } \mathrm{O}_{2} \text { constriction. Inhibition of these } \\
\text { channels, whether by 4-AP or } \mathrm{O}_{2} \text {, leads to vasoconstriction. The } \\
\text { proximal mitochondrial ETC serves as the } \mathrm{O}_{2} \text { sensor. Inhibition of } \\
\text { complex I or III inhibits } \mathrm{O}_{2} \text { constriction. The mediator, linking the } \\
\text { sensor and effector seems to be a ROS }\left(\mathrm{H}_{2} \mathrm{O}_{2}\right) \text {. The DASMCs express } \\
\text { several } \mathrm{O}_{2} \text { - and 4-AP- sensitive } \mathrm{K}^{+} \text {channels }\left(\mathrm{K}_{\mathrm{V}} 1.5 \text { and } \mathrm{K}_{\mathrm{V}} 2.1\right) \text {. In } \\
\text { tissue culture, normoxic } \mathrm{PO}_{2} \text { downregulated several } \mathrm{O}_{2} \text {-sensitive } \mathrm{K}_{\mathrm{V}} \\
\text { channels, including } \mathrm{K}_{\mathrm{V}} 1.5 \text { and } \mathrm{K}_{\mathrm{V}} 2.1 \text {. This was associated with } \\
\text { membrane depolarization and impaired ability of the membrane to } \\
\text { further depolarize to either } \mathrm{O}_{2} \text { or 4-AP, a process termed ionic } \\
\text { remodeling. }\end{array}$ & $\begin{array}{l}\mathrm{K}_{\mathrm{V}} \text { channels are the } \\
\text { effectors of } \mathrm{O}_{2} \text {-induced } \\
\text { constriction. The } \\
\text { proximal mitochondrial } \\
\text { ETC the sensor, and } \\
\mathrm{H}_{2} \mathrm{O}_{2} \text { the link. } \\
\text { Downregulation of } \\
\mathrm{K}_{\mathrm{V}} 1.5 \text { and } \mathrm{K}_{\mathrm{V}} 2.1 \\
\text { occurred after } \mathrm{O}_{2} \\
\text { exposure. }\end{array}$ \\
\hline $\begin{array}{l}\text { (Thebaud et al. } \\
\text { 2002) }\end{array}$ & Rabbit/30d & $\begin{array}{l}\text { Sildenafil reverses and prevents } \mathrm{O}_{2} \text { constriction in the DA by } \\
\text { increasing cGMP levels and activating DASMC large conductance } \\
\mathrm{Ca}^{2+} \text { activated } \mathrm{K}^{+}\left(\mathrm{BK}_{\mathrm{C}}\right) \text { channels. Sildenafil hyperpolarizes DASMC } \\
\text { by opening } \mathrm{K}^{+} \text {channels, causing vasodilation. }\end{array}$ & \\
\hline $\begin{array}{l}\text { (Olschewski et al. } \\
\text { 2004) }\end{array}$ & Rabbit & $\begin{array}{l}\text { Both PA and systemic arteries (including the DA) respond in similar } \\
\text { ways to vasoactive substances, with the exception of } \mathrm{O}_{2} \text {. Under } \\
\text { normoxic conditions, a reducing agent, DTT, acted as a potent } \\
\text { vasodilator in the DA through activation of } \mathrm{I}_{\mathrm{K}} \text {, and hyperpolarization, } \\
\text { while the opposite occurred in the PA. Under hypoxic conditions, an } \\
\text { oxidizing agent, DNTB (dithionitrobenzoic acid), caused contraction } \\
\text { through inactivation of } \mathrm{I}_{\mathrm{K}} \text { and depolarization. } \\
\end{array}$ & $\begin{array}{l}\text { Redox changes could } \\
\text { signal the opposite } \\
\text { effects of } \mathrm{O}_{2} \text { in DA and } \\
\text { PA. }\end{array}$ \\
\hline $\begin{array}{l}\text { (Thebaud et al. } \\
\text { 2004) }\end{array}$ & $\begin{array}{l}\text { Rabbit/26 and } \\
30 \mathrm{~d} \& \text { Human/ } \\
\text { term }\end{array}$ & $\begin{array}{l}\text { The preterm DA constricts less to } \mathrm{O}_{2} \text {, even after COX and NOS } \\
\text { inhibition, which enhanced the preterm response more. The weaker } \\
\text { constriction to 4-AP and } \mathrm{O}_{2} \text { is dependent on later } \mathrm{K}^{+} \text {channel } \\
\text { maturation and not on an immature contractile apparatus, indicated by } \\
\text { the smaller maturational changes in phenylephrine (Phe)-induced } \\
\text { constriction. Preterm DA is deficient in } \mathrm{K}_{\mathrm{V}} 1.5 \text { and } \mathrm{K}_{\mathrm{V}} 2.1 \text {. Gene transfer } \\
\text { restored channel expression and enhanced the } \mathrm{O}_{2} \text { responsiveness in the } \\
\text { preterm DA. In ionically remodeled human DA gene transfer of human } \\
\mathrm{K}_{\mathrm{V}} 1.5 \text { restores 4-AP and } \mathrm{O}_{2} \text {-induced constriction. }\end{array}$ & $\begin{array}{l}\text { Decreased } \mathrm{O}_{2} \\
\text { responsiveness of the } \\
\text { preterm results from an } \\
\text { immature } \mathrm{K}_{\mathrm{V}} \text { channel } \\
\text { effector mechanism in } \\
\text { the SMCs. }\end{array}$ \\
\hline (Keck et al. 2005) & $\begin{array}{l}\text { Lamb/ Near- } \\
\text { term }\end{array}$ & $\begin{array}{l}\text { Acute normoxia increases }\left[\mathrm{Ca}^{2+}\right]_{\mathrm{i}} \text { via release of } \mathrm{Ca}^{2+} \text { from } \mathrm{IP}_{3} \text {-sensitive } \\
\text { intracellular stores, and subsequent entry of extracellular } \mathrm{Ca}^{2+} \text {, thus the } \\
\text { response to } \mathrm{O}_{2} \text { is biphasic. Pharmacological inactivation of voltage- } \\
\text { sensitive, but not ATP- or } \mathrm{Ca}^{2+} \text {-sensitive } \mathrm{K}^{+} \text {-channels mimics the effect } \\
\text { of an acute increase in } \mathrm{O}_{2} \text { tension. }\end{array}$ & $\begin{array}{l}\text { Release of } \mathrm{Ca}^{2+} \text { from } \\
\mathrm{IP}_{3} \text {-sensitive stores } \\
\text { accounts for the initial } \\
\text { increase in DASMC } \\
{\left[\mathrm{Ca}^{2+}\right]_{\mathrm{i}} \text { in response to } \mathrm{O}_{2} \text {. }}\end{array}$ \\
\hline (Hong et al. 2006) & Rabbit/Term & $\begin{array}{l}\text { A significant normoxic contraction can occur after blocking of } \mathrm{K}_{\mathrm{V}} \\
\text { channels with 4-AP. This contraction was due to } \mathrm{Ca}^{2+} \text { entry through } \\
\text { SOC channels and increased } \mathrm{Ca}^{2+} \text {-sensitization. In the presence of } \\
\text { nifedipine and thapsigargin, a switch from } 0 \text { to } 2 \mathrm{mmol} / \mathrm{L} \mathrm{Ca}^{2+} \text { during } \\
\text { hypoxia results in an increase in tone. This indicates } \mathrm{Ca}^{2+} \text { entry through } \\
\text { SOC. Further contraction occur on switching from hypoxia to } \\
\text { normoxia, suggesting that normoxia facilitates } \mathrm{Ca}^{2+} \text { entry through SOC. }\end{array}$ & $\begin{array}{l}\text { Much of the normoxic } \\
\text { contraction is related to } \\
\mathrm{Ca}^{2+} \text { entry through SOC } \\
\text { channels and to } \\
\text { increased } \mathrm{Ca}^{2+}- \\
\text { sensitization. }\end{array}$ \\
\hline $\begin{array}{l}\text { (Kajimoto et al. } \\
2007)\end{array}$ & $\begin{array}{l}\text { Rabbit } / 26 \text { and } \\
\text { 30d \& Human/ } \\
\text { neonates }\end{array}$ & $\begin{array}{l}\text { A third phase in } \mathrm{O}_{2} \text { constriction, a } \mathrm{Ca}^{2+} \text {-sensitization, largely owing to } \\
\text { activation of ROK, maintains constriction while reducing the } \\
\text { requirement for } \mathrm{Ca}^{2+} \text { influx. ROK activation accounts for } 1 / 3 \text { of } \mathrm{O}_{2} \\
\text { constriction. Prolonged exposure to } \mathrm{O}_{2} \text { increases expression of RhoB } \\
\text { and ROCK-1, key components in the Rho-pathway, a positive feedback } \\
\text { loop, that is absent in preterm DA. Both ROK activation and increased } \\
\text { expression occur via a redox mechanism that involves an } \mathrm{O}_{2} \text {-dependent } \\
\text { increase in mitochondrial ROS production in human and rabbit DA. }\end{array}$ & $\begin{array}{l}\mathrm{O}_{2} \text { activates ROK and } \\
\text { increases ROK } \\
\text { expression in term } \\
\text { DASMC by a redox- } \\
\text { regulated positive- } \\
\text { feedback mechanism } \\
\text { that promotes sustained } \\
\text { vasoconstriction. }\end{array}$ \\
\hline $\begin{array}{l}\text { (Clyman et al. } \\
\text { 2007) }\end{array}$ & $\begin{array}{l}\text { Lamb/ 102-108 } \\
\text { and 132-142d }\end{array}$ & $\begin{array}{l}\text { 60\% of MAT (maximal active tension) is maintained under hypoxic } \\
\text { conditions compared to } 70 \% \text { under normoxic conditions, in mature } \\
\text { DA. The preterm DA generates smaller tensions than the mature in } \\
\text { normoxic conditions and an even more marked difference is present } \\
\text { under hypoxic conditions. This may be due to differences in ROK } \\
\text { activity between mature and immature, but mainly developmental } \\
\text { differences in the way the immature processes extracellular } \mathrm{Ca}^{2+} \text {, } \\
\text { through a significant increase in the expression of L-type channels with } \\
\text { advancing gestation. }\end{array}$ & $\begin{array}{l}\text { Immature DA develop } \\
\text { lower tensions than } \\
\text { mature DA, primarily } \\
\text { because of differences in } \\
\text { the way they process } \\
\mathrm{Ca}^{2+} \cdot \mathrm{Ca}^{2+} \text { L-type } \\
\text { channel expression } \\
\text { increases with advancing } \\
\text { gestation. }\end{array}$ \\
\hline
\end{tabular}




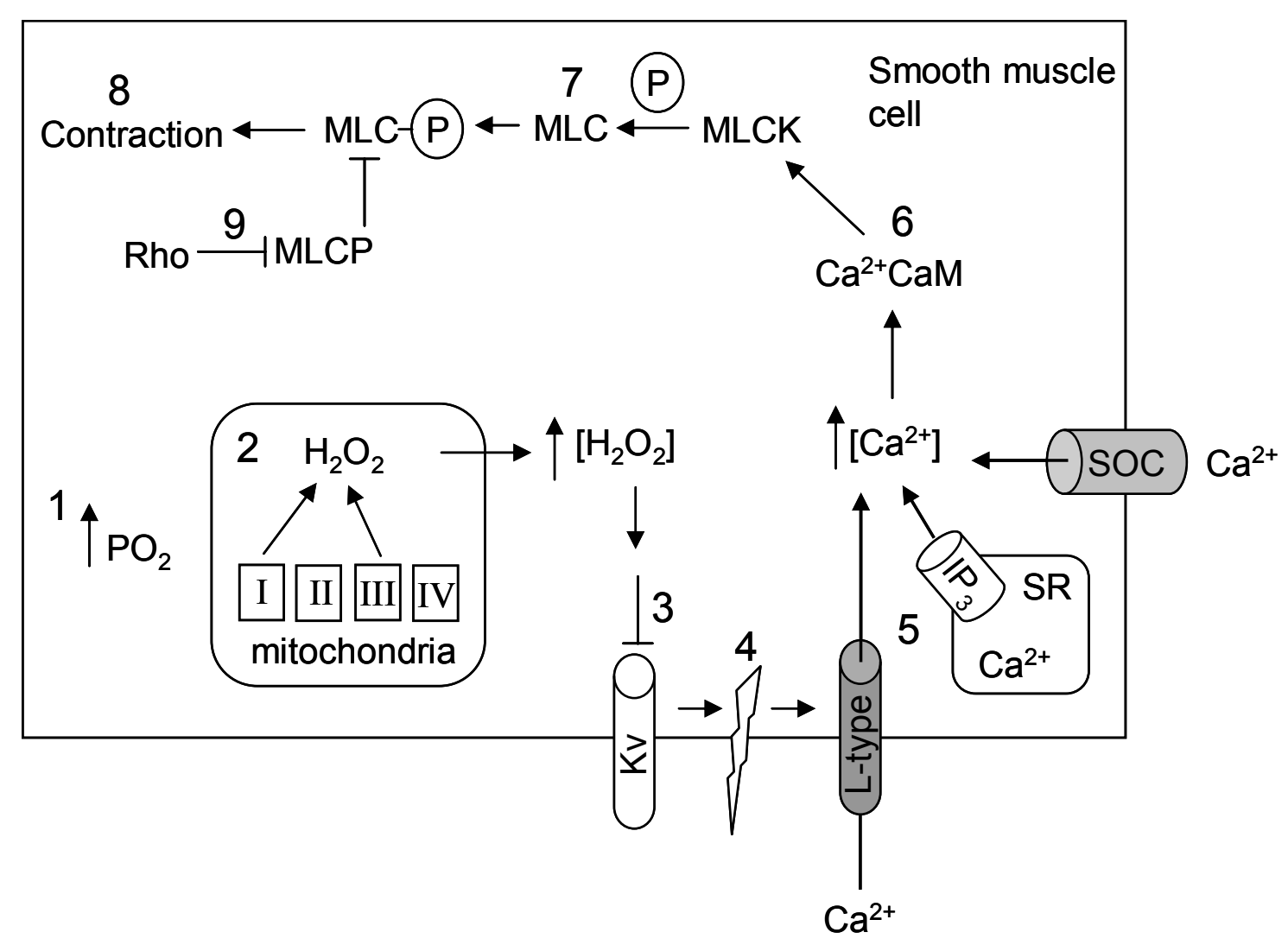

Figure 3. Suggested pathway for the action of oxygen. Increased oxygen (1) stimulates the mitochondria to release $\mathrm{H}_{2} \mathrm{O}_{2}$ (2). $\mathrm{H}_{2} \mathrm{O}_{2}$ antagonizes the $\mathrm{K}_{\mathrm{V}}$ channel (3), resulting in depolarization of the membrane (4). This result in opening of L-type $\mathrm{Ca}^{2+}$ channels, release of $\mathrm{Ca}^{2+}$ from sarcoplasmic reticulum (SR) through $\mathrm{IP}_{3}$-sensitive channels, and the opening of store operated $\mathrm{Ca}^{2+}$ channels (SOCs), allowing influx of $\mathrm{Ca}^{2+}(5)$. The $\mathrm{Ca}^{2+}$ binds with calmodulin (CaM, 6), and the $\mathrm{Ca}^{2+}$-CaM complex activates Myosin Light Chain (MLC) Kinase (MLCK, 7), which phosphorylates the MLC leading to muscle contraction (8). MLC phosphatase (MLCP) dephosphorylates MLC, allowing the cell to relax. The Rho associated protein (Rho) inhibits the action of MLCP, thereby increasing $\mathrm{Ca}^{2+}$-sensitivity of the DA contraction (9). The figure is a modified version of Greyner and Dzialowski 2008.

\section{Prostanoids}

PGs and thromboxanes (Txs), collectively named prostanoids, are mainly derived from AA (Wright et al. 2001). The initial reaction is catalyzed by PG G/H synthase, also known as COX, two isoforms of which have been identified. Both COX-1 and COX-2 catalyze the synthesis of $\mathrm{PGH}_{2}$, a product required for the formation of the various biologically active prostanoids (Clyman et al. 1999b; Coceani et al. 2001; Bos et al. 2004; Coceani et al. 2005). Several PGs are synthesized from the primary product $\mathrm{PGH}_{2}$ by individual enzymes (Wright et al. 2001). 
PGs contain a cyclopentane ring while Txs contain a cyclohexane ring. Modification of the pentane and hexane rings give rise to several different forms of prostanoids (Bos et al. 2004). Naturally existing PGs can be subdivided into PGD, PGE, PGF and PGI (Bos et al. 2004). The receptors for PGs have been named after the native PG that is its most potent agonist (Smith 1998; Wright et al. 2001). Thus the receptors are named DP, EP, FP and IP, and some of them are further subdivided with numbers, as example the PGE receptor family consists of $\mathrm{EP}_{1}-\mathrm{EP}_{4}$ (Bos et al. 2004).

In general prostanoid receptors can be grouped into three categories based on the cellular response (Wright et al. 2001). The first category consists of the relaxant receptors, IP, $\mathrm{EP}_{2}$ and $\mathrm{EP}_{4}$ and $\mathrm{DP}$ receptors, that in general activate the G-protein $\mathrm{G}_{\mathrm{S}}$, which stimulates cAMP production by adenylate cyclase (AC). The second category includes the contractile type of prostanoid receptors, TP, $\mathrm{EP}_{1}$ and $\mathrm{FP}$ that activates the G-protein $\mathrm{G}_{\mathrm{q}}$, mediating enhanced intracellular $\mathrm{Ca}^{2+}$ levels by influencing the phosphatidylinositol turnover. Finally the last group contains only $\mathrm{EP}_{3}$, which in general inhibits $A C$ via G-protein $\mathrm{G}_{\mathrm{i}}$.

\subsection{Thromboxane $A_{2}$}

$\mathrm{TxA}_{2}$ induces SM contraction, mediated by the TP receptor, a G-protein-coupled receptor, which typically triggers activation of PLC leading to an increase in $\left[\mathrm{Ca}^{2+}\right]_{\mathrm{i}}$ and $\mathrm{Ca}^{2+}$-sensitization of the contractile proteins (Wilson et al. 2005). TxA 2 has been shown to cause strong contractions of mammalian DA (Smith and McGrath 1995; Coceani et al. 1999). As mentioned above, the possible roles of Txs and contractile PGs in the $\mathrm{O}_{2}$-mediated ductal constriction have been suggested by some authors (Starling and Elliott 1974; Friedman et al. 1978) and opposed by others (Coceani and Olley 1973).

\subsection{Prostaglandins}

PGs and especially $\mathrm{PGE}_{2}$, play a major role in maintaining patency of mammalian foetal DA. Both circulating and locally produced $\mathrm{PGE}_{2}$ and $\mathrm{PGI}_{2}$ have been showed to be involved in the control of DA tone (Smith 1998; Kajino et al. 2000). As mentioned before, the amount of circulating PGs decreases dramatically at birth (Clyman et al. 1980). This loss of free circulating $\mathrm{PGE}_{2}$ has been postulated to be fundamental to the closure of the DA. A change in EP receptor expression is also seen during this time 
period, a loss of $\mathrm{EP}_{3}$ and especially $\mathrm{EP}_{4}$ receptors in the newborn is consistent with its decrease in responsiveness to $\mathrm{PGE}_{2}$ (Bouayad et al. 2002).

Table 3. Summary of literature concering the effect of prostaglandins on the DA.

\begin{tabular}{|c|c|c|c|}
\hline Reference & Species/ Age & Experiments/Results & Comments \\
\hline $\begin{array}{l}\text { (Clyman et al. } \\
1983)\end{array}$ & $\begin{array}{l}\text { Lamb/ 138- } \\
140 d\end{array}$ & $\begin{array}{l}\mathrm{PGE}_{2} \text {-infusion either dilated the DA (responders) or had no effect } \\
\text { (nonresponders). Isolated DA of nonresponders showed a limited ability to } \\
\text { relax to } \mathrm{PGE}_{2} \text { and to contract to } \mathrm{O}_{2} \text { and indomethacin, which was directly } \\
\text { related to the amount of left-to-right shunting. }\end{array}$ & \\
\hline $\begin{array}{l}\text { (Walsh and } \\
\text { Mentzer } \\
\text { 1987) }\end{array}$ & $\begin{array}{l}\text { Lamb/125- } \\
135 \mathrm{~d}\end{array}$ & $\begin{array}{l}\text { Both cAMP- and cGMP-induced relaxation exist in DASMC of fetal lambs. } \\
\text { PGE }_{1} \text { induced relaxation through increase in cAMP, while nitrovasodilators } \\
\text { stimulates increase in both cyclic nucleotides. }\end{array}$ & \\
\hline $\begin{array}{l}\text { Smith and } \\
\text { McGrath } \\
\text { 1995) }\end{array}$ & Rabbit/28d & $\begin{array}{l}\text { U46619 induced strong contractions, through Tx (TP) receptors. Picomolar } \\
\text { concentrations of } \mathrm{PGE}_{2} \text { could mask the effect of TxA } \mathrm{T}_{2} \text {. Sulprostone was } \\
\text { equipotent to U46619, and in other tissue it is } 500 \text {-fold less potent at TP } \\
\text { receptors, thus presence of a contractile EP receptor. }\end{array}$ & $\begin{array}{l}\text { The fetal rabbit DA has } \\
\text { at least two contractile } \\
\text { prostanoid receptors, TP } \\
\text { and EP. }\end{array}$ \\
\hline $\begin{array}{l}\text { (Momma et } \\
\text { al. 1998) }\end{array}$ & Rat/ 20-21d & $\begin{array}{l}\text { Increased constriction to indomethacin after vitamin A infusion show } \\
\text { accelerated maturation. Therapeutic doses of vitamin A can accelerate DA } \\
\text { maturation in preterm and near-term fetal rats. }\end{array}$ & $\begin{array}{l}\text { Fetal DA constriction } \\
\text { increased after vitamin A } \\
\text { pretreatment. }\end{array}$ \\
\hline $\begin{array}{l}\text { (Smith and } \\
\text { McGrath } \\
1988 \text { ) }\end{array}$ & $\begin{array}{l}\text { Rabbit// } \\
\text { Neonates }\end{array}$ & $\begin{array}{l}\text { Indomethacin did not change } \mathrm{O}_{2} \text {-induced contraction, but the vessel is under } \\
\text { tonic inhibition by PGs. Indomethacin increased DA sensitivity to NE } \\
\text { tenfold, implying that intramurally PGs, decrease the sensitivity to NE. } \mathrm{O}_{2} \\
\text { tension did not change the sensitivity of the DA to NE. }\end{array}$ & $\begin{array}{l}\text { COX products decrease } \\
\text { the sensitivity of the DA } \\
\text { to NE. }\end{array}$ \\
\hline $\begin{array}{l}\text { (Bateson et al. } \\
\text { 1999) }\end{array}$ & $\begin{array}{l}\text { Rabbit/29- } \\
30 \mathrm{~d}\end{array}$ & $\begin{array}{l}\text { PG synthesis crucial in } \mathrm{BK} \text { activation, in rabbit } \mathrm{DA} \text {, whereas NO formation } \\
\text { is secondarily involved and has both endothelial and nonendothelial sources. } \\
\mathrm{BK} \text { induced relaxation at low and contraction at high concentrations. } \\
\text { Neonatal } \mathrm{O}_{2} \text { tension enhanced the contraction. } \mathrm{B}_{2} \text {-receptors for relaxation, } \\
\text { while } \mathrm{B}_{1} \text {-receptors for contraction and only in intact vessels. }\end{array}$ & $\begin{array}{l}\text { PG synthesis the crucial } \\
\text { mechanism in BK } \\
\text { activation, in rabbit DA. }\end{array}$ \\
\hline \begin{tabular}{|l|}
$\begin{array}{l}\text { Clyman et al. } \\
1999 b)\end{array}$ \\
\end{tabular} & $\begin{array}{l}\text { Lamb/125- } \\
137 d\end{array}$ & $\begin{array}{l}\text { COX-1 is present in endothelial cells and SMC, while COX-2 is only present } \\
\text { in endothelial cells lining the lumen. COX-2 exerts a significant contribution } \\
\text { to PG formation and vasomotor tone. }\end{array}$ & \\
\hline $\begin{array}{l}\text { (Bhattacharya } \\
\text { et al. 1999) }\end{array}$ & \begin{tabular}{|l|} 
Pig/ 78-90, \\
$100-105 \mathrm{~d}$ and \\
term
\end{tabular} & $\begin{array}{l}\mathrm{EP}_{2}, \mathrm{EP}_{3} \text {, and } \mathrm{EP}_{4} \text { receptors were detected in the fetal } \mathrm{DA} \text {, in equivalent } \\
\text { proportions. In the neonatal pig only } \mathrm{EP}_{2} \text { receptors were detected, although in } \\
\text { a similar density as in the fetal. }\end{array}$ & \\
\hline $\begin{array}{l}\text { (Michelakis et } \\
\text { al. 2000) }\end{array}$ & $\begin{array}{l}\text { Human/ } \\
\text { Neonates }(2 d)\end{array}$ & $\begin{array}{l}\text { Inhibition of PG and } \mathrm{NO} \text { synthesis enhanced the } \mathrm{O}_{2} \text { constriction and } \\
\text { decreased the threshold of } \mathrm{PO}_{2} \text { needed for a response to occur. }\end{array}$ & \\
\hline $\begin{array}{l}\text { (Reese et al. } \\
2000)\end{array}$ & Mouse & $\begin{array}{l}\text { Minimal expression of COX-1 and COX-2 during labor and postnatal } \\
\text { closure. Selective COX-2 inhibition less effective on in utero DA } \\
\text { constriction. COX double null mice are viable throughout development but } \\
\text { die after birth with an open DA. }\end{array}$ & $\begin{array}{l}\text { DA patency is dependent } \\
\text { on circulating PGs. }\end{array}$ \\
\hline $\begin{array}{l}\text { (Takizawa et } \\
\text { al. 2000a) }\end{array}$ & Rat/21d & $\begin{array}{l}\text { Inhibition with indomethacin and L-NAME or methylene blue causes a rapid } \\
\text { increase in DA caliber followed by a subsequent decrease. }\end{array}$ & \\
\hline $\begin{array}{l}\text { (Takahashi et } \\
\text { al. 2000) }\end{array}$ & $\begin{array}{l}\text { Lamb/125- } \\
137 d\end{array}$ & $\begin{array}{l}\text { Selective COX-2 inhibitors (celecoxib and NS398) decreased PG production } \\
\text { and contracted isolated DA rings. They decreased fetal plasma concentration } \\
\text { of PGs and constricted fetal DA in vivo, but indomethacin tended to have a } \\
\text { greater effect. }\end{array}$ & $\begin{array}{l}\text { COX-2 inhibition } \\
\text { decreased PG production } \\
\text { and constricted the DA } \\
\text { both in vivo and in vitro. }\end{array}$ \\
\hline $\begin{array}{l}\text { Kajino et al. } \\
\text { 2001) }\end{array}$ & $\begin{array}{l}\text { Lamb/ 103- } \\
107 \text { and } 131- \\
137 d\end{array}$ & $\begin{array}{l}95 \% \mathrm{O}_{2} \text { reduced } \mathrm{PGE}_{2} \text { production, possibly through depletion of reduced } \\
\text { glutathione, necessary for } \mathrm{PGE}_{2} \text { synthesis. NOS and COX inhibitors } \\
\text { increased the sensitive to } \mathrm{O}_{2} \text {. The intrinsic tone not sensitive to } \mathrm{O}_{2} \text { was } 64 \pm \\
7 \% \text { in late gestation, while only } 34 \pm 10 \% \text { in the premature. Due to the poor } \\
\text { intrinsic tone in the immature DA and its exaggerated response to NO, the } \\
\text { effects of indomethacin may not be apparent in vivo, while it may appear to } \\
\text { have a greater effect in late gestation, due to the increased intrinsic tone and } \\
\text { decreased responsiveness to NO. }\end{array}$ & $\begin{array}{l}\text { The smaller intrinsic } \\
\text { tone and increased } \\
\text { sensitivity to } \\
\text { vasodilators can explain } \\
\text { the high rate of } \\
\text { reopening in extremely } \\
\text { premature infants. }\end{array}$ \\
\hline $\begin{array}{l}\text { (Bouayad et } \\
\text { al. 2002) }\end{array}$ & $\begin{array}{l}\text { Lamb/ 125- } \\
140 \mathrm{~d}\end{array}$ & $\begin{array}{l}\mathrm{EP}_{2}, \mathrm{EP}_{3 \mathrm{D}}, \text { and } \mathrm{EP}_{4} \text { receptors were detected, in equivalent proportions, in the } \\
\text { fetal, but decreased in the newborn to one third and only } \mathrm{EP}_{2} \text { was detected, } \\
\text { which is consistent with the decrease in responsiveness to } \mathrm{PGE}_{2} \text {. Stimulation } \\
\text { of } \mathrm{EP}_{2} \text { and } \mathrm{EP}_{4} \text { increased cAMP formation, while } \mathrm{EP}_{3} \text {-induced relaxation acts } \\
\text { through } \mathrm{K}_{\mathrm{ATP}} \text { channels and is blocked by glibenclamide. }\end{array}$ & $\begin{array}{l}\text { The loss of } \mathrm{EP}_{3} \text { and } \mathrm{EP}_{4} \\
\text { receptors in the newborn } \\
\text { is consistent with its } \\
\text { decrease in } \\
\text { responsiveness to } \mathrm{PGE}_{2} .\end{array}$ \\
\hline $\begin{array}{l}\text { (Baragatti et } \\
\text { al. 2003) }\end{array}$ & $\begin{array}{l}\text { Mouse/ 19d } \\
\text { and neonates }\end{array}$ & $\begin{array}{l}\text { Both COX-1 and COX-2 are present. NO contributes to the patency, but less } \\
\text { than PGs, implying a cooperative role between PGs and NO. }\end{array}$ & \\
\hline $\begin{array}{l}\text { (Karadas et al. } \\
\text { 2004) }\end{array}$ & Rat/ 16-21d & $\begin{array}{l}\text { Indomethacin constriction greater than DFU (COX-2 inhibitor), but both } \\
\text { increased with gestational age. }\end{array}$ & \\
\hline \begin{tabular}{l|l|} 
(Thebaud et \\
al. 2004)
\end{tabular} & $\begin{array}{l}\text { Rabbit/26 } \\
\text { and 30d \& } \\
\text { Human/term }\end{array}$ & $\begin{array}{l}\text { COX and NOS inhibition increase constriction to } \mathrm{O}_{2} \text { and even more in the } \\
\text { preterm, but the preterm DA still constricts less to } \mathrm{O}_{2} \text {. }\end{array}$ & \\
\hline $\begin{array}{l}\text { (Waleh et al. } \\
\text { 2004) }\end{array}$ & $\begin{array}{l}\text { Lamb/ 96-107 } \\
\text { and } 135-144 d\end{array}$ & $\begin{array}{l}\text { The immature DA is more sensitive to the relaxant effect of } \mathrm{PGE}_{2} \text { than late } \\
\text { gestation. EP receptor activation increases cAMP production and activation } \\
\text { of } \mathrm{K}_{\text {ATP }} \text { channels. Higher cAMP production in immature, but no change in }\end{array}$ & $\begin{array}{l}\text { The immature fetus is } \\
\text { more sensitive to the } \\
\text { relaxant effect of } \mathrm{PGE}_{2}\end{array}$ \\
\hline
\end{tabular}




\section{Endothelin-1}

ET-1, which is synthesized by the vascular endothelium, is a very powerful vasoconstrictor (Katzung 1995). An endothelin precursor, big ET-1 or pro-ET-1, is cleaved to ET-1 (21 amino acids) by an endothelin-converting enzyme (ECE) found on the endothelial cell membrane (Rubanyi and Botelho 1991). Two receptor subtypes, termed $\mathrm{ET}_{\mathrm{A}}$ and $\mathrm{ET}_{\mathrm{B}}$ have been identified. The $\mathrm{ET}_{\mathrm{A}}$ receptor is coupled to a G-protein linked to PLC and the formation of $\mathrm{IP}_{3}$ (Yoshida et al. 1994). $\mathrm{ET}_{\mathrm{B}}$ receptors are located on vascular endothelial cells, where they mediate relaxation (Yoshida et al. 1994). The complete sequence of the avian and mammalian $\mathrm{ET}_{\mathrm{A}}$ receptor displays a high similarity with conserved binding affinity for the mammalian ET-1 (Kempf et al. 1998).

ET-1 appears to play a role in producing the basal tone of the foetal ductus (Coceani et al. 1999) and may be involved in the closure of the DA. However, the actual role of endothelin as a mediator of ductus constriction at birth is debated. Blocking $\mathrm{ET}_{\mathrm{A}}$ and $\mathrm{ET}_{\mathrm{B}}$ receptors inhibit the closure of the $\mathrm{DA}$ in foetal rats (Taniguchi et al. 2001), but not in lambs (Fineman et al. 1998), nor in mice (Coceani et al. 1999). The postnatal closure, which is triggered by an increase in blood $\mathrm{O}_{2}$, may be mediated by ET-1 (Coceani et al. 1999; Taniguchi et al. 2001; Shen et al. 2002).

Table 4. Summary of literature concering the effect of endothelin on the DA.

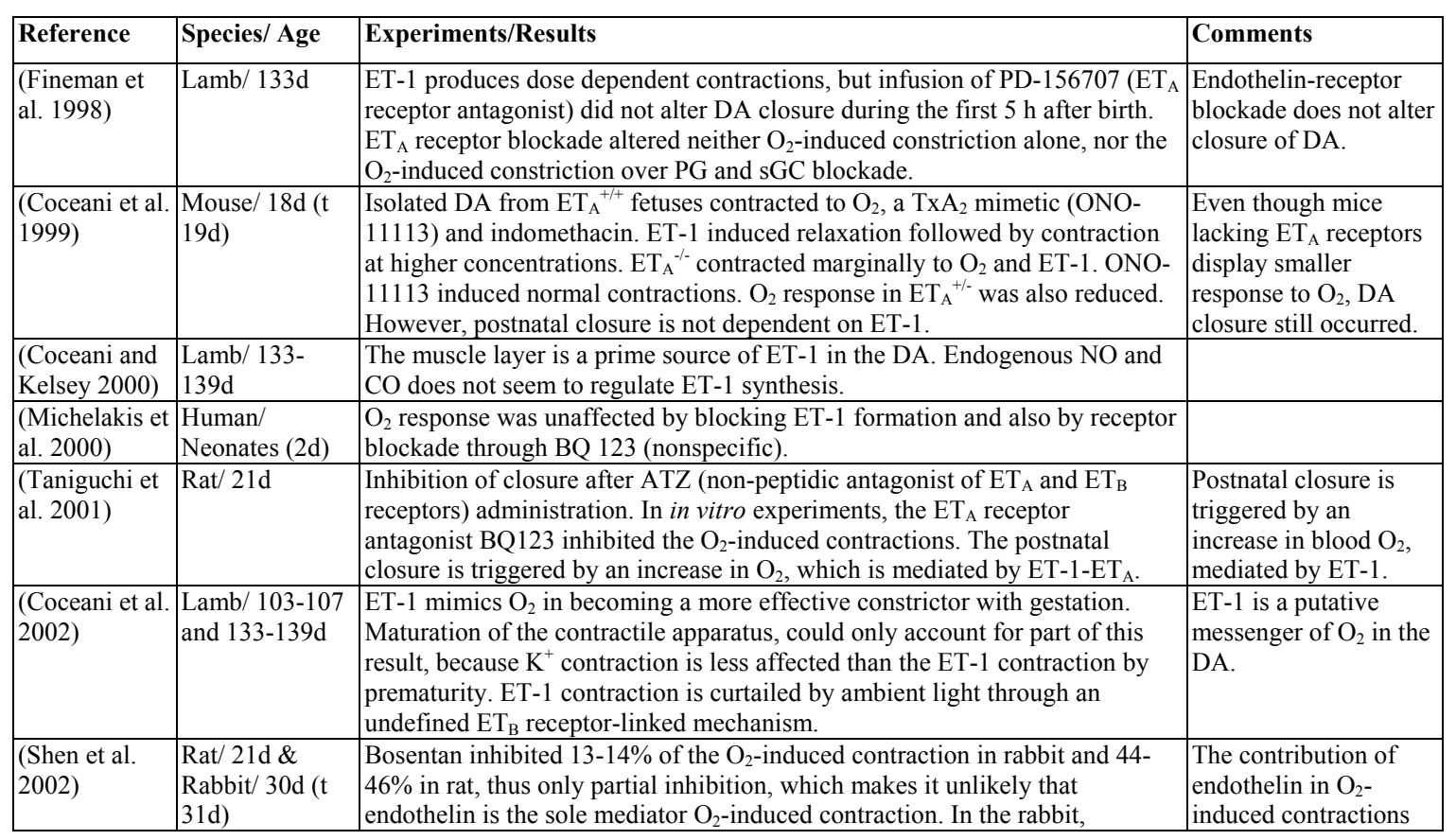




\begin{tabular}{|l|l|l|l|}
\hline & & $\begin{array}{l}\text { endothelin is present in both endothelium and VSM, but it is only released } \\
\text { from the endothelium in response to } \mathrm{O}_{2} .\end{array}$ & $\begin{array}{l}\text { differs between } \\
\text { species. }\end{array}$ \\
\hline $\begin{array}{l}\text { (Momma et } \\
\text { al. 2003) }\end{array}$ & Rat/19 and 21d & $\begin{array}{l}\text { Bosentan }\left(\mathrm{ET}_{\mathrm{A}} \text { and } \mathrm{ET}_{\mathrm{B}} \text { receptor antagonist) blocks fetal DA constriction, }\right. \\
\text { most effectively in combination with indomethacin. }\end{array}$ & \\
\hline
\end{tabular}

\section{NITRIC OXIDE}

$\mathrm{NO}$ is derived from the amino acid L-arginine. The conversion of L-arginine to Lcitrulline and NO is catalyzed by a family of enzymes termed NOS (Arnal et al. 1999). Several NOS isoenzymes have been isolated and purified (Rang et al. 1995). They can be divided into three main groups (Clyman et al. 1998): neuronal (nNOS), endothelial (eNOS) and inducible (iNOS). There is an essential distinction between the inducible form (iNOS, expressed in response to pathological stimuli) and the socalled constitutive forms of the enzyme that are present under physiological conditions (nNOS and eNOS, activated in the presence of $\mathrm{Ca}^{2+}$ ). $\mathrm{Ca}^{2+}$ catalyses the binding of CaM to NOS, and thereby activates the enzyme. The most important stimuli controlling endothelial NO synthesis under physiological conditions include mechanical factors, pulsatile flow and shear stress (Rang et al. 1995).

NO readily permeates biological membrane barriers, and diffuses into the cytosol, where it rapidly binds to the heme prosthetic group of soluble guanylate cyclase (sGC), and increases intracellular levels of the second messenger, cyclic guanosine monophosphate (cGMP, Takizawa et al. 2000b; Sendao Oliveira and Bendhack 2004, for more information on the action of cGMP see section III 7).

Several studies indicate that NO contributes to the patency of the DA, but to a lesser extent than dilator PGs, suggesting that $\mathrm{NO}$ is an accessory to $\mathrm{PGE}_{2}$ in the regulation of ductal patency (Coceani et al. 1994 (lamb); Takizawa et al. 1999 (rat); Seidner et al. 2001 (baboon)). Some experiments suggest a cooperative role of PGs and NO, since NO production increases in mouse DA if either COX enzyme is deleted (Baragatti et al. 2003).

Developmental changes in the role of PG and NO have been reported in several species. Animal studies suggest that in the immature foetus ( $<80 \%$ gestation) the DA expresses abundant NOS (primarily the endothelial isoform) relative to the near-term foetus, and that the products of this enzyme (i.e. NO) contribute significantly to DA patency (Takizawa et al. 2000b; Richard et al. 2004). Accordingly, inhibition of NOS was found to exert a greater effect in closing the DA of the immature foetus, whereas COX inhibition exerted greater effect in the nearterm foetus (Momma and Toyono 1999; Takizawa et al. 2000b; Kajino et al. 2001; 
Richard et al. 2004). The shift from NO to PGs in mediation of foetal ductal dilation

may be preparative for postnatal closure (Momma and Toyono 1999).

Table 5. Summary of literature concerning the effect of NO on the DA.

\begin{tabular}{|c|c|c|c|}
\hline Reference & Species/ Age & Experiments/Results & Comments \\
\hline $\begin{array}{l}\text { (Aronson et } \\
\text { al. 1970) }\end{array}$ & $\begin{array}{l}\text { Human/ 10-21 } \\
\text { wk }\end{array}$ & $\begin{array}{l}\text { The human DA contracted to ACh and BK. Dose-response curve to ACh } \\
\text { was similar in the aortic and pulmonary ends. }\end{array}$ & \\
\hline $\begin{array}{l}\text { (Knight et al. } \\
1973)\end{array}$ & $\begin{array}{l}\text { Dog/ Near- } \\
\text { term }\end{array}$ & $\begin{array}{l}\text { The DA constricted in response to ACh. After repeated challenges with } \mathrm{O}_{2} \text {, } \\
\text { the DA became refractory to } \mathrm{O}_{2} \text { but not to ACh or NE. Ductus from PDA- } \\
\text { related fetuses tended to be more widely patent, and responded less to ACh. }\end{array}$ & \\
\hline \begin{tabular}{|l} 
(Noel and \\
Cassin 1976)
\end{tabular} & $\begin{array}{l}\text { Guinea pigs/ } \\
\text { 40d-term } \\
(60 \mathrm{~d})\end{array}$ & $\begin{array}{l}\text { Over high }(95 \%) \mathrm{O}_{2} \text {-induced contraction, } \mathrm{BK} \text { and } \mathrm{ACh} \text { caused an } \\
\text { augmentation, while neither epinephrine nor NE did. }\end{array}$ & \\
\hline $\begin{array}{l}\text { Walsh and } \\
\text { Mentzer } \\
1987)\end{array}$ & $\begin{array}{l}\mathrm{Lamb} / 125- \\
135 \mathrm{~d}\end{array}$ & $\begin{array}{l}\text { Both cAMP- and cGMP-induced relaxation exist in DASMC of fetal } \\
\text { lambs. Nitrovasodilators stimulates increase in both cyclic nucleotides. } \\
\text { Nitroglycerin and nitroprusside are more effective relaxants than PGE }\end{array}$ & $\begin{array}{l}\text { Experiments without } \\
\text { indomethacin to block } \\
\text { basal PGs production. }\end{array}$ \\
\hline $\begin{array}{l}\text { (Coceani et al. } \\
1994)\end{array}$ & $\begin{array}{l}\mathrm{Lamb} / 133- \\
143 \mathrm{~d}\end{array}$ & $\begin{array}{l}\text { BK relaxed indomethacin contracted DA dose dependently with greater } \\
\text { peak relaxation at high } \mathrm{PO}_{2} \text {. The relaxation was abolished in endothelium- } \\
\text { denuded preparations. Pretreatment with NO inhibitors also prevented, in } \\
\text { part (methylene blue) or in full (L-NAME), the relaxant effect. L-NAME } \\
\text { and methylene blue contracted both intact and denuded. }\end{array}$ & $\begin{array}{l}\text { BK-induced relaxation } \\
\text { was abolished in } \\
\text { endothelium-denuded } \\
\text { preparations. }\end{array}$ \\
\hline \begin{tabular}{|l} 
(Bustamante \\
et al. 1996)
\end{tabular} & $\begin{array}{l}\text { Rat/21d (t } \\
21.5 \mathrm{~d})\end{array}$ & $\begin{array}{l}\text { NO, generated by iNOS, partly controls DA caliber in the rat fetus. L-NIL } \\
\text { (iNOS inhibitor) induced greater DA constriction, than L-NAME. }\end{array}$ & $\begin{array}{l}\text { iNOS inhibition caused } \\
\text { larger contractions than L- } \\
\text { NAME. }\end{array}$ \\
\hline $\begin{array}{l}\text { (Clyman et al. } \\
1998)\end{array}$ & $\begin{array}{l}\mathrm{Lamb} / 60- \\
139 \mathrm{~d}\end{array}$ & $\begin{array}{l}\text { L-NAME, methylene blue and LY83583 constriction at neonatal }(30 \%) \mathrm{O}_{2} \\
\text { tension, but had no or small effects at fetal }(0 \%) \mathrm{O}_{2} \text {. Relaxation to SNP and } \\
\text { Ca ionophore (A23187) decreased with age, while 8Br cGMP response did } \\
\text { not change. Both eNOS and iNOS were detected. eNOS was expressed in } \\
\text { endothelial cells of the lumen and in the vasa vasorum. Endothelial removal } \\
\text { partially blocks the effect of L-NAME, methylene blue and LY83583. }\end{array}$ & $\begin{array}{l}\text { Developmental decrease in } \\
\text { relaxations to SNP and a } \\
\text { Ca inonophor, but no } \\
\text { change in } 8 \text { Br cGMP- } \\
\text { induced relaxation with } \\
\text { age. }\end{array}$ \\
\hline $\begin{array}{l}\text { (Momma and } \\
\text { Toyono 1999) }\end{array}$ & $\begin{array}{l}\text { Rat/ } 19 \text { and } \\
21 \mathrm{~d}\end{array}$ & $\begin{array}{l}\text { NO plays a major role in DA patency in fetal rats at the } 19^{\text {th }} \text { day of } \\
\text { gestation, while it plays only a minor role in near-term fetuses. }\end{array}$ & \\
\hline $\begin{array}{l}\text { (Takizawa et } \\
\text { al. 1999) }\end{array}$ & Rat/21d & $\begin{array}{l}\text { L-NAME caused slight constriction of the DA, whereas methylene blue } \\
\text { and indomethacin caused marked constriction of the DA, suggesting that } \\
\text { the NO-cGMP system as well as PGs contributes to the DA patency. }\end{array}$ & $\begin{array}{l}\text { NO-cGMP as well as PGs } \\
\text { contributes to the DA } \\
\text { patency. }\end{array}$ \\
\hline \begin{tabular}{|l} 
(Takizawa et \\
al. 2000b)
\end{tabular} & Rat/ 17-21d & $\begin{array}{l}\text { The supplementary role of NO in determining the patency of the DA may } \\
\text { be restricted to 19-day-old and more immature fetuses, while PGs may not } \\
\text { play a leading role in the regulation of the DA at these stages. }\end{array}$ & $\begin{array}{l}\text { NO contributes more to } \\
\text { the regulation of DA } \\
\text { patency in the premature. }\end{array}$ \\
\hline $\begin{array}{l}\text { (Takizawa et } \\
\text { al. 2000a) }\end{array}$ & Rat/21d & $\begin{array}{l}\text { Inhibition with indomethacin and L-NAME or methylene blue causes a } \\
\text { rapid increase in DA caliber followed by a subsequent decrease. }\end{array}$ & \\
\hline $\begin{array}{l}\text { (Rairigh et al. } \\
2000)\end{array}$ & Lamb/ 128d & $\begin{array}{l}\text { nNOS was detected in DA media or adventitia. 7-NINA (nNOS- } \\
\text { antagonist) caused mild contraction of DA. }\end{array}$ & \\
\hline $\begin{array}{l}\text { (Michelakis et } \\
\text { al. 2000) }\end{array}$ & $\begin{array}{l}\text { Human/ } \\
\text { Neonates }\end{array}$ & $\begin{array}{l}\text { Inhibition of } \mathrm{PG} \text { and } \mathrm{NO} \text { synthesis enhanced the } \mathrm{O}_{2} \text { constriction and } \\
\text { decreased the threshold of } \mathrm{PO}_{2} \text { needed for a response to occur. }\end{array}$ & \\
\hline $\begin{array}{l}\text { (Kajino et al. } \\
2001)\end{array}$ & $\begin{array}{l}\text { Lamb/ 103- } \\
107 \text { and } 131- \\
137 d\end{array}$ & $\begin{array}{l}\text { NOS and COX inhibitors increased sensitivity to } \mathrm{O}_{2} \text {. A greater increment in } \\
\text { contractile force was obtained in the preterm, probably due to increased } \\
\text { sensitivity to PGs and NO. The intrinsic tone not sensitive to } \mathrm{O}_{2} \text { was } 64 \pm \\
7 \% \text { in late gestation, while only } 34 \pm 10 \% \text { in the premature. Due to the poor } \\
\text { intrinsic tone in the immature DA and its exaggerated response to NO, the } \\
\text { effects of indomethacin may not be apparent in vivo, while it may appear to } \\
\text { have a greater effect in late gestation, due to the increased intrinsic tone and } \\
\text { decreased responsiveness to NO. }\end{array}$ & $\begin{array}{l}\text { The smaller intrinsic tone, } \\
\text { and increased sensitivity to } \\
\text { vasodilators can explain } \\
\text { the high rate of reopening } \\
\text { in extremely premature } \\
\text { infants. }\end{array}$ \\
\hline $\begin{array}{l}\text { (Thebaud et } \\
\text { al. 2002) }\end{array}$ & Rabbit/ 30d & $\begin{array}{l}\text { Sildenafil reverses and prevents } \mathrm{O}_{2} \text { constriction in the DA by increasing } \\
\text { cGMP levels and activating DASMC BK } \mathrm{BK}_{\mathrm{Ca}} \text { channels. Sildenafil } \\
\text { hyperpolarizes DASMC by opening } \mathrm{K}^{+} \text {channels, causing vasodilation. }\end{array}$ & $\begin{array}{l}\text { Sildenafil hyperpolarizes } \\
\text { DASMC, causing } \\
\text { vasodilation. }\end{array}$ \\
\hline $\begin{array}{l}\text { (Baragatti et } \\
\text { al. 2003) }\end{array}$ & $\begin{array}{l}\text { Mouse/ 19d } \\
\text { and neonates }\end{array}$ & $\begin{array}{l}\text { NO contributes to the patency, but less than PGs, however deletion of } \\
\text { either COX enzyme caused an increased contraction induced by L-NAME, } \\
\text { implying a cooperative role between PGs and NO. eNOS appears to be the } \\
\text { only NO-forming enzyme in the mouse DA. }\end{array}$ & $\begin{array}{l}\text { Upregulation of NO } \\
\text { production occurs if either } \\
\text { COX enzyme is deleted. }\end{array}$ \\
\hline $\begin{array}{l}\text { (Richard et al. } \\
\text { 2004) }\end{array}$ & $\begin{array}{l}\text { Mouse/ 17- } \\
19 \mathrm{~d}\end{array}$ & $\begin{array}{l}\text { NO more important in the premature than in the term, despite persistent } \\
\text { eNOS expression even in the constricted postnatal DA. eNOS is the } \\
\text { predominant NOS isoform. Ductal closure in the mouse occurs in the } \\
\text { absence of vasa vasorum. Gestational maturity has significant, but opposite } \\
\text { effects on NO and PG regulation of the mouse DA. }\end{array}$ & $\begin{array}{l}\text { NO more important in DA } \\
\text { patency in the premature } \\
\text { than the term, while the } \\
\text { opposite occurs with PGs. }\end{array}$ \\
\hline $\begin{array}{l}\text { (Thebaud et } \\
\text { al. 2004) }\end{array}$ & $\begin{array}{l}\text { Rabbit/26 } \\
\text { and 30d \& } \\
\text { Human/ term }\end{array}$ & $\begin{array}{l}\text { Preterm DA constricts less to } \mathrm{O}_{2} \text {, even after COX and NOS inhibition, } \\
\text { which enhanced the preterm response more. }\end{array}$ & \\
\hline $\begin{array}{l}\text { (Momma et } \\
\text { al. 2005) }\end{array}$ & $\begin{array}{l}\text { Rat/ } 19 \text { and } \\
21 d\end{array}$ & $\begin{array}{l}\text { Sildenafil, dilated fetal DA constricted with indomethacin very effectively, } \\
\text { but only large doses induced a moderate dilation in neonatal DA. }\end{array}$ & $\begin{array}{l}\text { Sildenafil more effective } \\
\text { in fetal than neonatal. }\end{array}$ \\
\hline
\end{tabular}




\section{Cathecholamines}

Catecholamines are both neurotransmitters and hormones. They exert their effects by activation of cell surface adrenoceptors on VSMC (Salomonsson and Arendshorst 2001). Adrenoceptors are $G$ protein-coupled receptors that can be subdivided into three main families $\alpha_{1}, \alpha_{2}$ and $\beta$ (Wall et al. 2004) on the basis of both agonist and antagonist selectivity (Katzung 1995). Generally $\alpha$ receptors cause contractions through activation of the $\mathrm{IP}_{3}$ pathway, while $\beta$ receptors cause relaxation by activation of AC (Randall et al. 2001). VSM contains both $\alpha$ and $\beta$ adrenoceptors, thus the net response to an agonist depend not only on the agonist of use, but also on the relative importance of each receptor in that specific tissue (Guimaraes and Moura 2001).

Catecholamines are important both early and late in gestation. They are important in the formation of the aortic arches, and anomalies may be induced in chicken embryos via $\beta$-adrenoceptor stimulation (Gilbert et al. 1977). Moreover, activation of the $\beta$-adrenergic receptor mechanism is directly related to cardiovascular anomalies produced in the chick embryos (Hodach et al. 1975). While at birth, a marked increase in circulating plasma catecholamine concentration facilitates the transition to extrauterine life (Eliot et al. 1980; Wittmann and Prechtl 1991).

The human DA, as well as other mammalian DA, has been shown to be innervated with catecholamine containing nerves (Corbet 1998; Smith 1998). The abundant nerve supply in the human DA is distributed throughout the SM media and is present from an early stage of gestation (Boreus et al. 1969; Aronson et al. 1970). Both lamb and guinea pig DA contract in response to electrical field stimulation (Bodach et al. 1980) and the DA of several species contracted in response to exogenous NE (Kovalcik 1963; Aronson et al. 1970; Smith and McGrath 1988).

The role of $\beta$-adrenoceptors in the control of mammalian DA tone also varies among species (Smith 1998). Infusion of the $\beta$-adrenoceptor antagonist propanolol had no effect on ductal tone in the in vivo lamb (Friedman et al. 1983). Furthermore, in the presence of the $\alpha$-adrenoceptor antagonist phenoxybenzamine, NE was able to relax lamb DA preparations, but the effects were modest even at the highest doses (Bodach et al. 1980). In the newborn rat, propanolol paradoxically delayed DA closure (Arishima et al. 1995), but it has been suggested that this is secondary to the effects of $\beta$-adrenergic blockade on the perinatal cardiovascular homeostasis and not due to a direct effect on ductal tone (Smith 1998). On the other hand, in the guinea pig 
DA, phenoxybenzamine converts the contractile effect of NE to a relaxation and isoproterenol causes a marked relaxation (Bodach et al. 1980). These results together with the lack of a PG-mediated relaxation could point to a special role for $\beta$ adrenoceptors in prenatal patency in the guinea pig.

Table 6. Summary of literature concering the effect of catecholamines on the DA.

\begin{tabular}{|c|c|c|c|}
\hline Reference & Species/Age & Experiments/Results & Comments \\
\hline $\begin{array}{l}\text { (Kovalcik } \\
\text { 1963) }\end{array}$ & $\mathrm{Lamb} / 75-144 \mathrm{~d}$ & $\begin{array}{l}\text { NE and epinephrine have the same effect as } \mathrm{O}_{2} \text {. Atropine and } \\
\text { phentolamine excluded a role for release of ACh or catecholamines in the } \\
\text { response to } \mathrm{O}_{2} \text {. }\end{array}$ & \\
\hline $\begin{array}{l}\text { (Aronson et } \\
\text { al. 1970) }\end{array}$ & Human/ 10-21 wk & $\begin{array}{l}\text { The human DA is innervated with adrenergic nerves. NE, adrenaline } \\
\text { (inhibited by phenoxybenzamine) and tyramine (direct neuronal release), } \\
\text { but not isoproterenol, contracted the DA. Dose-response curves to ACh, } \\
\text { histamine, 5-hydroxytryptamine and NE were similar in the aortic and } \\
\text { pulmonary ends. }\end{array}$ & Human DA innervated \\
\hline $\begin{array}{l}\text { (Ikeda et al. } \\
1972)\end{array}$ & Lamb & $\begin{array}{l}\text { The pulmonary end contained more NE than the aortic end. A } \\
\text { concentration gradient from the pulmonary trunk through to the aorta was } \\
\text { observed. Catecholamine content and NE uptake was consistently higher } \\
\text { in the pulmonary end. }\end{array}$ & $\begin{array}{l}\text { Adrenergic nerve fibers } \\
\text { are unevenly distributed } \\
\text { in the lamb DA. }\end{array}$ \\
\hline $\begin{array}{l}\text { (Knight et al. } \\
1973)\end{array}$ & Dog/ Near-term & $\begin{array}{l}\text { The DA constricted in response to NE. Ductus from PDA-related fetuses } \\
\text { tended to be more widely patent, and responded less to NE. }\end{array}$ & \\
\hline $\begin{array}{l}\text { (Smith and } \\
\text { McGrath } \\
1988)\end{array}$ & Rabbit/ Neonates & $\begin{array}{l}\text { Indomethacin increased DA sensitivity to NE tenfold, implying that } \\
\text { intramurally PGs, decrease the sensitivity to NE. } \mathrm{O}_{2} \text { tension did not } \\
\text { change the sensitivity of the DA to NE. }\end{array}$ & $\begin{array}{l}\text { COX products decrease } \\
\text { the sensitivity of the DA } \\
\text { to NE. }\end{array}$ \\
\hline
\end{tabular}

\section{Cyclic nucleotides (cAMP, cGMP)}

The second messengers, cyclic nucleotides (cAMP and cGMP) play a regulatory role in SMCs (Matsumoto et al. 2003). Both cAMP and cGMP cause SM relaxation in large part through their effects to lower intracellular $\mathrm{Ca}^{2+}$ or activate myosin phosphatase (Rybalkin et al. 2003). The intracellular levels of cAMP and cGMP are tightly controlled both by their rate of synthesis (by AC and GC, respectively) in response to extracellular signals, and by their rate of hydrolysis by cyclic nucleotide phosphodiesterases (PDEs Matsumoto et al. 2003). NO, and NO donors regulate SM tone through activation of GC, elevation of cGMP, and activation of cGMP-dependent protein kinase, known as PKG (Rybalkin et al. 2003). The most common relaxant mechanism of PGs and $\beta$-adrenoceptor activation are induced through stimulation of a $\mathrm{G}$ protein-coupled receptor that changes the activity of $\mathrm{AC}$, leading to the production of the second messenger cAMP, and thus activation of the cAMP-dependent protein kinase, known as PKA (Katzung 1995; Bos et al. 2004). Both pathways facilitate 
relaxation by reducing cytoplasmic $\mathrm{Ca}^{2+}$ and decreasing the sensitivity of the contractile apparatus to $\mathrm{Ca}^{2+}$ (Sendao Oliveira and Bendhack 2004).

cGMP causes SM relaxation mainly via phosphorylation of several proteins by a cGMP-dependent protein kinase, known as PKG (Sendao Oliveira and Bendhack 2004). Thus, the signal transduction mechanism involving NO is relatively simple compared with that of $\mathrm{PGE}_{2}$, which requires a membrane-bound receptor to activate AC.

Eleven distinct PDE gene families (PDE1-11) are defined based on sequence, catalytic and regulatory considerations. PDE transforms cyclic nucleotides into inactive 5'-nucleotide monophosphates (Carvajal et al. 2000). Although members of the PDE1, PDE2, PDE3, PDE10 and PDE11 families can hydrolyze cAMP or cGMP, PDE4, PDE7, and PDE8 enzymes selectively hydrolyze cAMP. In contrast, PDE5, PDE6, and PDE9 family enzymes selectively hydrolyze cGMP (Maurice et al. 2003).

\section{Others vasoactive mediators}

\subsection{Carbon monoxide (CO)}

Heme oxygenase (HO) is the enzyme that forms $\mathrm{CO}$. $\mathrm{HO}$ exists in two forms, HO-1 and HO-2. Both forms have been found in the DA within the endothelial and SMCs (Coceani et al. 1997). Coceani et al. (1997), showed that CO is formed within the sheep DA, and that it exerts relaxing influence on the SM. CO may therefore contribute to the patency of the DA in vivo in combination with $\mathrm{PGE}_{2}$ and NO. However, under physiological conditions the amount of CO made by the DA does not seem to affect DA tone, but in situations where the synthesis is upregulated it may exert a relaxing effect (Clyman 2006). Thus, the importance of CO in prenatal DA patency is not clear.

\subsection{Endothelium derived hyperpolarizing factor}

EDHF causes hyperpolarization of the SM membrane, but the mechanism remains unclear (Bolotina et al. 1994; Coleman et al. 2004; Sendao Oliveira and Bendhack 2004). There are several main theories about the nature of EDHF, most of them involve the role of the endothelial $\mathrm{K}_{\mathrm{Ca}}$. One theory states that the endothelial hyperpolarization following $\mathrm{K}_{\mathrm{Ca}}$ channels activation spreads to the vascular myocytes via myoendothelial gap junctions (Coleman et al. 2004). Some variations between vascular beds and species in the density and relative importance of the different $\mathrm{K}_{\mathrm{Ca}}$ 
channels seem to occur. $\mathrm{BK}_{\mathrm{Ca}}$ may be important in some vessels, while intermediate and small $\mathrm{K}_{\mathrm{Ca}}$ channels $\left(\mathrm{IK}_{\mathrm{Ca}}\right.$ and $\left.\mathrm{SK}_{\mathrm{Ca}}\right)$ are more important in other vascular beds (Coleman et al. 2004). It is important to note that membrane hyperpolarization is a phenomenon that is measured only in vitro. Thus, the existence of a hyperpolarizing factor in vivo has been deduced to play a role in vasodilatation by the noted failure of NOS inhibitors to completely block endothelium dependent vasodilatation (Sendao Oliveira and Bendhack 2004). However, there are some evidence suggesting a role for EDHF in controlling blood pressure in rats, from experiments with double knockouts for both COX-1 and NOS (Scotland et al. 2005). Based on this study it seems to be a gender-related difference in the role of EDHF and that this decreases the risk of hypertension in females.

Only one study by Baragatti et al. (2007), have shown the presence of EDHF in the DA (mouse). A relaxation to $\mathrm{BK}$ after suppression of $\mathrm{NO}, \mathrm{CO}$ and $\mathrm{PGE}_{2}$ formation was found. Thus far this is the only study investigating the presences of EDHF in the DA. 


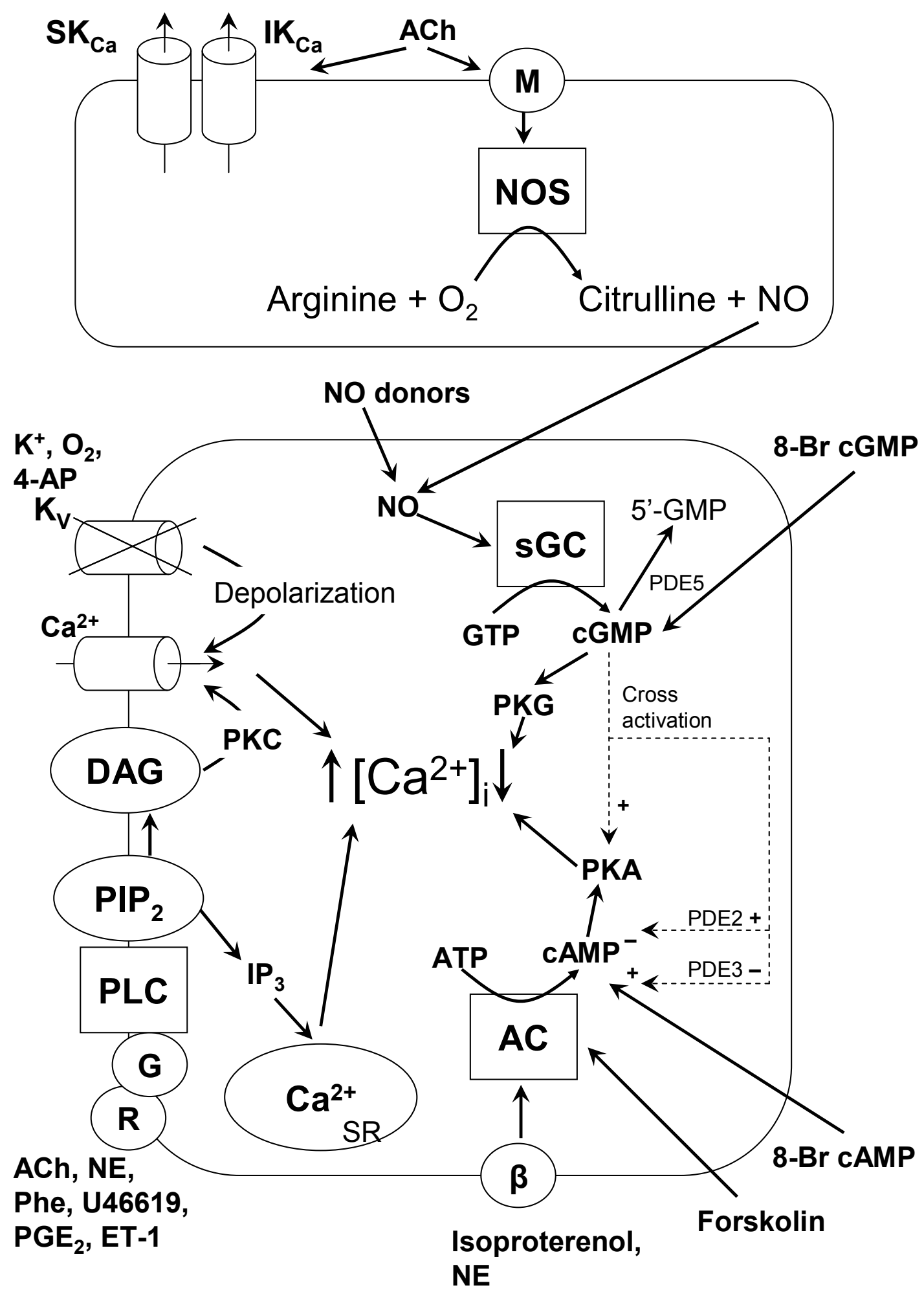

Figure 4. Schematic drawing over vascular responses, and action of different drugs. For more information see section III. 


\section{The chicken embryo/fetus as a model}

\section{General introduction}

\subsection{Why the chick embryo?}

The chicken embryo has a cardiovascular system that is similar to mammals. The basic mechanisms of controlling vascular contractility also seem to be very similar in chicken and mammalian species (Altimiras and Crossley 2000). However, even though the chicken embryo is seen as one of the standard models for studies of developmental biology (Wolpert et al. 2002), no one has ever studied the vascular reactivity of the chicken DA before. Through a search in PubMed over the most common animal models, it was found that the majority of studies of the DA were performed in lamb (39\%), dog (18\%) and rat models (12\%), while the amount of studies in chickens was less than $1 \%$ (Figure 5.). The complexity of the available, mammalian, models is causing a limitation of the knowledge (Sutendra and Michelakis 2007). As the chicken develops outside the mother, effects of prenatal stress can be studied without interference of maternal hormonal, metabolic or hemodynamic effects (Ruijtenbeek et al. 2002a). Many mammals also have a relatively long gestation period. The chicken embryo has even more advantages compared to mammalians:

- Eggs are widely available and cheap.

- The incubation in breeding machines makes it easy to monitor and maintain equal conditions.

- Short incubation period of only 21 days.

- The nutrient supply is separated from the respiration, which makes it easy to perform experiments with hypoxia or malnutrition.

In the last years, our group has accumulated a broad experience in the study of developmental circulation of chicken embryos and in the effects of adverse stimuli, such as hypoxia or malnutrition, on pulmonary and systemic vascular function and structure (le Noble et al. 2000; Ruijtenbeek et al. 2000; Ruijtenbeek et al. 2002a; Ruijtenbeek et al. 2002b; Villamor et al. 2002; Ruijtenbeek et al. 2003a; Ruijtenbeek et al. 2003b; Villamor et al. 2004; Villamor et al. 2005). 


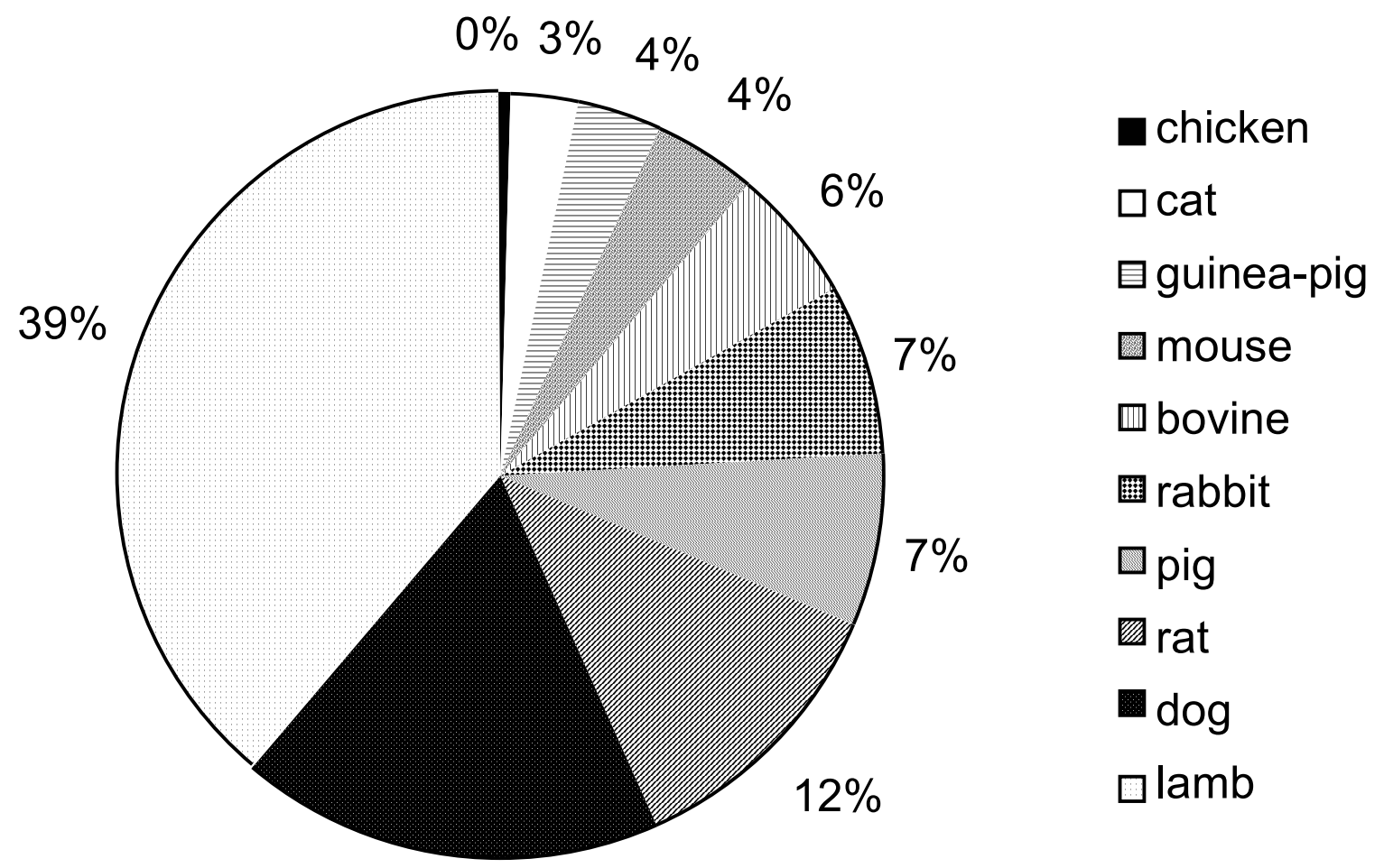

$18 \%$

Figure 5. The spread of studies on the ductus arteriosus in different animal models, based on a search in PubMed (http://www.ncbi.nlm.nih.gov/pubmed/).

\subsection{In ovo circulation compared to the mammalian foetal circulation}

The avian embryo has a mammalian-like circulation with an extra-embryonic circuit involved in the gas exchange, the chorioallatoic membrane or CAM (Metcalfe and Stock 1993). The CAM comes about through a fusion of the allantois and the chorion, at around 100 hours of incubation (Rahn et al. 1985). It is a very thin wellvascularized membrane on the inside of the eggshell. With the CAM's single umbilical vein, and the meshwork of fine capillaries, it displays similar functions as the homologue, the mammalian placenta, but it differs from the placenta anatomically (Rahn et al. 1985).

The chicken embryo derives food through the viteline vein which carries digested yolk material to the liver (White 1974). In the chicken embryo, unlike the mammal, the umbilical blood flows directly to the inferior vena cava without entering the liver (White 1974). Blood returning from the liver and from the CAM is mixed before entering the heart. Thus, in both chickens and mammals the oxygenated blood from the respiratory organ is diluted with blood from the posterior regions of the embryo before it enters the heart (White 1974). The blood entering from the inferior 
vena cava is shunted to the right atrium via the interatrial pores, which corresponds to the mammalian foramen ovale (White 1974). A considerable part of the output from the right ventricle bypasses the non-functional lungs by flowing through the two DA. The first vessel diverting from the aorta are the brachiocephalic arteries, leading highoxygenated blood to the head and neck region. This flow of blood and $\mathrm{O}_{2}$ is greater in the chicken embryo compared to the sheep foetus (White 1974). As a consequence, little blood from the left ventricle enters the dorsal aorta to return to the posterior body and the chorioallantois. For this reason the blood returning to the CAM has very low $\mathrm{O}_{2}$ saturation in the chicken compared to the mammal (30\% compared to $58 \%$ ). Another difference between mammals and chickens is the $\mathrm{O}_{2}$ gain in the respiratory system; the chicken seems to gain more $\mathrm{O}_{2}$ via the CAM than the mammal gains from the placenta. This might reflect the fact that the chicken derives its $\mathrm{O}_{2}$ directly from the air, whereas the mammalian fetus has to derive it from the maternal blood flow (White 1974). In the late stages of development the surface area of the CAM is not great enough to maintain a complete saturation of the umbilical blood or to eliminate the increasingly large amounts of carbon dioxide $\left(\mathrm{CO}_{2}\right)$ produced by the growing embryo (White 1974).

In summary, the main differences between the mammalian and chicken embryo is the separation between the $\mathrm{O}_{2}$ and nutrient supply in birds. This leads to some changes in the blood flow; especially there is no need for a ductus venosus in birds. In birds both the left and right DA are maintained operational throughout embryonic life (Bergwerff et al. 1999). Also in contrast to mammals, the aorta loops right in birds, whereas it loops left in mammals (Bellaris and Osmond 1998). The avian embryo has interatrial pores in the heart instead of the foramen ovale, however the function remains the same.

\subsection{Transition to ex ovo life}

During the incubation, the embryo loses water that is replaced by air, which at the blunt end of the egg creates the air sack. Because of the limited gas exchange capacity of the eggshell, on the one hand, and the increasing metabolic rate of the embryo, on the other hand, the partial pressure of $\mathrm{O}_{2}$ in the air sack decreases whereas the amount of $\mathrm{CO}_{2}$ increases with age, leading to a hypoxic state towards the end of the incubation (Wittmann and Prechtl 1991). The hypoxia reaches a maximum at around day 19 of incubation. At this time, internal pipping occurs and pulmonary ventilation 
is started, allowing the embryo to begin the transition from diffusive respiration to convective breathing (Rahn et al. 1985). Thus exposure to $\mathrm{O}_{2}$ occurs more gradually in the chicken embryo than in the mammalian foetus (Rahn et al. 1974). Internal pipping marks the end of the prenatal period and start of the paranatal period, that continues for about 24 hours. During the paranatal period the $\mathrm{O}_{2}$ uptake from the CAM declines and a gradual transition occurs toward convective gas exchange by the lungs. At the same time, the blood flow to the CAM declines and is routed towards the lungs (Rahn et al. 1985). On average $12.3 \mathrm{~h}$ after internal pipping the embryo penetrates the eggshell (Burton et al. 1989), a process called external pipping, and the embryo gains access to atmospheric air. The paranatal period ends with the hatching act (Rahn et al. 1985).

\section{Ontogeny of vascular reactivity in the chicken embryo}

Developmental changes in the vascular reactivity have been described in systemic and pulmonary vessels of the chicken embryo (le Noble et al. 2000; Villamor et al. 2002). The diameter of the vessels leading to an optimal contractile response (optimal diameter) increased with incubation from $\sim 360$ to $450 \mu \mathrm{m}$ in femoral arteries, from $\sim 370$ to $470 \mu \mathrm{m}$ in carotid artery between 15 and 19 days. The amplitude of contractions induced by high $\mathrm{K}^{+}$solution increased by 7 fold in the femoral artery and by 5 fold in the carotid artery in the same time period (le Noble et al. 2000). The optimal diameter in the PAs increased from $\sim 240$ to $520 \mu \mathrm{m}$ between 19 and 21 days (15 days not studied) and an almost 2 fold increase in amplitude occurred during the same time period (Villamor et al. 2002).

Adrenergic stimulation with NE and Phe induced strong contractions in the femoral artery that increased significantly with development (le Noble et al. 2000). The carotid artery responded to NE and Phe in the 19-day but not in the 15-day embryos (le Noble et al. 2000). Electrical field stimulation induced frequencydependent contractions only in the 19-day femoral artery (le Noble et al. 2000). The PAs displayed small contractions to NE and Phe, and the amplitude even decreased between 19 and 21 days (Villamor et al. 2002).

Other contractile agents such as the TxA 2 mimetic U46619 and ET-1 have been studied in the PAs. They induced concentration-dependent contractions, which increased in amplitude between 19 and 21 days (Villamor et al. 2002). 
Endothelium-dependent relaxations have previously been studied, by using ACh. Also relaxations through the NO donor SNP have been evaluated. Both induced concentration-dependent relaxations in all three types of vessels (le Noble et al. 2000; Villamor et al. 2002). The relaxations were almost complete in femoral and carotid arteries, while in PAs the relaxation was around 60-75\%. L-NAME halved the response in the PAs, while only small but significant changes were obtained in carotid and femoral arteries (le Noble et al. 2000; Villamor et al. 2002). Indomethacin did not change the ACh-induced relaxations in the PAs and was not tested in the carotid and PAs. The relaxations to both ACh and SNP were significantly higher after contraction with ET-1 than with $\mathrm{K}^{+}$in the PAs (Villamor et al. 2002).

\section{Effects of prenatal insults on chicken embryo vascular reactivity}

The effects of chronic hypoxia $\left(15 \% \mathrm{O}_{2}\right.$ instead of $21 \%$ ) during incubation have been studied in the chicken embryo. Hypoxia from day 6 of incubation to day 19 reduced embryo survival and in the surviving embryos the body mass at day 19 was significantly reduced (Ruijtenbeek et al. 2000; Villamor et al. 2004). Chronic hypoxia tended to increase the NE content of the femoral artery and increased the density of catecholamine-containing nerves (Ruijtenbeek et al. 2000). In vitro preparations of the femoral arteries responded to high $\mathrm{K}^{+}$and NE stimulation with contraction, where a slight decrease in sensitivity to NE was observed. The $\beta$-adrencergic agonist isoproterenol induced only marginal relaxation in $\mathrm{K}^{+}$contracted vessel, but there were no difference between hypoxic and control embryos (Ruijtenbeek et al. 2000).

PAs of hypoxic embryos showed reduced optimal diameter and amplitude to high $\mathrm{K}^{+}$solution (Villamor et al. 2004). Also the amplitudes of the contractions induced by NE, U46619, ET-1 or electrical field stimulation was significantly smaller in hypoxic embryos. However, the change in agonist-induced contraction was not present after normalization for $\mathrm{K}^{+}$response. Relaxations induced by $\mathrm{ACh}$, SNP or forskolin over $\mathrm{K}^{+}$contraction were not significantly different between hypoxic and normoxic embryos in either pulmonary or femoral arteries (Villamor et al. 2004).

Protein malnutrition by removal of $10 \%$ of total albumen content at day 0 resulted in decreased body weight at day 19 (Ruijtenbeek et al. 2003b). Protein reduction did not change optimal diameter but the amplitude of the response to high $\mathrm{K}^{+}$was significantly reduced. The relaxations induced by ACh and SNP were not significantly modified. 


\section{Embryology and development of chicken DA}

The pattern of development of the chicken embryonic arterial system is comparable with that of mammalian embryos (Bellaris and Osmond 1998). The aortic arches are blood vessels that supply the pharyngeal arches and serve as a communication between the ventral and dorsal aortae. The aortic arches do not develop at once and some are of a transitory nature, disappearing before others have even begun to form (Bellaris and Osmond 1998). The DA is developed from the sixth aortic arch. The sixth arch artery, or pulmonary arch artery, arises as a ventral outgrowth of the dorsal aorta and blends into a ventral splanchnic plexus before it connects to the aortic sac (de Ruiter et al. 1989).

Along the chicken DA, morphological heterogeneity can be directly observed under the dissection microscope. This heterogeneity have been extensively studied by Bergwerff et al. (1996), who characterized three morphological segments in the sixth aortic arch artery of the chicken by the time of hatching. The first proximal segment displays an elastic morphology, similar to that of the proximal aorta, until it bifurcates into two typically muscular arteries: the DA and the post-ductal PA that show strong actin expression in a small number of cell layers. Downstream from the muscular DA portion, a third elastic segment can be identified (Bergwerff et al. 1996). It has been suggested that this third segment results from the incorporation of dorsal aorta tissue into the sixth arch artery (Hughes 1943; Harms 1967; Bergwerff et al. 1996). Transition between the muscular (proximal) and the elastic (distal) segment of chicken DA can be easily identified because the first one narrows considerably during the last week of in ovo development (Harms 1967; Bergwerff et al. 1996).

Development of a specific phenotype compared to surrounding arteries provides the structural and biomechanical basis for DA constriction after birth (Reese 2006). In the case of the chicken DA, abrupt changes in morphological and functional vascular phenotypes are present along the vessel, indicating a genetic basis for its unique status (Bergwerff et al. 1996; Bergwerff et al. 1998; Bergwerff et al. 1999) and suggesting local differences in the mechanisms leading to its closure. 


\section{Aims and outline of the Thesis}

As mentioned above, significant progress in our understanding of the DA physiology and pathophysiology has been achieved with the use of animal models, including the sheep, the rabbit, the mouse, the rat or primates (Smith 1998; Sutendra and Michelakis 2007). However, mammalian models are technically complex and experimental manipulations affect both the mother and the fetus (Sutendra and Michelakis 2007). Therefore, there is a need for additional models, circumventing these limitations (Sutendra and Michelakis 2007). The general aim of the present Thesis was the implementation of the chicken embryo as an alternative and valid model for the study of the DA developmental physiology and pathophysiology. Therefore, we studied the developmental changes in the responsiveness of the chicken DA to several vasoactive mediators that have been involved in the control of tone and/or closure of the mammalian DA.

$\mathrm{O}_{2}$ is one of the most important factors for closure at birth and therefore we started to study the role of $\mathrm{O}_{2}$ and other vasoconstrictors, which are described in Chapter 2. As portrayed above $\mathrm{O}_{2}$ is not the only factor important for closure, but also the removal of relaxant agents is crucial. Relaxant agents are also involved in keeping the DA patent during the gestation. Many relaxant and contractile agents are produced in the vascular endothelium. Therefore in Chapter 3, we studied the role of endothelial relaxant factors and other agents in the NO-cGMP mediated pathway. PGs are the most important factor in maintaining the mammalian DA patent. In Chapter 4, PGs and other agents acting through the cAMP-mediated pathway are presented.

Respiratory and metabolic acidosis are common events in the clinical course of very preterm infants(Bancalari et al. 2005). However, how acidocis affect the DA has not been studied. In Chapter 5, we studied the influence of hypercarbic and normocarbic acidosis on the DA.

One of the advantages with the chicken embryo as a model is the ease by which chronic hypoxia can be studied. In the mammalian model, it is practically impossible to separate the effect of hypoxia on the embryo from the effect of hypoxia on the mother and the placenta. Since the chicken embryo develops outside the mother, the role of hypoxia can be studied without interference. In Chapter 6 we examined how hypoxia influences the properties and responses of the chicken DA. 
General discussion and future perspectives on the chicken embryo as a model for the study of the DA is presented in Chapter 7. 


\section{References}

Aaronson, P. I., T. P. Robertson, et al. (2006). "Hypoxic pulmonary vasoconstriction: mechanisms and controversies." J Physiol 570(Pt 1): 53-8.

Abman, S. H. (1999). "Abnormal vasoreactivity in the pathophysiology of persistent pulmonary hypertension of the newborn." Pediatr Rev 20(11): e103-9.

Abman, S. H., B. A. Chatfield, et al. (1990). "Role of endothelium-derived relaxing factor during transition of pulmonary circulation at birth." Am J Physiol 259(6 Pt 2): H1921-7.

Abman, S. H., B. A. Chatfield, et al. (1991). "Maturational changes in endotheliumderived relaxing factor activity of ovine pulmonary arteries in vitro." $\underline{\text { Am J }}$ Physiol 260(4 Pt 1): L280-5.

Agren, P., A. L. Cogolludo, et al. (2007). "Ontogeny of chicken ductus arteriosus response to oxygen and vasoconstrictors." Am J Physiol Regul Integr Comp Physiol 292(1): R485-96.

Ahola, T., V. Fellman, et al. (2004). "Plasma 8-isoprostane is increased in preterm infants who develop bronchopulmonary dysplasia or periventricular leukomalacia." Pediatr Res 56(1): 88-93.

Allegaert, K., C. Vanhole, et al. (2004). "Association of patent ductus arteriosus and severe hypothyroidism in term newborns: coincidence or causal?" J Matern Fetal Neonatal Med 16(6): 339-41.

Altimiras, J. and D. A. Crossley, 2nd (2000). "Control of blood pressure mediated by baroreflex changes of heart rate in the chicken embryo (Gallus gallus)." $\underline{\mathrm{Am} \mathrm{J}}$ Physiol Regul Integr Comp Physiol 278(4): R980-6.

Alzamora-Castro, V., G. Battilana, et al. (1960). "Patent ductus arteriosus and high altitude." Am J Cardiol 5: 761-3.

Archer, S. and E. Michelakis (2002). "The mechanism(s) of hypoxic pulmonary vasoconstriction: potassium channels, redox $\mathrm{O}(2)$ sensors, and controversies." News Physiol Sci 17: 131-7.

Archer, S. L., J. Huang, et al. (1993). "A redox-based O2 sensor in rat pulmonary

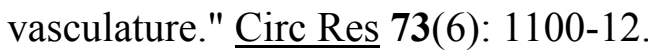

Archer, S. L., E. K. Weir, et al. (2000). "Molecular identification of O2 sensors and O2-sensitive potassium channels in the pulmonary circulation." Adv Exp Med Biol 475: 219-40. 
Arishima, K., T. Takizawa, et al. (1995). "Propranolol inhibits the spontaneous closure of the ductus arteriosus in newborn rats." J Vet Med Sci 57(5): 943-4.

Arnal, J. F., A. T. Dinh-Xuan, et al. (1999). "Endothelium-derived nitric oxide and vascular physiology and pathology." Cell Mol Life Sci 55(8-9): 1078-87.

Aronson, S., G. Gennser, et al. (1970). "Innervation and contractile response of the human ductus arteriosus." Eur J Pharmacol 11(2): 178-86.

Bancalari, E., N. Claure, et al. (2005). "Patent ductus arteriosus and respiratory outcome in premature infants." Biol Neonate 88(3): 192-201.

Baragatti, B., F. Brizzi, et al. (2003). "Cyclooxygenase-1 and cyclooxygenase- 2 in the mouse ductus arteriosus: individual activity and functional coupling with nitric oxide synthase." Br J Pharmacol 139(8): 1505-15.

Baragatti, B., F. Brizzi, et al. (2007). "Interactions between NO, CO and an endothelium-derived hyperpolarizing factor (EDHF) in maintaining patency of the ductus arteriosus in the mouse." Br J Pharmacol 151(1): 54-62.

Bateson, E. A., R. Schulz, et al. (1999). "Response of fetal rabbit ductus arteriosus to bradykinin: role of nitric oxide, prostaglandins, and bradykinin receptors." Pediatr Res 45(4 Pt 1): 568-74.

Belanger, C., J. Copeland, et al. (2008). "Morphological changes in the chicken ductus arteriosi during closure at hatching." Anat Rec (Hoboken) 291(8): 1007-15.

Bellaris, A. and M. Osmond (1998). The atlas of chick development, Academic Press. Benson, L. N. and K. N. Cowan (2002). The arterial duct: its persistence and its patency. Paediatric Cardiology. R. H. Anderson, E. J. Baker, F. J. Macartney, M. L. Rigby, E. A. Shinebourne and M. Tynan, Churchill Livingstone: 14051459 .

Bergwerff, M., M. C. DeRuiter, et al. (1999). "Comparative anatomy and ontogeny of the ductus arteriosus, a vascular outsider." Anat Embryol (Berl) 200(6): 55971.

Bergwerff, M., M. C. DeRuiter, et al. (1996). "Onset of elastogenesis and downregulation of smooth muscle actin as distinguishing phenomena in artery differentiation in the chick embryo." Anat Embryol (Berl) 194(6): 545-57.

Bergwerff, M., M. E. Verberne, et al. (1998). "Neural crest cell contribution to the developing circulatory system: implications for vascular morphology?" $\underline{\text { Circ }}$ Res 82(2): 221-31. 
Bhattacharya, M., P. Asselin, et al. (1999). "Developmental changes in prostaglandin $\mathrm{E}(2)$ receptor subtypes in porcine ductus arteriosus. Possible contribution in altered responsiveness to prostaglandin E(2)." Circulation 100(16): 1751-6.

Biau, S., S. Bayle, et al. (2006). "The chick embryo: an animal model for detection of the effects of hormonal compounds." Anal Bioanal Chem.

Blackburn, S. T. (2003). Maternal, fetal, and neonatal physiology : A clinical perspective, Saunders, Elsevier Science.

Bodach, E., F. Coceani, et al. (1980). "The response of the isolated ductus arteriosus to transmural stimulation and drugs." Br J Pharmacol 71(2): 419-27.

Boels, P. J., J. Deutsch, et al. (1999). "Maturation of the response to bradykinin in resistance and conduit pulmonary arteries." Cardiovasc Res 44(2): 416-28.

Bolotina, V. M., S. Najibi, et al. (1994). "Nitric oxide directly activates calciumdependent potassium channels in vascular smooth muscle." Nature 368(6474): 850-3.

Boreus, L. O., T. Malmfors, et al. (1969). "Demonstration of adrenergic receptor function and innervation in the ductus arteriosus of the human fetus." $\underline{\text { Acta }}$ Physiol Scand 77(3): 316-21.

Born, G. V., G. S. Dawes, et al. (1956). "The constriction of the ductus arteriosus caused by oxygen and by asphyxia in newborn lambs." J Physiol 132(2): 30442.

Bos, C. L., D. J. Richel, et al. (2004). "Prostanoids and prostanoid receptors in signal transduction." Int J Biochem Cell Biol 36(7): 1187-205.

Bouayad, A., X. Hou, et al. (2002). "Cyclooxygenase isoforms and prostaglandin E2 receptors in the ductus arteriosus." Current Therapeutic Research 63(10): 669681.

Bouayad, A., H. Kajino, et al. (2001). "Characterization of PGE2 receptors in fetal and newborn lamb ductus arteriosus." Am J Physiol Heart Circ Physiol 280(5): H2342-9.

Bruggeman, V., P. Van As, et al. (2002). "Developmental endocrinology of the reproductive axis in the chicken embryo." Comp Biochem Physiol A Mol Integr Physiol 131(4): 839-46.

Burton, F. G., J. M. Stevensson, et al. (1989). "The relationship between eggshell porosity and air space in gas tension measured before and during the 
parafoetal period and their effects on the hatching process in the domestic fowl." Respir. Physiology 77: 89-100.

Bustamante, S. A., Y. Pang, et al. (1996). "Inducible nitric oxide synthase and the regulation of central vessel caliber in the fetal rat." Circulation 94(8): 1948-53.

Carlo, W. F., E. Villamor, et al. (2001). "Chronic exposure to cigarette smoke extract impairs endothelium-dependent relaxation of chicken embryo pulmonary arteries." Biol Neonate 80(3): 247-50.

Carvajal, J. A., A. M. Germain, et al. (2000). "Molecular mechanism of cGMPmediated smooth muscle relaxation." J Cell Physiol 184(3): 409-20.

Chand, N. and P. Eyre (1976). "Effects of prostaglandins E1, E2 and F2 alpha and polyphloretin phosphate of domestic fowl." Arch Int Pharmacodyn Ther 221(2): 261-65.

Claeys, M., E. Wechsung, et al. (1981). "Prostaglandin E2 is the prevalent metabolite of arachidonic acid formed by aortic tissue of the chicken." Arch Int Pharmacodyn Ther 249(2): 312-5.

Clarke, J. A. (1965). "An X-ray microscopic study of the vasa vasorum of the human ductus arteriosus." J Anat 99(Pt 3): 527-37.

Clyman, R. I. (2006). "Mechanisms regulating the ductus arteriosus." Biology of the Neonate 89(4): 330-335.

Clyman, R. I., C. Y. Chan, et al. (1999a). "Permanent anatomic closure of the ductus arteriosus in newborn baboons: the roles of postnatal constriction, hypoxia, and gestation." Pediatr Res 45(1): 19-29.

Clyman, R. I., Y. Q. Chen, et al. (2001). "In utero remodeling of the fetal lamb ductus arteriosus: the role of antenatal indomethacin and avascular zone thickness on vasa vasorum proliferation, neointima formation, and cell death." Circulation 103(13): 1806-12.

Clyman, R. I., P. Hardy, et al. (1999b). "Cyclooxygenase-2 plays a significant role in regulating the tone of the fetal lamb ductus arteriosus." Am J Physiol 276(3 Pt 2): R913-21.

Clyman, R. I., F. Mauray, et al. (1989). "Influence of increased pulmonary vascular pressures on the closure of the ductus arteriosus in newborn lambs." Pediatr Res 25(2): 136-42.

Clyman, R. I., F. Mauray, et al. (1983). "Factors determining the loss of ductus arteriosus responsiveness to prostaglandin E." Circulation 68(2): 433-6. 
Clyman, R. I., F. Mauray, et al. (1980). "Age-dependent sensitivity of the lamb ductus arteriosus to indomethacin and prostaglandins." J Pediatr 96(1): 94-8.

Clyman, R. I., S. R. Seidner, et al. (2002). "VEGF regulates remodeling during permanent anatomic closure of the ductus arteriosus." Am J Physiol Regul Integr Comp Physiol 282(1): R199-206.

Clyman, R. I., N. Waleh, et al. (1998). "Regulation of ductus arteriosus patency by nitric oxide in fetal lambs: the role of gestation, oxygen tension, and vasa vasorum." Pediatr Res 43(5): 633-44.

Clyman, R. I., N. Waleh, et al. (2007). "Calcium-dependent and calcium-sensitizing pathways in the mature and immature ductus arteriosus." Am J Physiol Regul Integr Comp Physiol 293(4): R1650-6.

Coceani, F., C. Ackerley, et al. (2001). "Function of cyclo-oxygenase-1 and cyclooxygenase- 2 in the ductus arteriosus from foetal lamb: differential development and change by oxygen and endotoxin." Br J Pharmacol 132(1): $241-51$.

Coceani, F., S. Barogi, et al. (2005). "Cyclooxygenase isoenzymes and patency of ductus arteriosus." Prostaglandins Leukot Essent Fatty Acids 72(2): 71-7.

Coceani, F. and L. Kelsey (1991). "Endothelin-1 release from lamb ductus arteriosus: relevance to postnatal closure of the vessel." Can J Physiol Pharmacol 69(2): 218-21.

Coceani, F. and L. Kelsey (2000). "Endothelin-1 release from the lamb ductus arteriosus: are carbon monoxide and nitric oxide regulatory agents?" Life Sci 66(26): 2613-23.

Coceani, F., L. Kelsey, et al. (1992). "Evidence for an effector role of endothelin in closure of the ductus arteriosus at birth." Can J Physiol Pharmacol 70(7): 1061-4.

Coceani, F., L. Kelsey, et al. (1994). "Occurrence of endothelium-derived relaxing factor--nitric oxide in the lamb ductus arteriosus." Can J Physiol Pharmacol 72(1): 82-8.

Coceani, F., L. Kelsey, et al. (2002). "The response of the lamb ductus arteriosus to endothelin: developmental changes and influence of light." Life Sci 71(10): 1209-17. 
Coceani, F., L. Kelsey, et al. (1997). "Carbon monoxide formation in the ductus arteriosus in the lamb: implications for the regulation of muscle tone." $\underline{\mathrm{Br} \mathrm{J}}$ Pharmacol 120(4): 599-608.

Coceani, F., Y. Liu, et al. (1999). "Endothelin A receptor is necessary for O(2) constriction but not closure of ductus arteriosus." Am J Physiol 277(4 Pt 2): H1521-31.

Coceani, F., Y. A. Liu, et al. (2000). "Deletion of the endothelin-A-receptor suppresses oxygen-induced constriction but not postnatal closure of the ductus arteriosus." J Cardiovasc Pharmacol 36(5 Suppl 1): S75-7.

Coceani, F. and P. M. Olley (1973). "The response of the ductus arteriosus to prostaglandins." Can J Physiol Pharmacol 51(3): 220-5.

Cogolludo, A., L. Moreno, et al. (2009). "Activation of neutral sphingomyelinase is involved in acute hypoxic pulmonary vasoconstriction." Cardiovasc Res 82(2): 296-302.

Colbert, M. C., M. L. Kirby, et al. (1996). "Endogenous retinoic acid signaling colocalizes with advanced expression of the adult smooth muscle myosin heavy chain isoform during development of the ductus arteriosus." $\underline{\text { Circ Res }}$ 78(5): 790-8.

Coleman, H. A., M. Tare, et al. (2004). "Endothelial potassium channels, endothelium-dependent hyperpolarization and the regulation of vascular tone in health and disease." Clin Exp Pharmacol Physiol 31(9): 641-9.

Copeland, J. and E. M. Dzialowski (2009). "Effects of hypoxic and hyperoxic incubation on the reactivity of the chicken embryo (Gallus gallus) ductus arteriosi in response to catecholamines and oxygen." Exp Physiol 94(1): 15261.

Corbet, A. J. (1998). Medical Manipulation of the Ductus Arteriosus. The Science and Practice of Pediatric Cardiology. A. Garson, J. T. Bricker, D. J. Fisher and S. R. Neish. Baltimore, Maryland, Williams \& Wilkins. II.

Cotton, R. B., M. T. Stahlman, et al. (1978). "Medical management of small preterm infants with symptomatic patent ductus arteriosus." J Pediatr 92(3): 467-73.

de Ruiter, M. C., A. C. Gittenberger-de Groot, et al. (1989). "The special status of the pulmonary arch artery in the branchial arch system of the rat." Anat Embryol (Berl) 179(4): 319-25. 
Derzbach, L., A. Treszl, et al. (2005). "Gender dependent association between perinatal morbidity and estrogen receptor-alpha Pvull polymorphism." J Perinat Med 33(5): 461-2.

Doyle, L. W. (2001). "Outcome at 5 years of age of children 23 to 27 weeks' gestation: refining the prognosis." Pediatrics 108(1): 134-41.

Duchen, M. R. (1999). "Contributions of mitochondria to animal physiology: from homeostatic sensor to calcium signalling and cell death." J Physiol 516 ( Pt 1): $1-17$.

Dunn, L. K., S. K. Gruenloh, et al. (2005). "Chick chorioallantoic membrane as an in vivo model to study vasoreactivity: characterization of developmentdependent hyperemia induced by epoxyeicosatrienoic acids (EETs)." Anat Rec A Discov Mol Cell Evol Biol 285(2): 771-80.

Earley, S. and T. C. Resta (2002). "Estradiol attenuates hypoxia-induced pulmonary endothelin-1 gene expression." Am J Physiol Lung Cell Mol Physiol 283(1): L86-93.

Eldridge, F. L., H. N. Hultgren, et al. (1954). "The physiologic closure of the ductus arteriosus in newborn infants: a preliminary report." Science 119(3099): 7312.

Eliot, R. J., R. Lam, et al. (1980). "Plasma catecholamine concentrations in infants at birth and during the first 48 hours of life." J Pediatr 96(2): 311-5.

Elsmen, E., I. Hansen Pupp, et al. (2004). "Preterm male infants need more initial respiratory and circulatory support than female infants.[see comment]." Acta Paediatrica 93(4): 529-33.

Fabres, J., W. A. Carlo, et al. (2007). "Both extremes of arterial carbon dioxide pressure and the magnitude of fluctuations in arterial carbon dioxide pressure are associated with severe intraventricular hemorrhage in preterm infants." Pediatrics 119(2): 299-305.

Fay, F. S. (1971). "Guinea pig ductus arteriosus. I. Cellular and metabolic basis for oxygen sensitivity." Am J Physiol 221(2): 470-9.

Fay, F. S. and F. F. Jobsis (1972). "Guinea pig ductus arteriosus. 3. Light absorption changes during response to O 2." Am J Physiol 223(3): 588-95.

Fineman, J. R., Y. Takahashi, et al. (1998). "Endothelin-receptor blockade does not alter closure of the ductus arteriosus." Am J Physiol 275(5 Pt 2): H1620-6. 
Friedman, W. F., K. M. Fitzpatrick, et al. (1978). "The patent ductus arteriosus." $\underline{\text { Clin }}$ Perinatol 5(2): 411-36.

Friedman, W. F., M. P. Printz, et al. (1983). "The vasoactivity of the fetal lamb ductus arteriosus studied in utero." Pediatr Res 17(5): 331-7.

Furchgott, R. F. and P. M. Vanhoutte (1989). "Endothelium-derived relaxing and contracting factors." Faseb J 3(9): 2007-18.

Gersony, W. M., G. J. Peckham, et al. (1983). "Effects of indomethacin in premature infants with patent ductus arteriosus: results of a national collaborative study." J Pediatr 102(6): 895-906.

Gilbert, E. F., H. J. Bruyere, Jr., et al. (1977). "The effect of practolol and butoxamine on aortic arch malformation in beta adrenoreceptor stimulated chick embryos." Teratology 15(3): 317-23.

Gittenberger-de Groot, A. C., J. L. Strengers, et al. (1985). "Histologic studies on normal and persistent ductus arteriosus in the dog." J Am Coll Cardiol 6(2): 394-404.

Giuriato, L., M. Scatena, et al. (1993). "Rabbit ductus arteriosus during development: anatomical structure and smooth muscle cell composition." Anat Rec 235(1): 95-110.

Goldbarg, S. H., Y. Takahashi, et al. (2002). "In utero indomethacin alters O2 delivery to the fetal ductus arteriosus: implications for postnatal patency." $\underline{\mathrm{Am}}$ J Physiol Regul Integr Comp Physiol 282(1): R184-90.

Gonzalez-Luis, G., F. Perez-Vizcaino, et al. (2005). "Age-related differences in vasoconstrictor responses to isoprostanes in piglet pulmonary and mesenteric vascular smooth muscle." Pediatr Res 57(6): 845-52.

Greyner, H. and E. M. Dzialowski (2008). "Mechanisms mediating the oxygeninduced vasoreactivity of the ductus arteriosus in the chicken embryo." Am J Physiol Regul Integr Comp Physiol 295(5): R1647-59.

Groenendijk, B. C., B. P. Hierck, et al. (2005). "Changes in shear stress-related gene expression after experimentally altered venous return in the chicken embryo." Circ Res 96(12): 1291-8.

Guarnieri, G. F., N. Laforgia, et al. (2008). "Delayed closure of ductus arteriosus in term newborns with congenital hypothyroidism: effect of L-thyroxine therapy." Pediatr Cardiol 29(2): 455-6. 
Guimaraes, S. and D. Moura (2001). "Vascular adrenoceptors: an update." Pharmacol Rev 53(2): 319-56.

Hammerman, C. (1995). "Patent ductus arteriosus. Clinical relevance of prostaglandins and prostaglandin inhibitors in PDA pathophysiology and treatment." Clin Perinatol 22(2): 457-79.

Hardy, P., I. Dumont, et al. (2000). "Oxidants, nitric oxide and prostanoids in the developing ocular vasculature: a basis for ischemic retinopathy." $\underline{\text { Cardiovasc }}$ Res 47(3): 489-509.

Harms, D. (1967). "[On the occlusion of the ductus arteriosus of Gallus domesticus]." Z Zellforsch Mikrosk Anat 81(3): 433-44.

Hayashi, T., K. Yamada, et al. (1995). "Estrogen increases endothelial nitric oxide by a receptor-mediated system." Biochem Biophys Res Commun 214(3): 847-55.

Herrera, C., J. Holberton, et al. (2004). "Prolonged versus short course of indomethacin for the treatment of patent ductus arteriosus in preterm infants." Cochrane Database Syst Rev(1): CD003480.

Hodach, R. J., A. E. Hodach, et al. (1975). "The role of beta-adrenergic activity in the production of cardiac and aortic arch anomalies in chick embryos." Teratology 12(1): 33-45.

Hong, Z., F. Hong, et al. (2006). "Role of store-operated calcium channels and calcium sensitization in normoxic contraction of the ductus arteriosus." Circulation 114(13): 1372-9.

Hughes, A. F. W. (1943). "The histogenesis of the arteries of the chick embryo." J Anat 77: 266-287.

Hyvelin, J. M., C. O'Connor, et al. (2004). "Effect of changes in pH on wall tension in isolated rat pulmonary artery: role of the RhoA/Rho-kinase pathway." Am J Physiol Lung Cell Mol Physiol 287(4): L673-84.

Ikeda, M., R. R. Sonnenschein, et al. (1972). "Catecholamine content and uptake of the ductus arteriosus of the fetal lamb." Experientia 28(8): 914-5.

Ingemarsson, I. (2003). "Gender aspects of preterm birth." Bjog 110 Suppl 20: 34-8.

Ishikawa, T., T. Chijiwa, et al. (1989). "Thyroid hormones directly interact with vascular smooth muscle strips." Mol Pharmacol 35(6): 760-5.

Janssen, L. J. (2008). "Isoprostanes and lung vascular pathology." Am J Respir Cell Mol Biol 39(4): 383-9. 
Janssen, L. J., A. Catalli, et al. (2005). "The pulmonary biology of isoprostanes." Antioxid Redox Signal 7(1-2): 244-55.

Jourdan, K. B., T. W. Evans, et al. (1997). "Evidence for a dilator function of 8-iso prostaglandin F2 alpha in rat pulmonary artery." Br J Pharmacol 120(7): 12805.

Jurrus, E. R. and H. S. Weiss (1977). "In vitro tissue oxygen tensions in the rabbit aortic arch." Atherosclerosis 28(3): 223-32.

Kajimoto, H., K. Hashimoto, et al. (2007). "Oxygen activates the Rho/Rho-kinase pathway and induces RhoB and ROCK-1 expression in human and rabbit ductus arteriosus by increasing mitochondria-derived reactive oxygen species: a newly recognized mechanism for sustaining ductal constriction." Circulation 115(13): 1777-88.

Kajino, H., Y. Q. Chen, et al. (2000). "Tissue hypoxia inhibits prostaglandin and nitric oxide production and prevents ductus arteriosus reopening." Am J Physiol Regul Integr Comp Physiol 279(1): R278-86.

Kajino, H., Y. Q. Chen, et al. (2001). "Factors that increase the contractile tone of the ductus arteriosus also regulate its anatomic remodeling." Am J Physiol Regul Integr Comp Physiol 281(1): R291-301.

Kajino, H., S. Goldbarg, et al. (2002). "Vasa vasorum hypoperfusion is responsible for medial hypoxia and anatomic remodeling in the newborn lamb ductus arteriosus." Pediatr Res 51(2): 228-35.

Kajino, H., T. Taniguchi, et al. (2004). "An EP4 receptor agonist prevents indomethacin-induced closure of rat ductus arteriosus in vivo." Pediatr Res 56(4): 586-90.

Kamper, A. M., L. C. Paul, et al. (2002). "Prostaglandins are involved in acetylcholine- and 5-hydroxytryptamine-induced, nitric oxide-mediated vasodilatation in human forearm." J Cardiovasc Pharmacol 40(6): 922-9.

Karadas, B., T. Kaya, et al. (2004). "Comparison of effects of cyclooxygenase inhibitors on myometrial contraction and constriction of ductus arteriosus in rats." Eur J Pharmacol 485(1-3): 289-98.

Katzung, B. G. (1995). Basic and clinical pharmacology. Norwalk, Connecticut, Paramount Publishing Buiseness and Professional Group. 
Keck, M., E. Resnik, et al. (2005). "Oxygen increases ductus arteriosus smooth muscle cytosolic calcium via release of calcium from inositol triphosphatesensitive stores." Am J Physiol Lung Cell Mol Physiol 288(5): L917-23.

Kempf, H., C. Linares, et al. (1998). "Pharmacological inactivation of the endothelin type A receptor in the early chick embryo: a model of mispatterning of the branchial arch derivatives." Development 125(24): 4931-41.

Khalil, R. A. (2005). "Sex hormones as potential modulators of vascular function in hypertension." Hypertension 46(2): 249-54.

Kim, H. S., M. Aikawa, et al. (1993). "Ductus arteriosus. Advanced differentiation of smooth muscle cells demonstrated by myosin heavy chain isoform expression in rabbits." Circulation 88(4 Pt 1): 1804-10.

Kiserud, T. (2005). "Physiology of the fetal circulation." Semin Fetal Neonatal Med 10(6): 493-503.

Kitazawa, T., A. N. Polzin, et al. (2004). "CPI-17-deficient smooth muscle of chicken." J Physiol 557(Pt 2): 515-28.

Kluckow, M., N. Evans, et al. (1999). "Prostacyclin concentrations and transitional circulation in preterm infants requiring mechanical ventilation." Arch Dis Child Fetal Neonatal Ed 80(1): F34-7.

Knight, D. B. (2001). "The treatment of patent ductus arteriosus in preterm infants. A review and overview of randomized trials." Semin Neonatol 6: 63-73.

Knight, D. H., D. F. Patterson, et al. (1973). "Constriction of the fetal ductus arteriosus induced by oxygen, acteylcholine, and norepinephrine in normal dogs and those genetically predisposed to persistent patency." Circulation 47(1): 127-32.

Koch, J., G. Hensley, et al. (2006). "Prevalence of spontaneous closure of the ductus arteriosus in neonates at a birth weight of 1000 grams or less." Pediatrics 117(4): 1113-21.

Komuro, T., M. K. Borsody, et al. (2001). "The vasorelaxation of cerebral arteries by carbon monoxide." Exp Biol Med (Maywood) 226(9): 860-5.

Kovalcik, V. (1963). "The Response of the Isolated Ductus Arteriosus to Oxygen and Anoxia." J Physiol 169: 185-97.

le Noble, F. A., K. Ruijtenbeek, et al. (2000). "Contractile and relaxing reactivity in carotid and femoral arteries of chicken embryos." Am J Physiol Heart Circ Physiol 278(4): H1261-8. 
Leo, M. D., Y. K. Siddegowda, et al. (2008). "Role of nitric oxide and carbon monoxide in N(omega)-Nitro-L-arginine methyl ester-resistant acetylcholineinduced relaxation in chicken carotid artery." Eur J Pharmacol 596(1-3): 1117.

Leonhardt, A., A. Glaser, et al. (2003). "Expression of prostanoid receptors in human ductus arteriosus." Br J Pharmacol 138(4): 655-9.

Levin, M., S. Goldbarg, et al. (2005). "ATP depletion and cell death in the neonatal lamb ductus arteriosus." Pediatr Res 57(6): 801-5.

Levin, M., D. McCurnin, et al. (2006). "Postnatal constriction, ATP depletion, and cell death in the mature and immature ductus arteriosus." Am J Physiol Regul Integr Comp Physiol 290(2): R359-64.

Lindgren, I., B. Zoer, et al. (2009). "Chronic hypoxia and incubation age affects ßadrenoceptor -mediated relaxation in systemic but not chorioallantoic arteries of the broiler chicken fetus." Abstract, Book of the 35th Annual Meeting of FNPS. Page 135.

Liu, L., C. E. Dean, et al. (2003). "Thyroid hormones interact with glucocorticoids to affect somatotroph abundance in chicken embryonic pituitary cells in vitro." Endocrinology 144(9): 3836-41.

Liu, L. and T. E. Porter (2004). "Endogenous thyroid hormones modulate pituitary somatotroph differentiation during chicken embryonic development." $\underline{\mathrm{J}}$ Endocrinol 180(1): 45-53.

Lynch, F., M. Sweeney, et al. (2000). "Hypercapnia-induced contraction in isolated pulmonary arteries is endothelium-dependent." Respir Physiol 121(1): 65-74.

Macrez-Lepretre, N., F. Kalkbrenner, et al. (1997). "Distinct functions of Gq and G11 proteins in coupling alpha1-adrenoreceptors to $\mathrm{Ca} 2+$ release and $\mathrm{Ca} 2+$ entry in rat portal vein myocytes." J Biol Chem 272(8): 5261-8.

Malviya, M., A. Ohlsson, et al. (2008). "Surgical versus medical treatment with cyclooxygenase inhibitors for symptomatic patent ductus arteriosus in preterm infants." Cochrane Database Syst Rev(1): CD003951.

Mariani, G., J. Cifuentes, et al. (1999). "Randomized trial of permissive hypercapnia in preterm infants." Pediatrics 104(5 Pt 1): 1082-8.

Martinez-Lemus, L. A., R. K. Hester, et al. (2003). "Pulmonary artery vasoactivity in broiler and Leghorn chickens: an age profile." Poult Sci 82(12): 1957-64. 
Matsumoto, T., T. Kobayashi, et al. (2003). "Phosphodiesterases in the vascular system." J Smooth Muscle Res 39(4): 67-86.

Maurice, D. H., D. Palmer, et al. (2003). "Cyclic nucleotide phosphodiesterase activity, expression, and targeting in cells of the cardiovascular system." $\underline{\mathrm{Mol}}$ Pharmacol 64(3): 533-46.

McMurphy, D. M., M. A. Heymann, et al. (1972). "Developmental changes in constriction of the ductus arteriosus: responses to oxygen and vasoactive agents in the isolated ductus arteriosus of the fetal lamb." Pediatr Res 6(4): 231-8.

Metcalfe, J. and M. K. Stock (1993). "Current topic: oxygen exchange in the chorioallantoic membrane, avian homologue of the mammalian placenta." Placenta 14(6): 605-13.

Michelakis, E., I. Rebeyka, et al. (2000). "Voltage-gated potassium channels in human ductus arteriosus." Lancet 356(9224): 134-7.

Michelakis, E. D., I. Rebeyka, et al. (2002). "O2 sensing in the human ductus arteriosus: regulation of voltage-gated $\mathrm{K}+$ channels in smooth muscle cells by a mitochondrial redox sensor." Circ Res 91(6): 478-86.

Michelakis, E. D., B. Thebaud, et al. (2004). "Hypoxic pulmonary vasoconstriction: redox regulation of $\mathrm{O} 2$-sensitive $\mathrm{K}+$ channels by a mitochondrial $\mathrm{O} 2$-sensor in resistance artery smooth muscle cells." J Mol Cell Cardiol 37(6): 1119-36.

Miller, J. D. and W. A. Carlo (2007). "Safety and effectiveness of permissive hypercapnia in the preterm infant." Curr Opin Pediatr 19(2): 142-4.

Momma, K., T. Nakanishi, et al. (2003). "Inhibition of in vivo constriction of fetal ductus arteriosus by endothelin receptor blockade in rats." Pediatr Res 53(3): 479-85.

Momma, K. and M. Toyono (1999). "The role of nitric oxide in dilating the fetal ductus arteriosus in rats." Pediatr Res 46(3): 311-5.

Momma, K., M. Toyono, et al. (1998). "Accelerated maturation of fetal ductus arteriosus by maternally administered vitamin A in rats." Pediatr Res 43(5): 629-32.

Momma, K., K. Toyoshima, et al. (2005). "In vivo dilation of fetal and neonatal ductus arteriosus by inhibition of phosphodiesterase-5 in rats." Pediatr Res 58(1): 42-5. 
Mosalli, R. and K. Alfaleh (2008). "Prophylactic surgical ligation of patent ductus arteriosus for prevention of mortality and morbidity in extremely low birth weight infants." Cochrane Database Syst Rev(1): CD006181.

Moudgil, R., E. D. Michelakis, et al. (2005). "Hypoxic pulmonary vasoconstriction." J Appl Physiol 98(1): 390-403.

Mueed, I., T. Tazzeo, et al. (2008). "Isoprostanes constrict human radial artery by stimulation of thromboxane receptors, $\mathrm{Ca} 2+$ release, and RhoA activation." $\underline{\mathrm{J}}$ Thorac Cardiovasc Surg 135(1): 131-8.

Mulder, A. L., J. M. Golde, et al. (2000). "Developmental changes in plasma catecholamine concentrations during normoxia and acute hypoxia in the chick embryo." J Physiol 527 Pt 3: 593-9.

Mulder, A. L., A. Miedema, et al. (2002). "Sympathetic control of the cardiovascular response to acute hypoxemia in the chick embryo." Am J Physiol Regul Integr Comp Physiol 282(4): R1156-63.

Mulder, A. L., J. C. van Golde, et al. (1998). "Cardiac output distribution in response to hypoxia in the chick embryo in the second half of the incubation time." $\underline{J}$ Physiol 508 ( Pt 1): 281-7.

Mulder, A. L., C. A. van Goor, et al. (2001). "Alpha-adrenergic contribution to the cardiovascular response to acute hypoxemia in the chick embryo." Am J Physiol Regul Integr Comp Physiol 281(6): R2004-10.

Mulder, T. L., J. C. van Golde, et al. (1997). "Cardiac output distribution in the chick embryo from stage 36 to 45." Cardiovasc Res 34(3): 525-8.

Nakagawa, T. (1993). "Delayed closure of ductus arteriosus in premature infants with transient hypothyroidism." Lancet 341(8848): 839.

Nakanishi, T., H. Gu, et al. (1993). "Mechanisms of oxygen-induced contraction of ductus arteriosus isolated from the fetal rabbit." Circ Res 72(6): 1218-28.

Nathanielsz, P. W. (2006). "Animal models that elucidate basic principles of the developmental origins of adult diseases." Ilar J 47(1): 73-82.

Nguyen, M., T. Camenisch, et al. (1997). "The prostaglandin receptor EP4 triggers remodelling of the cardiovascular system at birth." Nature 390(6655): 78-81.

Nishimura, H., Y. Yang, et al. (2003). "Maturation-dependent changes of angiotensin receptor expression in fowl." Am J Physiol Regul Integr Comp Physiol 285(1): R231-42. 
Noel, S. and S. Cassin (1976). "Maturation of contractile response of ductus arteriosus to oxygen and drugs." American journal of physiology 231(1): 240-243.

Oberhansli-Weiss, I., M. A. Heymann, et al. (1972). "The pattern and mechanisms of response to oxygen by the ductus arteriosus and umbilical artery." Pediatr Res 6(9): 693-700.

Ojamaa, K., A. Kenessey, et al. (2000). "Thyroid hormone metabolism and cardiac gene expression after acute myocardial infarction in the rat." Am J Physiol Endocrinol Metab 279(6): E1319-24.

Oliveira, L., N. A. Stallwood, et al. (2000). "Effects of some isoprostanes on the human umbilical artery in vitro." Br J Pharmacol 129(3): 509-14.

Olschewski, A., Z. Hong, et al. (2004). "Opposite effects of redox status on membrane potential, cytosolic calcium, and tone in pulmonary arteries and ductus arteriosus." Am J Physiol Lung Cell Mol Physiol 286(1): L15-22.

Olson, K. R., R. A. Dombkowski, et al. (2006). "Hydrogen sulfide as an oxygen sensor/transducer in vertebrate hypoxic vasoconstriction and hypoxic vasodilation." J Exp Biol 209(Pt 20): 4011-23.

Orshal, J. M. and R. A. Khalil (2004). "Gender, sex hormones, and vascular tone." Am J Physiol Regul Integr Comp Physiol 286(2): R233-49.

Owen, P. J., R. Sabit, et al. (2007). "Thyroid disease and vascular function." $\underline{\text { Thyroid }}$ 17(6): 519-24.

Owens, G. K., M. S. Kumar, et al. (2004). "Molecular regulation of vascular smooth muscle cell differentiation in development and disease." Physiol Rev 84(3): 767-801.

Polderman, K. H., C. D. Stehouwer, et al. (1993). "Influence of sex hormones on plasma endothelin levels." Ann Intern Med 118(6): 429-32.

Rahn, H., S. Matalon, et al. (1985). Circulatory changes and oxygen delivery in the chick embryo prior to hatching. Cardiovascular shunts. Alfred Benzon Symposium 21. K. Johansen and W. W. Burggren. Copenhagen, Munksgaard: 199-215.

Rahn, H., C. V. Paganelli, et al. (1974). "The avian egg: air-cell gas tension, metabolism and incubation time." Respir Physiol 22(3): 297-309.

Rairigh, R. L., L. Storme, et al. (2000). "Role of neuronal nitric oxide synthase in regulation of vascular and ductus arteriosus tone in the ovine fetus." Am J Physiol Lung Cell Mol Physiol 278(1): L105-10. 
Randall, D., W. Burggren, et al. (2001). Eckert Animal Physiology - Mechanisms and Adaptations. New York, W. H. Freeman and Company.

Rang, H. P., M. Dale, et al. (1995). Pharmacology. New York, Churchill Livingstone.

Ratz, P. H., K. M. Berg, et al. (2005). "Regulation of smooth muscle calcium sensitivity: $\mathrm{KCl}$ as a calcium-sensitizing stimulus." Am J Physiol Cell Physiol 288(4): C769-83.

Reese, J. (2006). "Death, dying, and exhaustion in the ductus arteriosus: prerequisites for permanent closure." Am J Physiol Regul Integr Comp Physiol 290(2): R357-8.

Reese, J., B. C. Paria, et al. (2000). "Coordinated regulation of fetal and maternal prostaglandins directs successful birth and postnatal adaptation in the mouse." PNAS 97(17): 9759-9764.

Reeve, H. L., S. L. Archer, et al. (1997). "Ion channels in the pulmonary vasculature." Pulm Pharmacol Ther 10(5-6): 243-52.

Reeve, H. L., S. Tolarova, et al. (2001). "Redox control of oxygen sensing in the rabbit ductus arteriosus." J Physiol 533(Pt 1): 253-61.

Reynolds, S. R. M. (1953). "Circulatory adaptations to birth." The scientific monthly(October).

Richard, C., J. Gao, et al. (2004). "Patency of the preterm fetal ductus arteriosus is regulated by endothelial nitric oxide synthase and is independent of vasa vasorum in the mouse." Am J Physiol Regul Integr Comp Physiol 287(3): R652-60.

Rojas, M. A., A. Gonzalez, et al. (1995). "Changing trends in the epidemiology and pathogenesis of neonatal chronic lung disease." J Pediatr 126(4): 605-10.

Roulet, M. J. and R. F. Coburn (1981). "Oxygen-induced contraction in the guinea pig neonatal ductus arteriosus." Circ Res 49(4): 997-1002.

Rouwet, E. V., J. G. De Mey, et al. (2000). "Development of vasomotor responses in fetal mesenteric arteries." Am J Physiol Heart Circ Physiol 279(3): H1097105 .

Rowley, A. (1991). Eicosanoids: aspects of their structure, function, and evolution. The Phylogenesis of Immune Functions. G. Warr and N. Cohen, CRC Press, Boca Ration: 269-294.

Rubanyi, G. M. and L. H. Botelho (1991). "Endothelins." Faseb J 5(12): 2713-20. 
Ruijtenbeek, K., J. G. De Mey, et al. (2002a). "The chicken embryo in developmental physiology of the cardiovascular system: a traditional model with new possibilities." Am J Physiol Regul Integr Comp Physiol 283(2): R549-50; author reply R550-1.

Ruijtenbeek, K., C. G. Kessels, et al. (2003a). "Chronic moderate hypoxia during in ovo development alters arterial reactivity in chickens." Pflugers Arch 447(2): 158-67.

Ruijtenbeek, K., C. G. Kessels, et al. (2002b). "Direct effects of acute hypoxia on the reactivity of peripheral arteries of the chicken embryo." Am J Physiol Regul Integr Comp Physiol 283(2): R331-8.

Ruijtenbeek, K., L. C. Kessels, et al. (2003b). "Chronic moderate hypoxia and protein malnutrition both induce growth retardation, but have distinct effects on arterial endothelium-dependent reactivity in the chicken embryo." Pediatr Res 53(4): 573-9.

Ruijtenbeek, K., F. A. le Noble, et al. (2000). "Chronic hypoxia stimulates periarterial sympathetic nerve development in chicken embryo." Circulation 102(23): 2892-7.

Russell, M. J., R. A. Dombkowski, et al. (2008). "Effects of hypoxia on vertebrate blood vessels." J Exp Zool Part A Ecol Genet Physiol 309(2): 55-63.

Rybalkin, S. D., C. Yan, et al. (2003). "Cyclic GMP phosphodiesterases and regulation of smooth muscle function." Circ Res 93(4): 280-91.

Rzucidlo, E. M., K. A. Martin, et al. (2007). "Regulation of vascular smooth muscle cell differentiation." J Vasc Surg 45 Suppl A: A25-32.

Sader, M. A. and D. S. Celermajer (2002). "Endothelial function, vascular reactivity and gender differences in the cardiovascular system." Cardiovasc Res 53(3): 597-604.

Sakurai, H., R. Matsuoka, et al. (1996). "Expression of four myosin heavy chain genes in developing blood vessels and other smooth muscle organs in rabbits." Eur J Cell Biol 69(2): 166-72.

Salomonsson, M. and W. J. Arendshorst (2001). "Norepinephrine-induced calcium signaling pathways in afferent arterioles of genetically hypertensive rats." $\underline{\text { Am }}$ J Physiol Renal Physiol 281(2): F264-72. 
Salter, K. J. and R. Z. Kozlowski (1998). "Differential electrophysiological actions of endothelin-1 on $\mathrm{Cl}-$ and $\mathrm{K}+$ currents in myocytes isolated from aorta, basilar and pulmonary artery." J Pharmacol Exp Ther 284(3): 1122-31.

Salter, K. J., C. M. Wilson, et al. (1998). "Endothelin-1, delayed rectifier K channels, and pulmonary arterial smooth muscle." J Cardiovasc Pharmacol 31 Suppl 1: S81-3.

Schneider, D. J. and J. W. Moore (2006). "Patent ductus arteriosus." Circulation 114(17): 1873-82.

Schwertz, D. W. and S. Penckofer (2001). "Sex differences and the effects of sex hormones on hemostasis and vascular reactivity." Heart Lung 30(6): 401-26; quiz 427-8.

Scotland, R. S., M. Madhani, et al. (2005). "Investigation of vascular responses in endothelial nitric oxide synthase/cyclooxygenase-1 double-knockout mice: key role for endothelium-derived hyperpolarizing factor in the regulation of blood pressure in vivo." Circulation 111(6): 796-803.

Seidner, S. R., Y. Q. Chen, et al. (2001). "Combined prostaglandin and nitric oxide inhibition produces anatomic remodeling and closure of the ductus arteriosus in the premature newborn baboon." Pediatr Res 50(3): 365-73.

Sendao Oliveira, A. P. and L. M. Bendhack (2004). "Relaxation induced by acetylcholine involves endothelium-derived hyperpolarizing factor in 2-kidney 1-clip hypertensive rat carotid arteries." Pharmacology 72(4): 231-9.

Shen, J., T. Nakanishi, et al. (2002). "The role of endothelin in oxygen-induced contraction of the ductus arteriosus in rabbit and rat fetuses." $\underline{\text { Heart Vessels }}$ 16(5): 181-8.

Shimoda, L. A., J. T. Sylvester, et al. (1998). "Inhibition of voltage-gated K+ current in rat intrapulmonary arterial myocytes by endothelin-1." Am J Physiol 274(5 Pt 1): L842-53.

Silver, M. M., R. M. Freedom, et al. (1981). "The morphology of the human newborn ductus arteriosus: a reappraisal of its structure and closure with special reference to prostaglandin E1 therapy." Hum Pathol 12(12): 1123-36.

Smith, G. C. (1998). "The pharmacology of the ductus arteriosus." $\underline{\text { Pharmacol Rev }}$ 50(1): $35-58$. 
Smith, G. C., R. A. Coleman, et al. (1994). "Characterization of dilator prostanoid receptors in the fetal rabbit ductus arteriosus." J Pharmacol Exp Ther 271(1): 390-6.

Smith, G. C. and J. C. McGrath (1988). "Indomethacin, but not oxygen tension, affects the sensitivity of isolated neonatal rabbit ductus arteriosus, but not aorta, to noradrenaline." Cardiovasc Res 22(12): 910-5.

Smith, G. C. and J. C. McGrath (1993). "Characterisation of the effect of oxygen tension on response of fetal rabbit ductus arteriosus to vasodilators." Cardiovasc Res 27(12): 2205-11.

Smith, G. C. and J. C. McGrath (1995). "Contractile effects of prostanoids on fetal rabbit ductus arteriosus." J Cardiovasc Pharmacol 25(1): 113-8.

Somlyo, A. P. and A. V. Somlyo (2003). "Ca2+ sensitivity of smooth muscle and nonmuscle myosin II: modulated by $\mathrm{G}$ proteins, kinases, and myosin phosphatase." Physiol Rev 83(4): 1325-58.

Starling, M. B. and R. B. Elliott (1974). "The effects of prostaglandins, prostaglandin inhibitors, and oxygen on the closure of the ductus arteriosus, pulmonary arteries and umbilical vessels in vitro." Prostaglandins 8(3): 187-203.

Stevenson, D. K., J. Verter, et al. (2000). "Sex differences in outcomes of very low birthweight infants: the newborn male disadvantage." Arch Dis Child Fetal Neonatal Ed 83(3): F182-5.

Sutendra, G. and E. D. Michelakis (2007). "The chicken embryo as a model for ductus arteriosus developmental biology: cracking into new territory." Am J Physiol Regul Integr Comp Physiol 292(1): R481-4.

Sweeney, M., D. Beddy, et al. (1998). "Effects of changes in pH and CO2 on pulmonary arterial wall tension are not endothelium dependent." J Appl Physiol 85(6): 2040-6.

Sweeney, M., R. G. O'Regan, et al. (1999). "Effects of changes in pH and PCO2 on wall tension in isolated rat intrapulmonary arteries." Exp Physiol 84(3): 52939.

Takahashi, T., Y. Sugishita, et al. (2001). "Ets-1 is involved in transcriptional regulation of the chick inducible nitric oxide synthase gene in embryonic ventricular myocytes." Mol Cell Biochem 226(1-2): 57-65. 
Takahashi, Y., C. Roman, et al. (2000). "Cyclooxygenase-2 inhibitors constrict the fetal lamb ductus arteriosus both in vitro and in vivo." Am J Physiol Regul Integr Comp Physiol 278(6): R1496-505.

Takizawa, T., E. Horikoshi, et al. (1999). "Role of the nitric oxide-cGMP system in the regulation of ductus arteriosus patency in fetal rats." J Vet Med Sci 61(12): 1277-80.

Takizawa, T., E. Horikoshi, et al. (2000a). "Biphasic response of the ductus arteriosus to combined administration of indomethacin and L-NAME in fetal rats." Biol Neonate 78(4): 300-3.

Takizawa, T., T. Kihara, et al. (2000b). "Role of nitric oxide in regulating the ductus arteriosus caliber in fetal rats." J Vet Med Sci 62(7): 707-10.

Taniguchi, T., H. Azuma, et al. (2001). "Endothelin-1-endothelin receptor type A mediates closure of rat ductus arteriosus at birth." J Physiol 537(Pt 2): 579-85.

Tare, M., H. C. Parkington, et al. (2000). "EDHF, NO and a prostanoid: hyperpolarization-dependent and -independent relaxation in guinea-pig arteries." Br J Pharmacol 130(3): 605-18.

Teitel, D. F. and S. C. Cassidy (2001). Fetal and postnatal circulations: Systemic. Moss and Adams' Heart Disease in Infants, Children and Adolescents: Including the Fetus and Young Adult. H. D. Allen, H. P. Gutgesell, E. B. Clark and D. J. Driscoll. Philadelphia, Lippincott Williams \& Wilkins. 1.

Thebaud, B., E. Michelakis, et al. (2002). "Sildenafil reverses O2 constriction of the rabbit ductus arteriosus by inhibiting type 5 phosphodiesterase and activating BK(Ca) channels." Pediatr Res 52(1): 19-24.

Thebaud, B., E. D. Michelakis, et al. (2004). "Oxygen-sensitive Kv channel gene transfer confers oxygen responsiveness to preterm rabbit and remodeled human ductus arteriosus: implications for infants with patent ductus arteriosus." Circulation 110(11): 1372-9.

Thebaud, B., X. C. Wu, et al. (2008). "Developmental absence of the O2 sensitivity of L-type calcium channels in preterm ductus arteriosus smooth muscle cells impairs $\mathrm{O} 2$ constriction contributing to patent ductus arteriosus." Pediatr Res 63(2): 176-81.

Tomita, H., S. Fuse, et al. (1996). "Catecholamine-induced ductus arteriosus constriction in children." Am J Cardiol 77(15): 1372-5. 
Tristani-Firouzi, M., H. L. Reeve, et al. (1996). "Oxygen-induced constriction of rabbit ductus arteriosus occurs via inhibition of a 4-aminopyridine-, voltagesensitive potassium channel." J Clin Invest 98(9): 1959-65.

Trotter, A., L. Maier, et al. (1999). "Effects of postnatal estradiol and progesterone replacement in extremely preterm infants." J Clin Endocrinol Metab 84(12): 4531-5.

Tsang, S. Y., X. Yao, et al. (2004). "Differential regulation of $\mathrm{K}+$ and Ca2+ channel gene expression by chronic treatment with estrogen and tamoxifen in rat aorta." Eur J Pharmacol 483(2-3): 155-62.

Ungureanu-Longrois, D., Y. Bezie, et al. (1997). "Effects of exogenous and endogenous nitric oxide on the contractile function of cultured chick embryo ventricular myocytes." J Mol Cell Cardiol 29(2): 677-87.

Waleh, N., H. Kajino, et al. (2004). "Prostaglandin E2--mediated relaxation of the ductus arteriosus: effects of gestational age on $\mathrm{g}$ protein-coupled receptor expression, signaling, and vasomotor control." Circulation 110(16): 2326-32.

Waleh, N., S. Seidner, et al. (2005). "The role of monocyte-derived cells and inflammation in baboon ductus arteriosus remodeling." Pediatr Res 57(2): 254-62.

Wall, M. E., J. E. Faber, et al. (2004). "Norepinephrine-induced calcium signaling and expression of adrenoceptors in avian tendon cells." Am J Physiol Cell Physiol 287(4): C912-8.

Walsh, R. S. and R. M. Mentzer, Jr. (1987). "Role of cyclic nucleotides in relaxation of fetal lamb ductus arteriosus." Surgery 102(2): 313-8.

van Golde, J., T. Mulder, et al. (1997). "Changes in mean chorioallantoic artery blood flow and heart rate produced by hypoxia in the developing chick embryo." Pediatr Res 42(3): 293-8.

van Golde, J., T. Mulder, et al. (1996). "The chorioallantoic artery blood flow of the chick embryo from stage 34 to 43." Pediatr Res 40(6): 867-71.

van Golde, J. M., T. A. Mulder, et al. (1999). "Hyperoxia and local organ blood flow in the developing chick embryo." J Physiol 515 ( Pt 1): 243-8.

Van Overmeire, B. and S. Chemtob (2005). "The pharmacologic closure of the patent ductus arteriosus." Semin Fetal Neonatal Med 10(2): 177-84. 
van Wassenaer, A. G. and J. H. Kok (2008). "Trials with thyroid hormone in preterm infants: clinical and neurodevelopmental effects." Semin Perinatol 32(6): 42330.

Wang, R., Z. Wang, et al. (1997). "Carbon monoxide-induced vasorelaxation and the underlying mechanisms." Br J Pharmacol 121(5): 927-34.

Vatten, L. J. and R. Skjaerven (2004). "Offspring sex and pregnancy outcome by length of gestation." Early Hum Dev 76(1): 47-54.

Waypa, G. B. and P. T. Schumacker (2005). "Hypoxic pulmonary vasoconstriction: redox events in oxygen sensing." J Appl Physiol 98(1): 404-14.

Weinberger, B., S. Nisar, et al. (2006). "Lipid peroxidation in cord blood and neonatal outcome." Pediatr Int 48(5): 479-83.

Weir, E. K., Z. Hong, et al. (2002). "Redox signaling in oxygen sensing by vessels." Respir Physiol Neurobiol 132(1): 121-30.

Weir, E. K., J. Lopez-Barneo, et al. (2005). "Acute oxygen-sensing mechanisms." $\underline{N}$ Engl J Med 353(19): 2042-55.

Weir, E. K., M. Obreztchikova, et al. (2008). "Mechanisms of oxygen sensing: a key to therapy of pulmonary hypertension and patent ductus arteriosus." $\underline{\mathrm{Br} \mathrm{J}}$ Pharmacol 155(3): 300-7.

Werkstrom, V., L. Ny, et al. (1997). "Carbon monoxide-induced relaxation and distribution of haem oxygenase isoenzymes in the pig urethra and lower oesophagogastric junction." Br J Pharmacol 120(2): 312-8.

White, P. T. (1974). "Experimental studies on the circulatory system of the late chick embryo." J Exp Biol 61(3): 571-92.

Wideman, R. F., Jr., P. Maynard, et al. (1999). "Thromboxane mimics the pulmonary but not systemic vascular responses to bolus $\mathrm{HCl}$ injections in broiler chickens." Poult Sci 78(5): 714-21.

Villamor, E., C. G. Kessels, et al. (2003). "Role of superoxide anion on basal and stimulated nitric oxide activity in neonatal piglet pulmonary vessels." Pediatr Res 54(3): 372-81.

Villamor, E., C. G. Kessels, et al. (2004). "Chronic in ovo hypoxia decreases pulmonary arterial contractile reactivity and induces biventricular cardiac enlargement in the chicken embryo." Am J Physiol Regul Integr Comp Physiol 287(3): R642-51. 
Villamor, E., C. G. Kessels, et al. (2005). "Cardiopulmonary effects of chronic administration of the NO synthase inhibitor L-NAME in the chick embryo." Biol Neonate 88(3): 156-63.

Villamor, E., F. Perez-Vizcaino, et al. (2000). "Relaxant effects of carbon monoxide compared with nitric oxide in pulmonary and systemic vessels of newborn piglets." Pediatr Res 48(4): 546-53.

Villamor, E., K. Ruijtenbeek, et al. (2002). "Vascular reactivity in intrapulmonary arteries of chicken embryos during transition to ex ovo life." Am J Physiol Regul Integr Comp Physiol 282(3): R917-27.

Villamor, E., T. Ruiz, et al. (1997). "Endothelium-derived nitric oxide-dependent

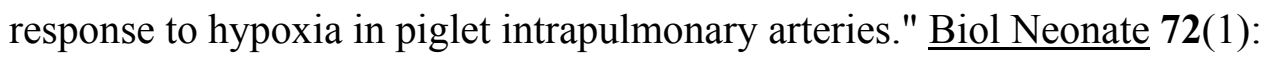
$62-70$.

Williams, M. L., J. E. Coleman, et al. (2006). "Lentiviral expression of retinal guanylate cyclase-1 (RetGC1) restores vision in an avian model of childhood blindness." PLoS Med 3(6): e201.

Wilson, D. P., M. Susnjar, et al. (2005). "Thromboxane A2-induced contraction of rat caudal arterial smooth muscle involves activation of $\mathrm{Ca} 2+$ entry and $\mathrm{Ca} 2+$ sensitization: Rho-associated kinase-mediated phosphorylation of MYPT1 at Thr-855, but not Thr-697." Biochem J 389(Pt 3): 763-74.

Wittmann, J. and J. Prechtl (1991). "Respiratory function of catecholamines during the late period of avian development." Respir Physiol 83(3): 375-86.

Wolinsky, H. and S. Glagov (1967). "Nature of species differences in the medial distribution of aortic vasa vasorum in mammals." Circ Res 20(4): 409-21.

Wolpert, L., R. Beddington, et al. (2002). Principles of Development, Oxford University Press.

Woodgate, P. G. and M. W. Davies (2001). "Permissive hypercapnia for the prevention of morbidity and mortality in mechanically ventilated newborn infants." Cochrane Database Syst Rev(2): CD002061.

Wray, S. and R. D. Smith (2004). "Mechanisms of action of pH-induced effects on vascular smooth muscle." Mol Cell Biochem 263(1-2): 163-72.

Wright, D. H., D. Abran, et al. (2001). "Prostanoid receptors: ontogeny and implications in vascular physiology." Am J Physiol Regul Integr Comp Physiol 281(5): R1343-60. 
Wu, G. R., S. Jing, et al. (2001). "The effect of vitamin A on contraction of the ductus arteriosus in fetal rat." Pediatr Res 49(6): 747-54.

Yi, S. L., C. Kantores, et al. (2006). "8-Isoprostane-induced endothelin-1 production by infant rat pulmonary artery smooth muscle cells is mediated by Rhokinase." Free Radic Biol Med 41(6): 942-9.

Yoshida, M., A. Suzuki, et al. (1994). "Mechanisms of vasoconstriction induced by endothelin-1 in smooth muscle of rabbit mesenteric artery." J Physiol 477 ( Pt 2): 253-65.

Zhang, Y., E. Pertens, et al. (2005). "8-isoprostaglandin E(2) activates $\mathrm{Ca}(2+)$ dependent $\mathrm{K}(+)$ current via cyclic AMP signaling pathway in murine renal artery." Eur J Pharmacol 520(1-3): 22-8.

Zhang, Y., T. Tazzeo, et al. (2003). "Vasodilatory and electrophysiological actions of 8-iso-prostaglandin E2 in porcine coronary artery." J Pharmacol Exp Ther 305(3): 1054-60.

Zoer, B., L. Kessels, et al. (2009). "Effects of prenatal hypoxia on pulmonary vascular reactivity in chickens prone to pulmonary hypertension." J Physiol Pharmacol 60(1): 119-30. 


\section{Chapter 2}

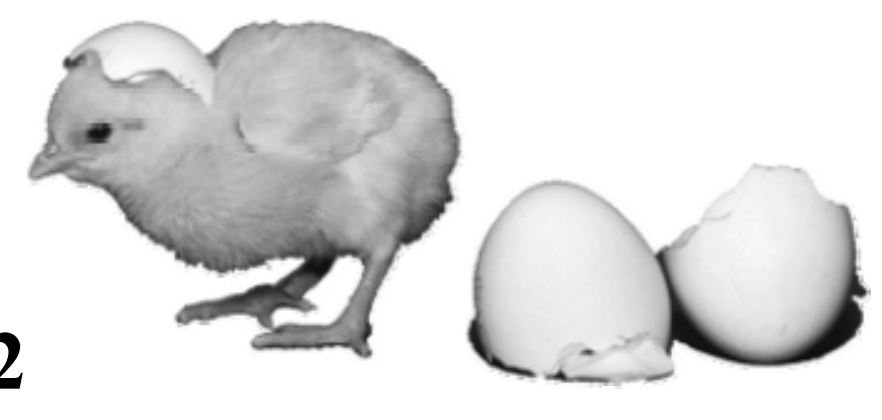

\section{ONTOGENY OF CHICKEN DUCTUS ARTERIOSUS RESPONSE TO OXYGEN AND VASOCONSTRICTORS}

Pia Ågren, Angel L. Cogolludo, Carolina G. A. Kessels, Francisco Pérez-Viscaíno, Jo G. R. De Mey, Carlos E. Blanco and Eduardo Villamor

Am J Physiol Regulatory Integrative Comp Physiol 292:485-496, 2007 


\title{
Ontogeny of chicken ductus arteriosus response to oxygen
}

\section{and vasoconstrictors}

\author{
Pia Ågren, ${ }^{1}$ Angel L. Cogolludo, ${ }^{1,2}$ Carolina G. A. Kessels, ${ }^{1}$ Francisco Pérez-Vizcaíno, ${ }^{2}$ \\ Jo G. R. De Mey, ${ }^{3}$ Carlos E. Blanco, ${ }^{1}$ and Eduardo Villamor ${ }^{1}$ \\ ${ }^{1}$ Department of Pediatrics, Maastricht University Hospital, Research Institute Growth and Development (GROW), \\ University of Maastricht, Maastricht; ${ }^{2}$ Department of Pharmacology, Institute of Pharmacology and Toxicology, \\ School of Medicine, Universidad Complutense, Madrid, Spain; and ${ }^{3}$ Department of Pharmacology and Toxicology, \\ Cardiovascular Research Institute Maastricht, University of Maastricht, Maastricht, The Netherlands
}

Submitted 21 March 2006; accepted in final form 7 August 2006

Ågren P, Cogolludo AL, Kessels CG, Pérez-Vizcaíno F, De Mey JG, Blanco CE, Villamor E. Ontogeny of chicken ductus arteriosus response to oxygen and vasoconstrictors. Am J Physiol Regul Integr Comp Physiol 292: R485-R495, 2007. First published August 17, 2006; doi:10.1152/ajpregu.00204.2006. - The present study aimed to characterize the contractile reactivity of the chicken ductus arteriosus (DA) from the last stage of prenatal development and throughout the perinatal period. Isolated DA rings from 15-day, noninternally-pipped 19-day, and externally-pipped 21-day embryos were studied using myograph techniques. On embryonic day 15 , the chicken DA did not respond to $\mathrm{O}_{2}$ (0 to $21 \%$ ), norepinephrine (NE), or phenylephrine (Phe) but contracted in response to high- $\mathrm{K}^{+}$solution, the inhibitor of voltage-gated channels 4-aminopyridine, U-46619, and endothelin (ET)-1. These responses increased with advancing incubation age. Contractile responses to $\mathrm{O}_{2}, \mathrm{NE}$, and Phe were present in the 19- and 21-day embryo. Oxygen-induced contraction was restricted to the pulmonary side of the DA and was augmented by the nitric oxide synthase inhibitor $\mathrm{N}^{\omega}$-nitro-L-arginine methyl ester and the soluble guanylate cyclase inhibitor $1 \mathrm{H}-[1,2,4]$ oxadiazolo[4,3-a]quinoxalin-1one and reduced by the peptidic $\mathrm{ET}_{\mathrm{A}}$ and $\mathrm{ET}_{\mathrm{B}}$-receptor antagonist PD-142,893. Transmural electrical stimulation of nerves, the nonselective cyclooxygenase (COX) inhibitor indomethacin, the COX-1 inhibitor valeryl salicylate, the COX-2 inhibitor nimesulide, the inhibitor of ATP-sensitive $\mathrm{K}^{+}$channels glibenclamide, and the inhibitor of $\mathrm{Ca}^{2+}$-activated $\mathrm{K}^{+}$channels tetraethylammonium did not cause contraction of the DA rings at any age. We conclude that transition to ex ovo life is accompanied by dramatic changes in chicken DA reactivity. At 0.7 incubation, excitation-contraction and pharmacomechanical coupling for several contractile agonists are already present, whereas the constrictor effects of $\mathrm{O}_{2}$ and cathecolamines appear later in development and are located in the pulmonary side of the DA.

ductus arteriosus; chicken embryo; potassium channels; oxygen sensing; cathecolamines.

THE DUCTUS ARTERIOSUS (DA) is a vessel that connects the pulmonary artery to the aorta and provides, during the fetal life, a pulmonary-to-systemic diversion that shunts more than half of the right ventricle output away from the nonventilated lungs into the systemic circulation $(43,47)$. The main factors maintaining patency of the DA in utero are low $\mathrm{O}_{2}$ tension, high levels of circulating $\mathrm{PGE}_{2}$, and locally produced $\mathrm{PGE}_{2}$ and $\mathrm{PGI}_{2}(24,43)$. Failure of DA closure after birth is a common complication of premature delivery that is still presenting

Address for reprint requests and other correspondence: E. Villamor. Dept of Pediatrics, Univ. Hospital Maastricht, P. Debyelaan 25. P.O. Box 5800. 6202 AZ Maastricht. The Netherlands (e-mail: eiv@paed.azm.nl). challenges in terms of diagnosis, assessment, and treatment options (43).

Although the isolated DA is sensitive to a wide range of contractile agonists, the major factor actively stimulating contraction at birth is increasing $\mathrm{O}_{2}$ tension, which has a profound effect on the DA, both directly and by modulating its response to vasodilators and vasoconstrictors (43). To constrict properly after birth, the DA prepares itself for this specific task from a quite early onset during development (3). This preparation is reflected by changes in responsiveness with advancing gestational age. These have been extensively characterized in numerous mammalian species including human, lamb, mouse, rat, guinea pig, dog, and rabbit (43). However, we are not aware of any reports dealing with the maturational changes in responsiveness to $\mathrm{O}_{2}$ and other vasoactive agents of a nonmammalian DA.

The chicken (Gallus gallus) embryo represents an excellent model for investigating developmental physiology of the cardiovascular system. Chicken embryos have a mammalian-like circulation, with an extraembryonic circuit involved in the gas exchange (the chorioallantois), analogous to the placenta, and they maintain bilaterally developed DA (3). During the past few years, our group has analyzed developmental changes in reactivity of chicken embryo systemic and pulmonary arteries $(26,38,51,52)$. In the present study, we hypothesized that the responsiveness of the chicken embryo DA to $\mathrm{O}_{2}$ and other vasoconstrictors is developmentally regulated. Therefore, our goal was to characterize the contractile properties of chicken embryo DA and to analyze how they are influenced by in ovo development and by transition to ex ovo life.

\section{METHODS}

Incubation of Chicken Embryos and Vessel Isolation

Experiments were performed in accordance with Dutch law for animal experimentation. Fertilized eggs of White Leghorn chickens were incubated at $37.8^{\circ} \mathrm{C}, 45 \%$ humidity, and rotated once per hour (Incubator model 25HS; Masalles Comercial). Embryos incubated for 15,19 , and 21 days of the 21-day incubation period were studied. The 19-day embryos were defined as noninternally-pipped embryos, as verified by candling, while the 21-day embryos were defined as externally-pipped when the beak of the embryo was observed in an opening of the eggshell. The embryos were taken out, immediately

The costs of publication of this article were defrayed in part by the payment of page charges. The article must therefore be hereby marked "advertisement" in accordance with 18 U.S.C. Section 1734 solely to indicate this fact. 
killed by decapitation, placed on the dorsal side on a petri dish coated with silicon and a midline laparotomy and sternotomy were performed. With the aid of a dissecting microscope, the right DA was carefully dissected free from surrounding connective tissue and severed distal to the takeoff of the right pulmonary artery and proximal to the insertion into the aorta (see Fig. 1). The in situ length (in mm) of right DA was 3.48 (SD 0.27), 4.71 (SD 0.40), and 5.58 (SD 0.40) at embryonic days 15,19 , and 21 , respectively, whereas the maximal vascular segment length allowed in the myograph was $2 \mathrm{~mm}$. Therefore, a similar amount of ductal tissue was severed from the pulmonary and aortic ends of the vessel to obtain vascular rings with a length of $\sim 2 \mathrm{~mm}$. The right DA was selected because its shorter length allowed a higher proportion of the vessel to be represented in the myograph. In another set of experiments, and to analyze putative functional differences along the DA, rings obtained from the pulmonary and aortic side of the same right DA were compared (see Fig. 7). The boundary between pulmonary and aortic segments was determined based on the marked differences of diameter observed, along the vessel in the 19- and 21-day embryos (see Fig. 1). In some experiments, rings of the pre- and postductal pulmonary arteries were also isolated.

\section{Recording of Arterial Reactivity}

Two stainless steel wires (diameter $40 \mu \mathrm{m}$ ) were inserted into the lumen of the endothelium-intact vessels, which were mounted as 1.5- to 2-mm ring segments between an isometric force transducer and a displacement device in a myograph (model 610M; Myo Technology, Aarhus, Denmark). The myograph organ bath $(5 \mathrm{ml}$ vol) was filled with Krebs-Ringer bicarbonate (KRB) buffer maintained at $39^{\circ} \mathrm{C}$ and continuously aerated with one of the following gas mixtures: $95 \%$ $\mathrm{N}_{2}-5 \% \mathrm{CO}_{2}\left(\mathrm{Po}_{2}=2.6-3.3 \mathrm{kPa}\right), 5 \% \mathrm{O}_{2}-90 \% \mathrm{~N}_{2}-5 \% \mathrm{CO}_{2}\left(\mathrm{PO}_{2}=\right.$ $6.8-7.2 \mathrm{kPa}), 21 \% \mathrm{O}_{2}-74 \% \mathrm{~N}_{2}-5 \% \mathrm{CO}_{2}\left(\mathrm{Po}_{2}=16-20 \mathrm{kPa}\right)$, or $95 \%$ $\mathrm{O}_{2}-5 \% \mathrm{CO}_{2}\left(\mathrm{PO}_{2}=72-76 \mathrm{kPa}\right)$. The final $\mathrm{pH}$ was $7.38-7.42$ and $\mathrm{PCO}_{2}$ was $4.6-5.6 \mathrm{kPa}$ in all solutions. The $\mathrm{PO}_{2}$ of the KRB buffer was measured with a blood gas analyzer (model 510 radiometer; ABL, Copenhagen, Denmark) and, in some experiments, was recorded continuously with an oxygen electrode (OXELP; World Precision Instruments, Berlin, Germany). Each DA ring was stretched to its individual optimal lumen diameter (i.e., the diameter at which it developed the strongest contractile response to $62.5 \mathrm{mM} \mathrm{KCl}$ ) using a diameter-tension protocol as previously described $(26,52)$. During the first phase of stabilization and determination of optimal diameter, the DA rings were maintained in $\mathrm{KRB}$ buffer aerated with $0 \% \mathrm{O}_{2}$. Afterward, and depending on the specific protocol, one of the abovedescribed gas mixtures was used.

\section{Contractile Responses}

Concentration-response curves to $\mathrm{KCl}(4.75-125 \mathrm{mM})$, norepinephrine (NE; $10 \mathrm{nM}-0.1 \mathrm{mM}$ ), phenylephrine (Phe; $10 \mathrm{nM}-0.3 \mathrm{mM}$ ), the thromboxane $\mathrm{A}_{2}$ mimetic U-46619 $(10 \mathrm{nM}-10 \mu \mathrm{M})$, and endothe-
Fig. 1. Anatomy and histology of chicken ductus arteriosus (DA). Note the differences in diameter between proximal and distal segments of DA from a 15-day $(A)$, a noninternally pipped 19 -day $(B)$, and an externallypipped 21-day $(C)$ chicken embryo. Black arrowheads in $B$ indicate the takeoff of postductal pulmonary arteries. Ao, aorta; RPA, right pulmonary artery; LPA, left pulmonary artery; RDA, right DA; LDA, left DA. $D$ : Elastin staining of a 19-day DA longitudinal section. P, pulmonary side; Ao, aortic side. $E-G$ : light micrographs showing double staining for elastin and $\alpha$-actin of cross sections of DA from a 19-day chicken embryo. Note the changes from the aortic side $(G)$ with lamellar actin expression to the central part $(F)$ of the DA with a dense $\alpha$-actin-positive media subjacent to the endothelium and few layers of elastin around the muscular layer. In the pulmonary side $(E)$, elastin fibers do not assemble into the neatly organized lamellar structures observed in the aortic side. Bars $1 \mathrm{~mm}(A-C)$, $200 \mu \mathrm{M}(D)$, and $20 \mu \mathrm{M}(E-G)$.
A

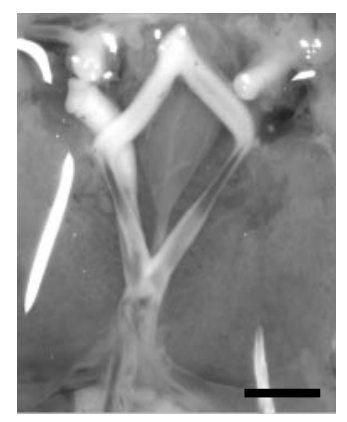

B
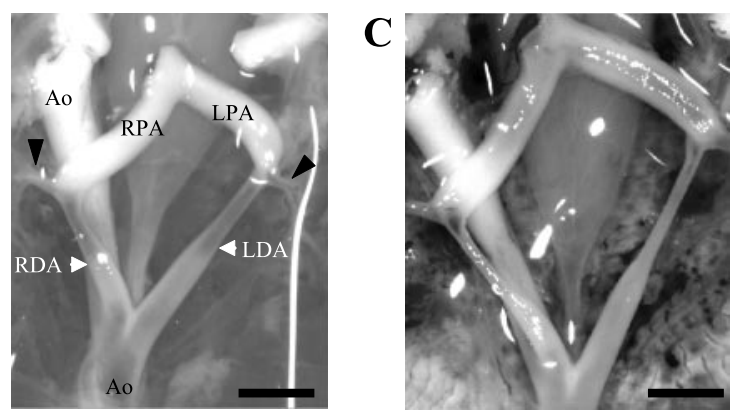

D

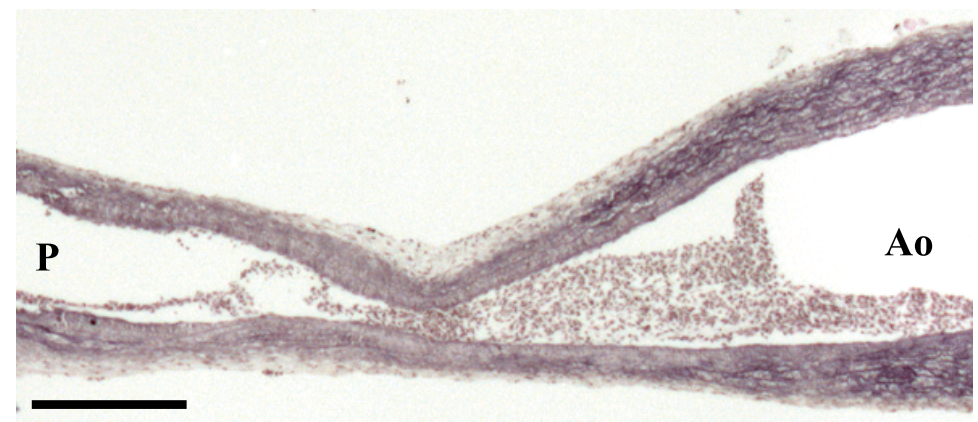

$\mathbf{E}$

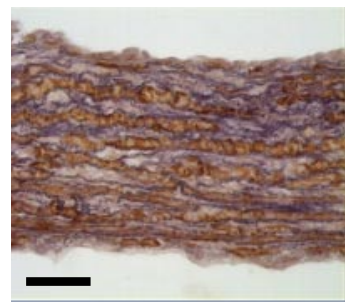

$\mathbf{F}$

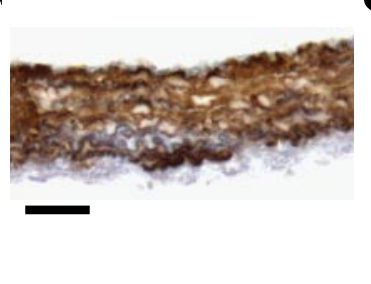

G

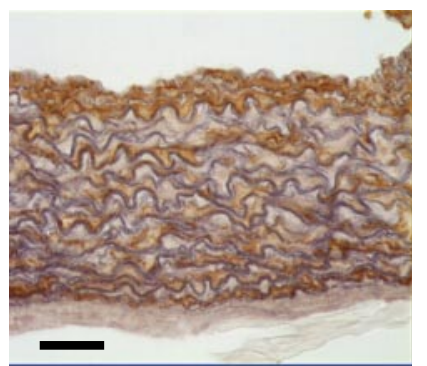


lin $(\mathrm{ET})-1(0.01 \mathrm{nM}-0.1 \mu \mathrm{M})$ were constructed by increasing the organ chamber concentration of the drug, by cumulative increments after a steady-state response had been reached with each increment. When two or more agonists were studied in the same arterial preparation, the vessels were repeatedly washed and allowed to equilibrate for at least $30 \mathrm{~min}$. If the tone did not recover to resting level, the vessels were discarded for further experiments. Sympathetic neuroeffector mechanisms were studied by using electrical field stimulation $(0.25-16 \mathrm{~Hz}, 2 \mathrm{~ms}, 85 \mathrm{~mA})$ via two platinum electrodes that were placed in the axial direction of the vessel. Constant-current pulses were delivered by a stimulator (Technical Services, Universiteit Maastricht, The Netherlands).

To determine the role of $\mathrm{K}^{+}$channels in DA contraction, we performed concentration-response curves to 4-aminopyridine (4-AP; $1 \mathrm{mM}-10 \mathrm{mM})$, glibenclamide $(1 \mu \mathrm{M}-10 \mu \mathrm{M})$, and tetraethylammonium (TEA; $1 \mathrm{mM}-10 \mathrm{mM}$ ), preferential inhibitors of voltage-gated $\left(\mathrm{K}_{\mathrm{V}}\right)$, ATP-sensitive $\left(\mathrm{K}_{\mathrm{ATP}}\right)$, and $\mathrm{Ca}^{2+}$-activated $\left(\mathrm{K}_{\mathrm{Ca}}\right) \mathrm{K}^{+}$channels, respectively. To analyze the putative contractile effects of cyclooxygenase $(\mathrm{COX})$ inhibition, DA rings were incubated for $30 \mathrm{~min}$ in the presence of the nonselective COX inhibitor indomethacin $(10 \mu \mathrm{M})$, the COX-1 inhibitor valeryl salicylate $(0.5 \mathrm{mM})$, or the COX-2 inhibitor nimesulide $(0.1 \mu \mathrm{M})$.

Response of chicken DA to $\mathrm{O}_{2}$. In a first set of experiments, DA rings were incubated for (at least) $30 \mathrm{~min}$ with $95 \% \mathrm{~N}_{2}-5 \% \mathrm{CO}_{2}$. Then the gas mixture was switched to $21 \% \mathrm{O}_{2}-74 \% \mathrm{~N}_{2}-5 \% \mathrm{CO}_{2}$. This gas was maintained for $10 \mathrm{~min}$ (a stable response to $\mathrm{O}_{2}$ was observed after 2-3 min, see RESULTS). In a second set of experiments, and to analyze the involvement of the nitric oxide (NO)/cGMP pathway and of ET-1 in $\mathrm{O}_{2}$-induced contraction, DA rings were exposed to $21 \% \mathrm{O}_{2}-74 \%$ $\mathrm{N}_{2}-5 \% \mathrm{CO}_{2}$ for 10 min to obtain a first response to $\mathrm{O}_{2}$. Afterward, DA rings were relaxed with $95 \% \mathrm{~N}_{2}-5 \% \mathrm{CO}_{2}$ and then incubated for 15 min with vehicle (control), the $\mathrm{NO}$ synthase inhibitor $\mathrm{N}^{\omega}$-nitro-Larginine methyl ester (L-NAME; $0.1 \mathrm{mM}$ ), the soluble guanylate cyclase inhibitor $1 \mathrm{H}-[1,2,4]$ oxadiazolo[4,3-a]quinoxalin-1-one (ODQ; $10 \mu \mathrm{M})$, or the peptidic $\mathrm{ET}_{\mathrm{A}}$ and $\mathrm{ET}_{\mathrm{B}}$-receptor antagonist PD-142,893 $(1 \mu \mathrm{M})$. After the incubation, a second stimulation with $21 \% \mathrm{O}_{2}$ was performed in the presence of the above blockers. In a third set of experiments, DA were contracted (under $95 \% \mathrm{~N}_{2}-5 \% \mathrm{CO}_{2}$ ) with $\mathrm{NE}$ $(1 \mu \mathrm{M})$ or $\mathrm{KCl}(62.5 \mathrm{mM})$, and when a stable response was achieved, the gas mixture was switched to $21 \% \mathrm{O}_{2}-74 \% \mathrm{~N}_{2}-5 \% \mathrm{CO}_{2}$. Finally, in a fourth group of experiments, concentration-response curves to $\mathrm{KCl}$ and $\mathrm{NE}$ were performed during aeration of the $\mathrm{KRB}$ buffer with $95 \% \mathrm{~N}_{2}-5 \% \mathrm{CO}_{2}, 5 \% \mathrm{O}_{2}-90 \% \mathrm{~N}_{2}-5 \% \mathrm{CO}_{2}$ or $95 \% \mathrm{O}_{2}-5 \% \mathrm{CO}_{2}$.

Histological analysis. For evaluation of vascular structure, paraffin cross and longitudinal sections $(4 \mu \mathrm{m})$ from the DA were prepared and double staining was performed for elastin (Lawson solution; Klinipath, Duiven, The Netherlands), and a monoclonal antibody against smooth muscle $\alpha$-actin (Dako, Carpinteria, CA, diluted 1:300 and using diaminobenzidine as the chromogen) (51). Perivascular adrenergic nerves were stained with glyoxylic acid in isolated whole mount preparations of DA segments, using femoral arteries as a positive control (26).

\section{Data Analysis}

Results are shown as means and SD of measurements in the number of embryos. Contractile responses are expressed in terms of active wall tension $(\mathrm{N} / \mathrm{m})$. Sensitivity to vasoconstrictors (expressed as $\mathrm{pD}_{2}=-\log \mathrm{EC}_{50}$ ) was determined for each artery by fitting individual concentration-response data to a nonlinear sigmoid regression curve and interpolating (Graphpad Prism version 2.01; Graphpad Software, San Diego, CA). Differences between mean values were assessed by one-way ANOVA followed by Bonferroni's post hoc $t$-test. Differences were considered significant at a $P<0.05$. All analyses were performed using a commercially available statistics package (GraphPad InStat).

\section{Drugs and Solutions}

KRB contained (in mmol/l): $118.5 \mathrm{NaCl}, 4.75 \mathrm{KCl}, 1.2$ $\mathrm{MgSO}_{4} \cdot 7 \mathrm{H}_{2} \mathrm{O}, 1.2 \mathrm{KH}_{2} \mathrm{PO}_{4}, 25.0 \mathrm{NaHCO}_{3}, 2.5 \mathrm{CaCl}_{2}, 5.5$ glucose. Solutions containing different concentrations of $\mathrm{K}^{+}$were prepared by replacing part of the $\mathrm{NaCl}$ by an equimolar amount of $\mathrm{KCl}$. Arterenol bitartrate (NE), Phe, indomethacin, 4-AP, glibenclamide, TEA, and L-NAME were obtained from Sigma (St. Louis, MO); ET-1, valeryl salicylate, nimesulide, and PD-142,893 were from Alexis Biochemicals (Lausen, Switzerland); U-46619 was from Cayman Chemical (Ann Arbor, MI), and ODQ was from Tocris (Ballwin, MO). All drugs were dissolved initially in distilled deionized water (except indomethacin, valeryl salicylate, and nimesulide in ethanol and U-46619, glibenclamide, and ODQ in DMSO) to prepare adequate stock solutions, and further dilutions were made in KRB.

\section{RESULTS}

\section{Chicken DA Anatomy and Histology}

On its emergence from the right ventricle, the main pulmonary trunk is directly divided into right and left pulmonary arteries that pass caudally and bifurcate into the DA and the postductal pulmonary arteries (Fig. 1, $A-C$ ). The postductal pulmonary artery segments arise in an angle of $90^{\circ}$ and enter immediately the lungs, whereas the two DA appear as the natural continuation of the preductal pulmonary arteries (Fig. $1, A-C)$. The right DA runs caudally adhered to descending aorta. As both DA pass caudally, they become progressively broader. Differences in diameter between proximal and distal segments of DA become more prominent with advancing incubation age (Fig. 1, $A-C$ ). Finally, both DA join the dorsal aorta with an acute angle of insertion.

Double staining for elastin and smooth muscle $\alpha$-actin demonstrated the presence of abrupt changes in vessel wall structure along the DA. As shown in Fig. $1, D$ and $G$, in the aortic side of the DA, elastic fibers fill the vascular wall arranged in concentric lamellae with $\alpha$-actin-positive smooth muscle cells embedded between the lamellae. From this elastic segment, and in aortopulmonary direction, a progressive reduction of medial thickness and elastin staining was observed (Fig. 1D). The narrow central segment of the DA displayed the structure of a muscular artery with a dense $\alpha$-actin-positive media subjacent to the endothelium and few layers of elastic fibers around the muscular layer (Fig. $1 F$ ). Finally, dense elastic fibers can again be observed in the vicinity of the pulmonary artery (Fig. 1E). These fibers completely fill the media but do not assemble into the neatly organized lamellar structures observed in the aortic side.

\section{Contractile Responses in Isolated DA Rings}

Isolated DA obtained from 15-, 19- and 21-day chicken embryos responded to depolarizing high- $\mathrm{K}^{+}$solution with a tonic contraction and the amplitude of this response significantly increased with age (Fig. 2A). The diameter at which a maximal response to $62.5 \mathrm{mM} \mathrm{KCl}$ was obtained did not significantly change between day $15(761 \mu \mathrm{m}, \mathrm{SD} 76, n=48)$ and day 19 (774 $\mu \mathrm{m}$, SD 94, $n=81, P=0.42$ vs. 15-day), but decreased at day 21 (549 $\mu \mathrm{m}, \mathrm{SD} 192, n=36, P<0.001$ vs. 15- and 19-day).

To identify the $\mathrm{K}^{+}$channel types involved in the control of DA tone, we tested the effects of glibenclamide, TEA, and 4-AP, which preferentially block $\mathrm{K}_{\mathrm{ATP}}, \mathrm{K}_{\mathrm{Ca}}$, and $\mathrm{K}_{\mathrm{V}}$ channels, 

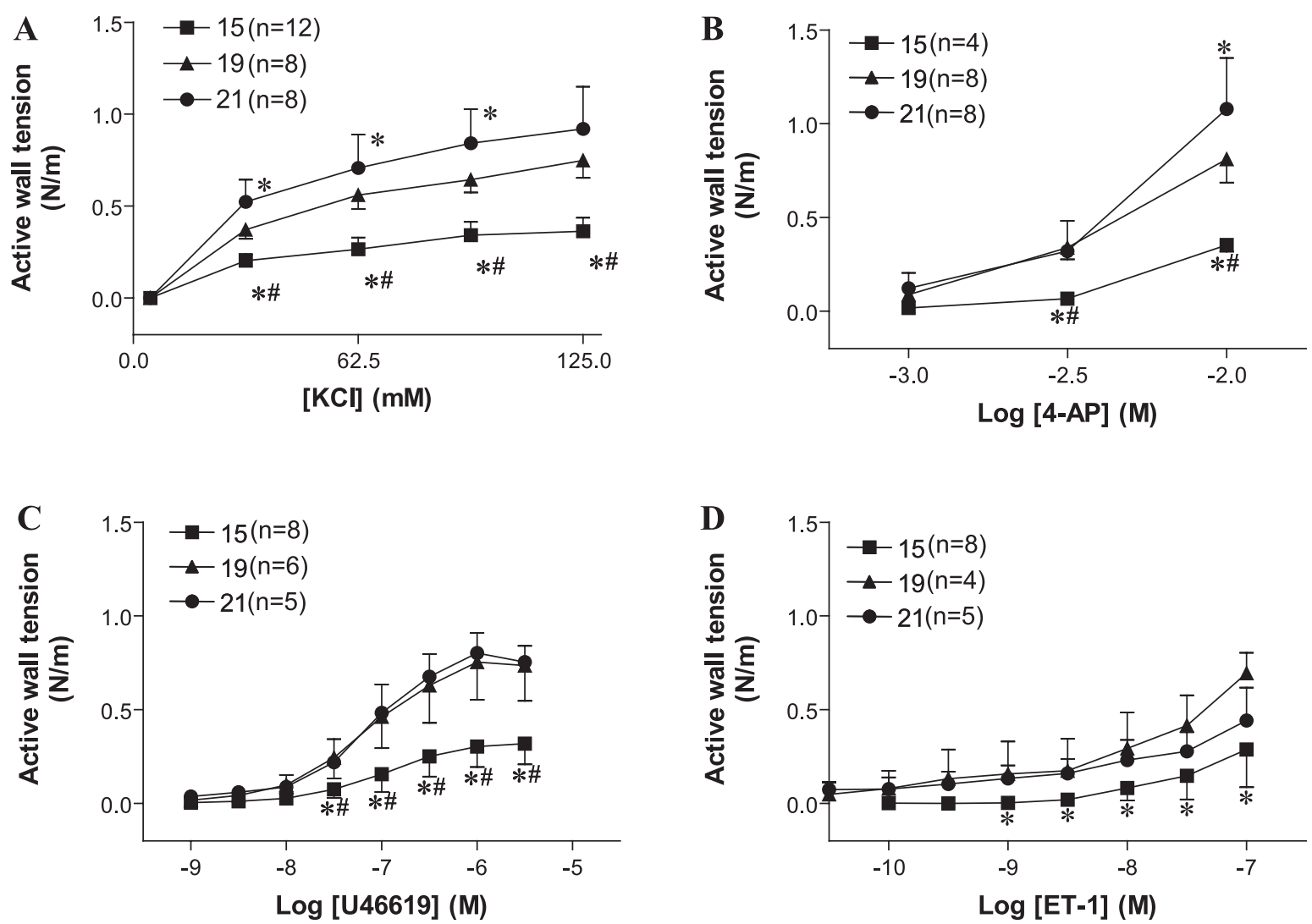

Fig. 2. Concentration-dependent contractile effects of $\mathrm{KCl}(A)$, 4-aminopyridine (4-AP; $B)$, U-46619 (C), and endothelin-1 (ET-1; $D$ ) in 15-, 19- and 21-day DA rings aerated with $5 \% \mathrm{O}_{2}-90 \% \mathrm{~N}_{2}-5 \% \mathrm{CO}_{2}$. Each point represents the mean and $\mathrm{SD}$ of the number of embryos. $* P<0.05$ for difference from 19 -day embryos, $\# P<0.05$ for difference from 21-day embryos.

respectively. Neither glibenclamide nor TEA had any effect on basal tone at any age (not shown). However, the $\mathrm{K}_{\mathrm{V}}$ channel inhibitor 4-AP caused a dose-dependent increase in tension, which increased significantly with age (Fig. 2B).

In another set of experiments, concentration-response curves to the polypeptide ET-1 (Fig. $2 D$ ) and the thromboxane $\mathrm{A}_{2}$ receptor (TP) agonist U-46619 (Fig. 2C) were performed. Both agonists contracted the 15-day DA and the responses were higher in older animals. Weak but significant contractile responses to ET-1 were observed at concentrations above 0.03 $\mathrm{nM}$ in 19-day and 21-day DA, whereas concentrations $\geq 3 \mathrm{nM}$ induced a clear contractile response in the three age groups. The maximal response to ET-1 could not be reached at concentrations up to $0.1 \mu \mathrm{M}$ at any age. The responses induced by U-46619 were markedly increased in the 19-day embryos [maximum contraction $\left(\mathrm{E}_{\max }\right)=0.81 \mathrm{~N} / \mathrm{m}, \mathrm{SD} 0.18, n=6$ ] and the 21-day embryos $\left(\mathrm{E}_{\max }=0.86 \mathrm{~N} / \mathrm{m}, \mathrm{SD} 0.15, n=5\right)$ compared with those obtained in the 15-day DA $\left(\mathrm{E}_{\max }=0.33\right.$ $\mathrm{N} / \mathrm{m}$, SD $0.10, n=8, P<0.001$ vs. 19 - and 21-day), although no significant changes in $\mathrm{pD}_{2}$ values (15-day: 6.91, $\mathrm{SD} 0.21$; 19-day: 7.08, SD 0.25; 21-day: 7.17, SD 0.22) were observed.

Maturational responses to adrenoceptor activation. In contrast to $\mathrm{KCl}, 4-\mathrm{AP}, \mathrm{ET}-1$, and U-46619, the nonselective adrenergic receptor agonist NE (Fig. 3A) and the $\alpha_{1}$-adrenegic receptor agonist Phe (Fig. $3 B$ ) failed to contract the 15-day DA. NE caused a concentration-dependent contraction of the 19day and 21-day DA, reaching a higher maximal response in the older animal. Thus, the $\mathrm{E}_{\max }$ induced by $\mathrm{NE}$ averaged 0.55
$\mathrm{N} / \mathrm{m}(\mathrm{SD} 0.31)$ at day $19(n=18)$ and $0.94 \mathrm{~N} / \mathrm{m}(\mathrm{SD} 0.15)$ at day $21(n=8, P=0.0029)$, but $\mathrm{pD}_{2}$ values were not significantly different at both ages (19-day: 6.22, SD 0.52; 21-day: 6.21, SD 0.18). The $\mathrm{E}_{\max }$ induced by Phe averaged $0.78 \mathrm{~N} / \mathrm{m}(\mathrm{SD} 0.18)$ at day $19(n=6)$ and $1.17 \mathrm{~N} / \mathrm{m}(\mathrm{SD} 0.46)$ at day $21(n=8, P=0.08)$ and mean $\mathrm{pD}_{2}$ were $5.58(\mathrm{SD} 0.28)$ and 5.56 (SD 0.16) at days 19 and 21, respectively. In contrast to the marked contractile responses to NE in the 19-day DA, we found no responses to NE in either pre- or postductal pulmonary arteries at this age (Fig. 3C). Electrical field stimulation did not consistently affect chicken DA tension (not shown). Furthermore, catecholamine-containing nerves were detected with glyoxylic acid staining in femoral arteries but not in DA from the same embryos (Fig. 3D).

Lack of response to COX inhibitors. Incubation with the nonselective COX inhibitor indomethacin $(10 \mu \mathrm{M})$, the COX-1 inhibitor valeryl salicylate $(0.5 \mathrm{mM})$, or the COX-2 inhibitor nimesulide $(0.1 \mu \mathrm{M})$ produced a weak contractile effect that was not significantly different from the contraction induced by the vehicle (ethanol, $0.1 \%$ final chamber bath concentration, Fig. 4A). Moreover, none of the COX inhibitors affected the contraction elicited by $\mathrm{KCl}$ (Fig. $4 B$ ) or NE (Fig. 4C).

Oxygen-induced contraction and modulation of responses to vasoconstrictors. Switching the $\mathrm{O}_{2}$ mixture from 0 to $21 \%$ produced a progressive increase of the $\mathrm{O}_{2}$ concentration in the organ chamber that reached a steady state after $\sim 3$ min (Fig. $5 A$ ). This switch in $\mathrm{O}_{2}$ concentration resulted in a contractile response in the DA from 19- and 21-day embryos, but not in 

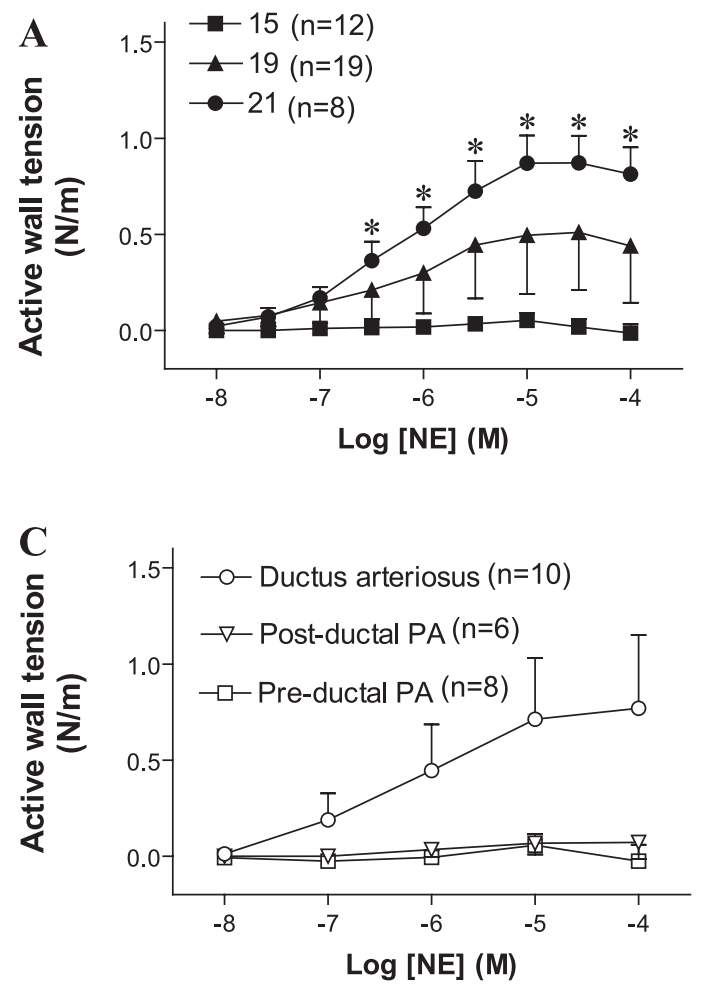

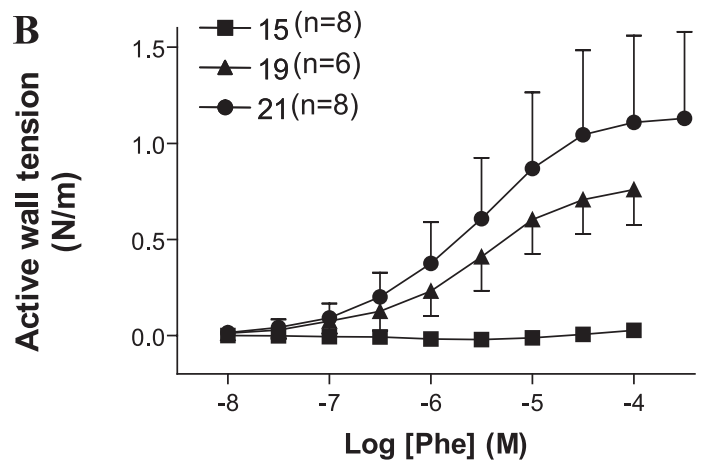

D

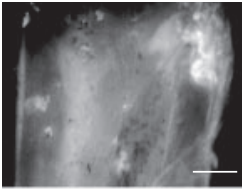

Ductus

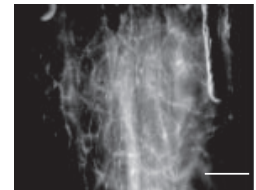

Femoral

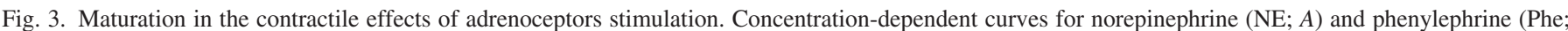

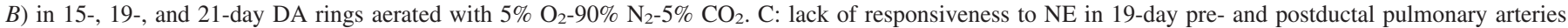

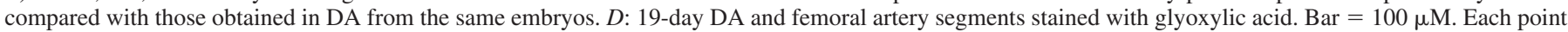
represents the mean and SD of the number of embryos. ${ }^{*} P<0.05$ for difference from 19 -day embryos.

those from 15-days (Fig. 5A). Oxygen-induced contractions were tonic, reversible, and reproducible. In the presence of NE $(1 \mu \mathrm{M})$ the change from 0 to $21 \% \mathrm{O}_{2}$ caused a further tonic constriction, which was significantly higher in the 21-day than in the 19-day DA (Fig. 5, B and D). In $62.5 \mathrm{mM} \mathrm{KCl-}$ contracted DA the contractile response to $\mathrm{O}_{2}$ was markedly reduced compared with that obtained in NE-stimulated DA (Fig. 5, $C$ and $D$ ).

The NO synthase inhibitor L-NAME $(0.1 \mathrm{mM})$ and the soluble guanylate cyclase inhibitor ODQ $(10 \mu \mathrm{M})$ induced a slight contraction of the 19-day DA (L-NAME: $0.04 \mathrm{~N} / \mathrm{m}, \mathrm{SD}$ 0.05, $n=8$; ODQ: $0.07 \mathrm{~N} / \mathrm{m}$, SD $0.05, n=8$ ). Either the presence of L-NAME or ODQ produced a marked increase in $\mathrm{O}_{2}$-evoked constriction (Fig. 5E). L-NAME did not produce any significant contractile effect and did not modify the (absent) response to $\mathrm{O}_{2}$ of the 15-day DA ( $n=4$, not shown). Incubation with the peptidic $\mathrm{ET}_{\mathrm{A}}$ and $\mathrm{ET}_{\mathrm{B}}$-receptor antagonist PD-142,893 (1 $\mu \mathrm{M})$ did not significantly modify the basal wall tension of the 19-day DA. The presence of PD-142,893 produced a significant reduction $(26.7 \%$, SD $21.4, n=12)$ of $\mathrm{O}_{2}$-evoked constriction (Fig. $5 E$ ). When the 19-day DA was incubated in the presence of both L-NAME and PD-142,893, no significant changes were observed in $\mathrm{O}_{2}$-induced constriction (Fig. 5E).

In another set of experiments, the contractions induced by $\mathrm{NE}$ or $\mathrm{KCl}$ were tested under different $\mathrm{O}_{2}$ concentrations $(0,5$ and $95 \%$ ) in 15- and 19-day embryos (Fig. 6). KCl-induced responses were not affected by changing the $\mathrm{O}_{2}$ tension at any age, whereas, in 19-day embryos, the maximal response to $\mathrm{NE}$ was significantly increased under $95 \% \mathrm{O}_{2}\left(\mathrm{E}_{\max }=0.80 \mathrm{~N} / \mathrm{m}\right.$,
SD $0.35, n=10)$ compared with $5 \% \mathrm{O}_{2}\left(\mathrm{E}_{\max }=0.46 \mathrm{~N} / \mathrm{m}, \mathrm{SD}\right.$ $0.29, n=18, P=0.01)$ but not compared with $0 \% \mathrm{O}_{2}\left(\mathrm{E}_{\max }=\right.$ $0.60 \mathrm{~N} / \mathrm{m}, \mathrm{SD} 0.30, n=9, P=0.2$ ) (Fig. 6).

Heterogeneity of contractile responses along the DA. The central part of the DA was used in the experiments described above (Figs. 2 to 6). In another set of experiments, the responses to $\mathrm{KCl}, \mathrm{NE}$, and $\mathrm{O}_{2}$ were compared in the aortic vs. the pulmonary side of the DA from 19- and 21-day embryos. The contractile response to $\mathrm{KCl}$ was increased in the aortic compared with the pulmonary side of the DA (Fig. 7A). In contrast, $\mathrm{NE}$-induced contractions were markedly reduced in the aortic vs. the pulmonary side of the DA (Fig. 7B). Either under basal conditions (Fig. 7, $C$ and $E$ ) or following the stimulation with $\mathrm{NE}$ (Fig. 7, $D$ and $E$ ), $\mathrm{O}_{2}$ induced contraction of the pulmonary side, but relaxed the aortic side of chicken DA.

\section{DISCUSSION}

In air-breathing vertebrates varying from lungfish to mammals, the DA derives from the sixth pharyngeal arch artery and, in preparation for its specific task, undergoes a morphologic and functional differentiation program, starting early in development $(3,43)$. For the first time, developmental changes in DA responsiveness to $\mathrm{O}_{2}$ and other vasoconstrictors have been characterized in a nonmammalian species. Our results can be summarized as follows. First, on embryonic day 15, the chicken DA did not respond to $\mathrm{O}_{2}$, NE, or Phe but demonstrated depolarization-, thromboxane $\mathrm{A}_{2-}$, and ET-1-induced constriction that increased with age. Second, responsiveness to $\mathrm{O}_{2}$ and catecholamines were present in the 19- and 21-day 

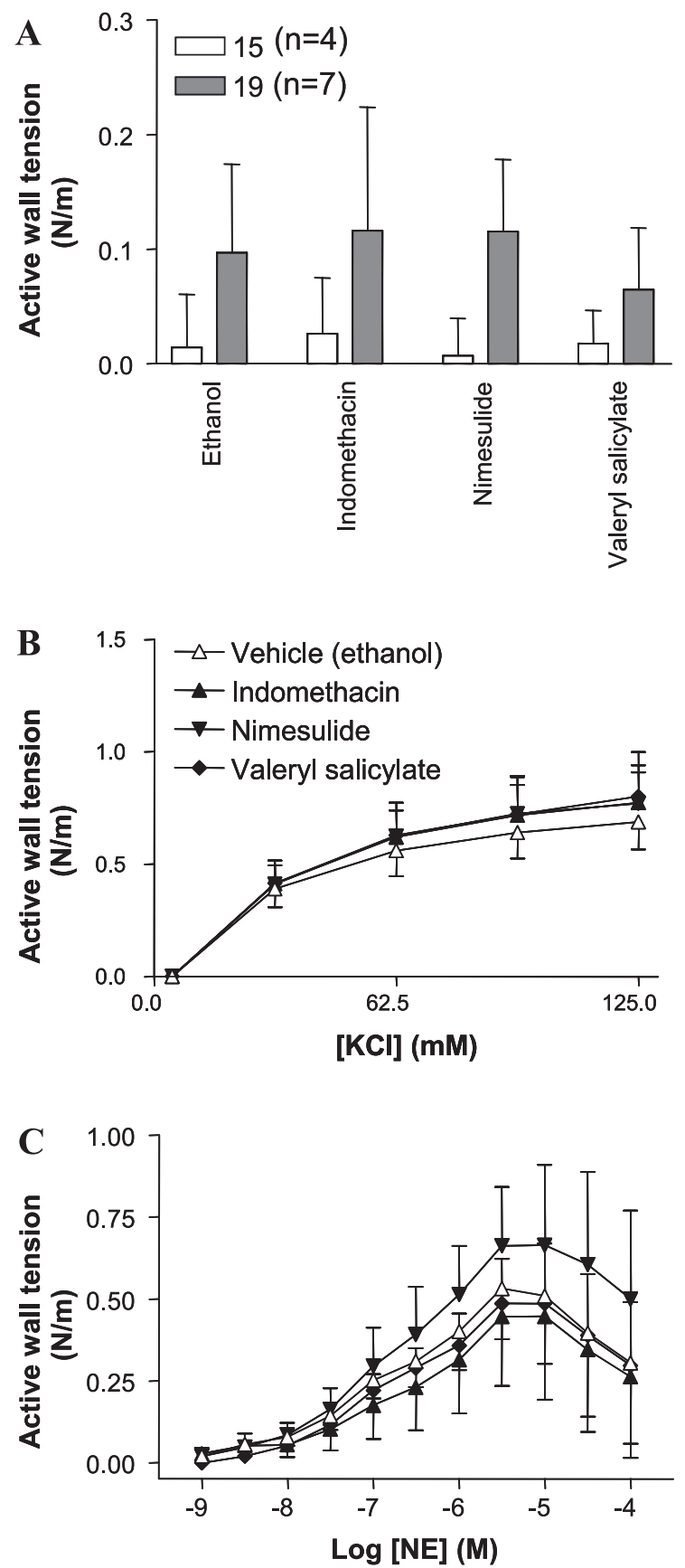

Fig. 4. A: contractile effects of $30 \mathrm{~min}$ of incubation with vehicle (ethanol $0.1 \%)$, the nonselective COX inhibitor indomethacin $(10 \mu \mathrm{M})$, the COX-1 inhibitor valeryl salicylate $(0.5 \mathrm{mM})$, or the COX-2 inhibitor nimesulide $(0.1$ $\mu \mathrm{M})$ in 15- and 19-day chicken embryos DA aerated with 5\% $\mathrm{O}_{2}-90 \% \mathrm{~N}_{2}-5 \%$ $\mathrm{CO}_{2}$. The effects of the vehicle, indomethacin, valeryl salicylate, and nimesulide on the contractions induced by $\mathrm{KCl}(B ; n=6$ in each group), and $\mathrm{NE}(C$ : $n=6$ in each group) in 19-day DA are also represented. Each bar or point represents the mean and SD of the number of embryos.

embryo DA with some further developmental differences, particularly in the response to NE. Oxygen not only increased tension of 19- and 21-day chicken DA but also potentiated NE-induced contraction. Third, the response to $\mathrm{O}_{2}$ was augmented by NO synthase and soluble guanylate cyclase inhibition and was reduced by the presence of an $\mathrm{ET}_{\mathrm{A}}$ and $\mathrm{ET}_{\mathrm{B}^{-}}$ receptor antagonist. Fourth, oxygen-induced contraction was located in the pulmonary side of the DA, whereas the aortic side demonstrated $\mathrm{O}_{2}$-evoked relaxation and a weaker NEinduced contraction. Finally, neither transmural stimulation of nerves nor COX inhibition consistently constricted the chicken DA, suggesting lack of involvement of neural vasoconstriction and locally formed dilatory PGs on chicken DA tone control, respectively.

\section{Changes in Chicken DA Responsiveness with Advancing Gestational Age}

We observed that the responses of chicken DA to $\mathrm{O}_{2}$ and to receptor-independent (i.e., high- $\mathrm{K}^{+}$solution) and -dependent (i.e., NE, Phe, U-46619, and ET-1) vasoconstrictors increased with gestational age. Similar findings have been reported in almost all mammalian species studied $(28,33,43,49)$. The reduced contractile response of mammalian preterm DA to $\mathrm{O}_{2}$ and vasoconstrictors may reflect greater inhibition by locally released vasodilators (i.e., PGs) (43). However, several studies have demonstrated alterations of contractile pathways with advancing gestational age (47), suggesting a maturation of contractility rather than merely a reduced degree of inhibition by PGs (43).

Potassium-evoked depolarization induced significant contraction in the DA of 15-day embryos. This indicates that at this developmental stage DA smooth muscle cells are already equipped with contractile proteins and an excitation-contraction coupling. This receptor-independent contractile response increased, in the chicken DA, twofold between day 15 and day 19, whereas in chicken embryo carotid and femoral arteries depolarization-evoked contraction increased five- to sevenfold during the same incubation period (26). Moreover, the presence of responses to the thromboxane $\mathrm{A}_{2}$ mimetic U-46619 and ET-1, in the 15-day DA, indicates that pharmacomechanical coupling is also developed rather early in this vessel. Accordingly, several studies in mammals indicate that the smooth muscle cells in the DA are more differentiated than those in other fetal arteries $(16,25,39)$. Expression of the adult-specific vascular smooth muscle myosin heavy chain isoform, SM2, is developmentally regulated and not detected, before birth, in the aorta or pulmonary artery of the rabbit, but expressed in the fetal DA $(16,25,39)$. Moreover, advanced differentiation has also been reported in the human DA that highly expressed the actin binding proteins calponin and caldesmon, when compared with the fetal aorta (42).

\section{Responsiveness to Catecholamines}

Secretion of catecholamines plays an important role in several of the adaptations that characterize the transition from the pre- to the neonatal period (31). In the present study, we observed marked developmental differences in the response of chicken DA to adrenergic agonists. Thus, NE and Phe had no effects in 15-day DA but caused marked concentration-dependent contractions in 19- and 21-day DA. The lack of responses to NE and Phe in the 15-day DA seems to reflect a specific immaturity of the $\alpha$-adrenergic pathway since both receptordependent [ET-1 and thromboxane $\left.\mathrm{A}_{2}\left(\mathrm{TXA}_{2}\right)\right]$ and -independent contractions were present. Furthermore, developmental increase of responses to NE and Phe was observed in the DA but not in either pre- or postductal pulmonary arteries (present study and Ref. 52), indicating a specific maturation of 

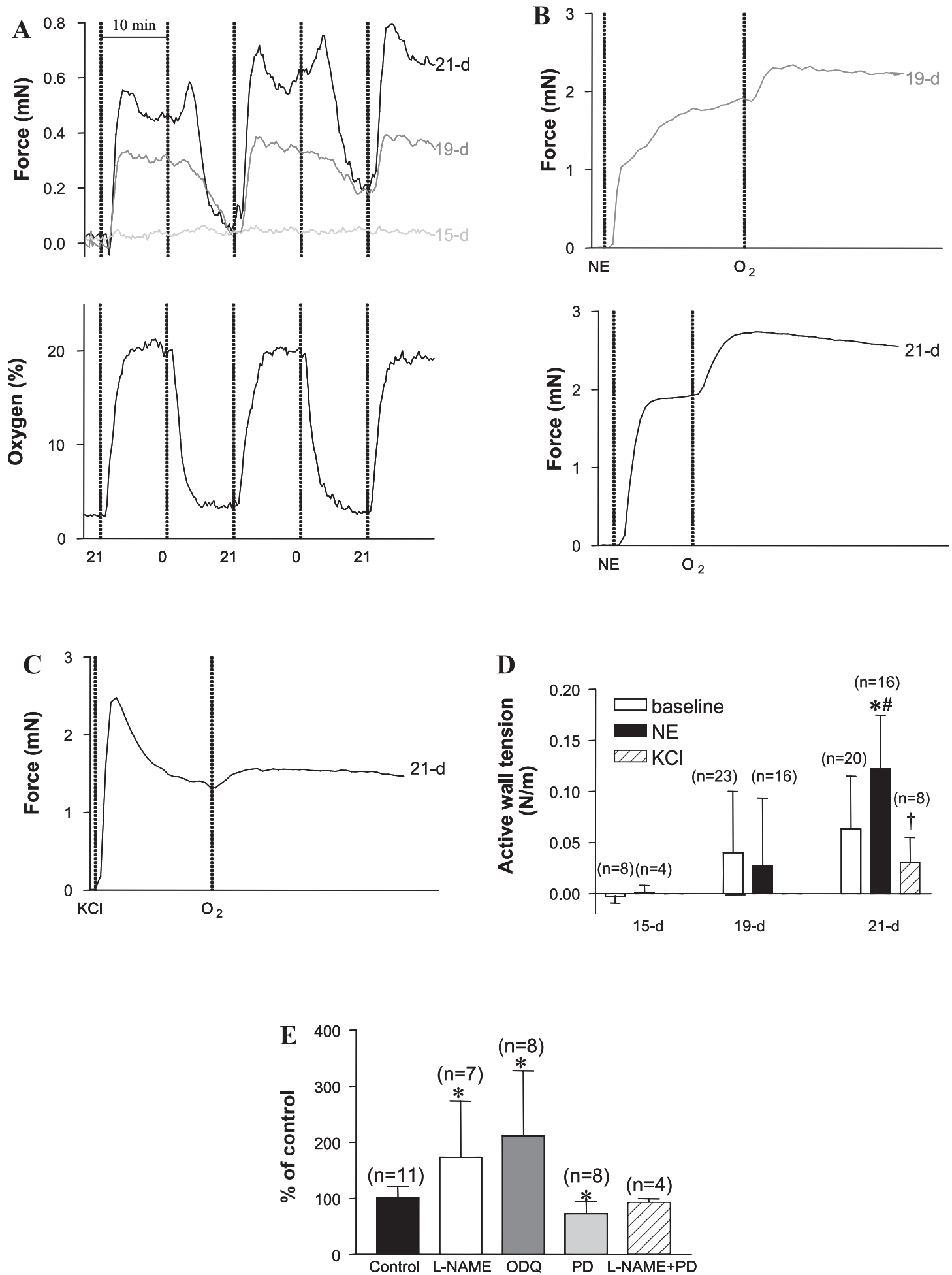

Fig. 5. Response of chicken DA to oxygen. The $21 \% \mathrm{O}_{2}$ challenge was performed by switching the bubbling gas from $95 \% \mathrm{~N}_{2}-5 \% \mathrm{CO}_{2}$ to $21 \% \mathrm{O}_{2}-74 \% \mathrm{~N}_{2}-5 \%$ $\mathrm{CO}_{2}$. A: representative traces demonstrating $\mathrm{O}_{2}$-evoked contraction in 19- and 21-day but not in 15-day DA. $B-C$ : representative traces of the effects of $\mathrm{O}_{2}$ in 19- and 21-day DA precontracted with NE $(1 \mu \mathrm{M} ; B)$ and in 21-day DA precontracted with $62.5 \mathrm{mM} \mathrm{KCl}(C)$. $D$ : averaged contractile effects of $\mathrm{O}_{2}$ over basal tone and in precontracted DA. $* P<0.05$ for difference from 19-day. $\# P<0.05$ for difference from not precontracted DA. $† P<0.05$ for difference from NE-precontracted DA. $E$ : effects of the NO synthase inhibitor L-NAME $(0.1 \mathrm{mM})$, the soluble guanylate cyclase inhibitor $1 \mathrm{H}$-[1,2,4]oxadiazolo[4,3-a]quinoxalin1-one (ODQ; $10 \mu \mathrm{M}$ ), and the peptidic $\mathrm{ET}_{\mathrm{A}}$ and $\mathrm{ET}_{\mathrm{B}}$-receptor antagonist PD-142,893 $(1 \mu \mathrm{M})$ on the response of 19-day DA to $\mathrm{O}_{2}$. Results are expressed as the percentage of the response to a first $\mathrm{O}_{2}$ challenge in the absence of the inhibitor. $* P<0.05$ for difference from control. Each bar in $D$ and $E$ represents the mean and SD of the number of embryos. 

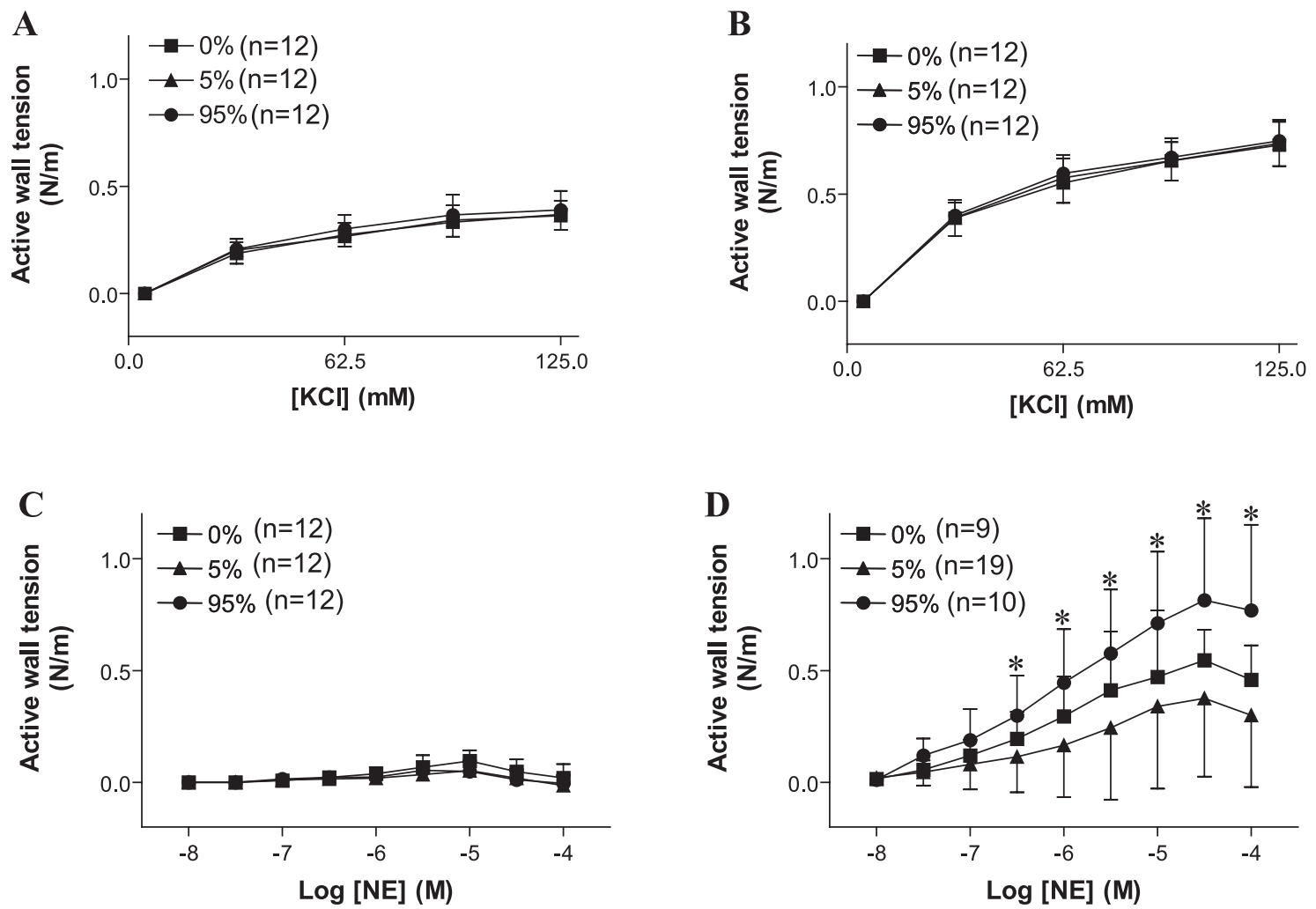

Fig. 6. Concentration-dependent contractile effects of $\mathrm{KCl}(A$ and $B)$ and $\mathrm{NE}(C$ and $D)$ in DA rings from 15-day $(A$ and $C)$ and 19 -day $(B$ and $D)$ chicken embryos, aerated with one of the following gas mixtures: 95\% $\mathrm{N}_{2}-5 \% \mathrm{CO}_{2}\left(\mathrm{PO}_{2}=2.6-3.3 \mathrm{kPa}\right), 5 \% \mathrm{O}_{2}-90 \% \mathrm{~N}_{2}-5 \% \mathrm{CO}_{2}\left(\mathrm{PO}_{2}=6.8-7.2 \mathrm{kPa}\right)$, or $95 \% \mathrm{O}_{2}-5 \%$ $\mathrm{CO}_{2}\left(\mathrm{PO}_{2}=72-76 \mathrm{kPa}\right)$. Each point represents the mean and SD of the number of embryos. $* P<0.05$ for difference from $5 \% \mathrm{O}_{2}$.

$\alpha$-adrenergic pathway in the DA. Interestingly, the time course of catecholamines in the plasma of chicken embryos is characterized by a maximum of epinephrine and $\mathrm{NE}$ at day 19 , shortly before lung ventilation (i.e., internal pipping) is initiated $(31,54)$. In a previous study, developmental changes in the response of chicken embryo femoral and carotid arteries to adrenergic agents were also observed (26). Similarly to the DA, the carotid arteries of 15-day embryos did not respond to $\mathrm{NE}$ or Phe, but a contraction was observed at embryonic day 19. In contrast, the responses to $\mathrm{NE}$ and Phe were already present at day 15 in femoral arteries (26). Therefore, the presence of high catecholamine concentrations in the chicken embryo during transition to ex ovo life, together with the developmental increase of the responsiveness of DA and systemic arteries and the lack of pulmonary artery sensitivity to these neurohormones, suggest a relevant role of catecholamines on the circulatory transition (i.e., closure of the DA, increase in systemic vascular resistance, and fall of pulmonary vascular resistance) of the chicken fetus.

Lack of response to electrical field stimulation and glyoxylic acid-induced histofluorescence indicate the absence of catecholamine-containing nerves in chicken DA. Accordingly, immunohistochemical staining with anti-neurofilament antibodies did hardly reveal innervations of the DA in either mouse or chicken embryos $(3,50)$. In contrast, catecholamine containing nerves have been demonstrated in human (2), lamb (23), and guinea pig (6) DA, but nerve density appears very low compared with third and fourth pharyngeal arch-derived vessels, and there is no information on the extent to which innervation of the DA is involved in its peculiar reactivity $(3,43)$.

\section{Responsiveness to Oxygen}

The cellular pathways initiated by $\mathrm{O}_{2}$ and leading to mammalian DA constriction are still controversial. Several studies have suggested that changes in $\mathrm{O}_{2}$ tension are signaled by changes in redox status and that $\mathrm{O}_{2}$-induced contraction of the DA is, at least partly, induced by membrane depolarization, which then results in entry of calcium through L-type voltageoperated $\mathrm{Ca}^{2+}$ channels $(32,43,49,53)$. Nakanishi et al. (32) hypothesized that, in the rabbit DA, membrane depolarization is related to $\mathrm{O}_{2}$-induced closure of a $\mathrm{K}_{\mathrm{ATP}}$ channel. In contrast, Tristani-Firouzi et al. (49) suggested that a $\mathrm{K}_{\mathrm{V}}$ channel was responsible for the $\mathrm{O}_{2}$-induced membrane depolarization of rabbit DA. Moreover, ex vivo transfer of the gene for Kv1.5 or $\mathrm{Kv} 2.1$ partially restores constriction to $\mathrm{O}_{2}$ in the preterm rabbit DA (47). Accordingly, regulation by a mitochondrial redox sensor of $\mathrm{K}_{\mathrm{V}}$ channels in human DA smooth muscle cells has been demonstrated by Michelakis et al. $(28,29)$. On the other hand, Coceani et al. (11-14) suggested that cytochrome $P-450$ acts as $\mathrm{O}_{2}$ sensor and that its interaction with $\mathrm{O}_{2}$ might increase ET-1 production by the ductal smooth muscle cells, resulting in contraction. Therefore, $\mathrm{O}_{2}$ may, either directly or mediated by ET-1, cause membrane depolarization of the smooth muscle cells, and increase intracellular $\mathrm{Ca}^{2+}$ concentration through the increase of $\mathrm{Ca}^{2+}$ influx, or the induction of $\mathrm{Ca}^{2+}$ release from intracellular store sites, and finally cause DA contraction.

In the present work, we observed that $\mathrm{O}_{2}$-induced contraction of chicken DA was not affected or even augmented by NE pretreatment. However, in high $\mathrm{K}^{+}$-stimulated DA the response to $\mathrm{O}_{2}$ was reduced, suggesting that membrane depolar- 
A
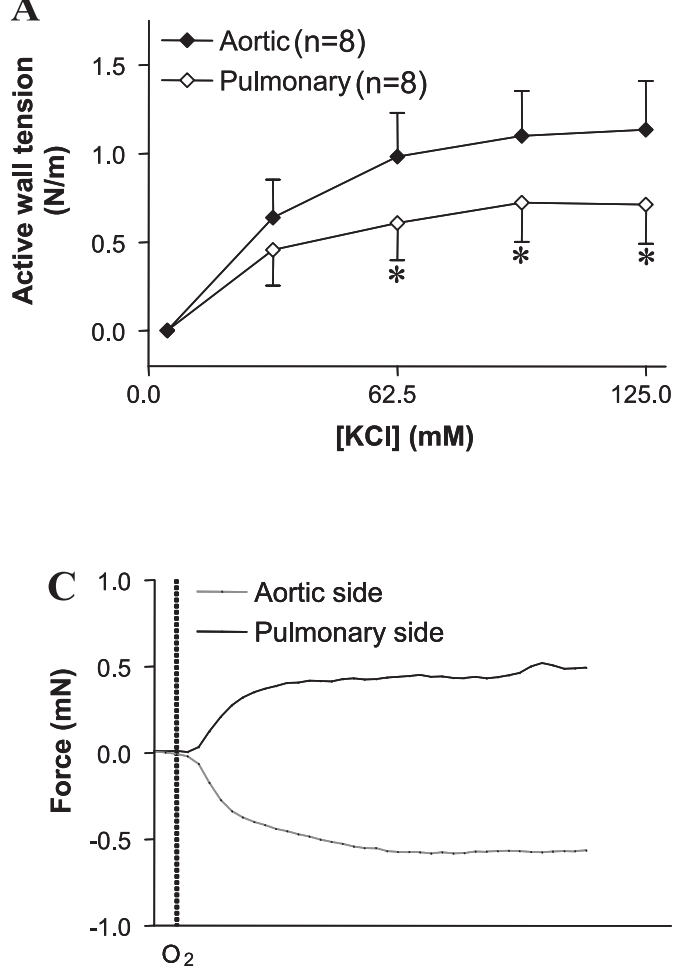
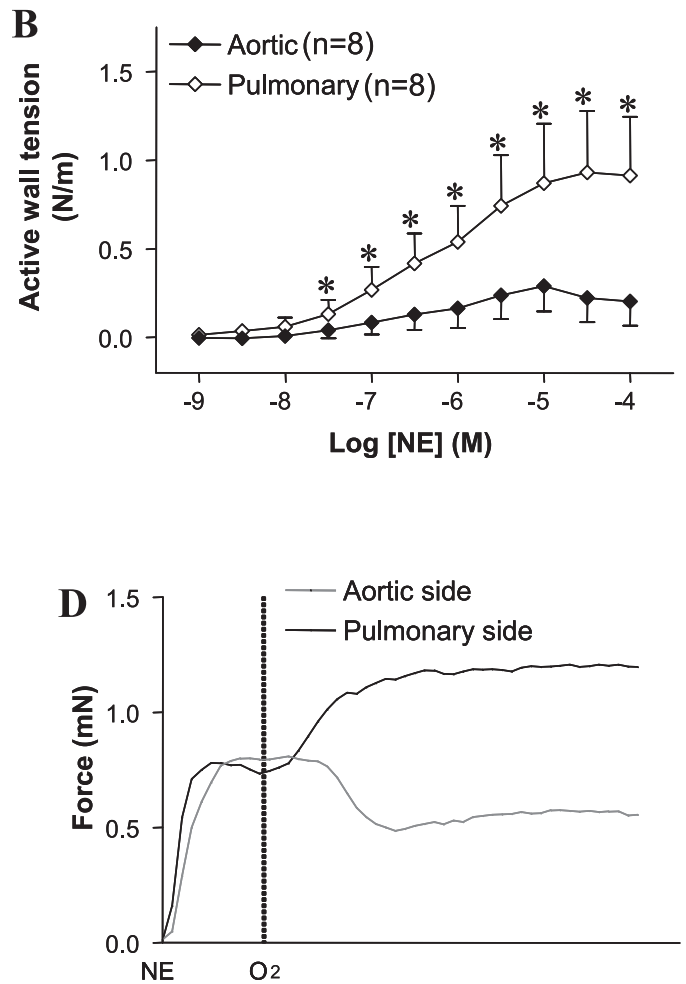

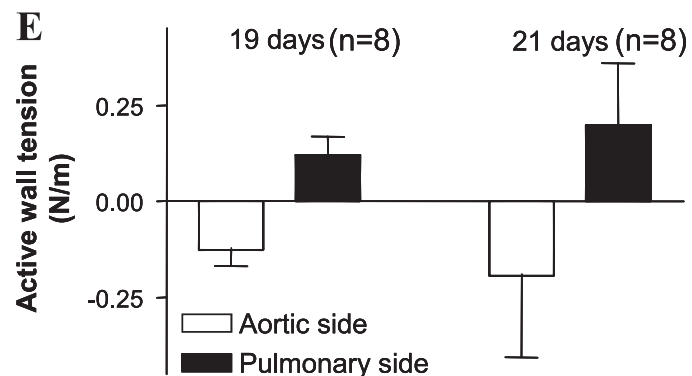

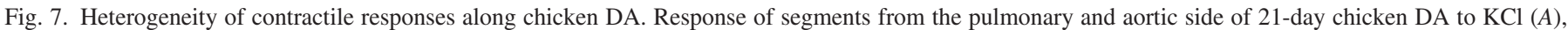

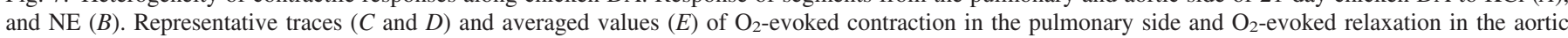

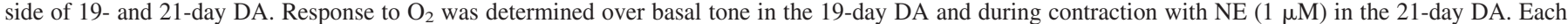
bar or point represents the mean and SD of the number of embryos.

ization may be a key mechanism mediating $\mathrm{O}_{2}$-induced contraction in the chicken DA. From the variety of $\mathrm{K}^{+}$channels present in the vascular smooth muscle cells, $\mathrm{K}_{\mathrm{V}}$ channels seem to be the main determinants in controlling resting membrane potential in chicken DA smooth muscle cells, as demonstrated by the potent constriction induced by the preferential $\mathrm{K}_{\mathrm{V}}$ channel inhibitor 4-AP and the lack of effect of the $\mathrm{K}_{\mathrm{ATP}}$ inhibitor glibenclamide and the $\mathrm{K}_{\mathrm{Ca}}$ inhibitor TEA. Thebaud et al. (47) demonstrated a parallel maturation of $\mathrm{O}_{2}$ - and 4-APinduced contraction of rabbit DA. In our experiments, the contractile responses to $\mathrm{O}_{2^{-}}$and 4-AP also increased with gestational age in chicken DA. However, contractile responses to 4-AP but not to $\mathrm{O}_{2}$ were already observed at day 15. Lack of this parallelism in the chicken DA does not preclude a putative role of $\mathrm{K}_{V}$ channels in $\mathrm{O}_{2}$-induced contraction because $\mathrm{K}_{\mathrm{V}}$ channels have a remarkable diversity (53) and our experiments with 4-AP could have detected a population of 4-AP- sensitive $/ \mathrm{O}_{2}$-insensitive $\mathrm{K}_{\mathrm{V}}$ channels, whereas $\mathrm{O}_{2}$-sensitive channels might appear later during development. Another possibility is that, as discussed above, $\mathrm{K}_{\mathrm{V}}$ channels might not be directly regulated by $\mathrm{O}_{2}$ but by a mitochondrial-derived reactive oxygen species, specifically $\mathrm{H}_{2} \mathrm{O}_{2}(29,53)$. Therefore, premature chicken DA may fail to constrict to $\mathrm{O}_{2}$ due to an immaturity of this or another $\mathrm{O}_{2}$ sensing system and not because its smooth muscle cells are deficient in $\mathrm{K}_{\mathrm{V}}$ channels.

Oxygen-induced contraction of chicken DA was reduced by the presence of an ET-receptor blocker. Numerous findings implicate ET-1 as a regulator of mammalian DA tone and as a messenger in the constriction of the DA to $\mathrm{O}_{2}(11-14,34,41$, 43). Interference with ET-1 synthesis or action, whether achieved pharmacologically or through genetic manipulation, curtails the constrictor effect of $\mathrm{O}_{2}(12,14,30,41)$. However, there is a marked species difference in the degree of contribution of ET-1 to the $\mathrm{O}_{2}$-induced ductal contraction. Thus, 
reduction of $\mathrm{O}_{2}$-evoked contraction by ET-receptor antagonists is more marked in the lamb (12) and rat (41) than in the rabbit (41) or chicken (present work) DA. Whether maturational differences in the chicken DA response to $\mathrm{O}_{2}$ and ET-1 are due to developmental changes in ET-1 receptor expression or in transductional pathways and the putative role of ET-1 in chicken DA closure warrant further investigation.

Compounds that inhibit NO synthesis constrict the DA of several mammalian species, providing indirect evidence of endogenous NO production and implying NO in DA regulation $(37,46)$. Moreover, endogenous NO appears to play a more relevant role in regulating the patency of the mammalian DA in earlier fetal stages than in the near-term fetus $(37,46,47)$. In contrast, we observed that the constriction induced by the NO synthase inhibitor L-NAME was absent in the DA of 15-day chicken embryos but present at day 19. In addition, L-NAME and the soluble guanylate cyclase inhibitor ODQ produced a marked augmentation of $\mathrm{O}_{2}$-evoked constriction in the 19-day DA, whereas the absence of response to $\mathrm{O}_{2}$ of the 15-day DA was not modified by L-NAME. Interestingly, the DA of 15- and 19-day chicken embryos demonstrated a similar relaxation to endothelium-derived NO and to NO donors (1), indicating that the mechanisms of NO production and relaxation are already active in the 15-day DA.

An increase in $\mathrm{O}_{2}$ tension produces not only constriction of the DA but also has a profound modulatory effect on other vasoactive systems $(23,43,44)$. We have observed that the efficacy (but not the potency) of NE increased when 19-day DA were bubbled with high $\mathrm{O}_{2}$ concentrations. In addition, when 21-day DA was precontracted with $\mathrm{NE}$, the $\mathrm{O}_{2}$-evoked response was larger than under basal conditions. Therefore, regarding our results, one might speculate that the presence of higher $\mathrm{O}_{2}$ tension, higher catecholamines concentrations, the positive interactions between $\mathrm{O}_{2-}$ and NE-induced contractions, and a developmental increase in the sensitivity of DA to these vasoactive mediators are critical factors involved in the closure of chicken DA during transition to ex ovo life.

\section{Lack of Responsiveness to COX Inhibitors}

In mammals, prenatal patency of the DA is critically dependent on PGs, with ample evidence implicating $\mathrm{PGE}_{2}$, both locally formed and blood-borne, as the prime effector $(8,24)$. This $\mathrm{PGE}_{2}$-based relaxing mechanism develops early in gestation and in the premature embryo is potent enough to override the constrictor action of $\mathrm{O}_{2}(10,43)$. The only mammalian species studied where PGs have not been shown to exert a significant dilator effect is the guinea pig $(6,43)$. The initial reaction in the synthesis of all PGs is catalyzed by COX, two isoforms of which (COX-1 and COX-2) have been identified $(8,9)$. Both COX-1 and COX-2 are present in the chicken and expressed in the vascular endothelium $(27,35)$. Lamb, mouse, rat, rabbit, and piglet ductus preparations contracted upon treatment with indomethacin and other COX inhibitors $(15,19$, $20,40,43,45)$. In contrast, we observed that, in the chicken DA, COX inhibitors did not produce significant contractile effects. These results indicate that locally derived PGs do not exert a tonic relaxant effect on chicken DA but do not exclude that blood-borne PGs might regulate chicken DA tone in vivo.

\section{Heterogeneity of Contractile Responses Along the Chicken DA}

In the chicken, the connection between the pulmonary artery and the aorta (i.e., the anatomical DA) is a bilateral structure that is proportionally longer than the unilateral DA of mammalians. Along the chicken DA, morphological heterogeneity can be directly observed under the dissection microscope (see Fig. 1). This heterogeneity have been extensively studied by Bergwerff et al. (4), who characterized three morphological segments in the sixth pharyngeal arch artery of the chicken by the time of hatching. The first proximal segment displays an elastic morphology, similar to that of the proximal aorta, until it bifurcates into two typically muscular arteries: the DA and the postductal pulmonary artery that show strong actin expression in a small number of cell layers. Downstream from the muscular DA portion, a third elastic segment can be identified (4). It has been suggested that this third segment results from the incorporation of dorsal aorta tissue into the sixth arch artery $(4,21,22)$. Transition between the muscular (proximal) and the elastic (distal) segment of chicken DA can be easily identified because the first one narrows considerably during the last week of in ovo development $(4,21)$.

In the present work, we confirmed the histological observations of Bergwerff et al. $(3,4)$ and we found an interesting functional correlation. Oxygen-induced contraction was located in the proximal segment of the DA, whereas the distal segment responded with relaxation. Moreover, a markedly higher contractile efficacy of NE was observed in the pulmonary side of the chicken DA. Similarly, higher contractile effects of cathecolamines have been observed in the pulmonary end of human DA (48). In the majority of mammals, normal DA closure takes place from the pulmonary artery to the aortic end $(17,18)$, but the presence of areas with so marked differences in reactivity has not been described. Development of a specific phenotype compared with surrounding arteries provides the structural and biomechanical basis for DA constriction after birth (36). In the case of the chicken DA, abrupt changes in morphological and functional vascular phenotypes are present along the vessel, indicating a genetic basis for its unique status (3-5) and suggesting local differences in the mechanisms leading to its closure. Our results support the idea that vascular smooth muscle cells from different embryological origins and with a differential contribution of neural crest derivatives reside within the wall of chicken DA (3-5).

\section{Perspectives}

There is currently tremendous interest in understanding how the physiology of individual animals changes and develops during ontogeny and to what extent the timing of the onset of a particular physiological regulatory system can be altered (7). Because avian embryos developed in a self-contained egg, they have long been favored animals for investigating how vertebrate cardiovascular physiological regulation unfolds during development (7). In the present work, we describe the developmental changes of the responses to $\mathrm{O}_{2}$ and other vasoconstrictors in the chicken DA. Our data support the concept that increasing $\mathrm{O}_{2}$ tension plays a critical role in the closure of DA also in nonmammalian species. In addition, we document how the chicken DA preparation for its specific task of postnatal closure is reflected in critical maturational changes in reactiv- 
ity. A patent DA complicates the clinical course of preterm infants, increasing their risks of developing chronic lung disease, necrotizing enterocolitis, and intraventricular hemorrhage $(36,43)$. Understanding the basic mechanisms of either normal or altered functional and structural development of the DA, as well as inter-species differences in DA homeostasis, may provide insights into human patent DA pathophysiology and treatment.

\section{REFERENCES}

1. Agren P, Van der Weerden M, Kessels CG, Altimiras J, De Mey J, Blanco C, Villamor E. Response of chicken embryo ductus arteriosus to NO/cyclic GMP- and cyclic AMP-mediated relaxation (Abstract). Pediatr Res 58: 354, 2005.

2. Aronson S, Gennser G, Owman C, Sjoberg NO. Innervation and contractile response of the human ductus arteriosus. Eur J Pharmacol 11: $178-186,1970$.

3. Bergwerff M, DeRuiter MC, Gittenberger-de Groot AC. Comparative anatomy and ontogeny of the ductus arteriosus, a vascular outsider. Anat Embryol (Berl) 200: 559-571, 1999.

4. Bergwerff M, DeRuiter MC, Poelmann RE, Gittenberger-de Groot AC. Onset of elastogenesis and downregulation of smooth muscle actin as distinguishing phenomena in artery differentiation in the chick embryo. Anat Embryol (Berl) 194: 545-557, 1996.

5. Bergwerff M, Verberne ME, DeRuiter MC, Poelmann RE, Gittenberger-de Groot AC. Neural crest cell contribution to the developing circulatory system: implications for vascular morphology? Circ Res 82: 221-231, 1998.

6. Bodach E, Coceani F, Dumbrille A, Okpako DT, Olley PM. The response of the isolated ductus arteriosus to transmural stimulation and drugs. Br J Pharmacol 71: 419-427, 1980.

7. Burggren W, Warburton S. Comparative developmental physiology: an interdisciplinary convergence. Апnи Rev Physiol 67: 203-223, 2005.

8. Clyman RI, Hardy P, Waleh N, Chen YQ, Mauray F, Fouron JC, Chemtob S. Cyclooxygenase-2 plays a significant role in regulating the tone of the fetal lamb ductus arteriosus. Am J Physiol Regul Integr Comp Physiol 276: R913-R921, 1999.

9. Coceani F, Ackerley C, Seidlitz E, Kelsey L. Function of cyclooxygenase- 1 and cyclo-oxygenase- 2 in the ductus arteriosus from foetal lamb: differential development and change by oxygen and endotoxin. $\mathrm{Br} \mathrm{J}$ Pharmacol 132: 241-251, 2001.

10. Coceani F, Huhtanen D, Hamilton NC, Bishai I, Olley PM. Involvement of intramural prostaglandin E2 in prenatal patency of the lamb ductus arteriosus. Can J Physiol Pharmacol 64: 737-744, 1986.

11. Coceani F, Kelsey L. Endothelin-1 release from lamb ductus arteriosus: relevance to postnatal closure of the vessel. Can J Physiol Pharmacol 69: 218-221, 1991.

12. Coceani F, Kelsey L, Seidlitz E. Evidence for an effector role of endothelin in closure of the ductus arteriosus at birth. Can J Physiol Pharmacol 70: 1061-1064, 1992.

13. Coceani F, Kelsey L, Seidlitz E. The response of the lamb ductus arteriosus to endothelin: developmental changes and influence of light. Life Sci 71: 1209-1217, 2002.

14. Coceani F, Liu YA, Seidlitz E, Kelsey L, Kuwaki T, Ackerley C, Yanagisawa M. Deletion of the endothelin-A-receptor suppresses oxygen-induced constriction but not postnatal closure of the ductus arteriosus. J Cardiovasc Pharmacol 36, Suppl 1: S75-S77, 2000.

15. Coceani F, Olley PM, Bodach E. Lamb ductus arteriosus: effect of prostaglandin synthesis inhibitors on the muscle tone and the response to prostaglandin E2. Prostaglandins 9: 299-308, 1975.

16. Colbert MC, Kirby ML, Robbins J. Endogenous retinoic acid signaling colocalizes with advanced expression of the adult smooth muscle myosin heavy chain isoform during development of the ductus arteriosus. Circ Res 78: 790-798, 1996

17. Gittenberger-de Groot AC, Strengers JL, Mentink M, Poelmann RE, Patterson DF. Histologic studies on normal and persistent ductus arteriosus in the dog. J Am Coll Cardiol 6: 394-404, 1985.

18. Giuriato L, Scatena M, Chiavegato A, Guidolin D, Pauletto P, Sartore S. Rabbit ductus arteriosus during development: anatomical structure and smooth muscle cell composition. Anat Rec 235: 95-110, 1993.

19. Goldbarg SH, Takahashi Y, Cruz C, Kajino H, Roman C, Liu BM, Chen YQ, Mauray F, Clyman RI. In utero indomethacin alters $\mathrm{O}_{2}$ delivery to the fetal ductus arteriosus: implications for postnatal patency. Am J Physiol Regul Integr Comp Physiol 282: R184-R190, 2002.

20. Guerguerian AM, Hardy P, Bhattacharya M, Olley P, Clyman RI, Fouron JC, Chemtob S. Expression of cyclooxygenases in ductus arteriosus of fetal and newborn pigs. Am J Obstet Gynecol 179: 1618-1626, 1998.

21. Harms D. [On the occlusion of the ductus arteriosus of Gallus domesticus]. Z Zellforsch Mikrosk Anat 81: 433-444, 1967.

22. Hughes AFW. The histogenesis of the arteries of the chick embryo. J Anat 77: 266-287, 1943.

23. Ikeda M, Sonnenschein RR, Masuoka DT. Catecholamine content and uptake of the ductus arteriosus of the fetal lamb. Experientia 28: 914-915, 1972.

24. Kajino H, Chen YQ, Chemtob S, Waleh N, Koch CJ, Clyman RI. Tissue hypoxia inhibits prostaglandin and nitric oxide production and prevents ductus arteriosus reopening. Am J Physiol Regul Integr Comp Physiol 279: R278-R286, 2000.

25. Kim HS, Aikawa M, Kimura K, Kuro-o M, Nakahara K, Suzuki T, Katoh H, Okamoto E, Yazaki Y, Nagai R. Ductus arteriosus. Advanced differentiation of smooth muscle cells demonstrated by myosin heavy chain isoform expression in rabbits. Circulation 88: 1804-1810, 1993.

26. le Noble FA, Ruijtenbeek K, Gommers S, de Mey JG, Blanco CE. Contractile and relaxing reactivity in carotid and femoral arteries of chicken embryos. Am J Physiol Heart Circ Physiol 278: H1261-H1268, 2000.

27. Mathonnet M, Lalloue F, Danty E, Comte I, Lievre CA. Cyclooxygenase 2 tissue distribution and developmental pattern of expression in the chicken. Clin Exp Pharmacol Physiol 28: 425-432, 2001.

28. Michelakis E, Rebeyka I, Bateson J, Olley P, Puttagunta L, Archer S. Voltage-gated potassium channels in human ductus arteriosus. Lancet 356 : 134-137, 2000.

29. Michelakis ED, Rebeyka I, Wu X, Nsair A, Thebaud B, Hashimoto K, Dyck JR, Haromy A, Harry G, Barr A, Archer SL. $\mathrm{O}_{2}$ sensing in the human ductus arteriosus: regulation of voltage-gated $\mathrm{K}^{+}$channels in smooth muscle cells by a mitochondrial redox sensor. Circ Res 91: 478-486, 2002.

30. Momma K, Nakanishi T, Imamura S. Inhibition of in vivo constriction of fetal ductus arteriosus by endothelin receptor blockade in rats. Pediatr Res 53: 479-485, 2003.

31. Mulder AL, Golde JM, Goor AA, Giussani DA, Blanco CE. Developmental changes in plasma catecholamine concentrations during normoxia and acute hypoxia in the chick embryo. J Physiol 527: 593-599, 2000.

32. Nakanishi T, Gu H, Hagiwara N, Momma K. Mechanisms of oxygeninduced contraction of ductus arteriosus isolated from the fetal rabbit. Circ Res 72: 1218-1228, 1993.

33. Noel S, Cassin S. Maturation of contractile response of ductus arteriosus to oxygen and drugs. Am J Physiol 231: 240-243, 1976.

34. Perreault T, Coceani F. Endothelin in the perinatal circulation. Can J Physiol Pharmacol 81: 644-653, 2003.

35. Reed DW, Bradshaw WS, Xie W, Simmons DL. In vivo and in vitro expression of a non-mammalian cyclooxygenase-1. Prostaglandins 52: 269-284, 1996.

36. Reese J. Death, dying, and exhaustion in the ductus arteriosus: prerequisites for permanent closure. Am J Physiol Regul Integr Comp Physiol 290: R357-R358, 2006.

37. Richard C, Gao J, LaFleur B, Christman BW, Anderson J, Brown N, Reese $\mathbf{J}$. Patency of the preterm fetal ductus arteriosus is regulated by endothelial nitric oxide synthase and is independent of vasa vasorum in the mouse. Am J Physiol Regul Integr Comp Physiol 287: R652-R660, 2004.

38. Ruijtenbeek K, De Mey JG, Blanco CE. The chicken embryo in developmental physiology of the cardiovascular system: a traditional model with new possibilities. Am J Physiol Regul Integr Comp Physiol 283: R549-R550, 2002.

39. Sakurai H, Matsuoka R, Furutani Y, Imamura S, Takao A, Momma K. Expression of four myosin heavy chain genes in developing blood vessels and other smooth muscle organs in rabbits. Eur J Cell Biol 69: 166-172, 1996.

40. Sharpe GL, Larsson KS, Thalme B. Studies on closure of the ductus arteriosus. XII. In utero effect of indomethacin and sodium salicylate in rats and rabbits. Prostaglandins 9: 585-596, 1975.

41. Shen J, Nakanishi T, Gu H, Miyagawa-Tomita S, Wu GR, Momma K, Nakazawa M. The role of endothelin in oxygen-induced contraction of the ductus arteriosus in rabbit and rat fetuses. Heart Vessels 16: 181-188, 2002. 
42. Slomp J, Gittenberger-de Groot AC, Glukhova MA, Conny van Munsteren J, Kockx MM, Schwartz SM, Koteliansky VE. Differentiation, dedifferentiation, and apoptosis of smooth muscle cells during the development of the human ductus arteriosus. Arterioscler Thromb Vasc Biol 17: 1003-1009, 1997.

43. Smith GC. The pharmacology of the ductus arteriosus. Pharmacol Rev 50: 35-58, 1998.

44. Smith GC, McGrath JC. Characterisation of the effect of oxygen tension on response of fetal rabbit ductus arteriosus to vasodilators. Cardiovasc Res 27: 2205-2211, 1993.

45. Takahashi Y, Roman C, Chemtob S, Tse MM, Lin E, Heymann MA, Clyman RI. Cyclooxygenase-2 inhibitors constrict the fetal lamb ductus arteriosus both in vitro and in vivo. Am J Physiol Regul Integr Comp Physiol 278: R1496-R1505, 2000.

46. Takizawa T, Horikoshi E, Kamata A. Role of the nitric oxide-cGMP system in the regulation of ductus arteriosus patency in fetal rats. $J$ Vet Med Sci 61: 1277-1280, 1999.

47. Thebaud B, Michelakis ED, Wu XC, Moudgil R, Kuzyk M, Dyck JR, Harry G, Hashimoto K, Haromy A, Rebeyka I, Archer SL. Oxygensensitive $K_{v}$ channel gene transfer confers oxygen responsiveness to preterm rabbit and remodeled human ductus arteriosus: implications for infants with patent ductus arteriosus. Circulation 110: 1372-1379, 2004
48. Tomita H, Fuse S, Chiba S. Catecholamine-induced ductus arteriosus constriction in children. Am J Cardiol 77: 1372-1375, 1996.

49. Tristani-Firouzi M, Reeve HL, Tolarova S, Weir EK, Archer SL. Oxygen-induced constriction of rabbit ductus arteriosus occurs via inhibition of a 4-aminopyridine-, voltage-sensitive potassium channel. J Clin Invest 98: 1959-1965, 1996.

50. Verberne ME, Gittenberger-De Groot AC, Van Iperen L, Poelmann RE. Contribution of the cervical sympathetic ganglia to the innervation of the pharyngeal arch arteries and the heart in the chick embryo. Anat Rec 255: 407-419, 1999.

51. Villamor E, Kessels CG, Ruijtenbeek K, van Suylen RJ, Belik J, de Mey JG, Blanco CE. Chronic in ovo hypoxia decreases pulmonary arterial contractile reactivity and induces biventricular cardiac enlargement in the chicken embryo. Am J Physiol Regul Integr Comp Physiol 287: R642-R651, 2004.

52. Villamor E, Ruijtenbeek K, Pulgar V, De Mey JG, Blanco CE. Vascular reactivity in intrapulmonary arteries of chicken embryos during transition to ex ovo life. Am J Physiol Regul Integr Comp Physiol 282: R917-R927, 2002.

53. Weir EK, Lopez-Barneo J, Buckler KJ, Archer SL. Acute oxygensensing mechanisms. N Engl J Med 353: 2042-2055, 2005.

54. Wittmann J, Prechtl J. Respiratory function of catecholamines during the late period of avian development. Respir Physiol 83: 375-386, 1991.

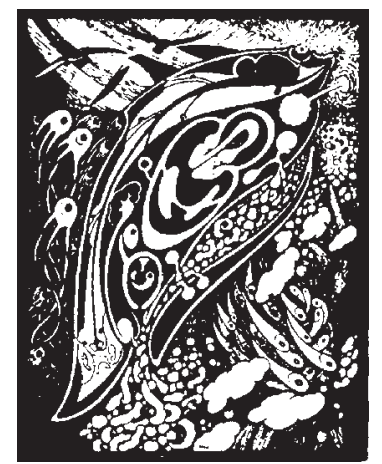




\section{Chapter 3}

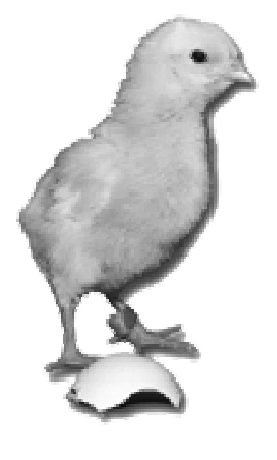

\section{DEVELOPMENTAL CHANGES IN ENDOTHELIUM- DEPENDENT RELAXATION OF THE CHICKEN DUCTUS ARTERIOSUS}

Pia Ågren, Saskia van der Sterren, Angel L. Cogolludo, Giovanna Frazziano, Jo G. R. De Mey, Carlos E. Blanco and Eduardo Villamor

Journal of physiology and pharmacology, 2008, 59, 1, 55-76 
P. ÅGREN ${ }^{1}$, S. VAN DER STERREN ${ }^{1}$, A.L. COGOLLUDO ${ }^{1,2}$, G. FRAZZIANO ${ }^{2}$, J.G.R. DE $\mathrm{MEY}^{3}$, C.E. BLANCO ${ }^{1}$, E. VILLAMOR ${ }^{1}$

\section{DEVELOPMENTAL CHANGES IN ENDOTHELIUM-DEPENDENT RELAXATION OF THE CHICKEN DUCTUS ARTERIOSUS}

${ }^{1}$ Department of Pediatrics, Maastricht University Hospital, Research Institute Growth and Development (GROW), University of Maastricht, Maastricht, The Netherlands.

${ }^{2}$ Department of Pharmacology, Institute of Pharmacology and Toxicology,

School of Medicine, Universidad Complutense, Madrid, Spain.

${ }^{3}$ Department of Pharmacology and Toxicology, Cardiovascular Research Institute Maastricht (CARIM), University of Maastricht, Maastricht, The Netherlands

We tested the hypothesis that endothelium-dependent relaxation in the chicken ductus arteriosus (DA) is developmentally regulated. Isolated DA rings from 15-, 19and 21-day-old (externally pipped) chicken embryos relaxed to acetylcholine (ACh). This relaxation was unaffected by indomethacin but impaired by endothelium removal, by the NO synthase inhibitor L-NAME, and by the soluble guanylate cyclase inhibitor ODQ, suggesting the involvement of NO. This NO production was confirmed with the fluorescent probe DAF-2DA. The combination of apamin and charybdotoxin with L-NAME produced a further inhibition of ACh-induced relaxation, suggesting the participation of a putative EDHF. In the 21-day DA, the relaxations induced by ACh and sodium nitroprusside (SNP) were markedly reduced and scanning electron microscopy demonstrated an irregular endothelial lining with protrusion and detachment of endothelial cells. The relaxations induced by BAY 412272 and 8 -Br cGMP were not affected by age. When compared with $5 \%$, lower $(0 \%)$ and higher $(21,95 \%) \mathrm{O}_{2}$ concentrations impaired ACh-induced relaxation. In summary, we found that $\mathrm{ACh}$ induces endothelium-dependent relaxation of the chicken DA and that NO and EDHF are involved in this response. During chicken DA closure, endothelial cells undergo morphologic and functional alterations that result in the lack of endothelium-dependent relaxation.

Key words: ductus arteriosus, chicken embryo, endothelium, EDHF, nitric oxide. 


\section{INTRODUCTION}

Possibly, the most momentous change that has occurred in the field of vascular biology in the past 50 years has been the discovery and elucidation of the endocrine/paracrine roles of the endothelium (1). In simple, but elegant experiments, Furchgott and Zawadzki (2) found that relaxation with cholinergic agonists through muscarinic receptors in precontracted vessels was only possible if endothelial cells were present. Several endothelium-derived relaxing factors have been found, including nitric oxide (NO), prostaglandins (PGs, mainly prostacyclin $\mathrm{PGI}_{2}$ ), carbon monoxide $(\mathrm{CO})$ and a yet unidentified factor called endothelium-derived hyperpolarizing factor (EDHF, 3, 4). The contribution of each of these factors to endothelium-dependent relaxation varies across vascular beds and also with the physiological or pharmacological stimuli used to stimulate the endothelium $(1,3)$.

The ductus arteriosus (DA) is a large fetal shunt connecting the pulmonary artery to the aorta, allowing most right ventricular blood to bypass the unexpanded lungs. Patency of the DA in utero is an active state that occurs in an environment of low oxygen tension and through the vasorelaxant actions of both circulating and locally released PGs and to a lesser extent other mediators including NO and CO (4-10). The current information about the role of other components of endothelium-dependent relaxation, such as the EDHF, in the control of DA tone is scarce (4).

The normal vascular endothelium maintains a low vascular tone, suppresses vascular smooth muscle growth, inhibits platelet adherence and aggregation, and stems inflammation (11). A damaged endothelium is characterized by the increased elaboration of vasoconstrictors, mitogens, and prothrombotic and proinflammatory mediators (11) that can be deleterious for other blood vessels but necessary for one, the DA, which requires a process of occlusion. In fact, a unique feature of DA development is the process of intimal thickening that the vessel undergoes and appears to be critical for its postnatal closure. Intimal thickening formation in the DA closely resembles pathological intimal thickening and it starts with lifting of the endothelial cells that is followed by migration of smooth muscle cells through the fragmented elastic lamina into the subendothelial region (12-14). Although numerous investigations have been focused on these endothelial structural alterations, fewer efforts have been made to explore the subsequent changes on endothelial function.

The chicken embryo has been a mainstay of developmental biology studies. In the last years, our laboratory accumulated experience in the study of developmental circulatory changes in the chicken embryo and in the effects of adverse stimuli, such as hypoxia or malnutrition, on pulmonary and systemic vascular function and structure (15-18). In these studies, a central role of endothelium-dependent relaxation in vascular tone control was observed in both pulmonary and systemic vessels. Very recently, we analyzed the ontogeny of the 
chicken DA responses to oxygen and other vasoconstrictors. We found that at 0.7 incubation excitation-contraction and pharmaco-mechanical coupling for several contractile agonists were already present, whereas the constrictor effects of $\mathrm{O}_{2}$ and cathecolamines appeared later in development (19). Interestingly, $\mathrm{O}_{2}$-induced contraction was augmented by NO synthase inhibition and reduced by endothelin receptors blockade, indicating that DA responsiveness to $\mathrm{O}_{2}$ is modulated by endothelium-derived vasoactive agonists (19).

In the present study, we hypothesized that endothelium-dependent relaxation in the chicken DA is developmentally regulated. Therefore, our aims were to investigate this response at different incubation ages and during transition to ex ovo life, to analyze the participation of NO, PGs and EDHF, to analyze the modulatory role of $\mathrm{O}_{2}$, and to determine the presence of segmental differences along the DA in the sensitivity to endothelium-derived relaxation.

\section{MATERIAL AND METHODS}

\section{Embryos incubation and vessel isolation}

Experiments were performed in accordance with Dutch law for animal experimentation. Fertilized eggs of White Leghorn chickens were incubated at $37.8^{\circ} \mathrm{C}, 45 \%$ humidity and rotated once per hour (Incubator model 25HS, Masalles Comercial, Spain). Embryos incubated for 15, 19 and 21 days of the 21-day incubation period were studied. The majority of the experiments were performed in 19 days (non-internally pipped) embryos, while for the study of developmental changes all three ages were compared (see below). On the experimental day the embryos were killed by decapitation and the right DA was carefully dissected free and severed distal to the takeoff of the right pulmonary artery and proximal to the insertion into the dorsal aorta. The average in situ length (in $\mathrm{mm}$ ) of the right DA was $3.48,4.71$, and 5.58 at embryonic day 15, 19, and 21 respectively (19), whereas the maximal length allowed in the myograph was $2 \mathrm{~mm}$. Therefore, a similar length of ductal tissue was removed from the pulmonary and aortic ends of the vessel to obtain a segment of the central part of the DA with a length of approximately $2 \mathrm{~mm}$. The right DA was selected because its shorter length allowed having a higher proportion of the vessel represented in the myograph. The endothelium of some vessels was removed mechanically by rubbing the intimal surface with a metal rod. The absence of the endothelium was confirmed by scanning electron microscopy in a subset of 10 vessels.

\section{Recording of arterial reactivity}

Two stainless steel wires (diameter $40 \mu \mathrm{m}$ ) were inserted into the lumen of the DA, which was mounted as a ring segment between an isometric force transducer and a displacement device in a myograph (Danish Myo Technology A/S model 610M, Aarhus, Denmark). The myograph organ bath $\left(5 \mathrm{ml}\right.$ vol) was filled with Krebs-Ringer bicarbonate (KRB) buffer maintained at $39^{\circ} \mathrm{C}$ and continuously aerated with one of the following gas mixtures: $0 \% \mathrm{O}_{2} / 95 \% \mathrm{~N}_{2} / 5 \% \mathrm{CO}_{2}\left(\mathrm{pO}_{2}=2.6\right.$ $3.3 \mathrm{kPa}), 5 \% \mathrm{O}_{2} / 90 \% \mathrm{~N}_{2} / 5 \% \mathrm{CO}_{2}\left(\mathrm{pO}_{2}=6.8-7.2 \mathrm{kPa}\right), 21 \% \mathrm{O}_{2} / 74 \% \mathrm{~N}_{2} / 5 \% \mathrm{CO}_{2}\left(\mathrm{pO}_{2}=16-20 \mathrm{kPa}\right)$, or $95 \% \mathrm{O}_{2} / 5 \% \mathrm{CO}_{2}\left(\mathrm{pO}_{2}=72-76 \mathrm{kPa}\right)$. The final $\mathrm{pH}$ was $7.38-7.42$ and $\mathrm{pCO}_{2}$ was $4.6-5.6 \mathrm{kPa}$ in all solutions. Each DA was stretched to its individual optimal lumen diameter, i.e., the diameter at which it developed the strongest contractile response to $62.5 \mathrm{mM} \mathrm{K}^{+}$, using a diameter-tension protocol as previously described $(16,19)$. During the first phase of stabilization and determination 
of optimal diameter, DA was maintained in $\mathrm{KRB}$ buffer aerated with $0 \% \mathrm{O}_{2}$. Afterwards, oxygen concentration was switched to $5 \%$, unless the effect of $\mathrm{O}_{2}$ on the relaxant responses was evaluated. When two or more agonists were studied in the same arterial preparation, the vessels were repeatedly washed and allowed to equilibrate for at least $30 \mathrm{~min}$. If the tone did not recover to resting level or $62.5 \mathrm{mM} \mathrm{K}^{+}$failed to induce an adequate level of contraction, the vessels were discarded for further experiments.

\section{Relaxant responses}

Relaxations induced by ACh $(10 \mathrm{nM}-0.1 \mathrm{mM})$ were studied in vessels contracted with norepinephrine $(\mathrm{NE}, 1 \mu \mathrm{M})$ or $\mathrm{K}^{+}(62.5 \mathrm{mM})$. When stable contractions were obtained, ACh was added cumulatively to the bath until a maximal response was achieved. In some experiments and in order to analyze the involvement of NO, PGs, and EDHF, ACh-induced relaxations were studied in the presence of the NOS inhibitor $\mathrm{N}^{\omega}$-Nitro-L-arginine methyl ester (L-NAME, $0.1 \mathrm{mM}$ ), the soluble guanylate cyclase (sGC) inhibitor $1 \mathrm{H}-[1,2,4]$ oxadiazolo[4,3-a]quinoxalin-1-one (ODQ, 10 $\mu \mathrm{M})$, the cyclooxygenase (COX) inhibitor indomethacin $(10 \mu \mathrm{M})$, or the combination of the specific inhibitor of small conductance calcium-activated potassium channels $\left(\mathrm{SK}_{\mathrm{Ca}}\right)$ apamin $(1 \mu \mathrm{M})$ and the nonselective inhibitor of intermediate, ( $\left.\mathrm{IK}_{\mathrm{Ca}}\right)$ and large $\left(\mathrm{BK}_{\mathrm{Ca}}\right) \mathrm{K}_{\mathrm{Ca}}$-channels and some voltagedependent $\mathrm{K}^{+}$-channels charybdotoxin $(0.1 \mu \mathrm{M})$ (3). In other experiments, relaxations induced by bradykinin (10 $\mathrm{nM}-0.1 \mathrm{mM}$ ), the NO donor sodium nitroprusside (SNP, $10 \mathrm{nM}-0.1 \mathrm{mM}$ ), the cyclic GMP-specific phosphodiesterase (PDE5) inhibitor sildenafil (1 nM- $10 \mu \mathrm{M})$, the NO-independent stimulator of sGC BAY 41-2272 $(10 \mathrm{nM}-1 \mu \mathrm{M})$ or the non-hydrolysable cGMP analog 8-Br cGMP $(0.1 \mu \mathrm{M}-100 \mu \mathrm{M})$, were analyzed. To evaluate basal production of NO, cumulative concentrationresponse curves to L-NAME $(10 \mu \mathrm{M}-1 \mathrm{mM})$ were performed in DA rings of 15-, 19- and 21-day embryos, under basal tone. Contractile responses were taken as an indication that there was attenuation of tone by endogenous NO.

\section{Changes in relaxation depending on development, $\mathrm{O}_{2}$, and region of the $D A$.}

To analyze developmental changes on relaxation, the responses to ACh, SNP, BAY 41-2272, and 8-Br cGMP were studied in the central part of DAs from 15-, 19-, and 21-day-old embryos. The 21-day embryos were externally pipped.

To evaluate the modulatory role of $\mathrm{O}_{2}$ in DA relaxation, the responses to ACh, SNP, BAY 412272 , and $8 \mathrm{Br}-\mathrm{cGMP}$ were studied under $0 \%, 5 \%, 21 \%$, and $95 \% \mathrm{O}_{2}$. In these experiments, optimal diameter was determined at $0 \% \mathrm{O}_{2}$. Thereafter the $\mathrm{O}_{2}$ concentration was switched to the appropriate level and the vessels were allowed to equilibrate for at least $30 \mathrm{~min}$ before the concentrationresponse curve for the agonists was obtained. In another group of experiments, and in order to analyze the involvement of endogenously produced $\mathrm{NO}$ in $\mathrm{O}_{2}$-induced contraction of the DA, DA rings of 19- and 21-day embryos were exposed to a change from $0 \%$ to $21 \% \mathrm{O}_{2}$, as previously described (19). In these experiments, DA rings were incubated for (at least) 30 min with $0 \% \mathrm{O}_{2} / 95 \%$ $\mathrm{N}_{2} / 5 \% \mathrm{CO}_{2}$. Then the gas mixture was switched to $21 \% \mathrm{O}_{2} / 74 \% \mathrm{~N}_{2} / 5 \% \mathrm{CO}_{2}$. This gas was maintained for $10 \mathrm{~min}$ (a stable response to $\mathrm{O}_{2}$ was observed after 2-3 min). Afterwards, DA rings were relaxed with $0 \% \mathrm{O}_{2} / 95 \% \mathrm{~N}_{2} / 5 \% \mathrm{CO}_{2}$ and then incubated for 15 min with vehicle (control) or L-NAME $(0.1 \mathrm{mM})$. After the incubation, a second stimulation with $21 \% \mathrm{O}_{2}$ was performed. This second response to $\mathrm{O}_{2}$ is expressed as a percentage of the first response.

In order to analyze the differences along the DA in the relaxations induced by ACh, SNP, and BAY 41-2272, we performed experiments in which the pulmonary and the aortic parts of the vessel were compared in 19- and 21-day old embryos. The boundary between pulmonary and aortic 
segments was determined during the dissection based on the marked differences of diameter observed along the chicken DA (see 19).

\section{In situ assessment of NO production}

ACh-induced NO release was assessed in DA using a membrane-permeable 4,5diaminofluorescein diacetate (DAF-2DA) probe that hydrolyzes inside the cells, releasing DAF-2 (20). In the presence of NO, DAF-2 converts into a detectable fluorescent product, DAF-2 triazole (DAF-2T, 20, 21). Endothelium intact segments of the DA from 19-day and 21-day embryos were incubated with DAF-2DA $(10 \mu \mathrm{M})$ for $30 \mathrm{~min}$ at $37^{\circ} \mathrm{C}$ in HEPES buffer of composition (in $\mathrm{mmol} / \mathrm{L}$ ): $\mathrm{NaCl} 130, \mathrm{KCl} 5, \mathrm{MgCl}_{2} 1.2, \mathrm{CaCl}_{2} 1.5$, glucose 10, HEPES 10 (pH 7.3 with $\left.\mathrm{NaOH}\right)$. DA rings were placed in the stage of a fluorescent inverted microscope (Leica DM IRB, Wetzlar, Germany), superfused with HEPES buffer solution $\left(2 \mathrm{ml} \cdot \mathrm{min}^{-1}\right)$ and illuminated through the luminal surface using a 450-490 nm band-pass filter. The emitted fluorescence of the whole vessel was filtered using a $515 \mathrm{~nm}$ long-pass emission filters. Images were taken at $1 \mathrm{~min}$ intervals with a Leica DC300F colour digital camera and saved for off-line analysis. Fluorescence was quantified using ImageJ (version $1.32 \mathrm{j}, \mathrm{NIH}$, http://rsb.info.nih/ij/). Intensity values are reported as a percent of the initial values after subtracting background. Preparations were allowed to equilibrate for $30 \mathrm{~min}$ before the application of ACh $(1 \mu \mathrm{M})$. In additional experiments, vessels were incubated with LNAME $(0.1 \mathrm{mM})$ for $15 \mathrm{~min}$ before and during the addition of $\mathrm{ACh}$.

\section{Scanning Electron Microscopy}

The endothelial surface of DA rings was examined by scanning electron microscopy. Harvested DA rings were fixed overnight at $4{ }^{\circ} \mathrm{C}$ in $2.5 \%$ glutaraldehyde in $0.13 \mathrm{~mol} / \mathrm{L}$ cacodylate buffer, $\mathrm{pH}$ 7.4. After being rinsed twice in buffer, specimens were postfixed in $1 \%$ ostium tetroxide at $4^{\circ} \mathrm{C}$ for $1.5 \mathrm{~h}$, rinsed three times in cacodylate buffer, and dehydrated through graded concentrations of ethanol. The specimens were critical point-dried from $100 \%$ ethanol with liquid $\mathrm{CO}_{2}$. After the specimens were dried, they were bisected to expose the luminal surface, mounted on stubs, and sputter-coated with gold. The samples were viewed and photographed at $10 \mathrm{kV}$ with a scanning electron microscope (Philips XL30, Eindhoven, The Netherlands).

\section{Data analysis}

Results are shown as means (SD) of measurements in $n$ embryos. For clarity, results are shown in the figures as means $\pm \mathrm{SE}$. Contractions are expressed in terms of active wall tension $(\mathrm{N} / \mathrm{m})$, calculated as the force divided by twice the length of the segment, while the relaxant responses are expressed as the percentage of reduction of the contraction induced by $\mathrm{NE}$ or $\mathrm{K}^{+}$. Sensitivity (expressed as $\mathrm{pD}_{2}=-\log \mathrm{EC}_{50}$ ) and maximal relaxation $\left(\mathrm{E}_{\max }\right)$ to agonists was determined for each artery by fitting individual concentration-response data to a non-linear sigmoidal regression curve and interpolating (Graphpad Prism version 2.01; GraphPad Software Inc, San Diego, CA, U.S.A.). When a drug produced a biphasic response (e.g. ACh, which produces relaxation at low concentrations and contraction at high concentrations) only the relaxant concentrations were taken into account for the regression curve. When a maximal response was not achieved with a given agonist, the regression curve could not be calculated and the responses for each concentration of the agonist were used for comparison. Differences between mean values were assessed by one-way ANOVA followed by Bonferroni post hoc t-test. Non-paired t-tests were used if only two groups were compared. Differences were considered significant at a $P<0.05$. All analyses were performed using a commercially available statistics package (GraphPad InStat version 3.00, GraphPad Software Inc, San Diego, CA, U.S.A.). 


\section{Drugs and solutions}

Krebs-Ringer bicarbonate buffer (KRB) contained (in mmol L-1): $\mathrm{NaCl}, 118.5 ; \mathrm{KCl}, 4.75$; $\mathrm{MgSO}_{4} \cdot 7 \mathrm{H}_{2} \mathrm{O}, 1.2 ; \mathrm{KH}_{2} \mathrm{PO}_{4}, 1.2 ; \mathrm{NaHCO}_{3}, 25.0 ; \mathrm{CaCl}_{2}, 2.5$; glucose, 5.5. Solutions containing different concentrations of $\mathrm{K}^{+}$were prepared by replacing part of the $\mathrm{NaCl}$ by an equimolar amount of $\mathrm{KCl}$. Arterenol bitartrate (NE), SNP, apamin, L-NAME, bradykinin, indomethacin, 8 Br-cGMP, DAF-2DA, and ACh were obtained from Sigma Chemical Co (St. Louis, MO). ODQ was obtained from Tocris (Ballwin, MO) and charybdotoxin and BAY 41-2272 from Alexis Biochemicals (Uithoorn, The Netherlands). Sildenafil was a kind gift from Pfizer (Sandwich, Kent, UK). All the drugs were dissolved initially in distilled deionised water (except ODQ, sildenafil, and BAY 412272 that were dissolved in DMSO and indomethacin that was dissolved in ethanol) to prepare a $10^{-1} \mathrm{M}, 10^{-2} \mathrm{M}$ or $10^{-3} \mathrm{M}$ stock solution and further dilutions were made in KRB.

\section{RESULTS}

Isolated DA obtained from 15-, 19- and 21-day chicken embryos responded to depolarizing high- $\mathrm{K}^{+}$solution with a tonic contraction and this response significantly increased with age (15-day: $0.90 \mathrm{~N} / \mathrm{m}, \mathrm{SD} 0.27, n=16, P<0.05$ from both 19 and 21-day; 19-day: $2.01 \mathrm{~N} / \mathrm{m}$, SD $0.7, \mathrm{n}=25 ; 21$-day $2.99 \mathrm{~N} / \mathrm{m}$, SD 0.7 , $\mathrm{n}=12, P<0.05$ from 19-day old). The diameter at which a maximal response to $62.5 \mathrm{mM} \mathrm{KCl}$ was obtained increased between day $15(764 \mu \mathrm{m}, \mathrm{SD} 88, n=35)$ and 19 ( $846 \mu \mathrm{m}$, SD 113, $n=70, P<0.001 v$ s. 15-day), but decreased at day 21 (505 $\mu \mathrm{m}$, SD 211, $n=27, P<0.001 v s .15$ - and 19-day). NE $(1 \mu \mathrm{M})$ induced a tonic contraction of the DA that was not significantly different $(P=0.2669)$ between the 19-day $(1.45 \mathrm{~N} / \mathrm{m}, \mathrm{SD} 0.5, \mathrm{n}=9)$ and the 21 -day $(1.79 \mathrm{~N} / \mathrm{m}, \mathrm{SD} 0.73, \mathrm{n}=9)$ and that was absent in the 15-day DA (not shown).

\section{Endothelium-dependent relaxation}

Fig. 1 illustrates the effect of ACh on 19-day DA contracted with NE or 62.5 $\mathrm{mM} \mathrm{K}$. In endothelium intact $\mathrm{DA}$, ACh evoked a biphasic response: low concentrations induced relaxation, while concentrations above $10 \mu \mathrm{M}$ induced contraction. The relaxant efficacy of ACh was significantly higher $(\mathrm{P}<0.01)$ in DAs contracted with NE $\left(\mathrm{E}_{\max }=96.1 \%\right.$, SD $21 ; \mathrm{pD}_{2}: 6.37$, SD $\left.0.22, n=9\right)$ than in DAs contracted with high $\mathrm{K}^{+}$solution $\left(\mathrm{E}_{\max }=42.6 \%\right.$, SD 16.6; $\mathrm{pD}_{2}: 6.18$, SD $0.24, \mathrm{n}=19)$. In DA without endothelium ACh-induced relaxation was markedly reduced $\left(\mathrm{E}_{\max }=24.0 \%\right.$, SD 12.9, $P<0.0001 v$ s. endothelium intact, Fig. $\left.1 A\right)$. The effective removal of the endothelium was verified by scanning electron microscopy (Fig. 3E). The relaxation induced by the NO donor SNP was not affected by endothelium removal (Fig. 1B) but the relaxation evoked by the PDE5 inhibitor sildenafil was significantly reduced in the endothelium-denuded DA (Fig. 1C). No relaxation to bradykinin was observed (not shown).

As shown in Fig. 1D, ACh-induced relaxation of $\mathrm{K}^{+}$-contracted DAs was abolished by the the sGC inhibitor ODQ and significantly reduced by the NOS inhibitor L-NAME $\left(\mathrm{E}_{\max }=11.7 \%\right.$, SD 6.1; $\mathrm{pD}_{2}: 5.47$, $\mathrm{SD} 0.14, n=8, \mathrm{P}<0.05 v \mathrm{~s}$ 


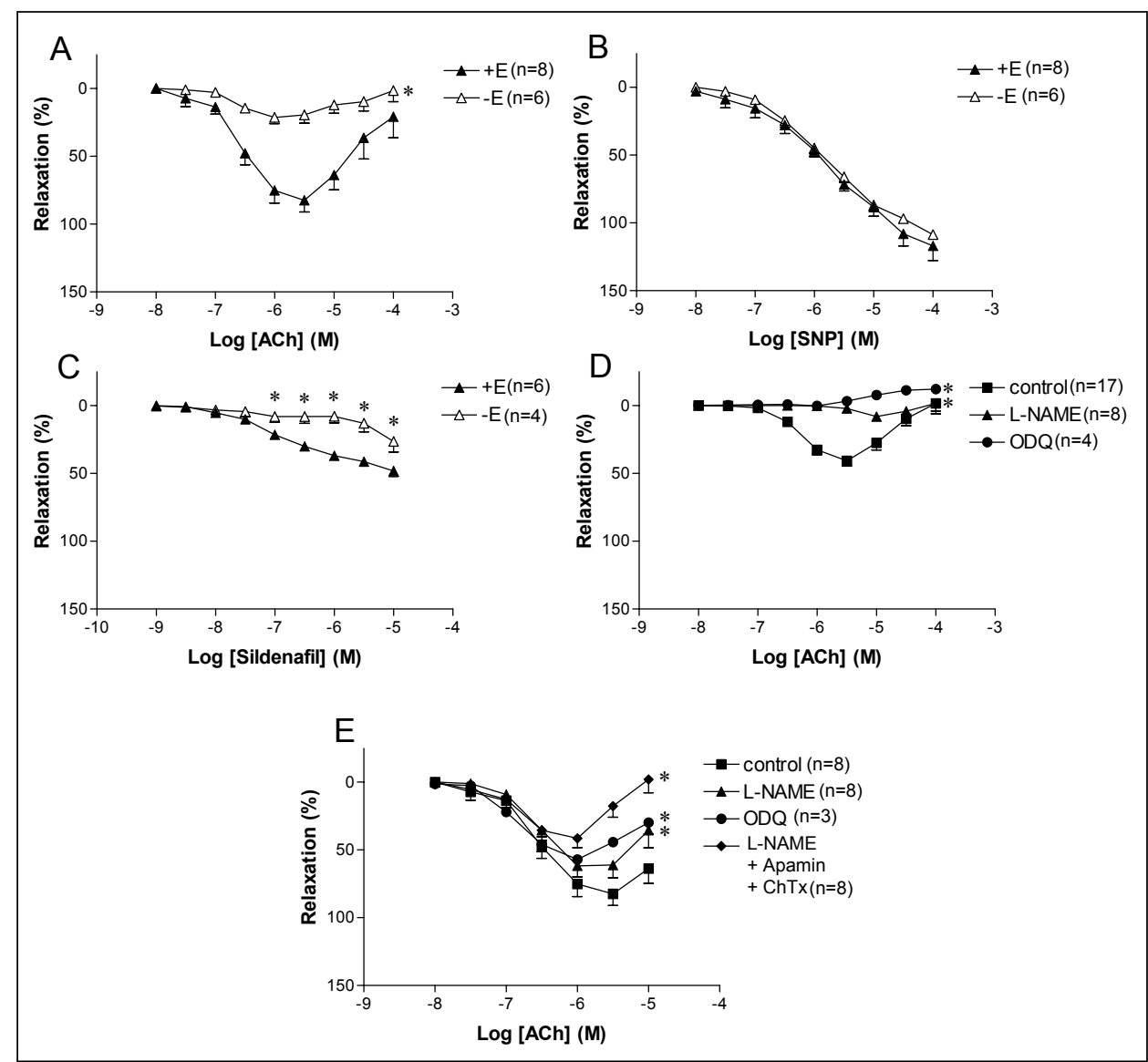

Fig. 1. Concentration-dependent relaxant effects of acetylcholine (ACh, A, D and E), sodium nitroprusside (SNP, B) and sildenafil (C) in 19-day DA rings with (+E) and without (-E) endothelium. The vessels were contracted with norepinephrine $(1 \mu \mathrm{M}, \mathrm{A}, \mathrm{B}$ and $\mathrm{E})$ or $\mathrm{K}^{+}(62.5 \mathrm{mM}, \mathrm{C}$ and $\mathrm{D})$ and aerated with $5 \% \mathrm{O}_{2} / 90 \% \mathrm{~N}_{2} / 5 \% \mathrm{CO}_{2}$. The effects of the nitric oxide synthase inhibitor L-NAME $(0.1$ $\mathrm{mM})$, the soluble guanylate cyclase inhibitor ODQ $(10 \mu \mathrm{M})$ and the combination of L-NAME, apamin $(1 \mu \mathrm{M})$ and charybdotoxin $(0.1 \mu \mathrm{M})$ are also shown. Each point represents the mean and SE of $n$ embryos. ${ }^{*} P<0.05$ for difference (in $\mathrm{E}_{\max }$ or in a given concentration) from control ( $+\mathrm{E}$ in $\mathrm{A}, \mathrm{B}$ and $\mathrm{C}$ ).

control). ACh-induced relaxation of NE-contracted DAs was also significantly reduced by L-NAME $\left(\mathrm{E}_{\max }=69.5 \%\right.$, SD 19.8, $P<0.05$ vs control; $\mathrm{pD}_{2}: 6.5$, SD $0.23, n=7)$ and ODQ $\left(\mathrm{E}_{\max }=58.4 \%\right.$, SD $0.36, P<0.05 v s$ control; $\mathrm{pD}_{2}: 6.85, \mathrm{SD}$ $0.08, n=3, \mathrm{P}<0.05$ vs. control, Fig. $1 E$ ). The combination of L-NAME with apamin and charybdotoxin produced a further inhibition of ACh-induced relaxation $\left(\mathrm{E}_{\max }=46.74 \%, \mathrm{SD} 17 ; \mathrm{pD}_{2}: 6.77, \mathrm{SD} 0.16, n=8\right)$ than that produced by L-NAME alone $(P<0.05$, Fig. $1 E)$. The COX inhibitor indomethacin did not affect ACh-induced relaxation of the chicken DA (not shown). 
Changes during transition to ex ovo life

We studied changes in the relaxations induced by ACh and several agonists acting at different steps of the NO-sGC-cGMP pathway in DA from 15-, 19- and 21-day embryos. As shown in Figs 2A, $2 B$ and Table 1, the relaxant efficacy of ACh was markedly reduced in the 21-day DA. No marked differences in AChinduced relaxation were observed between 15- and 19-day DAs, but ACh-

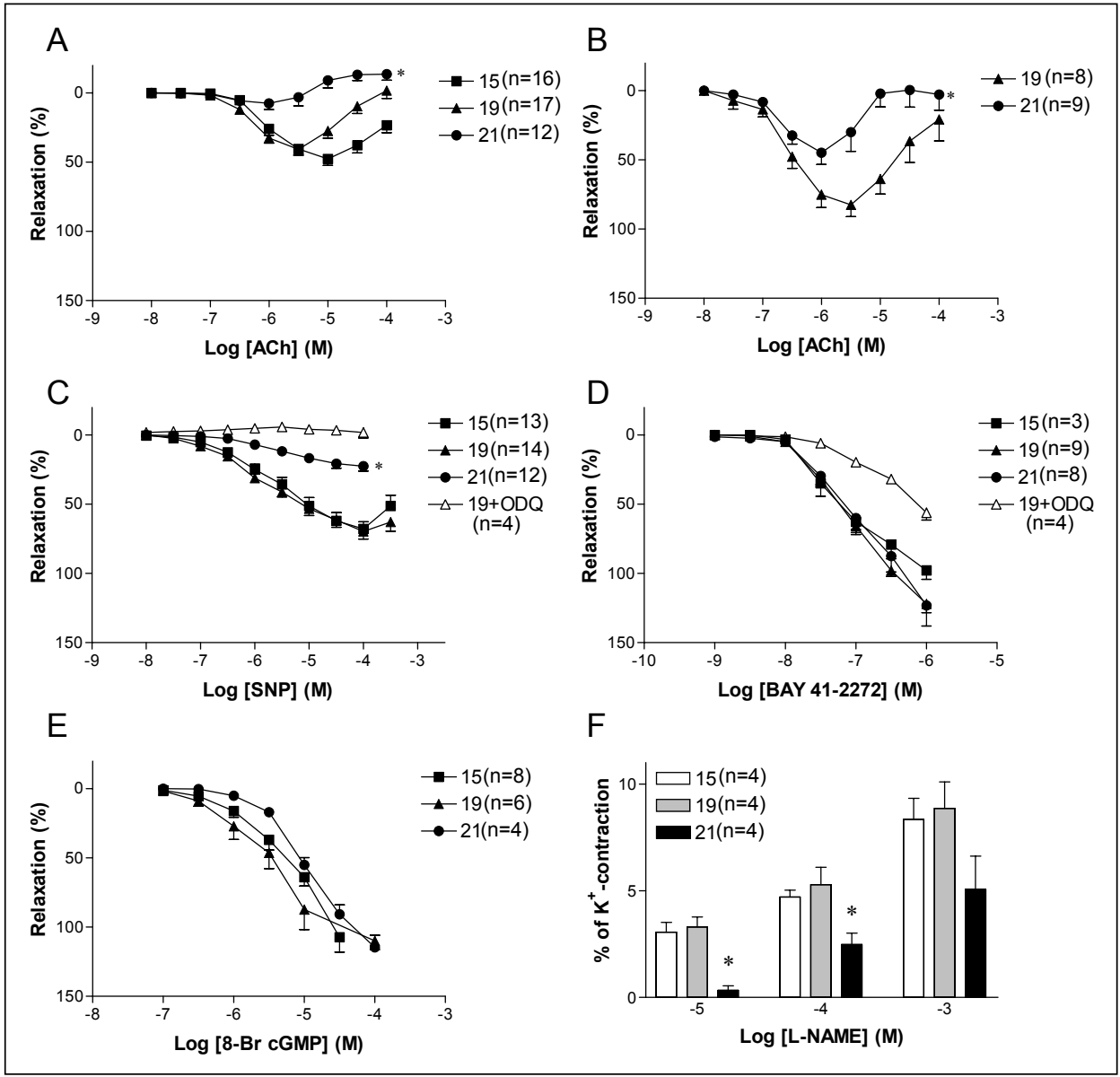

Fig. 2. Developmental changes of relaxations induced by acetylcholine (ACh, A and B), the NO donor sodium nitroprusside (SNP, C) the NO-independent stimulator of sGC BAY 41-2272 (D), and the cGMP analog 8-Br cGMP (E) and on the contractions induced by the NO synthase inhibitor LNAME (F) in 15-, 19- and 21-day DA rings aerated with $5 \% \mathrm{O}_{2} / 90 \% \mathrm{~N}_{2} / 5 \% \mathrm{CO}_{2}$. The effects of the soluble guanylate cyclase inhibitor ODQ $(10 \mu \mathrm{M})$ on SNP- and BAY 41-2272-induced relaxations are also shown (only in the 19-day DA). For relaxation experiments DAs were contracted with $\mathrm{K}^{+}(62.5 \mathrm{mM}, \mathrm{A}, \mathrm{C}, \mathrm{D}, \mathrm{E})$ or norepinephrine $(1 \mu \mathrm{M}, \mathrm{B}) .{ }^{*} P<0.05$ for difference (in $\mathrm{E}_{\max }$ or in a given concentration) from 15- and 19-day DA. 
Table 1. Concentration-response parameters for acetylcholine (ACh), sodium nitroprusside (SNP), 8-Br cGMP and BAY 41-2272 in ductus arteriosus from 15-, 19- and 21-day chicken embryos.

\begin{tabular}{|c|c|c|c|c|c|c|c|c|c|}
\hline & \multicolumn{3}{|c|}{ 15-day-old } & \multicolumn{3}{|c|}{ 19-day-old } & \multicolumn{3}{|c|}{ 21-day-old } \\
\hline & $\mathrm{E}_{\max }$ & $\mathrm{pD}_{2}$ & $n$ & $\mathrm{E}_{\max }$ & $\mathrm{pD}_{2}$ & $n$ & $\mathrm{E}_{\max }$ & $\mathrm{pD}_{2}$ & $n$ \\
\hline $\mathrm{ACh}$ & $51.84(14.8)$ & $5.86(0.42)$ & 16 & $45.34(17.3)$ & $6.17(0.32)$ & 19 & $13.57(14.7)^{*}$ & $6.57(0.32)^{*}$ & 12 \\
\hline SNP & $73.44(19.4)$ & $5.47(0.52)$ & 13 & $72.06(22.9)$ & $5.92(0.40)$ & 14 & $23.81(12.4)^{*}$ & $5.42(0.39)$ & 12 \\
\hline 8-Br cGMP & $129.51(26.9)$ & $5.06(0.16)$ & 8 & $123.78(18.2)$ & $5.32(0.34)$ & 6 & $118.00(17.7)$ & $4.94(0.09)$ & 4 \\
\hline BAY 41-2272 & $97.98(11.2)$ & - & 3 & $122.17(18.7)$ & - & 9 & $123.31(42.1)$ & - & 8 \\
\hline
\end{tabular}

Values are means (SD); $n=$ no. of embryos (arteries); $\mathrm{pD}_{2}=-\log \mathrm{EC}_{50} ; \mathrm{E}_{\max }$, maximal relaxant effect (\% of contraction). ${ }^{*} P<0.05$ from both 15 and 19-day old. $\left(5 \% \mathrm{O}_{2}\right.$ and precontraction with $62.5 \mathrm{mM} \mathrm{K}^{+}$). As maximal effect was not achieved with BAY 41-2272, $\mathrm{pD}_{2}$ was not calculated and $\mathrm{E}_{\max }$ represents the response to $1 \mu \mathrm{M}$.

induced contraction started at lower concentrations in the 19-day vessels (Fig. $2 A$ ). The NO donor SNP also caused a concentration-dependent relaxation with developmental differences (Fig. $2 \mathrm{C}$ and Table 1). Thus, the maximal relaxation was markedly attenuated in vessels from 21-day embryos as compared to the other ages (Fig. 2C and Table 1). However, the sensitivity to SNP did not change with age (Table 1). The sGC inhibitor ODQ completely abolished the response to SNP (Fig. 2C), indicating that the drug was essentially acting through the activation of sGC. Both, BAY 41-2272 and 8-Br cGMP relaxed $\mathrm{K}^{+}$-induced contractions with much more efficacy (full relaxation) than SNP at all ages (Fig. 2 and Table 1). Furthermore, no age-related differences were found for either BAY 41-2272 or 8-Br cGMP (Fig. 2D, 2E and Table 1).

The 19-day DA exhibited a marked increase in DAF-2T fluorescence during incubation with ACh $(1 \mu \mathrm{M})$ indicating increased NO generation. The increase in DAF-2T fluorescence with ACh was completely blocked by L-NAME (Figs $4 \mathrm{~A}$ and $4 B$ ), indicating specificity of the signal for NO. In contrast, ACh did not evoke significant changes in DAF-2T fluorescence in the 21-day DA. L-NAME produced a concentration-dependent contraction that was reduced in the 21-day when compared with the 15- and the 19-day DA (Fig. $2 F$ ). However, maximal response to L-NAME only represented $\sim 3-8 \%$ of $\mathrm{KCl}$-induced contraction. In addition, the presence of L-NAME produced an increase of $\mathrm{O}_{2}$-induced contraction in the 19 -day DA $\left(173.5 \%\right.$ of the first $\mathrm{O}_{2}$-induced contraction, SD $72.4)$ but no significant changes in the 21-day DA $\left(89.1 \%\right.$ of the first $\mathrm{O}_{2}$-induced contraction, SD 19.6).

When examined by scanning electron microscopy, the endothelium of the 19day DA showed a smooth and continuous surface with small cytoplasmic structures (similar to microvilli) protruding toward the lumen (Figs $3 \mathrm{~A}$ and $3 \mathrm{~B}$ ). By contrast, the intimal surface of segments harvested from the pulmonary side of the 21-d DA, demonstrated an irregular endothelial lining with protrusion and 
detachment of endothelial cells, leaving large areas of exposed subendothelial tissue (Fig. 3C). These irregularities of the endothelial surface were markedly less

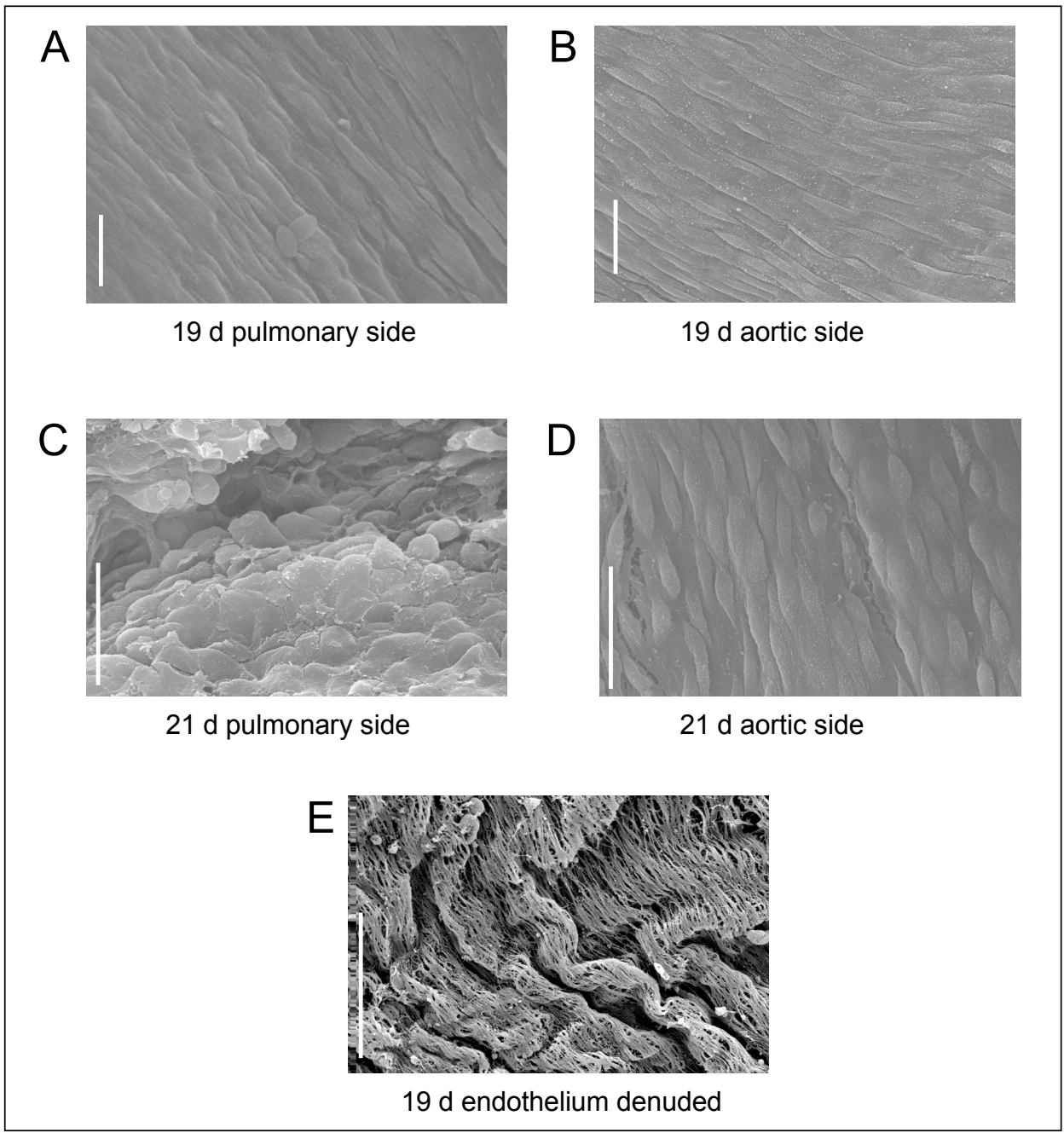

Fig. 3. Scanning electronic micrographs of the endothelial surface of DA rings from 19-day (A and B) and 21-day (C and D) chicken embryos. In the 19-day DA, the endothelium showed a smooth and continuous surface with small cytoplasmic structures (similar to microvilli) protruding toward the lumen. By contrast, the intimal surface of segments harvested from the pulmonary side of the 21-d DA (C), demonstrated an irregular endothelial lining with protrusion and detachment of endothelial cells, leaving large areas of exposed subendothelial tissue. These irregularities of the endothelial surface were markedly less apparent in the aortic side of the 21-day DA (D) in which only small areas of exposed subendothelial tissue were observed between endothelial cells. E: Exposed subendothelial fibers and absence of endothelial cells in a 19-day chicken DA segment after mechanical removal of the endothelium by gently rubbing the intimal surface with a metal rod. Bars $20 \mu \mathrm{m}$. 


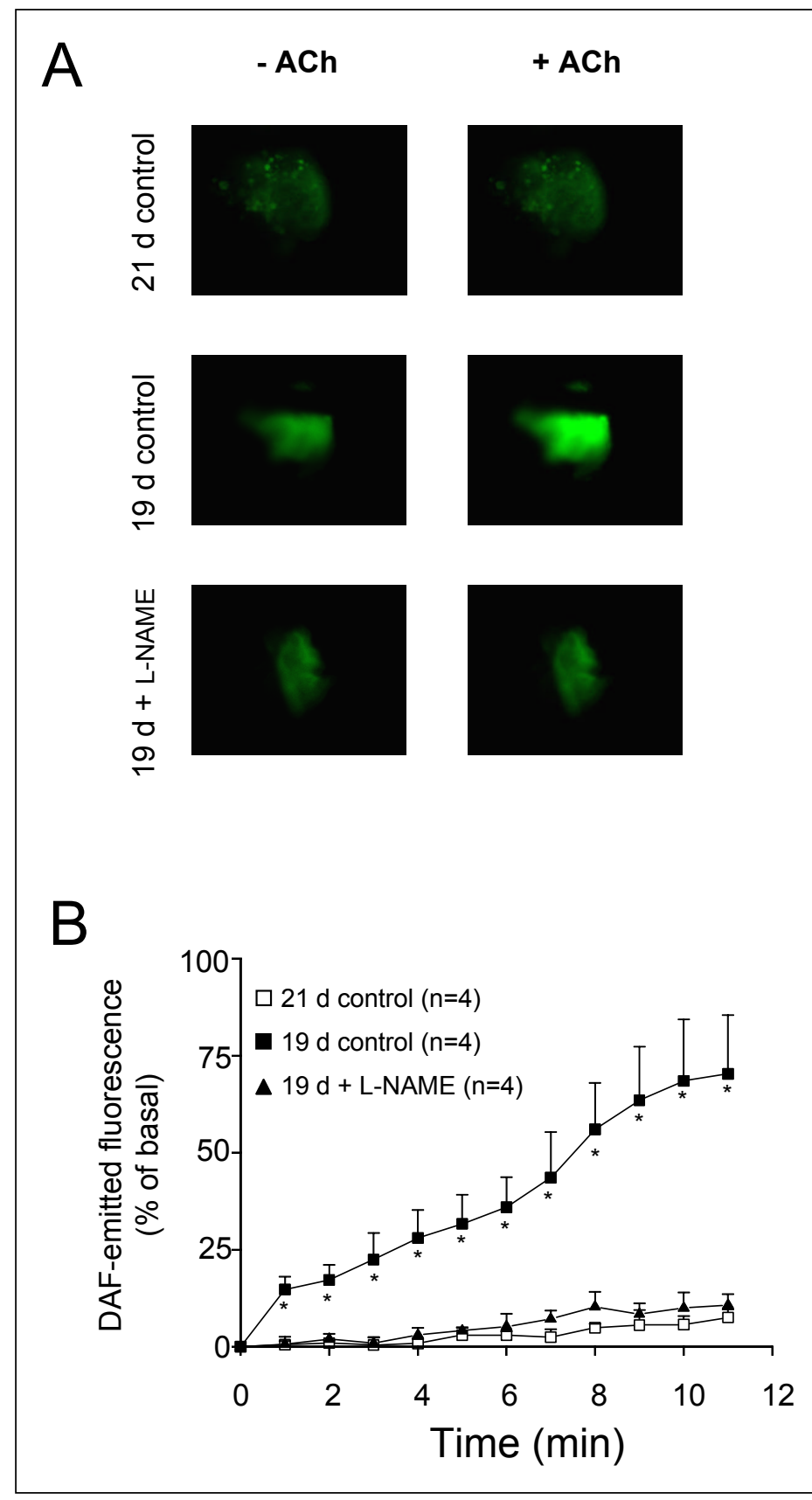

Fig. 4. Acetylcholine (ACh, $1 \mu \mathrm{M}$ ) -stimulated NO production visualized with DAF2DA. A: representative microscopic images showing the AChevoked changes of $\mathrm{NO}$ levels measured by DAF-2T fluorescence intensity in the DA (pulmonary side) of 19and 21-day chicken embryos in the absence or the presence of $\mathrm{L}$ NAME $(0.1 \mathrm{mM})$. B: time courses of the increase in DAF-2T fluorescence after the addition of $\mathrm{ACh}$ in the absence or in the presence of L-NAME. Each point represents the mean and SE of $n$ embryos. ${ }^{*} P<0.05$ for difference from 21-day DA.

apparent in the aortic side of the 21-day DA in which only small areas of exposed subendothelial tissue were observed between endothelial cells (Fig. 3D). 
Modulatory role of oxygen

To analyze the influence of external $\mathrm{O}_{2}$ concentration on the relaxation induced by ACh, SNP, BAY 41-2272, and 8Br-cGMP, concentration-response curves to

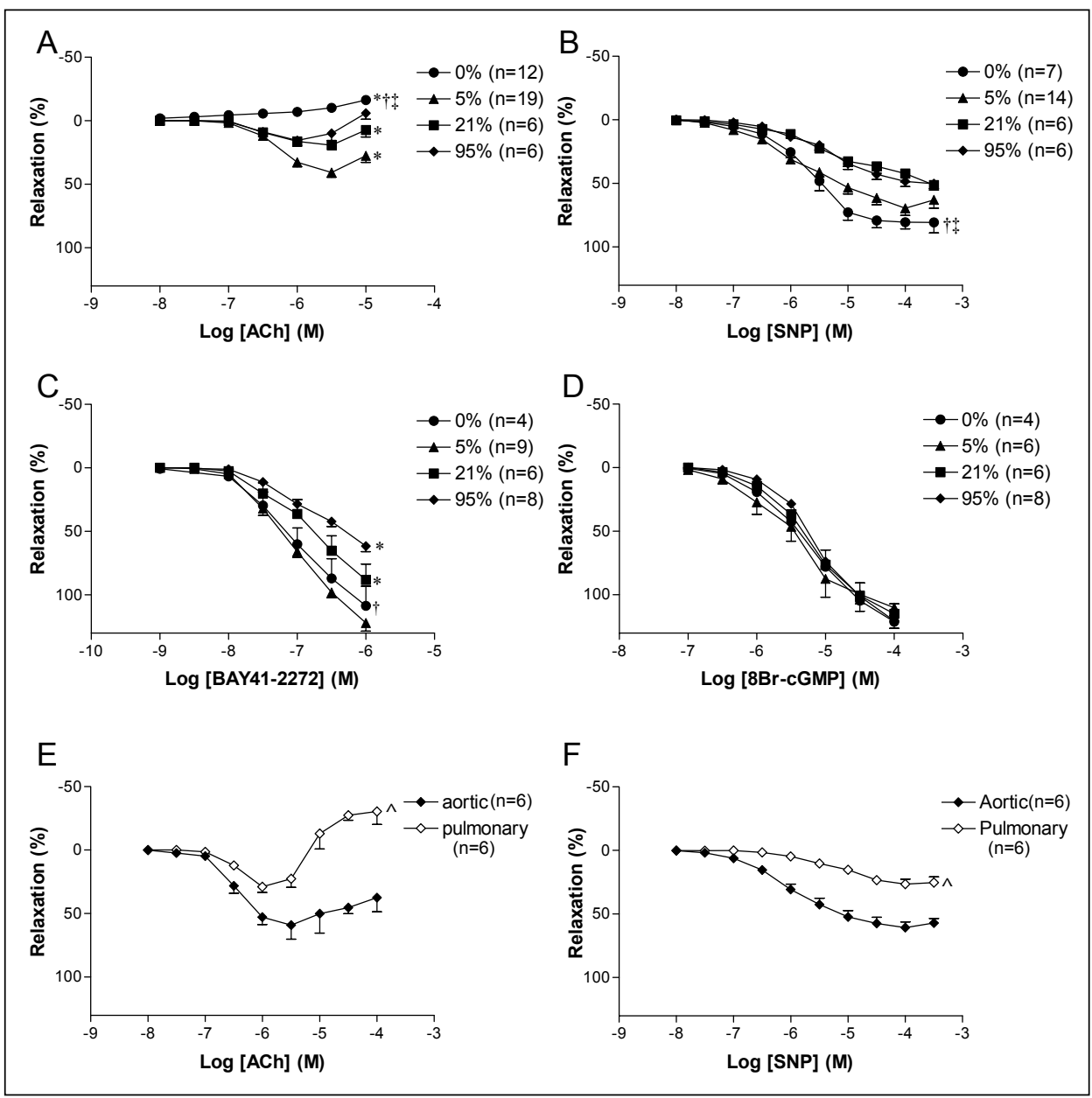

Fig. 5. Effects of oxygen. Concentration-dependent relaxant effects of acetylcholine (ACh, A), the NO donor sodium nitroprusside (SNP, B) the NO-independent stimulator of sGC BAY 41-2272 (C), and the cGMP analog 8-Br cGMP (D) in DA rings (central parts) from 19-day chicken embryos, aerated with one of the following gas mixtures: $0 \% \mathrm{O}_{2} / 95 \% \mathrm{~N}_{2} / 5 \% \mathrm{CO}_{2}\left(\mathrm{PO}_{2}=2.6-3.3 \mathrm{kPa}\right), 5 \%$ $\mathrm{O}_{2} / 90 \% \mathrm{~N}_{2} / 5 \% \mathrm{CO}_{2}\left(\mathrm{PO}_{2}=6.8-7.2 \mathrm{kPa}\right), 21 \% \mathrm{O}_{2} / 74 \% \mathrm{~N}_{2} / 5 \% \mathrm{CO}_{2}\left(\mathrm{pO}_{2}=16-20 \mathrm{kPa}\right)$, or $95 \%$ $\mathrm{O}_{2} / 5 \% \mathrm{CO}_{2}\left(\mathrm{PO}_{2}=72-76 \mathrm{kPa}\right)$. Panels $\mathrm{E}$ and $\mathrm{F}$ : concentration-dependent relaxant effects of $\mathrm{ACh}$ (E) and SNP (F) in the aortic and the pulmonary sides of DA rings from 19-day chicken embryos, aerated with $5 \% \mathrm{O}_{2} / 90 \% \mathrm{~N}_{2} / 5 \% \mathrm{CO}_{2}$. Vessels were contracted with $\mathrm{K}^{+}(62.5 \mathrm{mM}) .{ }^{*} P<0.05$ for $\mathrm{E}_{\max }$ difference from $5 \% \mathrm{O}_{2} .{ }^{\dagger} P<0.05$ for $\mathrm{E}_{\max }$ difference from $21 \% \mathrm{O}_{2} .{ }^{\star} P<0.05$ for $\mathrm{E}_{\max }$ difference from $95 \% \mathrm{O}_{2} . \wedge P<0.05$ for difference (in $\mathrm{E}_{\max }$ ) from aortic side. 
these agonists were performed in the 19-day DA under four different $\mathrm{O}_{2}$ concentrations $(0 \%, 5 \%, 21 \%$, and $95 \%)$. The purpose of selecting $95 \% \mathrm{O}_{2}$ was to provide a wide spectrum of in vitro oxygenation and not to attempt to mimic levels of oxygenation that yield cardiovascular effects in vivo (16). As shown in Fig. $5 \mathrm{~A}$ and Table 2, bubbling the organ chamber with $0 \% \mathrm{O}_{2}$ completely inhibited AChinduced relaxation and the relaxation obtained under 21 and $95 \% \mathrm{O}_{2}$ was significantly reduced when compared with $5 \% \mathrm{O}_{2}$ (Table 2). Also, when compared with 5\% $\mathrm{O}_{2}$ (Table 2), the responses to SNP (Fig. 5B) and BAY 41-2272 (Fig. 5C) were significantly reduced by 21 and $95 \% \mathrm{O}_{2}$ (Table 2) but unaffected by $0 \% \mathrm{O}_{2}$ (Table 2). $\mathrm{O}_{2}$ tension did not affect 8Br-cGMP-induced relaxation (Fig. 5D).

\section{Changes in relaxation along the $D A$}

We compared the relaxations induced by ACh, SNP, and BAY 41-2272 in the pulmonary and the aortic side of the DA. The contraction induced by $62.5 \mathrm{mM}$ $\mathrm{K}^{+}$in the pulmonary side $(2.37 \mathrm{~N} / \mathrm{m}, \mathrm{SD} 0.52, \mathrm{n}=20)$ was not significantly different from that induced in the aortic side $(2.48 \mathrm{~N} / \mathrm{m}$, SD $0.55, \mathrm{n}=20, P=$ 0.5229). As shown in Figure 5E, the relaxant efficacy of ACh was significantly higher in the aortic (19-day aortic DA: $\mathrm{E}_{\max }=61.97 \%$, SD 23.6; $\mathrm{pD}_{2} 6.46, \mathrm{SD} 0.33$ $\mathrm{n}=6$; 21-day aortic DA: $\mathrm{E}_{\max }=28.87 \%$, SD 7.6; $\mathrm{pD}_{2} 6.49$, SD $0.15, \mathrm{n}=8,21$ day DA not shown in figure) than in the pulmonary part of the chicken DA (19day pulmonary DA: $\mathrm{E}_{\max }=34.36 \%$, SD $10.7 ; \mathrm{pD}_{2} 6.35, \mathrm{SD} 0.18, \mathrm{n}=6 ; 21$-day pulmonary DA: $\mathrm{E}_{\max }=18.09 \%, \mathrm{SD} 16 ; \mathrm{pD}_{2} 6.77, \mathrm{SD} 0.2, \mathrm{n}=8,21$-day DA not shown in figure). Moreover, the contraction induced by high doses of ACh was more marked in the pulmonary side. Relaxations induced by BAY41-2272 (not shown) and SNP (Fig. $5 F$ ) were also markedly smaller in the pulmonary (19-day

Table 2. Concentration-response parameters for acetylcholine (ACh), sodium nitroprusside (SNP), 8-Br cGMP and BAY 41-2272 in 19-day chicken ductus arteriosus at different oxygen concentrations.

\begin{tabular}{|c|c|c|c|c|c|c|c|c|c|}
\hline & \multicolumn{3}{|c|}{$0 \%$ oxygen } & \multicolumn{3}{|c|}{$21 \%$ oxygen } & \multicolumn{3}{|c|}{$95 \%$ oxygen } \\
\hline & $\mathrm{E}_{\max }$ & $\mathrm{pD}_{2}$ & $n$ & $\mathrm{E}_{\max }$ & $\mathrm{pD}_{2}$ & $n$ & $\mathrm{E}_{\max }$ & $\mathrm{pD}_{2}$ & $n$ \\
\hline $\mathrm{ACh}$ & $0^{* \dagger}$ & - & 12 & $21.11(14.2)^{*}$ & $6.44(0.36)$ & 6 & $19.04(13.9)^{*}$ & $6.20(0.66)$ & 13 \\
\hline SNP & $82.57(14.5)^{\dagger t}$ & $5.62(0.25)$ & 7 & $51.78(13.9)$ & $5.27(0.29)^{*}$ & 6 & $52.47(10.1)$ & $5.31(0.25)^{*}$ & 6 \\
\hline 8-Br cGMP & $131.0(28.0)$ & $5.18(0.29)$ & 4 & $122.6(19.3)$ & $5.17(0.30)$ & 6 & $124.8(15.5)$ & $5.10(0.15)$ & 8 \\
\hline BAY41-2272 & $108.7(31.0)^{\ddagger}$ & - & 4 & $88.21(22.4)^{*}$ & - & 6 & $61.64(12.2)^{*}$ & - & 8 \\
\hline
\end{tabular}

Values are means (SD); $n=$ no. of embryos (arteries); $\mathrm{pD}_{2}=-\log \mathrm{EC}_{50} ; \mathrm{E}_{\max }$, maximal relaxant effect (\% of contraction). ${ }^{*} P<0.05$ from $5 \%$ oxygen (in Table 3$) \dagger P<0.05$ from $21 \%$ oxygen. ${ }^{\ddagger} P<0.05$ from $95 \%$ oxygen. Precontraction with $62.5 \mathrm{mM} \mathrm{K}^{+}$. The gas mixtures were composed of $0 \%$ $\mathrm{O}_{2} / 95 \% \mathrm{~N}_{2} / 5 \% \mathrm{CO}_{2}\left(\mathrm{PO}_{2}=2.6-3.3 \mathrm{kPa}\right), 5 \% \mathrm{O}_{2} / 90 \% \mathrm{~N}_{2} / 5 \% \mathrm{CO}_{2}\left(\mathrm{PO}_{2}=6.8-7.2 \mathrm{kPa}\right), 21 \% \mathrm{O}_{2} / 74$ $\% \mathrm{~N}_{2} / 5 \% \mathrm{CO}_{2}\left(\mathrm{pO}_{2}=16-20 \mathrm{kPa}\right)$, or $95 \% \mathrm{O}_{2} / 5 \% \mathrm{CO}_{2}\left(\mathrm{PO}_{2}=72-76 \mathrm{kPa}\right)$. As maximal effect was not achieved with BAY 41-2272, $\mathrm{pD}_{2}$ was not calculated and $\mathrm{E}_{\max }$ represents the response to $1 \mu \mathrm{M}$. 
pulmonary DA: $\mathrm{E}_{\max }=30 \%$, $\mathrm{SD} 9.7 ; \mathrm{pD}_{2} 5.12, \mathrm{SD} 0.33, \mathrm{n}=6 ; 21$-day pulmonary DA: $\mathrm{E}_{\max }=16.65 \%$, SD 11.5; $\mathrm{pD}_{2} 5.24, \mathrm{SD} 0.32, \mathrm{n}=8,21$-day DA not shown in figure) than in the aortic side (19-day aortic $\mathrm{DA}: \mathrm{E}_{\max }=63.08 \%, \mathrm{SD} 9.5 ; \mathrm{pD}_{2} 5.94$, SD $0.25 \mathrm{n}=6$; 21-day aortic DA: $\mathrm{E}_{\max }=46.98 \%$, SD 7.6; $\mathrm{pD}_{2}$ 5.86, SD 0.11, $\mathrm{n}=$ 8,21 -day DA not shown in figure).

\section{DISCUSSION}

Surprisingly, the classical experiment of Furchgott and Zawadzki (2) on the loss of ACh-induced relaxation upon mechanical removal of the endothelium had not been performed in the DA of any species. Therefore, we report for the first time that (i) ACh produces endothelium-dependent relaxation of the isolated DA of the chicken; (ii) that NO and a putative EDHF, but not PGs, are involved in this response; (iii) that $\mathrm{ACh}$-induced relaxation varies along the DA length, is affected by environmental $\mathrm{O}_{2}$ tension, and undergoes during transition to ex ovo life, particularly in the pulmonary side of the DA, a marked decrease that is accompanied by dramatic alterations in endothelial morphology; (iv) that DA endothelium-independent relaxations mediated by agonists acting through the NO-sGC signalling pathway, such as the NO donor SNP or the NO-independent stimulator of sGC BAY 41-2272, are also altered by development and $\mathrm{O}_{2}$ concentration and vary along the DA length.

\section{Endothelium-dependent relaxation in chicken DA}

Numerous earlier studies failed to demonstrate ACh-induced relaxation in the DA of several mammalian species (22-27). However, in these studies endothelium integrity was not taken into account and in the majority of them the effects of ACh were evaluated on the basal tone of the vessels (i.e. without precontraction). In addition, it should be noted that the absence of ACh-induced relaxation has been reported in several vascular preparations including the human umbilical vessels and bovine intrapulmonary veins $(28,29)$. Contrary to ACh, the presence of bradykinin-induced endothelium-dependent relaxation in lamb and mouse DA has been previously demonstrated (6). NO appeared to be the only agent responsible for that relaxation, as suggested by its complete prevention in the presence of L-NAME. In contrast, we have not observed bradykinin-induced relaxation of chicken DA. However, it should be noted that bradykinin shows low, if any, affinity for the ornithokinin (the "avian bradyikinin") receptor when compared with the authentic ligand ornithokinin ([Thr ${ }^{6}$ Leu $\left.^{8}\right]$ bradykinin) (30).

\section{Nitric oxide and chicken DA}

Although the lack of molecular evidence on NOS expression is an important limitation of the present study, our functional experiments indicate that 
endothelium-derived $\mathrm{NO}$ is a central component of $\mathrm{ACh}$-induced relaxation in the chicken DA, as demonstrated by its complete (when vessels were pre-contracted with high $\mathrm{K}^{+}$solution) or partial (when vessels were pre-contracted with $\mathrm{NE}$ ) prevention in the presence of the NOS inhibitor L-NAME or the SGC inhibitor ODQ. In addition, we demonstrated that $\mathrm{ACh}$ induced ductal NO production, as assessed by DAF-2T fluorescence, which was blocked by the presence of LNAME. The COX products PGs (and more particularly $\mathrm{PGE}_{2}$ ) are classically considered as the major relaxant agents of the mammalian DA (5) but, more recently, a role of NO in opposing DA constriction has also been postulated. In fact, the combined use of a NOS inhibitor and a COX inhibitor (indomethacin) produced a much greater degree of DA constriction than indomethacin alone either in vivo or in vitro $(6,7,31)$. Moreover, the three isoforms of NOS (i.e. eNOS, nNOS and iNOS) have been detected in the lamb DA and the contractile effects induced by NOS inhibitors have been described in several species $(4,31$ 35). However, endothelium-derived NO appears to be not critical for ductus patency, as demonstrated in mice lacking the eNOS gene (4).

Interestingly, it has been suggested that NO contributes to regulation of DA tone in the premature more than the term fetus (35). Among species, there is a high degree of variability concerning the extent of DA maturation before physiological constriction is necessary (13). A unique feature of DA development in some mammalian species, including humans, is the formation of intimal cushions during the last third of gestation $(13,33)$. This process is accompanied by phenotypic changes in endothelial and vascular smooth muscle cells and starts with lifting of the endothelium from the internal elastic lamina, accumulation of glycosaminoglycans and migration of endothelial and smooth muscle cells into the subendothelial region $(12-14,33)$. A mechanistic role for NO in smooth muscle cell migration into the ductal neointima has been suggested (33). Other species, including chicken, rat, mouse and rabbit show no intimal cushion formation prior to DA constriction (13). However, during ductal closure in these species, apposition of the endothelial lining due to media constriction is also accompanied by fragmentation of the internal elastic lamina, migration of smooth muscle cells into the subendothelial space, and protrusion and detachment of endothelial cells $(13,36)$. In the present study, scanning electron microscopy demonstrated that chicken DA constriction was accompanied by dramatic alterations in endothelial cells shape and attachment. Our results also show a clear correlation between these morphologic alterations and endothelial function. Thus, ACh-induced relaxation and NO production were markedly impaired in the 21day DA. In addition, the presence of L-NAME produced a modest but significant increase of $\mathrm{O}_{2}$-induced contraction in the 19-day but not in the 21-day DA. These data indicate that during chicken DA closure endothelial cells undergo a process of morphologic and functional impairment that results in the lack of endotheliumdependent relaxation. 
NO activates smooth muscle sGC, which increases intracellular cGMP levels, causing vasodilatation. cGMP in turn, is rapidly degraded by the cGMP-specific PDE5. We observed that the PDE5 inhibitor sildenafil induced endotheliumdependent relaxation in the chicken DA. In combination with the L-NAMEinduced contractions, our observations with sildenafil suggest basal NO production in the chicken DA. Relaxant effects of sildenafil in the rabbit DA have been previously characterized by Thebaud et al. (37). Interestingly, they found that sildenafil was indirectly acting as a $\mathrm{BK}_{\mathrm{Ca}}$ channel opener via a cGMP-dependent mechanism (37). Our experiments with sildenafil were performed during depolarization-induced contraction with high $\mathrm{K}^{+}$solution. Under this condition, sildenafil was still able to reduce vascular tone, suggesting that mechanisms not related to hyperpolarization were responsible for its action in the chicken DA.

\section{Prostaglandins and chicken DA}

Vasodilating PGs are important regulators of mammalian DA tone and have a central role in the development of pathways that control DA response to vasoactive stimulus $(5,10)$. Lamb, mouse, rat, rabbit, and piglet DA preparations contracted upon treatment with indomethacin and other COX inhibitors (5). In contrast, we observed that, in the isolated DA of the chicken, COX inhibitors did not produce significant contractile effects and did not affect receptor-dependent and-independent DA contraction (19). In the present work, we observed that the presence of indomethacin did not affect endothelium-dependent relaxation of the isolated DA of the chicken. Therefore, our data suggest that locally produced PGs are not important mediators in the control of chicken ductal tone. Accordingly, it has been speculated that the $\mathrm{DA} \mathrm{O}_{2}$-sensing mechanism might have preceded the PG mechanisms in evolution (38). Interestingly, we have observed that $\mathrm{PGE}_{2}$, the most significant PG in regulating the patency of the mammalian DA (5), failed to relax and even produced contraction of the chicken DA (39).

\section{EDHF and chicken $D A$}

The existence of an additional (partially or totally resistant to inhibitors of COX and NOS) endothelial relaxing pathway that involves smooth muscle hyperpolarization has been attributed to a non-characterized endothelial factor called EDHF (see 3 for a review). The molecular identity of a putative EDHF is not resolved, but potential candidates range from endothelium-derived $\mathrm{K}^{+}$to arachidonic acid metabolites (3). A hallmark of the EDHF-mediated response is its abolition by the combination of apamin plus charybdotoxin (3). In the present study, we observed that ACh-induced relaxation was markedly reduced when chicken DA was contracted by high $\mathrm{K}^{+}$depolarizing solution and that under this condition LNAME and ODQ produced a complete inhibition of ACh-induced relaxation. In contrast, the larger relaxation induced by ACh in NE-precontracted DA was only partially reduced by L-NAME or ODQ and a higher degree of inhibition was 
observed when L-NAME was combined with apamin and charybdotoxin. These data suggest that a putative EDHF plays a role in the endothelial control of chicken DA tone. However, our results are limited by the lack of assessment of ACh-evoked changes on membrane potential in DA smooth muscle cells. Very recently, Baragatti et al. (5) observed that a putative EDHF was responsible for the bradykinin-induced relaxations of mouse DA, when NO, PGs and CO formation were inhibited. Interestingly, the proposed mechanism for $\mathrm{O}_{2}$-evoked DA contraction includes the closure of $\mathrm{O}_{2}$ - and redox-sensitive $\mathrm{K}_{\mathrm{V}}$ channels that causes smooth muscle cells depolarisation, opening of the voltage-gated $\mathrm{Ca}^{2+}$ channels, increase in intracellular $\mathrm{Ca}^{2+}$ concentration, and vasoconstriction $(19,40,41)$. Therefore, the hyperpolarisation mediated by a putative EDHF might partially counteract the effects of $\mathrm{O}_{2}$ in the DA. This issue remains to be investigated and the chicken DA appears the ideal model for that purpose.

\section{Changes in endothelium -independent relaxation during transition to ex ovo life}

As mentioned above, ACh-induced relaxation and NO production were markedly decreased in the DA of the externally-pipped 21-day chicken. In contrast, the relaxation induced by the cell-permeable analog of cGMP 8-Br-cGMP was not affected by age, suggesting that the mechanisms mediating cGMP-induced relaxation are preserved in the vascular smooth muscle of the closing DA. We also observed that the response to the NO donor SNP was impaired by age, which might have suggested that transition to ex ovo life is accompanied by a reduction in $\mathrm{sGC}$ activity. However, the response to BAY 41-2272 remained unchanged in the 21-day DA. The recent discoveries of compounds that stimulate or activate sGC independently of $\mathrm{NO}$ allow this pharmacological target to be approached from a new perspective. NO-independent but haem-dependent stimulators of sGC (such as YC-1 and BAY 41-2272, 42, 43), as well as NO- and haem-independent sGC activators, are emerging as valuable pharmacological tools (42). Oxidation by ODQ of the prosthetic haem moiety of sGC (42) impaired both SNP- and BAY 41-2272induced relaxation, suggesting that both agonists share a common haem-dependent mechanism of sGC stimulation (42). To explain the differences between SNP and BAY 41-2272, it should be taken into account that the release of NO from SNP is coupled to a process of bioactivation in the vascular tissue (44) and this process might be altered by age in the DA. In addition, BAY 41-2272 shows a strong synergism when combined with NO (42). Although we have observed a marked decrease in NO production in the 21-day DA, we cannot discard the possibility that part of the BAY 41-2272-evoked relaxation might be the consequence of an increase in the relaxant effects of the residual endogenous NO (42).

\section{The modulatory role of oxygen on DA relaxation}

An increase in $\mathrm{O}_{2}$ tension produces not only constriction of the DA but also has a profound modulatory effect on other vasoactive systems $(5,45,46)$. We 
observed that low $(0 \%) \mathrm{O}_{2}$ concentrations abolished ACh- induced relaxation but did not significantly affect SNP-, BAY 41-2272-, or 8-Br-cGMP-induced relaxations. Interestingly, when the DAs were bubbled with 21 or $95 \% \mathrm{O}_{2}$ (instead of $5 \% \mathrm{O}_{2}$ ) the responses to ACh, SNP, and BAY 41-2272 were reduced but the responses to 8-Br-cGMP remained unchanged. Our results with 8-Br-cGMP indicate that signaling events downstream of $\mathrm{sGC}$ activation are not affected by $\mathrm{O}_{2}$ tension in the chicken DA. Other investigators have shown that increasing $\mathrm{O}_{2}$ tension desensitized the mammalian DA to a range of vasodilators including bradykinin (6) and SNP (5). In contrast, the response of ovine DA to NOS inhibitors was reduced at low $\mathrm{O}_{2}$ concentrations, suggesting a reduced production of NO under that condition (31). Moreover, severe hypoxia produced increased tension in the ovine DA by inhibiting PG- and NO-mediated relaxation (47). Interestingly, we have previously observed that, in contrast to the DA, in chicken embryo pulmonary arteries ACh- and SNP-evoked relaxation were higher under $95 \%$ than under $5 \% \mathrm{O}_{2}(16)$. Therefore, the modulatory effects of $\mathrm{O}_{2}$ on NOevoked relaxation appear to vary depending on the vessel studied. The mechanisms that regulate these differences between vessels warrant further investigation.

\section{Heterogeneity along the $D A$}

The chicken DA presents morphological and functional heterogeneity along its path between the pulmonary artery and the aorta $(13,19,48)$. Thus, the pulmonary side shows the structure of a muscular artery and responds to $\mathrm{O}_{2}$ with contraction, whereas the aortic part shows the morphology of an elastic artery and relaxes in response to $\mathrm{O}_{2}(13,19,48)$. The contractile effect of cathecolamines is also more marked in the pulmonary side of the chicken DA (19). In the present work, we observed that ACh-induced relaxation was higher in the aortic side of the vessel. Similarly SNP- and BAY 41-2272-induced relaxations were also more marked in the aortic side. In addition, the endothelial alterations that we observed by scanning electron microscopy in the 21-day DA were dramatically more marked in the pulmonary side. Our data support the suggestion of Bergwerff et al. (48) that the distal part of the chicken DA is not derived from the sixth aortic arch but is the result of the incorporation of dorsal aorta tissue. Therefore, the chicken DA is composed of cell populations with different embryological origin and phenotypes (13) and this is reflected in the response to vasoconstrictors (19) and vasodilators (present work) and in the morphologic alterations that the vessel undergoes during its occlusion.

\section{Concluding remarks and perspectives}

In summary, we have demonstrated that endothelium-dependent ACh-induced relaxation is present in the chicken DA and that NO and a putative EDHF are involved in it. The relaxations induced by $\mathrm{ACh}$, as well as the relaxations 
mediated by agonists acting through the NO-sGC signalling pathway, are altered by development and $\mathrm{O}_{2}$ concentration, and vary along the DA length.

With our previous publication (19) and the present work, we have demonstrated that, as occurs in the mammalian DA $(5,10)$, the effects of vasoactive mediators on chicken DA tone are developmentally regulated with loss of responsiveness to vasodilators and increase of responsiveness to vasoconstrictors with advancing age. When human premature birth occurs, DA maturation has not been completed, which is reflected in the high incidence of a patent DA, a clinical condition that is still presenting challenges in terms of diagnosis, assessment and treatment options $(5,38)$. Previous studies have demonstrated that the endothelium of the DA undergoes extensive changes during the perinatal period $(14,48,49)$. The processes of separation of endothelial cells from their basal lamina and neointimal formation are required for closure of the DA when it constricts in newborns $(14,48,49)$. Our results indicate that this process of endothelial detachment is accompanied by a marked impairment in NO production and endothelium-mediated relaxation. Endothelial damage is common to vascular diseases but, interestingly, occurs as a normal developmental process in the DA. Therefore, a better understanding of the mechanisms governing this physiologic endothelial damage in the perinatal DA might not only provide deeper insights into the pathophysiology of patent DA, but also of other vascular pathologies.

Acknowledgements: This work was supported by a grant from "Fundación de Investigación Médica Mutua Madrileña". We would like to thank Hans Duimel, Paul Bomans and Peter Frederik from the Department of Electron Microscopy of the Maastricht University for their collaboration in processing and visualizing the scanning images of the DA.

\section{REFERENCES}

1. Ignarro LJ. Nitric oxide as a unique signaling molecule in the vascular system: a historical overview. J Physiol Pharmacol 2002; 53: 503-514.

2. Furchgott RF, Zawadzki JV. The obligatory role of endothelial cells in the relaxation of arterial smooth muscle by acetylcholine. Nature 1980; 288: 373-376.

3. Busse R, Edwards G, Feletou M, et al. EDHF: bringing the concepts together. Trends Pharmacol Sci 2002; 23: 374-380.

4. Baragatti B, Brizzi F, Barogi S, et al. Interactions between NO, CO and an endothelium-derived hyperpolarizing factor (EDHF) in maintaining patency of the ductus arteriosus in the mouse. $\mathrm{Br}$ J Pharmacol 2007; 151: 54-62.

5. Smith GC. The pharmacology of the ductus arteriosus. Pharmacol Rev 1998; 50: 35-58.

6. Coceani F, Kelsey L, Seidlitz E. Occurrence of endothelium-derived relaxing factor-nitric oxide in the lamb ductus arteriosus. Can J Physiol Pharmacol 1994; 72: 82-88.

7. Seidner SR, Chen YQ, Oprysko PR, et al. Combined prostaglandin and nitric oxide inhibition produces anatomic remodeling and closure of the ductus arteriosus in the premature newborn baboon. Pediatr Res 2001; 50: 365-373. 
8. Momma K, Toyono M. The role of nitric oxide in dilating the fetal ductus arteriosus in rats. Pediatr Res 1999; 46: 311-315.

9. Takizawa T, Kihara T, Kamata A, Yamamoto M, Arishima K. Role of nitric oxide in regulating the ductus arteriosus caliber in fetal rats. J Vet Med Sci 2000; 62: 707-710.

10. Reese J, Anderson JD, Brown N, Roman C, Clyman RI. Inhibition of Cyclooxygenase Isoforms in Late- but not Mid-Gestation Decreases Contractility of the Ductus Arteriosus and Prevents Postnatal Closure in Mice. Am J Physiol Regul Integr Comp Physiol 2006 (In press).

11. Cooke JP. A novel mechanism for pulmonary arterial hypertension? Circulation 2003; 108: 1420-1421.

12. de Reeder EG, Poelmann RE, van Munsteren JC, Patterson DF, Gittenberger-de Groot AC. Ultrastructural and immunohistochemical changes of the extracellular matrix during intimal cushion formation in the ductus arteriosus of the dog. Atherosclerosis 1989; 79: 29-40.

13. Bergwerff M, DeRuiter MC, Gittenberger-de Groot AC. Comparative anatomy and ontogeny of the ductus arteriosus, a vascular outsider. Anat Embryol (Berl) 1999; 200: 559-571.

14. Slomp J, van Munsteren JC, Poelmann RE, et al. Formation of intimal cushions in the ductus arteriosus as a model for vascular intimal thickening. An immunohistochemical study of changes in extracellular matrix components. Atherosclerosis 1992; 93: 25-39.

15. le Noble FA, Ruijtenbeek K, Gommers S, de Mey JG, Blanco CE. Contractile and relaxing reactivity in carotid and femoral arteries of chicken embryos. Am J Physiol Heart Circ Physiol 2000; 278: H1261-1268.

16. Villamor E, Ruijtenbeek K, Pulgar V, De Mey JG, Blanco CE. Vascular reactivity in intrapulmonary arteries of chicken embryos during transition to ex ovo life. Am J Physiol Regul Integr Comp Physiol 2002; 282: R917-927.

17. Villamor E, Kessels CG, Ruijtenbeek K, et al. Chronic in ovo hypoxia decreases pulmonary arterial contractile reactivity and induces biventricular cardiac enlargement in the chicken embryo. Am J Physiol Regul Integr Comp Physiol 2004; 287: R642-651.

18. Ruijtenbeek K, le Noble FA, Janssen GM, et al. Chronic hypoxia stimulates periarterial sympathetic nerve development in chicken embryo. Circulation 2000; 102: 2892-2897.

19. Agren P, Cogolludo AL, Kessels CG, et al. Ontogeny of chicken ductus arteriosus response to oxygen and vasoconstrictors. Am J Physiol Regul Integr Comp Physiol 2007; 292: R485-496.

20. Kojima H, Nakatsubo N, Kikuchi K, et al. Detection and imaging of nitric oxide with novel fluorescent indicators: diaminofluoresceins. Anal Chem 1998; 70: 2446-2453.

21. Sylvester FA, Stepp DW, Frisbee JC, Lombard JH. High-salt diet depresses acetylcholine reactivity proximal to NOS activation in cerebral arteries. Am J Physiol Heart Circ Physiol 2002; 283: H353-363.

22. Bodach E, Coceani F, Dumbrille A, Okpako DT, Olley PM. The response of the isolated ductus arteriosus to transmural stimulation and drugs. Br J Pharmacol 1980; 71: 419-427.

23. Boreus LO, Malmfors T, McMurphy DM, Olson L. Demonstration of adrenergic receptor function and innervation in the ductus arteriosus of the human fetus. Acta Physiol Scand 1969; 77: 316-321.

24. Aronson S, Gennser G, Owman C, Sjoberg NO. Innervation and contractile response of the human ductus arteriosus. Eur J Pharmacol 1970; 11: 178-186.

25. Knight DH, Patterson DF, Melbin J. Constriction of the fetal ductus arteriosus induced by oxygen, acteylcholine, and norepinephrine in normal dogs and those genetically predisposed to persistent patency. Circulation 1973; 47: 127-132.

26. McMurphy DM, Heymann MA, Rudolph AM, Melmon KL. Developmental changes in constriction of the ductus arteriosus: responses to oxygen and vasoactive agents in the isolated ductus arteriosus of the fetal lamb. Pediatr Res 1972; 6: 231-238. 
27. Oberhansli-Weiss I, Heymann MA, Rudolph AM, Melmon KL. The pattern and mechanisms of response to oxygen by the ductus arteriosus and umbilical artery. Pediatr Res 1972; 6: 693-700.

28. Ignarro LJ, Byrns RE, Wood KS. Endothelium-dependent modulation of cGMP levels and intrinsic smooth muscle tone in isolated bovine intrapulmonary artery and vein. Circ Res 1987; 60: 82-92.

29. Van de Voorde J, Vanderstichele H, Leusen I. Release of endothelium-derived relaxing factor from human umbilical vessels. Circ Res 1987; 60: 517-522.

30. Schroeder C, Beug H, Muller-Esterl W. Cloning and functional characterization of the ornithokinin receptor. Recognition of the major kinin receptor antagonist, HOE140, as a full agonist. J Biol Chem 1997; 272: 12475-12481.

31. Clyman RI, Waleh N, Black SM, et al. Regulation of ductus arteriosus patency by nitric oxide in fetal lambs: the role of gestation, oxygen tension, and vasa vasorum. Pediatr Res 1998; 43: 633-644.

32. Fox JJ, Ziegler JW, Ivy DD, et al. Role of nitric oxide and cGMP system in regulation of ductus arteriosus tone in ovine fetus. Am J Physiol 1996; 271: H2638-2645.

33. Mason CA, Chang P, Fallery C, Rabinovitch M. Nitric oxide mediates LC-3-dependent regulation of fibronectin in ductus arteriosus intimal cushion formation. FASEB $J$ 1999; 13: 1423-1434.

34. Rairigh RL, Storme L, Parker TA, et al. Role of neuronal nitric oxide synthase in regulation of vascular and ductus arteriosus tone in the ovine fetus. Am J Physiol Lung Cell Mol Physiol 2000; 278: L105-110.

35. Richard C, Gao J, LaFleur B, et al. Patency of the preterm fetal ductus arteriosus is regulated by endothelial nitric oxide synthase and is independent of vasa vasorum in the mouse. $A m \mathrm{~J}$ Physiol Regul Integr Comp Physiol 2004; 287: R652-660.

36. Yoder MJ, Baumann FG, Goodyear JI, Imparato AM. Endothelial alterations in the constricting rabbit ductus arteriosus: relationship to smooth muscle cell bleb formation. Scan Electron Microsc 1980; 3: 271- 276.

37. Thebaud B, Michelakis E, Wu XC, et al. Sildenafil reverses O2 constriction of the rabbit ductus arteriosus by inhibiting type 5 phosphodiesterase and activating $\mathrm{BK}(\mathrm{Ca})$ channels. Pediatr Res 2002; 52: 19-24.

38. Sutendra G, Michelakis ED. The chicken embryo as a model for Ductus Arteriosus developmental biology: cracking into new territory. Am J Physiol Regul Integr Comp Physiol 2007; 292: R481-484.

39. Agren P, Van Der Weerden M, Kessels CG, et al. Response of chicken embryo ductus arteriosus to NO/cyclic GMP- and cyclic AMP-mediated relaxation (abstract). Pediatric Research 2005; 58: 354 .

40. Michelakis ED, Rebeyka I, Wu X, et al. $\mathrm{O} 2$ sensing in the human ductus arteriosus: regulation of voltage-gated $\mathrm{K}+$ channels in smooth muscle cells by a mitochondrial redox sensor. Circ Res 2002; 91: 478-486.

41. Weir EK, Lopez-Barneo J, Buckler KJ, Archer SL. Acute oxygen-sensing mechanisms. N Engl $J$ Med 2005; 353: 2042-2055.

42. Evgenov OV, Pacher P, Schmidt PM, et al. NO-independent stimulators and activators of soluble guanylate cyclase: discovery and therapeutic potential. Nat Rev Drug Discov 2006; 5: 755-768.

43. Gonzalez-Luis G, Cogolludo A, Moreno L, et al. Relaxant effects of the soluble guanylate cyclase activator and NO sensitizer YC-1 in piglet pulmonary arteries. Biol Neonate 2006; 90: 66-72.

44. Feelisch M. The use of nitric oxide donors in pharmacological studies. Naunyn Schmiedebergs Arch Pharmacol 1998; 358: 113-122. 
45. Ikeda M, Sonnenschein RR, Masuoka DT. Catecholamine content and uptake of the ductus arteriosus of the fetal lamb. Experientia 1972; 28: 914-915.

46. Smith GC, McGrath JC. Characterisation of the effect of oxygen tension on response of fetal rabbit ductus arteriosus to vasodilators. Cardiovasc Res 1993; 27: 2205-2211.

47. Kajino H, Chen YQ, Chemtob S, et al. Tissue hypoxia inhibits prostaglandin and nitric oxide production and prevents ductus arteriosus reopening. Am J Physiol Regul Integr Comp Physiol 2000; 279: R278-286.

48. Bergwerff M, DeRuiter MC, Poelmann RE, Gittenberger-de Groot AC. Onset of elastogenesis and downregulation of smooth muscle actin as distinguishing phenomena in artery differentiation in the chick embryo. Anat Embryol (Berl) 1996; 194: 545-557.

49. de Reeder EG, van Munsteren CJ, Poelmann RE, Patterson DF, Gittenberger-de Groot AC. Changes in distribution of elastin and elastin receptor during intimal cushion formation in the ductus arteriosus. Anat Embryol (Berl) 1990; 182: 473-480.

Received: September 4, 2007

Accepted: January 22,2008

Author's address: E. Villamor. Dept of Pediatrics, University Hospital Maastricht. P. Debyelaan 25. P.O. Box 5800. 6202 AZ Maastricht. The Netherlands.Phone +31 43-3877246, fax +31 433875246; e-mail: eiv@paed.azm.nl 


\section{Chapter 4}

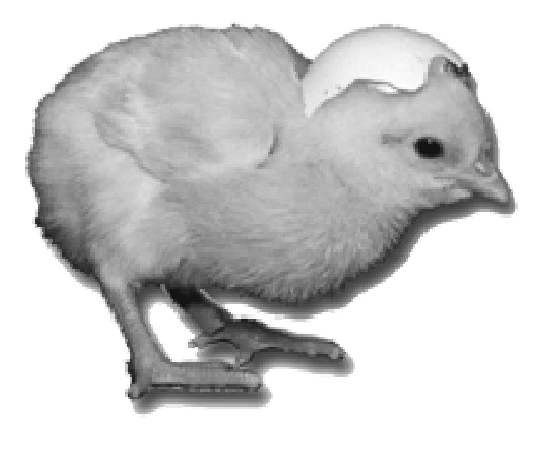

\section{DEVELOPMENTAL CHANGES IN THE EFFECTS OF PROSTAGLANDIN $E_{2}$ IN THE CHICKEN DUCTUS ARTERIOSUS}

Pia Ågren, Saskia van der Sterren, Angel L. Cogolludo, Carlos E. Blanco and Eduardo Villamor

J Comp Physiol B (2009) 179: 133-143 


\title{
Developmental changes in the effects of prostaglandin $E_{2}$ in the chicken ductus arteriosus
}

\author{
Pia Ågren · Saskia van der Sterren • \\ Angel L. Cogolludo $\cdot$ Carlos E. Blanco • \\ Eduardo Villamor
}

Received: 1 April 2008 / Revised: 10 July 2008 / Accepted: 3 August 2008 / Published online: 26 August 2008

(C) The Author(s) 2008. This article is published with open access at Springerlink.com

\begin{abstract}
Prostaglandin $\mathrm{E}_{2}\left(\mathrm{PGE}_{2}\right)$ is the major vasodilator prostanoid of the mammalian ductus arteriosus (DA). In the present study we analyzed the response of isolated DA rings from 15-, 19- and 21-day-old chicken embryos to $\mathrm{PGE}_{2}$ and other vascular smooth muscle relaxing agents acting through the cyclic AMP signaling pathway. $\mathrm{PGE}_{2}$ exhibited a relaxant response in the 15-day DA, but not in the 19- and 21-day DA. Moreover, high concentrations of $\mathrm{PGE}_{2}$ ( $\geq 3 \mu \mathrm{M}$ in 15-day and $\geq 1 \mu \mathrm{M}$ in 19-day and 21-day DA) induced contraction of the chicken DA. The presence of the TP receptor antagonist SQ29,548, unmasked a relaxant effect of $\mathrm{PGE}_{2}$ in the 19- and 21-day DA and increased the relaxation induced by $\mathrm{PGE}_{2}$ in the 15-day DA. The presence of the EP receptor antagonist AH6809 abolished $\mathrm{PGE}_{2}$-mediated relaxation. The relaxant responses induced by $\mathrm{PGE}_{2}$ and the $\beta$-adrenoceptor agonist isoproterenol, but not those elicited by the adenylate cyclase activator forskolin or the phosphodiesterase 3 inhibitor milrinone, decreased with maturation. High oxygen concentrations (95\%) decreased the relaxation to $\mathrm{PGE}_{2}$. The relaxing potency and efficacy of isoproterenol and milrinone were
\end{abstract}

Communicated by H.V. Carey.

P. Ågren · S. van der Sterren · C. E. Blanco · E. Villamor $(\bowtie)$ Department of Pediatrics,

Maastricht University Medical Center (MUMC+),

Research Institute Growth and Development (GROW),

University Hospital Maastricht, P. Debyelaan 25,

P.O. Box 5800, 6202 AZ Maastricht, The Netherlands

e-mail: eiv@paed.azm.nl

\section{A. L. Cogolludo}

Department of Pharmacology, School of Medicine,

Universidad Complutense, CIBER Enfermedades

Respiratorias (CibeRes), 28040 Madrid, Spain higher in the pulmonary than in the aortic side of the DA, whereas no regional differences were found in the response to $\mathrm{PGE}_{2}$. We conclude that, in contrast to the mammalian situation, $\mathrm{PGE}_{2}$ is a weak relaxant agent of the chicken DA and, with advancing incubation, it even stimulates TP vasoconstrictive receptors.

Keywords Ductus arteriosus · Chicken embryo · Prostaglandins · Adenylate cyclase · cAMP

\section{Introduction}

The ductus arteriosus (DA), a fetal arterial connection between the pulmonary artery and the descending aorta, is indispensable for fetal life. Considerable evidence supports a major role for the cyclooxygenase (COX) product prostaglandin $(\mathrm{PG}) \mathrm{E}_{2}$ in maintaining mammalian fetal patency and for the rapid decline in $\mathrm{PGE}_{2}$ levels as trigger of DA closure after birth (see Clyman 2006; Smith 1998 for reviews).

In blood vessels, $\mathrm{PGE}_{2}$ acts on four different prostanoid receptors: $\mathrm{EP}_{1}, \mathrm{EP}_{2}, \mathrm{EP}_{3}$ and $\mathrm{EP}_{4}$. Both $\mathrm{EP}_{2}$ - and $\mathrm{EP}_{4}$-receptor subtypes mediate $\mathrm{PGE}_{2}$ relaxation through a cyclic AMPdependent mechanism (Narumiya and FitzGerald 2001). $\mathrm{EP}_{1}$ is a constrictive receptor and $\mathrm{EP}_{3}$ induces a decline in cAMP, inhibiting smooth muscle relaxation (Narumiya and FitzGerald 2001). The main receptor responsible for $\mathrm{PGE}_{2}$-induced DA relaxation varies among mammalian species and was reported as $\mathrm{EP}_{4}$ in rabbits (Smith 1998; Smith et al. 1994; Smith and McGrath 1995), mice (Nguyen et al. 1997), rats (Kajino et al. 2004), lambs (Waleh et al. 2004), baboon (Waleh et al. 2004), and humans (Leonhardt et al. 2003), and as $\mathrm{EP}_{2}$ in pigs (Bhattacharya et al. 1999) and lambs (Bouayad et al. 2001). The cAMP-inhibiting $\mathrm{EP}_{3}$ receptor is also present in the rabbit and piglet DA, modulating the dilating effect of $\mathrm{PGE}_{2}$ 
(Bhattacharya et al. 1999; Smith 1998; Smith et al. 1994; Smith and McGrath 1995). In contrast, stimulation of $\mathrm{EP}_{3}$ receptor in the lamb DA produces not contraction but relaxation via a cAMP-independent pathway (Bouayad et al. 2001).

Significant progress in our understanding of the ductal effects of $\mathrm{PGE}_{2}$, as well as other aspects of DA physiology and pathophysiology, has been achieved with the use of mammalian models (Sutendra and Michelakis 2007). However, these models are technically complex and experimental manipulations affect both the mother and the fetus. Therefore, there is a need for additional models, addressing these limitations (Sutendra and Michelakis 2007). Recently, we analyzed the ontogeny of the chicken DA response to $\mathrm{O}_{2}$ and other vasoconstrictors (Agren et al. 2007), as well as the relaxation induced by agonists acting through the nitric oxide (NO)-soluble guanylate cyclase (sGC)-cyclic GMP (cGMP) pathway (Agren et al. 2008). We found that the effects of vasoactive mediators on chicken DA tone are developmentally regulated with loss of responsiveness to vasodilators and increase of responsiveness to vasoconstrictors with advancing incubation age.

Most of the physiological functions that prostanoids exhibit in mammals seem to be present in avian and other non-mammalian vertebrates (Rowley 1991). Prostanoids are produced in chicken blood vessels and participate in the regulation of vascular tone (Chand and Eyre 1976; Claeys et al. 1981; Wideman et al. 1999). However, we have observed that in the chicken DA COX inhibitors did not produce significant contractile effects (Agren et al. 2007) and did not affect endothelium-dependent relaxation (Agren et al. 2008), suggesting that locally produced PGs are not important mediators in the control of chicken ductal tone. Accordingly, Dzialowski and Greyner (2008) demonstrated that $\mathrm{COX}$ inhibition did not produce any change in the basal tension of DA of another avian species, the emu. However, they also observed that the emu DA was relaxed by exogenous $\mathrm{PGE}_{2}$ (Dzialowski and Greyner 2008). This indicates that $\mathrm{PGE}_{2}$, the most potent vasodilator in the regulation of mammalian DA tone, is also active in the avian DA. In the present study we hypothesized that the chicken DA is responsive to $\mathrm{PGE}_{2}$ and that its responsiveness is developmentally regulated. Therefore, we analyzed, at different ages, the ex vivo response of chicken DA to $\mathrm{PGE}_{2}$ and other vascular smooth muscle relaxing agents acting through the cAMP signaling pathway.

\section{Material and methods}

Embryos incubation and vessel isolation

Experiments were performed in accordance with Dutch law for animal experimentation. Fertilized eggs of White
Leghorn chickens were incubated at $37.8^{\circ} \mathrm{C}, 45 \%$ humidity and rotated once per hour (Incubator model 25HS, Masalles Comercial, Spain). Embryos incubated for 15, 19 and 21 days of the 21-day incubation period were studied. The majority of the experiments were performed in 19-day (non-internally pipped) embryos, while for the study of developmental changes all three ages were compared (see below). On the experimental day the embryos were killed by decapitation and the right DA was carefully dissected free and severed distal to the takeoff of the right pulmonary artery and proximal to the insertion into the dorsal aorta. The average in situ length (in $\mathrm{mm}$ ) of the right DA was 3.48 (SD 0.27), 4.71 (SD 0.40), and 5.58 (SD 0.40) at embryonic day 15, 19, and 21, respectively, (Agren et al. 2007), whereas the maximal length allowed in the myograph was $2 \mathrm{~mm}$. Therefore, a similar length of ductal tissue was removed from the pulmonary and aortic ends of the vessel to obtain a segment of the central part of the DA with a length of approximately $2 \mathrm{~mm}$. The right DA was selected because its shorter length allowed having a higher proportion of the vessel represented in the myograph.

\section{Recording of arterial reactivity}

Two stainless steel wires (diameter $40 \mu \mathrm{m}$ ) were inserted into the lumen of the DA, which was mounted as a ring segment between an isometric force transducer and a displacement device in a myograph (Danish Myo Technology A/S model $610 \mathrm{M}$, Aarhus, Denmark). The myograph organ bath $(5 \mathrm{~mL}$ vol) was filled with Krebs-Ringer bicarbonate (KRB) buffer maintained at $39^{\circ} \mathrm{C}$ and continuously aerated with one of the following gas mixtures: $0 \% \mathrm{O}_{2} / 95 \%$ $\mathrm{N}_{2} / 5 \% \quad \mathrm{CO}_{2}\left(\mathrm{pO}_{2}=2.6-3.3 \mathrm{kPa}\right), 5 \% \quad \mathrm{O}_{2} / 90 \% \mathrm{~N}_{2} / 5 \% \quad \mathrm{CO}_{2}$ $\left(\mathrm{pO}_{2}=6.8-7.2 \mathrm{kPa}\right)$, or $95 \% \quad \mathrm{O}_{2} / 5 \% \quad \mathrm{CO}_{2} \quad\left(\mathrm{pO}_{2}=72-\right.$ $76 \mathrm{kPa}$ ). The final $\mathrm{pH}$ was 7.38-7.42 and $\mathrm{pCO}_{2}$ was 4.6$5.6 \mathrm{kPa}$ in all solutions. Each DA was stretched to its individual optimal lumen diameter, i.e., the diameter at which it developed the strongest contractile response to $62.5 \mathrm{mM} \mathrm{K}^{+}$, using a diameter-tension protocol as previously described (Agren et al. 2007; Villamor et al. 2002). During the first phase of stabilization and determination of optimal diameter, DA rings were maintained in KRB buffer with a $\mathrm{pO}_{2}$ of $\sim 3 \mathrm{kPa}$. Afterward, oxygen concentration was switched to $5 \%\left(\mathrm{pO}_{2} \sim 7 \mathrm{kPa}\right)$, unless the effect of $\mathrm{O}_{2}$ on the relaxant responses was evaluated. When two or more agonists were studied in the same arterial preparation, the vessels were repeatedly washed and allowed to equilibrate for at least $30 \mathrm{~min}$. If the tone did not recover to resting level or $62.5 \mathrm{mM} \mathrm{K}^{+}$failed to induce an adequate level of contraction, the vessels were discarded for further experiments.

The effects of $\mathrm{PGE}_{2}(0.1 \mathrm{nM}-10 \mu \mathrm{M})$, the direct activator of adenylate cyclase forskolin $(0.1-10 \mu \mathrm{M})$, the $\beta$-adrenoceptor 
agonist isoproterenol $(1 \mathrm{nM}-10 \mu \mathrm{M})$ and the phosphodiesterase 3 (PDE3) inhibitor milrinone $(0.1 \mu \mathrm{M}-0.1 \mathrm{mM})$ were evaluated in DA rings contracted with $\mathrm{K}^{+}(62.5 \mathrm{mM})$, or the thromboxane (Tx) $\mathrm{A}_{2}$-mimetic (selective TP-receptor agonist) U46619 $(0.1 \mu \mathrm{M})$. When stable contractions were obtained, agonists were added cumulatively to the bath until a maximal response was achieved. In some experiments, the relaxation evoked by $\mathrm{PGE}_{2}$ was studied in the presence of the TP-receptor antagonist SQ29,548 $(10 \mu \mathrm{M})$, or the non-selective EP receptor antagonist AH6809 (6-isopropoxy-9-oxoxanthene-2-carboxylic acid; $10 \mu \mathrm{M}$ ) and the relaxations evoked by isoproterenol and forskolin were studied in the presence of the non-selective COX inhibitor indomethacin $(10 \mu \mathrm{M})$, the COX-1 inhibitor valeryl salicylate $(0.5 \mathrm{mM})$, or the COX-2 inhibitor nimesulide $(0.1 \mu \mathrm{M})$.

In order to analyze developmental changes on relaxation, the responses to $\mathrm{PGE}_{2}$, forskolin, isoproterenol, and milrinone were studied in the central part of DA from 15-, 19-, and 21-day-old embryos. The 21-day embryos were externally pipped for about 1-3 h. In another set of experiments, aimed to evaluate the modulatory role of $\mathrm{O}_{2}$ in DA relaxation, the responses to $\mathrm{PGE}_{2}$, were studied under three different conditions of $\mathrm{pO}_{2}: \sim 3,7$, and $74 \mathrm{kPa}$. In these experiments, optimal diameter was determined at $3 \mathrm{kPa}$. Thereafter the $\mathrm{O}_{2}$ concentration was switched to the appropriate level and the vessels were allowed to equilibrate for at least $30 \mathrm{~min}$ before the concentration- response curve for the agonists was obtained. Finally and in order to analyze the differences along the DA in the responses to $\mathrm{PGE}_{2}$, forskolin, isoproterenol, milrinone and U46619, we performed a third set of experiments in which the pulmonary and the aortic parts of the vessel were compared in 19-day embryos. The responses to U46619 and milrinone were also analyzed in the pulmonary and the aortic parts of the DA from 15-day embryos. The boundary between pulmonary and aortic segments was determined during the dissection based on the marked differences of diameter observed along the chicken DA (see Agren et al. 2007).

Data analysis

Results are shown as mean (SD) of measurements in $n$ embryos. For clarity, results are shown in the figures as mean \pm SE. Contractions are expressed in terms of active wall tension $(\mathrm{N} / \mathrm{m})$, calculated as the force divided by twice the length of the segment, while the relaxant responses are expressed as the percentage of reduction of the contraction induced by $\mathrm{K}^{+}$, or U46619. Sensitivity (expressed as $\left.\mathrm{pD}_{2}=-\log \mathrm{EC}_{50}\right)$ and maximal relaxation $\left(E_{\max }\right)$ to agonists was determined for each artery by fitting individual concentration-response data to a non-linear sigmoidal regression curve and interpolating (Graphpad Prism version
2.01; GraphPad Software Inc, San Diego, CA, USA). When a maximal response was not achieved with a given agonist, the regression curve could not be calculated and the responses for each concentration of the agonist were used for comparison. Differences between mean values were assessed by one-way ANOVA followed by Bonferroni post hoc $t$ test. Non-paired $t$ tests were used if only two groups were compared. Differences were considered significant at a $P<0.05$. All analyses were performed using a commercially available statistics package (GraphPad InStat version 3.00; GraphPad Software Inc, San Diego, CA, USA).

Drugs and solutions

PGE $_{2}$, U46619, SQ29,548, and AH6809 were obtained from Cayman Chemical (Ann Arbor, MI, USA). Valeryl salicylate, nimesulide, and milrinone were obtained from Alexis Biochemicals (Lausen, Switzerland). All the other drugs were obtained from Sigma Chemical Co (St Louis, MO, USA). $\mathrm{PGE}_{2}, \mathrm{U} 46619$, and AH6809 were dissolved in DMSO and SQ29,548 indomethacin, valeryl salicylate, nimesulide and milrinone in ethanol to prepare adequate stock solutions and further dilutions were made in KRB. The final bath concentration of DMSO and ethanol did not exceed $0.1 \%$, which we have found elsewhere to have little or no effect on mechanical activity (Agren et al. 2007). All the other drugs were dissolved initially in distilled deionised water.

\section{Results}

Potassium-induced contraction

Isolated DA obtained from 15-, 19- and 21-day chicken embryos responded to depolarizing high- $\mathrm{K}^{+}(62.5 \mathrm{mM})$ solution with a tonic contraction and this response significantly increased with age (15-day: $0.21 \mathrm{~N} / \mathrm{m}$, SD 0.05 , $n=30, P<0.001$ from both 19 and 21-day; 19-day: $0.61 \mathrm{~N} /$ m, SD $0.19, n=69 ; 21$-day: $0.99 \mathrm{~N} / \mathrm{m}, \mathrm{SD} 0.37, n=21$, $P<0.001$ from 19-day old.). The diameter at which a maximal response to $62.5 \mathrm{mM} \mathrm{KCl}$ was obtained increased between day $15(787 \mu \mathrm{m}, \mathrm{SD} 89, n=30)$ and $19(830 \mu \mathrm{m}$, SD $121, n=69, P<0.001$ vs.15-day), but decreased at day 21 (483 $\mu \mathrm{m}, \mathrm{SD} 227, n=21, P<0.001$ vs. 15 - and 19-day).

\section{Effects of $\mathrm{PGE}_{2}$ in chicken DA}

In the first set of experiments we tested the relaxant effects induced by $\mathrm{PGE}_{2}$ in chicken DA stimulated with $\mathrm{KCl}$ $62.5 \mathrm{mM}$. We found that $\mathrm{PGE}_{2}$ exhibited a relaxant response in 15-day DA (Figs. 1a, 2a; Table 1), but no significant relaxation was observed in 19- and 21-day DA 

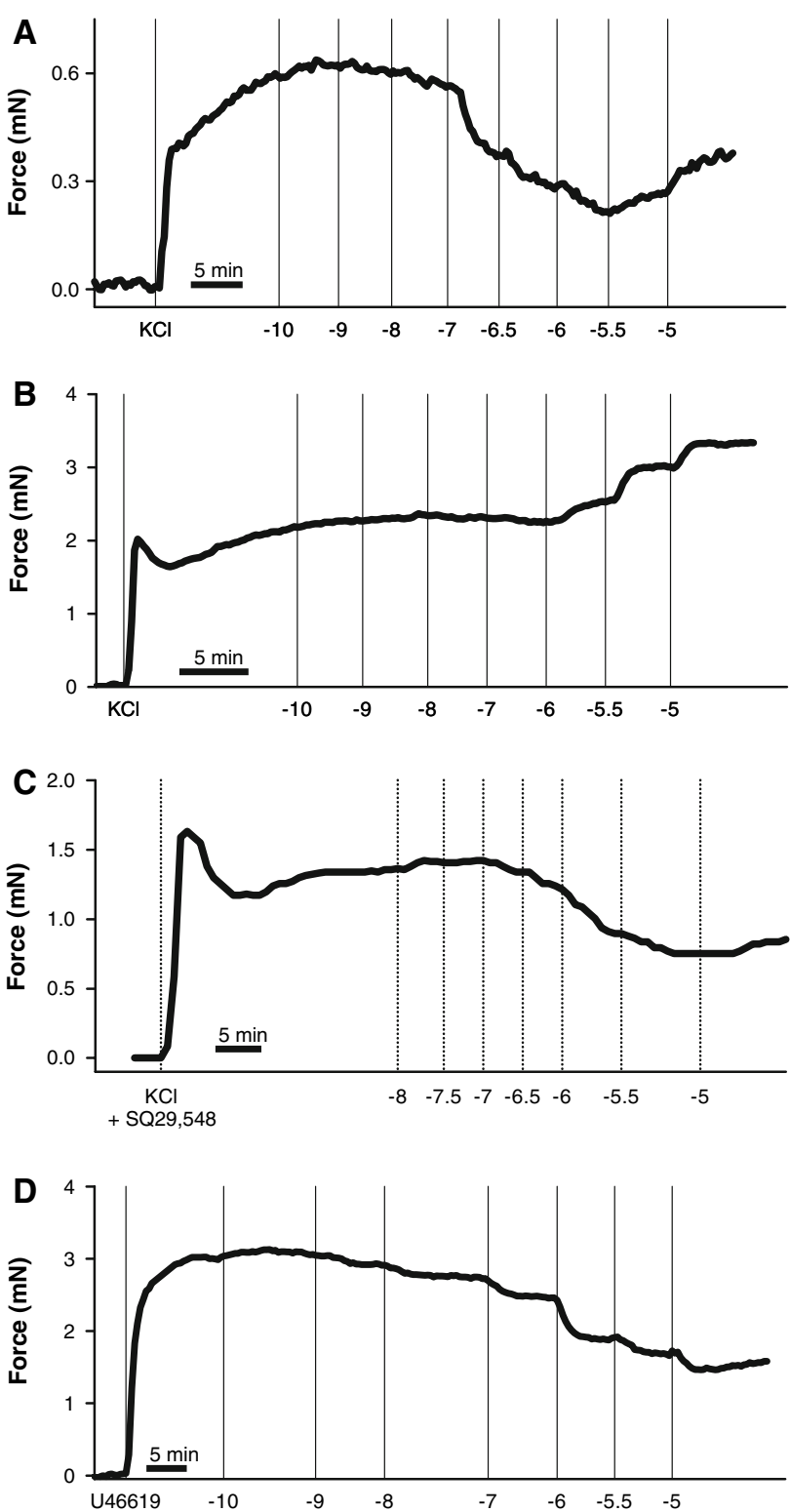

Fig. 1 Typical tracings illustrating the vascular effects of prostaglandin $\mathrm{E}_{2}\left(\mathrm{PGE}_{2}\right)$ in chicken DA. During contraction induced by $\mathrm{K}^{+}$ (62.5 mM), $\mathrm{PGE}_{2}$ induced a concentration-dependent relaxation of the 15-day DA (a) but a contraction of the 19-day DA (b). In the presence of the TP receptor antagonist SQ 29,548 $(10 \mu \mathrm{M}$, c $)$ or when the vessel was contracted with the TP receptor agonist U46619 $(0.1 \mu \mathrm{M}, \mathbf{d})$, a relaxant effect of $\mathrm{PGE}_{2}$ was observed in the 19-day DA

(Figs. 1b, 2a; Table 1). Moreover, high concentrations of $\mathrm{PGE}_{2}(\geq 3 \mu \mathrm{M}$ in 15-day and $\geq 1 \mu \mathrm{M}$ in 19- and 21-day DA) induced contraction of the chicken DA (Figs. 1a, b, 2a). The presence of the TP receptor antagonist SQ29,548, unmasked a relaxant effect of $\mathrm{PGE}_{2}$ in the 19- (Figs. 1c, 2b; Table 1) and 21-day DA (Fig. 2b; Table 1) and increased the relaxation induced by $\mathrm{PGE}_{2}$ in the 15-day DA (Fig. 2b; Table 1). Under these conditions (i.e., presence of SQ29,548), the maximal relaxant response induced by $\mathrm{PGE}_{2}$ was reduced in term (externally pipped 21-day) ver- sus preterm (non-internally pipped 15-day and 19-day) chicken DA, while the sensitivity to $\mathrm{PGE}_{2}$ was not affected by age (Table 1). When the 19-day DA was contracted with the TP receptor agonist $\mathrm{U} 46619(0.1 \mu \mathrm{M}), \mathrm{PGE}_{2}$ induced a concentration-dependent relaxation with a threshold concentration of $1 \mathrm{nM}$ (Figs. 1d, 2d) and without achieving the maximal effect with the highest concentration tested $(10 \mu \mathrm{M})$. The presence of the EP receptor antagonist AH6809 reduced the contraction induced by U46619 from $0.8 \mathrm{~N} / \mathrm{m}$ (SD $0.11, n=6$ ) to $0.58 \mathrm{~N} / \mathrm{m}$ (SD 0.12, $n=6$, $P<0.01$ vs. control) and abolished $\mathrm{PGE}_{2}$-mediated relaxation of U46619-contracted DA (Fig. 2d). As shown in Fig. 2c, bubbling the organ chamber with $95 \% \mathrm{O}_{2}\left(\mathrm{pO}_{2}\right.$ $\sim 74 \mathrm{kPa}$ ) produced a marked reduction of the relaxation evoked by $\mathrm{PGE}_{2}$ in 19-day DA (contracted with $62.5 \mathrm{mM} \mathrm{K}^{+}$and in the presence of SQ29,548).

Relaxant effects of isoproterenol, forskolin, and milrinone in chicken DA

In $\mathrm{K}^{+}$-stimulated DA, the addition of the $\beta$-adrenoceptor agonist isoproterenol, the direct activator of adenylate cyclase forskolin, or the PDE3 inhibitor milrinone caused a concentration-dependent relaxation (Fig. 3a, c, e; Table 1). As expected the $\beta$-adrenergic receptor blocker propanolol drastically reduced the relaxation response induced by isoproterenol (Fig. 3a). Similar to $\mathrm{PGE}_{2}$, the relaxation induced by isoproterenol was markedly diminished in 21day versus 15- or 19-day chicken DA (Fig. 3a). In contrast, the relaxant effect of forskolin did not change with age (Fig. 3c; Table 1) and milrinone was less potent (but similarly efficacious) in relaxing the 15-day than the 19-, or 21day chicken DA (Fig. 3e; Table 1). Finally, as shown in Fig. $3 b$ and d, the relaxation evoked by isoproterenol and forskolin were not significantly affected by the presence of the COX inhibitors indomethacin, valeryl salicylate, or nimesulide, compared to control vessels (incubated with vehicle, ethanol $0.1 \%$ ).

Heterogeneity of relaxant responses along the DA

In the last set of experiments the responses to the drugs studied above were compared in the pulmonary versus the aortic side of the DA. The contractions induced by $\mathrm{KCl}$ were not significantly different when the pulmonary and the aortic side of the DA from the 19-day (pulmonary: $0.72 \mathrm{~N} /$ $\mathrm{m}, \mathrm{SD} 0.16, n=14$; aortic: $0.67 \mathrm{~N} / \mathrm{m}, \mathrm{SD} 0.2, n=14$ ) and 15-day embryos (pulmonary: $0.21 \mathrm{~N} / \mathrm{m}, \mathrm{SD} 0.03, n=6$; aortic: $0.24 \mathrm{~N} / \mathrm{m}, \mathrm{SD} 0.05, n=6$ ) were compared. Similarly, the optimal diameters were not significantly different between the pulmonary and the aortic side of the 19-day DA (pulmonary: $889 \mu \mathrm{m}$, SD $88, n=14$; aortic: $936 \mu \mathrm{m}$, SD $87, n=14$ ) and 15 -day DA (pulmonary: $742 \mu \mathrm{m}, \mathrm{SD}$ 

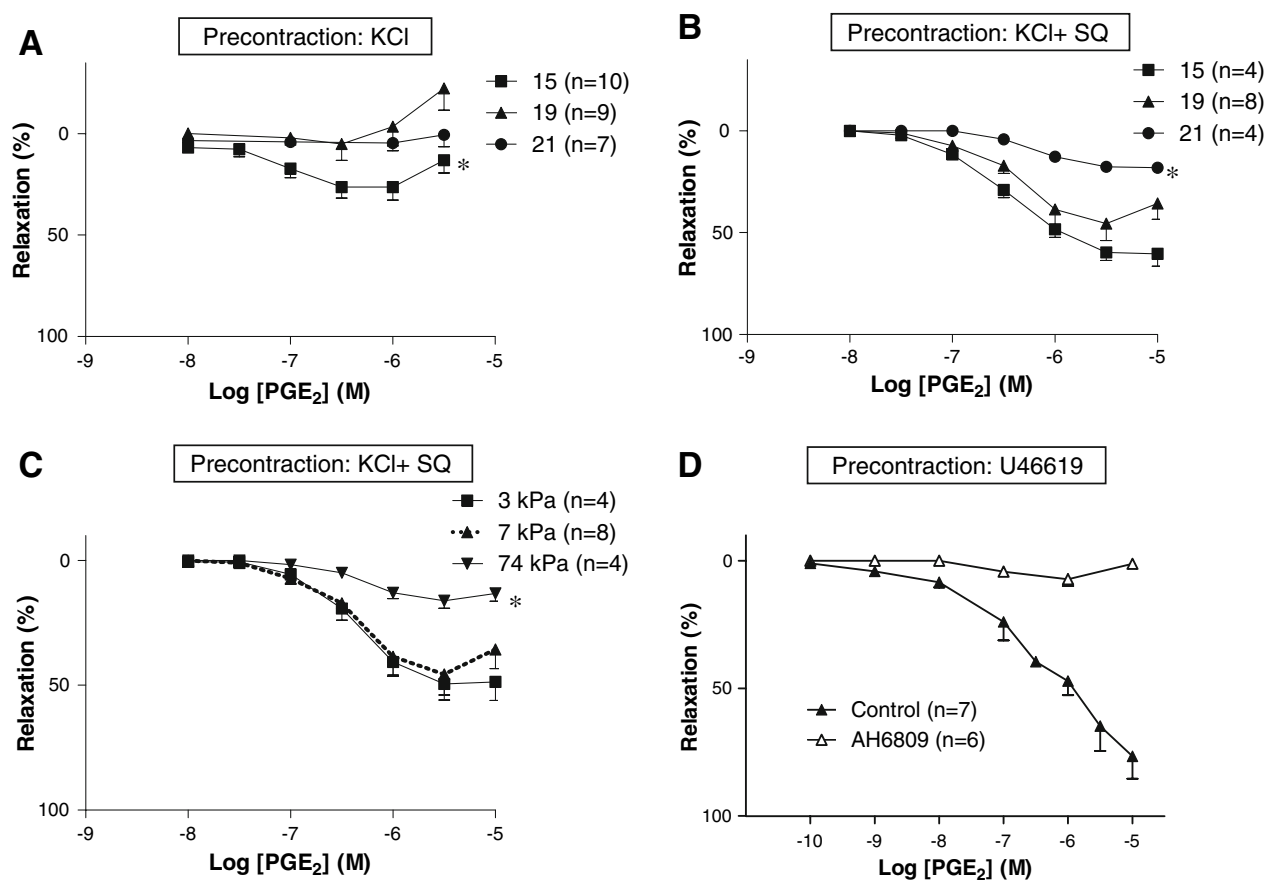

Fig. 2 Concentration-dependent relaxant effects of prostaglandin $E_{2}$ $\left(\mathrm{PGE}_{2}\right)$ ) in chicken DA during contraction induced by $\mathrm{K}^{+}(62.5 \mathrm{mM}$, a), $\mathrm{K}^{+}$in the presence of the TP receptor antagonist SQ 29,548 (b and c), or the TP receptor agonist $\mathrm{U} 46619(0.1 \mu \mathrm{M}, \mathbf{d})$. The organ chambers were areated with $5 \% \mathrm{O}_{2} / 90 \% \mathrm{~N}_{2} / 5 \% \mathrm{CO}_{2}(\mathbf{a}, \mathbf{b}, \mathbf{d})$. The effect of different oxygen concentrations on the relaxations induced by $\mathrm{PGE}_{2}$ in the 19-day DA is depicted in $\mathbf{c}$, in which the DA rings were aerated

with $0 \% \mathrm{O}_{2} / 95 \% \mathrm{~N}_{2} / 5 \% \mathrm{CO}_{2}$, or $95 \% \mathrm{O}_{2} / 5 \% \mathrm{CO}_{2}$. For clarity, the curve to $\mathrm{PGE}_{2}$ in $5 \% \mathrm{O}_{2}$ from panel $\mathrm{B}$ is repeated in $\mathbf{c}$ (dashed line). The effects of the EP receptor antagonist AH6809 $(10 \mu \mathrm{M})$ on $\mathrm{PGE}_{2^{-}}$ induced relaxation is depicted $\mathbf{d}$ (19-day DA). ${ }^{*} P<0.05$ for difference from the other ages $(\mathbf{a}, \mathbf{b})$ and for difference from other oxygen concentrations (c)

Table 1 Concentration-response parameters for relaxant substances in chicken ductus arteriosus

\begin{tabular}{|c|c|c|c|c|c|c|c|c|c|}
\hline & \multicolumn{3}{|l|}{ 15-day-old } & \multicolumn{3}{|l|}{ 19-day-old } & \multicolumn{3}{|c|}{ 21-day-old, e.p. } \\
\hline & $E_{\max }$ & $\mathrm{pD}_{2}$ & $n$ & $E_{\max }$ & $\mathrm{pD}_{2}$ & $n$ & $E_{\max }$ & $\mathrm{pD}_{2}$ & $n$ \\
\hline $\mathrm{PGE}_{2}$ & $29.79(20.1)$ & $7.15(0.43)$ & 10 & $5.06(24.0)$ & - & 9 & $4.7(8.1)$ & - & 7 \\
\hline $\mathrm{PGE}_{2}(\mathrm{SQ})$ & $64.14(11.5)$ & $6.45(0.21)$ & 4 & $46.89(24.5)$ & $6.36(0.06)$ & 8 & $18.27(3.7)^{*}$ & $6.19(0.15)$ & 4 \\
\hline Isoproterenol & $120.7(25.2)$ & $6.63(0.31)^{\dagger}$ & 8 & $107.3(23.8)$ & $7.03(0.46)$ & 29 & $64.0(15.3)^{*}$ & $6.99(0.26)$ & 12 \\
\hline Forskolin & $97.2(9.5)$ & $5.59(0.09)$ & 8 & $124.6(37.5)$ & $5.58(0.28)$ & 7 & $111.7(21.3)$ & $5.44(0.05)$ & 8 \\
\hline Milrinone & $75.12(10.1)$ & $5.4(0.14)^{\ddagger}$ & 6 & $86.31(9.8)$ & $6.0(0.15)$ & 8 & $86.16(19.4)$ & $6.06(0.18)$ & 8 \\
\hline
\end{tabular}

Values are means (SD); $n=$ no. of embryos (arteries), e.p. externally pipped embryos; $\mathrm{pD}_{2}=-\log \mathrm{EC}_{50} ; E_{\max }$, maximal relaxant effect. The $\mathrm{pD}_{2}$ was not calculated when a non-significant relaxation was observed

$* P<0.05$ from both 15 and 19 -day old; ${ }^{\dagger} P<0.05$ from 19 -day old; ${ }^{\ddagger} P<0.05$ for 19 and 21 -day old $\left(5 \% \mathrm{O}_{2}\right.$ and precontraction with $62.5 \mathrm{mM}$ $\mathrm{KCl})$

38, $n=6$; aortic: $792 \mu \mathrm{m}$, SD 49, $n=6$ ). As shown in Fig. $4 \mathrm{a}$, the relaxation induced by $\mathrm{PGE}_{2}$ (vessels were contracted with $62.5 \mathrm{mM} \mathrm{K}^{+}$in the presence of SQ29,548) was similar in both sides of the DA. In contrast, the relaxing potency and efficacy of isoproterenol (Fig. 4b) was significantly higher $(P<0.05)$ in the pulmonary $\left(\mathrm{pD}_{2} 7.71, \mathrm{SD}\right.$ $\left.0.26, E_{\max } 117.95 \%, \mathrm{SD} 8.3, n=6\right)$ than in the aortic side $\left(\mathrm{pD}_{2} 7.37, \mathrm{SD} 0.15 ; E_{\max } 72.77 \%\right.$, SD 3.1, $\left.n=6\right)$. Forskolin (Fig. 4c) also induced a higher relaxation in the pulmonary than in the aortic side of the 19-day DA, but significant differences were only observed with the highest concentra- tion tested $(10 \mu \mathrm{M})$. Similarly to isoproterenol, the relaxing potency and efficacy of milrinone (Fig. 4d) was significantly $(P<0.05)$ higher in the pulmonary $\left(\mathrm{pD}_{2} 5.96\right.$, SD $\left.0.16, E_{\max } 80.2 \%, \mathrm{SD} 9.8, n=6\right)$ than in the aortic side $\left(\mathrm{pD}_{2}\right.$ 5.0, SD 0.16; $E_{\max } 59.2 \%$, SD 14, $n=4$ ). The effects of milrinone were also studied in the 15-day DA and a similar significantly higher relaxation was observed in the pulmonary $\left(\mathrm{pD}_{2} 5.4, \mathrm{SD} 0.18, E_{\max } 77.1 \%, \mathrm{SD} 9.4, n=6\right)$ than in the aortic side $\left(\mathrm{pD}_{2} 4.9, \mathrm{SD} 0.17, E_{\max } 47.2 \%, \mathrm{SD} 11\right.$, $n=6$ ). Finally, as shown in Fig. $4 \mathrm{e}$, the contractile potency and efficacy of U46619 was also significantly higher 
Fig. 3 Concentration-dependent relaxant effects of isoproterenol $(\mathbf{a}, \mathbf{b})$, forskolin $(\mathbf{c}, \mathbf{d})$ and milrinone (e) in 15,19 and 21 day DA rings aerated with $5 \%$ $\mathrm{O}_{2} / 90 \% \mathrm{~N}_{2} / 5 \% \mathrm{CO}_{2}$. The effects of the $\beta$-adrenergic receptor blocker propanolol (prop) on isoproterenol-evoked relaxation are shown in $\mathbf{a}$. b, $\mathbf{d}$ Depict the effects of the nonselective COX inhibitor indomethacin $(10 \mu \mathrm{M})$, the COX-1 inhibitor valeryl salicylate (Val. salic., $0.5 \mathrm{mM}$ ), or the COX-2 inhibitor nimesulide $(0.1 \mu \mathrm{M})$ on the relaxations induced by isoproterenol (b) and forskolin (d) in 19-day DA.

Potassium (62.5 mM) was used as precontractile agent.

$* P<0.05$ for difference in $E_{\max }$ from the other ages. $\neq P<0.05$ for difference in $E_{\max }$ from 19 day. $\dagger P<0.05$ for difference in $\mathrm{pD}_{2}$ from the other ages
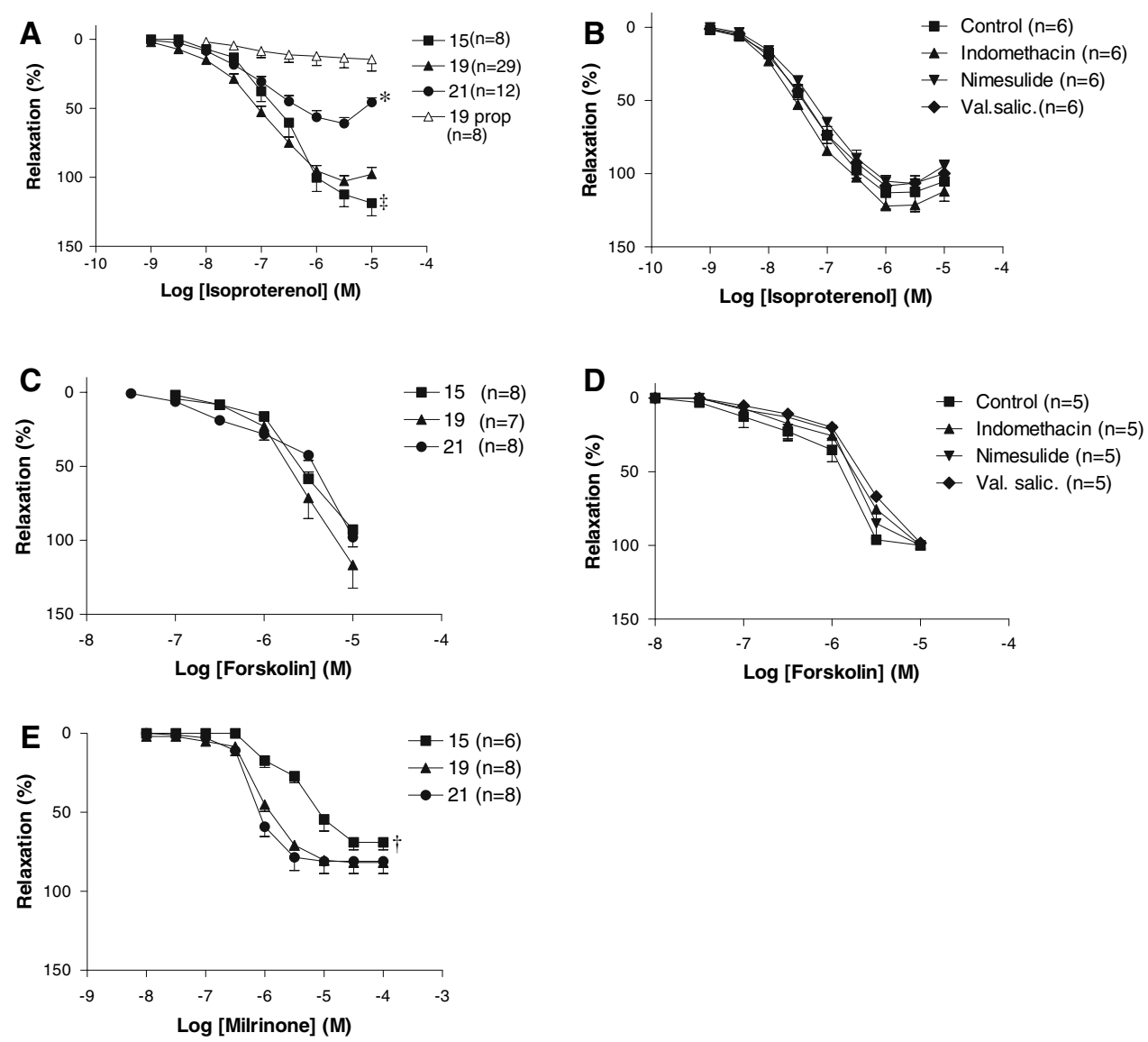

$(P<0.05)$ in the pulmonary than in the aortic side of the 19-day (pulmonary: $\mathrm{pD}_{2} 6.52, \mathrm{SD} 0.15, E_{\max } 1.58 \mathrm{~N} / \mathrm{m}, \mathrm{SD}$ $0.61, n=6$; aortic: $\mathrm{pD}_{2} 6.1$, SD $0.13, E_{\max } 0.34 \mathrm{~N} / \mathrm{m}$, SD $0.18, n=6$ ) and the 15-day (pulmonary: $\mathrm{pD}_{2} 6.84$, SD $0.185, E_{\max } 0.33 \mathrm{~N} / \mathrm{m}$, SD $0.24, n=6$; aortic: $\mathrm{pD}_{2} 5.3$, SD 0.16, $E_{\max } 0.08 \mathrm{~N} / \mathrm{m}, \mathrm{SD} 0.06, n=6$ ) chicken DA.

\section{Discussion}

$\mathrm{PGE}_{2}$ plays a major role in prenatal patency and postnatal closure of the mammalian DA, namely during fetal life by exerting a potent relaxant effect (Clyman 2006; Smith 1998), possibly in conjunction with nitric oxide (NO, Coceani et al. 1994; Momma and Toyono 1999; Seidner et al. 2001; Takizawa et al. 2000), and after birth by abruptly withdrawing its action. We have previously shown that the transition to ex ovo life is accompanied by dramatic changes in chicken DA reactivity (Agren et al. 2007, 2008). In the present paper, we have characterized, for the first time, the effects of $\mathrm{PGE}_{2}$ and other drugs acting through the adenylate cyclase/cAMP pathway on chicken ductal tone. Our main findings are: (1) $\mathrm{PGE}_{2}$ induced an EP receptormediated relaxation of the chicken DA that was partially or wholly masked by a simultaneous contractile effect medi- ated through TP receptors; (2) the relaxant responses induced by $\mathrm{PGE}_{2}$ and the $\beta$-adrenoceptor agonist isoproterenol, but not those elicited by the adenylate cyclase activator forskolin or the PDE3 inhibitor milrinone, decreased with maturation, (3) relaxations to $\mathrm{PGE}_{2}$ are decreased with increasing oxygen concentrations and (4) the effects of $\mathrm{PGE}_{2}$ were similar in the pulmonary and aortic sides of the DA, whereas isoproterenol and milrinone caused a more efficient relaxation in the pulmonary side of the chicken DA.

As mentioned elsewhere, COX inhibitors did not induce significant changes in the basal tension of the chicken (Agren et al. 2007) or the emu (Dzialowski and Greyner 2008) DA and did not alter the vasoactive effects of other agonists in the chicken DA (Agren et al. 2007, 2008), suggesting that locally produced PGs are not important mediators in the control of ductal tone in these avian species. However, Dzialowski and Greyner (2008) observed that exogenous $\mathrm{PGE}_{2}$ relaxed the oxygen-constricted emu DA with a threshold concentration of $0.1-1 \mu \mathrm{M}$ and a full relaxation at $10 \mu \mathrm{M}$, the highest concentration tested. In the present paper, we demonstrate that exogenous $\mathrm{PGE}_{2}$ is indeed a DA vasodilator in the chicken but its relaxant response is masked by its ability to activate TP receptors. We found that TP receptor occupancy either by an agonist 
Fig. 4 Heterogeneity of relaxant and contractile responses along chicken ductus arteriosus (DA). Response of segments from the pulmonary and aortic side of 19-day chicken DA to $\mathrm{PGE}_{2}(\mathbf{a})$, isoproterenol (b), and forskolin (c), milrinone (d), and U46619 (e). The responses to milrinone and U46619 in the pulmonary and aortic side of 15 day chicken DA are also shown. Relaxations were studied during contraction induced by $\mathrm{K}^{+}$ (62.5 mM). The TP receptor antagonist SQ 29,548 $(10 \mu \mathrm{M})$ was present in the experiments involving $\mathrm{PGE}_{2}$. The vessels were aerated with $5 \% \mathrm{O}_{2} /$ $90 \% \mathrm{~N}_{2} / 5 \% \mathrm{CO}_{2}\left(\mathrm{pO}_{2} \sim 7 \mathrm{kPa}\right)$. $* P<0.05$ for difference in $E_{\max }$ aortic versus pulmonary side. $\$ P<0.05$ for difference in the response to a given concentration. $\dagger P<0.05$ for difference in $\mathrm{pD}_{2}$ aortic versus pulmonary side
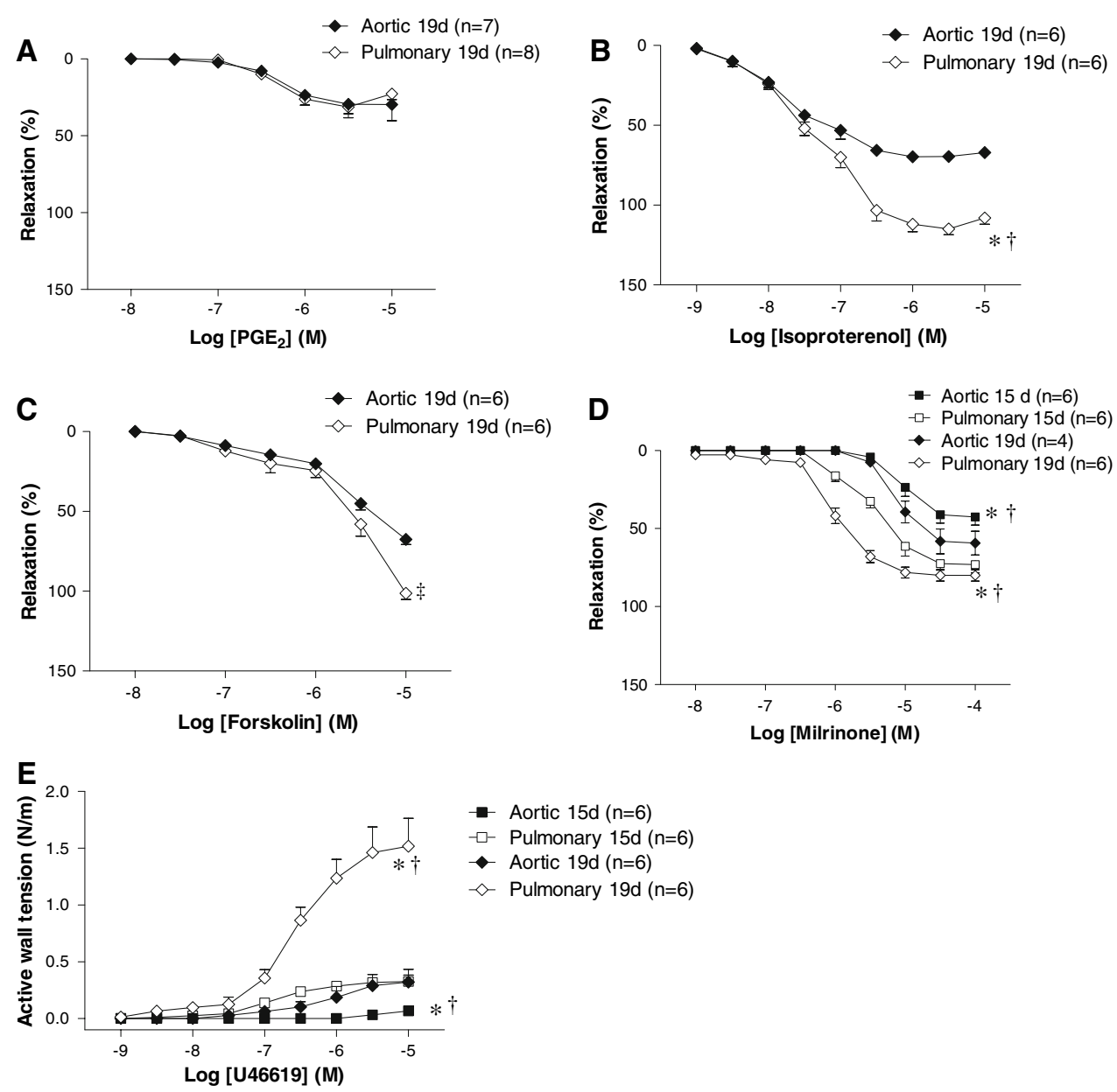

(U46619) or an antagonist (SQ29,548) results in the appearance or the increase of the relaxant response to $\mathrm{PGE}_{2}$. This is consistent with a stimulatory action of $\mathrm{PGE}_{2}$ on TP receptors. The $\mathrm{PGE}_{2}$ promiscuous interaction with TP receptors, especially at concentrations higher than $1 \mu \mathrm{M}$, has also been observed in several vascular tissues including human umbilical arteries (Boersma et al. 1999) and veins (Daray et al. 2003), human uterine arteries (Baxter et al. 1995) and aorta of the spontaneously hypertensive rat (Tang et al. 2008). An alternative explanation for the effects of $\mathrm{SQ} 29,548$ on $\mathrm{PGE}_{2}$-induced relaxation might be the blockade of a baseline $\mathrm{TxA}_{2}$ - or isoprostaneinduced tone (Gonzalez-Luis et al. 2005), allowing greater relaxatory actions of $\mathrm{PGE}_{2}$ on its dilatory receptors. However, this possibility is unlikely, since SQ29,548 have no effect on DA mechanical activity, suggesting the lack of basal release of a TP receptor stimulator.

$\mathrm{PGE}_{2}$-induced relaxation of the chicken DA was abolished by AH6809 suggesting the involvement of EP receptors. However, AH6809 is a non selective EP receptor antagonist, which may also block DP and TP receptors (Tang et al. 2008). Accordingly, we observed that AH6809 impaired the contraction induced by U46619. Future func- tional experiments with more selective EP antagonists, as well as investigations addressing the expression and binding activity of prostanoid receptors in the chicken DA are, therefore, warranted. Nevertheless, we observed that the relaxant potency and efficacy of $\mathrm{PGE}_{2}$ in the chicken DA, even after blocking its effect on the TP receptor, was very low. Dzialowski and Greyner (2008) also described a low relaxant potency of $\mathrm{PGE}_{2}$ in the emu DA. In contrast, $\mathrm{PGE}_{1}$ and $\mathrm{PGE}_{2}$ in the picomolar and low nanomolar range relaxed the rat, rabbit, pig and lamb DA (Bhattacharya et al. 1999; Clyman et al. 1983, 1980; Smith 1998; Waleh et al. 2004), while the only mammalian species studied where PGs have not been shown to exert a significant DA relaxation is the guinea pig (Bodach et al. 1980; Smith 1998). With our present results we can only speculate about the functional consequences of the low relaxant potency of $\mathrm{PGE}_{2}$ in the chicken DA. In the mammalian fetus, circulating concentrations of $\mathrm{PGE}_{2}$ appear to be of placental origin (Clyman 2006). To the best of our knowledge, there is no study in the literature examining prostanoids levels in avian embryos or the role of the choriallantoic membrane, the analogous of mammalian placenta, in the production of prostaglandins. These issues remain to be investigated. 
In mammals, the immature fetal DA is more sensitive than the late-gestation fetal DA to the relaxing effects of PGE $_{2}$ (Bhattacharya et al. 1999; Clyman et al. 1983, 1980; Waleh et al. 2004). Herein, we have found that chicken DA is more sensitive to $\mathrm{PGE}_{2}$ in preterm than in term. The activation of TP receptors by $\mathrm{PGE}_{2}$ is, at least partially, responsible for these changes with age. Thus, in the absence of TP antagonist a relaxant response is observed in the 15-day DA, whereas no relaxation, but contraction, is found in the 19-day DA. However, in the presence of the TP antagonist the relaxant responses to $\mathrm{PGE}_{2}$ are similar in 15 and 19 days. These results indicate that the contribution of TP receptor activation in the response to $\mathrm{PGE}_{2}$ increases during maturation. Accordingly, we have previously demonstrated a developmental increase in the sensitivity of chicken DA to the specific TP agonist U46619 (Agren et al. 2007). In addition, from 19- to 21-day there is an additional reduction in the relaxant responses to $\mathrm{PGE}_{2}$ when $\mathrm{SQ} 29,548$ is present (i.e., independent of TP receptor activation). Similar to $\mathrm{PGE}_{2}$, the $\beta$-adrenoceptor agonist isoproterenol induced less relaxation in 21-day when compared with 15- or 19day DA. $\mathrm{PGE}_{2}$ and isoproterenol induced relaxation, at least partially, through the adenylate cyclase/cAMP pathway. Therefore, our results suggest a developmental decrease in the relaxant efficacy of this pathway during the transition to ex ovo life. Nevertheless, direct activation of adenylate cyclase with forskolin induced a similar relaxation at all stages of incubation. Thus, the developmental differences in the responses to $\mathrm{PGE}_{2}$ and isoproterenol from 19- to 21-day seem to be due to changes in the coupling between their receptors and adenylate cyclase. Accordingly, Waleh et al. (2004) found that the EP receptor agonists $\mathrm{PGE}_{2}$ (nonselective), butaprost $\left(\mathrm{EP}_{2}\right.$ selective) and $\mathrm{M} \& \mathrm{~B} 28767$ ( $\mathrm{EP}_{3}$ selective) produced a greater increase in cAMP production in the immature than in the mature lamb DA. However, there were no differences between the immature and mature ductus in the relaxation or cAMP production induced by forskolin (Waleh et al. 2004). In the emu, the other avian DA that has been studied, Dzialowski and Greyner found similar $\mathrm{PGE}_{2}$-relaxations in the day 45 and day 49 DA (total incubation in the emu: 50 days) (Dzialowski and Greyner 2008). Unfortunately, they did not analyze the response to $\mathrm{PGE}_{2}$ of the DA of less mature emu ductus.

The role of $\beta$-adrenoceptors in the control of mammalian DA tone also varies among species (Smith 1998). Infusion of the $\beta$-adrenoceptor antagonist propanolol had no effect on ductal tone in the in vivo lamb (Friedman et al. 1983). Furthermore, in the presence of the $\alpha$-adrenoceptor antagonist phenoxybenzamine, norepinephrine was able to relax lamb DA preparations, but the effects were modest even at the highest doses (Bodach et al. 1980). In the newborn rat, propanolol paradoxically delayed DA closure (Arishima et al. 1995), but it has been suggested that this is secondary to the effects of $\beta$-adrenergic blockade on the perinatal cardiovascular homeostasis and not due to a direct effect on ductal tone (Smith 1998). On the other hand, in the guinea pig DA, phenoxybenzamine converts the contractile effect of norepinephrine to a relaxation and isoproterenol causes a marked relaxation (Bodach et al. 1980). These results together with the lack of a prostaglandin-mediated relaxation could point to a special role for $\beta$-adrenoceptors in prenatal patency in the guinea pig. Herein, we have observed a similar pattern in the chicken DA. Previously, we demonstrated that the nonselective adrenergic receptor agonist norepinephrine and the $\alpha_{1}$-adrenegic receptor agonist phenylephrine induced a developmentally increased contraction of the chicken DA. Secretion of catecholamines plays an important role in several of the adaptations that characterize the transition of the chicken to ex ovo life (Mulder et al. 2000; Wittmann and Prechtl 1991). The augmentation of the $\alpha$-adrenergic-mediated contraction and the concomitant reduction of the $\beta$-adrenergic-mediated relaxation suggest an active participation of catecholamines in the closure of the chicken DA.

The cyclic nucleotides cAMP and cGMP are considered the main intracellular secondary messengers involved in smooth muscle relaxation (Omori and Kotera 2007; Rybalkin et al. 2003). These molecules are degraded by a family of enzymes known as phosphodiesterases (PDEs). There are now known to be 11 different PDE families expressed in mammalian tissues. Depending on the species, the major PDEs present in vascular smooth muscle are PDE1, PDE3 and PDE5 (Moreno et al. 2004; Omori and Kotera 2007; Rybalkin et al. 2003). PDE3 s are termed cGMP-inhibited cAMP PDEs, whereas PDE5 specifically hydrolyzes cGMP (Moreno et al. 2004; Omori and Kotera 2007; Rybalkin et al. 2003). We have demonstrated that the chicken DA is relaxed by the PDE5 inhibitor sildenafil (Agren et al. 2008) and by the PDE3 inhibitor milrinone (present work). When clinically used in premature infants, it appeared that PDE3 inhibitors inhibited closure of the DA (Toyoshima et al. 2006). Toyoshima et al. (2006) demonstrated that the PDE3 inhibitors milrinone and amrinone exhibited dose-dependent DA-dilating effects in rat fetuses and pups and were more effective in the preterm than in the near-term period. Liu et al. (2008) observed, in the ovine DA, a developmental increase in the activity and expression of PDE1, 3, 4, and 5 and reported that the mature ductus required higher concentrations of PDE1, PDE3, and PDE4 inhibitors to inhibit its tension to the same extent as in the immature ductus. In contrast, we have observed a reduced relaxant effect of milrinone in the 15-day chicken DA when compared with the 19- or 21-day DA. This reduced response to milrinone in the 15-day DA was homogeneously present when segments of the central part, the pulmonary end or the 
aortic end of the DA were analyzed (see below). Our results might suggest that an increase in PDE3-mediated cAMP hydrolysis is involved in the age-related decrease of $\mathrm{PGE}_{2}$ and isoproterenol-induced relaxation observed in the chicken DA. However, if that was the case, the relaxation induced by forskolin should also have exhibited a reduction with maturation.

Another observation of the present work was that hyperoxia markedly impaired $\mathrm{PGE}_{2}$-induced relaxation. Previously, we reported that high oxygen concentrations decreased the endothelium- dependent and -independent relaxation induced by, respectively, acetylcholine and the nitric oxide donor, sodium nitroprusside and increased the contraction mediated by adrenergic agonists (Agren et al. 2007, 2008). Accordingly, it has been demonstrated that increasing oxygen tension from fetal to neonatal levels desensitizes the rabbit DA to a range of vasodilators, including $\mathrm{PGE}_{2}$ (Smith and McGrath 1991, 1993). Thus the postnatal increase in $\mathrm{O}_{2}$ is not only one of the main triggers for constriction of the DA but also has a profound modulatory effect on other vasoactive systems favoring the action of vasoconstrictors and decreasing the action of vasodilators (Smith 1998).

The chicken DA presents morphological and functional heterogeneity along its path between the pulmonary artery and the aorta (Agren et al. 2007; Belanger et al. 2008; Bergwerff et al. 1999, 1996). Thus, the pulmonary side shows the structure of a muscular artery and responds to $\mathrm{O}_{2}$ with contraction, whereas the aortic part shows the morphology of an elastic artery and relaxes in response to $\mathrm{O}_{2}$ (Agren et al. 2007; Belanger et al. 2008; Bergwerff et al. 1999, 1996). In addition, acetylcholine, SNP and the NOindependent stimulator of sGC BAY 41-2272 induced larger relaxations in the aortic side of the vessel (Agren et al. 2008). In the present work, we observed that isoproterenol, forskolin, and milrinone evoked significantly larger relaxations in the pulmonary than in the aortic side of the chicken DA. This might indicate that the pulmonary side of the vessel is more sensitive to the vasodilators acting through cAMP, whereas the aortic side would be more sensitive to cGMP-mediated relaxation. However, and surprisingly, the relaxation evoked by $\mathrm{PGE}_{2}$ was similar in both regions of the DA. We can only speculate about the nature of this finding. As the contraction induced by the TP receptor agonist U46619 was significantly higher in the pulmonary side, the masking effect of $\mathrm{PGE}_{2}$-induced $\mathrm{TP}$ stimulation might be smaller in the aortic than in the pulmonary side. However, the experiments were performed in the presence of TP antagonism. Another speculation might be that cAMP-mediated mechanisms are less involved in the relaxation evoked by $\mathrm{PGE}_{2}$ in the aortic side. In fact, it has been demonstrated that $\mathrm{PGE}_{2}$ dilates the late gestation fetal lamb DA through pathways that involve either cAMP (via $\mathrm{EP}_{2}$ and $\mathrm{EP}_{4}$ receptors) or ATP-dependent potassium channels (via EP3, Bouayad et al. 2001). However, in the experiments that compared the pulmonary and the aortic side of the chicken DA, the vessels were contracted with a high potassium solution which precluded the relaxation induced by potassium channels activation.

The heterogeneity of the chicken DA makes the vessel particularly attractive for the study of its developmental vascular biology but also poses a methodological problem. As we mentioned elsewhere, the maximal length of the rings allowed in the myographs that we used is $2 \mathrm{~mm}$, whereas the length of the chicken DA is $\sim 4-6 \mathrm{~mm}$. Although the pulmonary and the aortic side of the ductus can be clearly differentiated during the dissection (Agren et al. 2007), when mounting the central portion of the DA it is difficult to control for the exact amount of tissue of each part that is finally present in the myograph. In addition, putative developmental changes in the proportion between the two parts of the DA, might influence developmental changes in the responsiveness to the different agonists. This limitation of our experimental setting was particularly relevant when the response to milrinone was analyzed. We observed that milrinone-induced relaxation increased with development but also was higher in the pulmonary than in the aortic side of the DA. Therefore the reduced relaxation in the 15-day DA could be related to the presence of higher amounts of tissue from the aortic side of the vessel. We controlled for this possibility by analyzing the response to milrinone in the pulmonary and aortic sides of the 15-day DA and we observed that the developmental increase was present in both sides of the vessel.

In summary, with the present and our previous studies (Agren et al. 2007, 2008), we have completed an extensive characterization of the pharmacology of the chicken DA and demonstrated its sensitivity to a wide range of vasoactive agonists including oxygen, prostanoids, potassium channels blockers, NO, catecholamines, endothelin-1, adenylate cyclase activators, guanylate cyclase activators and PDE inhibitors. As occurs in the mammalian, the multiplicity of these vasoactive systems seems at odds with the relatively simple physiological role of the DA (Smith 1998). The main vasoconstrictor of the mammalian DA, the postnatal increase in oxygen tension, appears to play also a relevant role in the closure of the chicken DA (Agren et al. 2007; Belanger et al. 2008), whereas the main vasodilator of the mammalian DA, $\mathrm{PGE}_{2}$, is a weak relaxant agent of the chicken DA which even stimulates vasoconstrictive receptors. As the mammalian DA, the chicken DA undergoes a process of maturation to prepare the task of postnatal closure. Due to the above similarities and taking into account the differences, the chicken embryo appears as an extremely interesting model for translational developmental vascular biology (Sutendra and Michelakis 2007). 
Ackowledgments This work was partially supported by a Grant from "Fundación de Investigación Médica Mutua Madrileña".

Open Access This article is distributed under the terms of the Creative Commons Attribution Noncommercial License which permits any noncommercial use, distribution, and reproduction in any medium, provided the original author(s) and source are credited.

\section{References}

Agren P, Cogolludo AL, Kessels CG, Perez-Vizcaino F, De Mey JG, Blanco CE, Villamor E (2007) Ontogeny of chicken ductus arteriosus response to oxygen and vasoconstrictors. Am J Physiol Regul Integr Comp Physiol 292:R485-R496

Agren P, van der Sterren S, Cogolludo AL, Frazziano G, de Mey JG, Blanco CE, Villamor E (2008) Developmental changes in endothelium-dependent relaxation of the chicken ductus arteriosus. J Physiol Pharmacol 59:55-76

Arishima K, Takizawa T, Oda T, Yamamoto M, Togashi H, Somiya H, Eguchi Y (1995) Propranolol inhibits the spontaneous closure of the ductus arteriosus in newborn rats. J Vet Med Sci 57:943-944

Baxter GS, Clayton JK, Coleman RA, Marshall K, Sangha R, Senior J (1995) Characterization of the prostanoid receptors mediating constriction and relaxation of human isolated uterine artery. Br J Pharmacol 116:1692-1696

Belanger C, Copeland J, Muirhead D, Heinz D, Dzialowski EM (2008) Morphological changes in the chicken ductus arteriosi during closure at hatching. Anat Rec (Hoboken)

Bergwerff M, DeRuiter MC, Gittenberger-de Groot AC (1999) Comparative anatomy and ontogeny of the ductus arteriosus, a vascular outsider. Anat Embryol (Berl) 200:559-571

Bergwerff M, DeRuiter MC, Poelmann RE, Gittenberger-de Groot AC (1996) Onset of elastogenesis and downregulation of smooth muscle actin as distinguishing phenomena in artery differentiation in the chick embryo. Anat Embryol (Berl) 194:545-557

Bhattacharya M, Asselin P, Hardy P, Guerguerian AM, Shichi H, Hou X, Varma DR, Bouayad A, Fouron JC, Clyman RI, Chemtob S (1999) Developmental changes in prostaglandin E(2) receptor subtypes in porcine ductus arteriosus. Possible contribution in altered responsiveness to prostaglandin $\mathrm{E}(2)$. Circulation 100:1751-1756

Bodach E, Coceani F, Dumbrille A, Okpako DT, Olley PM (1980) The response of the isolated ductus arteriosus to transmural stimulation and drugs. Br J Pharmacol 71:419-427

Boersma JI, Janzen KM, Oliveira L, Crankshaw DJ (1999) Characterization of excitatory prostanoid receptors in the human umbilical artery in vitro. Br J Pharmacol 128:1505-1512

Bouayad A, Kajino H, Waleh N, Fouron JC, Andelfinger G, Varma DR, Skoll A, Vazquez A, Gobeil F Jr, Clyman RI, Chemtob S (2001) Characterization of PGE2 receptors in fetal and newborn lamb ductus arteriosus. Am J Physiol Heart Circ Physiol 280:H2342-H2349

Chand N, Eyre P (1976) Effects of prostaglandins E1, E2 and F2 alpha and polyphloretin phosphate of domestic fowl. Arch Int Pharmacodyn Ther 221:261-265

Claeys M, Wechsung E, Herman AG, Nugteren DH (1981) Prostaglandin E2 is the prevalent metabolite of arachidonic acid formed by aortic tissue of the chicken. Arch Int Pharmacodyn Ther 249:312315

Clyman RI (2006) Mechanisms regulating the ductus arteriosus. Biol Neonate 89:330-335

Clyman RI, Mauray F, Roman C, Heymann MA, Payne B (1983) Effect of gestational age on ductus arteriosus response to circulating prostaglandin E2. J Pediatr 102:907-911
Clyman RI, Mauray F, Rudolph AM, Heymann MA (1980) Agedependent sensitivity of the lamb ductus arteriosus to indomethacin and prostaglandins. J Pediatr 96:94-98

Coceani F, Kelsey L, Seidlitz E (1994) Occurrence of endothelium-derived relaxing factor-nitric oxide in the lamb ductus arteriosus. Can J Physiol Pharmacol 72:82-88

Daray FM, Minvielle AI, Puppo S, Rothlin RP (2003) Pharmacological characterization of prostanoid receptors mediating vasoconstriction in human umbilical vein. Br J Pharmacol 139:1409-1416

Dzialowski EM, Greyner H (2008) Maturation of the contractile response of the Emu ductus arteriosus. J Comp Physiol 178:401-412

Friedman WF, Printz MP, Kirkpatrick SE, Hoskins EJ (1983) The vasoactivity of the fetal lamb ductus arteriosus studied in utero. Pediatr Res 17:331-337

Gonzalez-Luis G, Perez-Vizcaino F, Garcia-Munoz F, de Mey JG, Blanco CE, Villamor E (2005) Age-related differences in vasoconstrictor responses to isoprostanes in piglet pulmonary and mesenteric vascular smooth muscle. Pediatr Res 57:845-852

Kajino H, Taniguchi T, Fujieda K, Ushikubi F, Muramatsu I (2004) An EP4 receptor agonist prevents indomethacin-induced closure of rat ductus arteriosus in vivo. Pediatr Res 56:586-590

Leonhardt A, Glaser A, Wegmann M, Schranz D, Seyberth H, Nusing R (2003) Expression of prostanoid receptors in human ductus arteriosus. Br J Pharmacol 138:655-659

Liu H, Manganiello V, Waleh N, Clyman RI (2008) Expression, activity and function of phosphodiesterases in the mature and immature ductus arteriosus. Pediatric research

Momma K, Toyono M (1999) The role of nitric oxide in dilating the fetal ductus arteriosus in rats. Pediatr Res 46:311-315

Moreno L, Losada B, Cogolludo A, Lodi F, Lugnier C, Villamor E, Moro M, Tamargo J, Perez-Vizcaino F (2004) Postnatal maturation of phosphodiesterase 5 (PDE5) in piglet pulmonary arteries: activity, expression, effects of PDE5 inhibitors, and role of the nitric oxide/cyclic GMP pathway. Pediatr Res 56:563-570

Mulder AL, Golde JM, Goor AA, Giussani DA, Blanco CE (2000) Developmental changes in plasma catecholamine concentrations during normoxia and acute hypoxia in the chick embryo. J Physiol 527(Pt 3):593-599

Narumiya S, FitzGerald GA (2001) Genetic and pharmacological analysis of prostanoid receptor function. J Clin Invest 108:25-30

Nguyen M, Camenisch T, Snouwaert JN, Hicks E, Coffman TM, Anderson PA, Malouf NN, Koller BH (1997) The prostaglandin receptor EP4 triggers remodelling of the cardiovascular system at birth. Nature 390:78-81

Omori K, Kotera J (2007) Overview of PDEs and their regulation. Circ Res 100:309-327

Rowley A (1991) Eicosanoids: aspects of their structure, function, and evolution. In: Warr G, Cohen N (eds) The phylogenesis of immune functions. CRC Press, Boca Ration, pp 269-294

Rybalkin SD, Yan C, Bornfeldt KE, Beavo JA (2003) Cyclic GMP phosphodiesterases and regulation of smooth muscle function. Circ Res 93:280-291

Seidner SR, Chen YQ, Oprysko PR, Mauray F, Tse MM, Lin E, Koch C, Clyman RI (2001) Combined prostaglandin and nitric oxide inhibition produces anatomic remodeling and closure of the ductus arteriosus in the premature newborn baboon. Pediatr Res 50:365-373

Smith GC (1998) The pharmacology of the ductus arteriosus. Pharmacol Rev 50:35-58

Smith GC, Coleman RA, McGrath JC (1994) Characterization of dilator prostanoid receptors in the fetal rabbit ductus arteriosus. J Pharmacol Exp Ther 271:390-396

Smith GC, McGrath JC (1991) Prostaglandin E2 and fetal oxygen tension synergistically inhibit response of isolated fetal rabbit ductus arteriosus to norepinephrine. J Cardiovasc Pharmacol 17:861866 
Smith GC, McGrath JC (1993) Characterisation of the effect of oxygen tension on response of fetal rabbit ductus arteriosus to vasodilators. Cardiovasc Res 27:2205-2211

Smith GC, McGrath JC (1995) Contractile effects of prostanoids on fetal rabbit ductus arteriosus. J Cardiovasc Pharmacol 25:113-118

Sutendra G, Michelakis ED (2007) The chicken embryo as a model for ductus arteriosus developmental biology: cracking into new territory. Am J Physiol Regul Integr Comp Physiol 292:R481-R484

Takizawa T, Kihara T, Kamata A, Yamamoto M, Arishima K (2000) Role of nitric oxide in regulating the ductus arteriosus caliber in fetal rats. J Vet Med Sci 62:707-710

Tang EH, Jensen BL, Skott O, Leung GP, Feletou M, Man RY, Vanhoutte PM (2008) The role of prostaglandin E and thromboxaneprostanoid receptors in the response to prostaglandin E2 in the aorta of Wistar Kyoto rats and spontaneously hypertensive rats. Cardiovasc Res 78:130-138

Toyoshima K, Momma K, Imamura S, Nakanishi T (2006) In vivo dilatation of the fetal and postnatal ductus arteriosus by inhibition of phosphodiesterase 3 in rats. Biol Neonate 89:251-256
Villamor E, Ruijtenbeek K, Pulgar V, De Mey JG, Blanco CE (2002) Vascular reactivity in intrapulmonary arteries of chicken embryos during transition to ex ovo life. Am J Physiol Regul Integr Comp Physiol 282:R917-R927

Waleh N, Kajino H, Marrache AM, Ginzinger D, Roman C, Seidner SR, Moss TJ, Fouron JC, Vazquez-Tello A, Chemtob S, Clyman RI (2004) Prostaglandin E2-mediated relaxation of the ductus arteriosus: effects of gestational age on g protein-coupled receptor expression, signaling, and vasomotor control. Circulation 110:2326-2332

Wideman RF Jr, Maynard P, Bottje WG (1999) Thromboxane mimics the pulmonary but not systemic vascular responses to bolus $\mathrm{HCl}$ injections in broiler chickens. Poult Sci 78:714-721

Wittmann J, Prechtl J (1991) Respiratory function of catecholamines during the late period of avian development. Respir Physiol $83: 375-386$ 


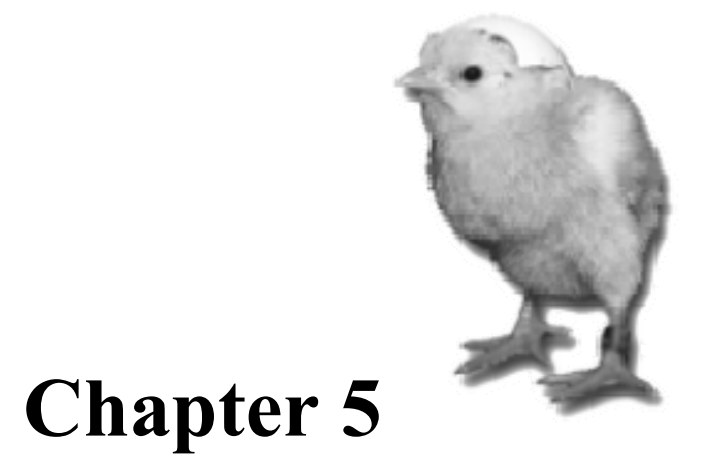

\section{RESPONSE OF CHICKEN DUCTUS ARTERIOSUS TO HYPERCARBIC AND NORMOCARBIC ACIDOSIS}

Rob M. Moonen, Pia Ågren, Angel L. Cogolludo, Francisco Pérez-Vizcaíno and Eduardo Villamor

Neonatology (in press) 


\title{
R.M.J Moonen ${ }^{1}$, P. Ågren ${ }^{1}$, A.L. Cogolludo ${ }^{2}$, F. Pérez-Viscaíno ${ }^{2}$, E. Villamor ${ }^{1}$ \\ RESPONSE OF CHICKEN DUCTUS ARTERIOSUS TO HYPERCARBIC AND NORMOCARBIS ACIDOSIS
}

\author{
${ }^{1}$ Department of Pediatrics, Maastricht University Medical Center (MUMC+), School for \\ Oncology and Developmental Biology (GROW), Maastricht, 6202 AZ, the Netherlands. \\ ${ }^{2}$ Department of Pharmacology, School of Medicine, Universidad Complutense, CIBER \\ Enfermedades Respiratorias (CibeRes), Madrid, 28040, Spain.
}

Background: Changes in $\mathrm{pH}$ can have profound effects on vascular tone and reactivity but its influence on the ductus arteriosus (DA) remains unknown.

Objective: To analyze the effects of hypercarbic and normocarbic acidosis on the reactivity of the chicken DA. Methods: DA rings from 19-d chicken fetuses (total incubation time, 21-d) were mounted in a wire myograph for isometric tension recording.

Results: In DA rings (pulmonary side) stimulated with $\mathrm{O}_{2}$, norepinephrine (NE), $\mathrm{KCl}$, or U46619 changes from control conditions $\left(5 \% \mathrm{CO}_{2}, 24 \mathrm{mM} \mathrm{NaHCO} 3, \mathrm{pH} 7.40\right)$ to $7.5 \% \mathrm{CO}_{2}(\mathrm{pH} 7.25)$ or $10 \% \mathrm{CO}_{2}(\mathrm{pH} 7.14)$ induced a concentration-dependent relaxation that reached $43.0 \%$ (SD 21.3) of the $\mathrm{O}_{2-}, 28.6 \%$ (SD 23.1) of the NE-, $10.4 \%$ (SD 18.7) of the KCl-, and 6.8\% (SD 12.6) of the U46619- induced contraction. Hypercarbic acidosis-induced relaxation was impaired by the non selective $\mathrm{K}^{+}$channel blocker tetraethylammonium or the $\mathrm{BK}_{\mathrm{Ca}}$ channel inhibitor iberiotoxin. Normocarbic acidosis $\left(5 \% \mathrm{CO}_{2}, 12 \mathrm{mM} \mathrm{NaHCO}_{3}, \mathrm{pH} 7.13\right)$ induced transient relaxation of the DA that was not affected by the presence of tetraethylammonium or iberiotoxin. Euhydric hypercarbia $\left(10 \% \mathrm{CO}_{2}, 48 \mathrm{mM}\right.$ $\mathrm{NaHCO}_{3}, \mathrm{pH} 7.46$ ) induced a transient contraction of the DA.

Conclusions: Our results indicate that the chicken DA is very sensitive to changes in extracellular $\mathrm{pH}$ and that stimulation of $\mathrm{BK}_{\mathrm{Ca}}$ channels may account for the ductal relaxing effects of hypercarbic acidosis.

Keywords: ductus arteriosus, acidosis, permissive hypercapnia, potassium channels. 


\section{INTRODUCTION}

Respiratory and metabolic acidosis are frequent events in the clinical course of very preterm infants (Woodgate and Davies 2001; Bancalari et al. 2005; Thome et al. 2006; Fabres et al. 2007; Jadhav et al. 2007; Miller and Carlo 2007; Sutendra and Michelakis 2007; Bouissou et al. 2008). Changes in $\mathrm{pH}$ can have profound influence on pulmonary and systemic vascular resistance and on the reactivity of the vessels to agonists. It is generally accepted that extracellular acidosis causes pulmonary arterial vasoconstriction, whereas it induces vasodilation in the systemic circulation. However, the experimental data on these effects are conflicting and extracellular acidosis has been reported to induce contraction, relaxation, or no effect in pulmonary and systemic vessels (Sweeney et al. 1998; Sweeney et al. 1999; Lynch et al. 2000; Hyvelin et al. 2004; Wray and Smith 2004). The effects of acidosis on the reactivity of the vessel that connects the pulmonary and the systemic circulation during fetal life, i.e. the ductus arteriosus (DA), have been scarcely studied. In one of the earliest studies on DA reactivity, Kovalcik (1963) reported that changing the $\mathrm{pH}$ of the Tyrode solution over the range $\mathrm{pH} 6$ to $\mathrm{pH} 8$ did not alter the response to $\mathrm{O}_{2}$ of DA rings from fetal guinea-pigs. Also, increasing the $\mathrm{CO}_{2}$ content of the gas passing through the Tyrode solution had no direct contractile effect but increased the ductal relaxation induced by hypoxia (Kovalcik 1963).

In the last years the chicken fetus has emerged as an excellent model for the study of DA vascular biology (Agren et al. 2007; Sutendra and Michelakis 2007; Agren et al. 2008; Belanger et al. 2008; Greyner and Dzialowski 2008; Agren et al. 2009; Cogolludo et al. 2009; Van der Sterren et al. 2009). Our group and another laboratory have characterized the developmental changes in the responsiveness of the chicken DA to $\mathrm{O}_{2}$ as well as other vasoactive agonists including prostaglandins, $\mathrm{NO}$ and catecholamines. In the present study we hypothesized that $\mathrm{pH}$ alterations over a clinically significant range would affect DA tone and responsiveness. Therefore, we analyzed the effects of in vitro hypercarbic and normocarbic acidosis on the reactivity of the chicken DA.

\section{METHODS}

Incubation of chicken embryos and vessel isolation.

Experiments were performed in accordance with Dutch law for animal experimentation. Fertilized eggs of White Leghorn chickens were incubated at $37.8^{\circ} \mathrm{C}, 45 \%$ humidity and rotated 
once per hour (Incubator model 25HS, Masalles Comercial, Spain). Embryos incubated for 19 days of the 21-day incubation period were studied. The 19-day were defined as non-internallypipped embryos, as verified by candling. The embryos were taken out, immediately killed by decapitation and a midline laparotomy and sternotomy were performed. With the aid of a dissecting microscope, the right and the left DA were carefully dissected free from surrounding tissue, severed distal to the takeoff of the right or left pulmonary artery and proximal to the insertion into the aorta, and divided in two segments referred to as pulmonary side and aortic side. The boundary between pulmonary and aortic side was determined based on the marked differences in diameter observed along the chicken DA (Agren et al. 2007; Van der Sterren et al. 2009).

\section{Recording of DA reactivity}

Two stainless steel wires (diameter $40 \mu \mathrm{m}$ ) were inserted into the lumen of the DA, which was mounted as a ring segment between an isometric force transducer and a displacement device in a myograph (Danish Myo Technology A/S model 610M, Aarhus, Denmark). The myograph organ

bath $\left(5 \mathrm{~mL}\right.$ vol) was filled with Krebs-Ringer bicarbonate (KRB, composition in $\mathrm{mmol} \mathrm{L}^{-1}: \mathrm{NaCl}$, 118.5; KCl, 4.75; $\mathrm{MgSO}_{4} \cdot 7 \mathrm{H}_{2} \mathrm{O}, 1.2 ; \mathrm{KH}_{2} \mathrm{PO}_{4}, 1.2 ; \mathrm{NaHCO}_{3}, 25.0 ; \mathrm{CaCl}_{2}, 2.5 ;$ glucose, 5.5.) buffer maintained at $39^{\circ} \mathrm{C}$. DA rings were normalized to a resting pretension corresponding to an intraluminal pressure of $20 \mathrm{mmHg}$. During the first phase of mounting and stabilization, DA rings were maintained in $\mathrm{KRB}$ buffer aerated with $0 \% \mathrm{O}_{2} / 95 \% \mathrm{~N}_{2} / 5 \% \mathrm{CO}_{2}\left(\mathrm{PO}_{2}=2.6-3.3 \mathrm{kPa}\right)$. Afterwards, the gas mixture was switched to $21 \% \mathrm{O}_{2} / 74 \% \mathrm{~N}_{2} / 5 \% \mathrm{CO}_{2}\left(\mathrm{PO}_{2}=16-20 \mathrm{kPa}\right)$. This change in oxygenation induced contraction in the pulmonary side and relaxation in the aortic side of the DA. In some experiments, the effects of hypercarbic and normocarbic acidosis were studied on the tone induced by $21 \% \mathrm{O}_{2}$. In other experiments a second contractile agonist was added in vessels already exposed to $21 \% \mathrm{O}_{2} . \mathrm{KCl}(62.5 \mathrm{mM})$, norepinephrine (NE; $\left.10 \mu \mathrm{M}\right)$, and the thromboxane $\mathrm{A}_{2}$ mimetic $\mathrm{U} 46619(1 \mu \mathrm{M})$ were the agonist used in these experiments.

\section{Hypercarbic acidosis, normocarbic acidosis and euhydric hypercarbia}

Hypercarbic acidosis was produced by switching the gas mixture from $21 \% \mathrm{O}_{2} / 74 \% \mathrm{~N}_{2} / 5 \% \mathrm{CO}_{2}$ (pH 7.40, SD 0.05, $\mathrm{n}=12$ ) to $21 \% \mathrm{O}_{2} / 71.5 \% \mathrm{~N}_{2} / 7.5 \% \mathrm{CO}_{2}(\mathrm{pH} 7.25$, SD $0.05, \mathrm{n}=10$ ) When 7.5\% $\mathrm{CO}_{2}$ induced a stable response (or after $5 \mathrm{~min}$ when no response was observed) a second switch 
to $21 \% \mathrm{O}_{2} / 69 \% \mathrm{~N}_{2} / 10 \% \mathrm{CO}_{2}(\mathrm{pH} 7.14, \mathrm{SD} 0.04, \mathrm{n}=10)$ was performed. Ten minutes later, the bath solution was returned to control conditions $\left(5 \% \mathrm{CO}_{2}\right)$. Normocarbic acidosis was induced by exchanging the standard KRB buffer to a $\mathrm{pH} 7.13$ (SD 0.05, $\mathrm{n}=10$ ) solution in which the concentration of $\mathrm{NaHCO}_{3}$ was reduced to $12 \mathrm{mmol} \mathrm{L}^{-1}$ (isosmotically replaced by $\mathrm{NaCl}$ ). Aeration with $21 \% \mathrm{O}_{2} / 74 \% \mathrm{~N}_{2} / 5 \% \mathrm{CO}_{2}$ was maintained during these experiments. Ten minutes later, the bath solution was returned to control conditions. Euhydric hypercarbia was induced by exchanging the standard KRB buffer for one containing $48 \mathrm{mmol} \mathrm{L}^{-1} \mathrm{NaHCO}_{3}$ (replacing $\mathrm{NaCl}$ isosmotically). This solution was gassed with $21 \% \mathrm{O}_{2} / 74 \% \mathrm{~N}_{2} / 10 \% \mathrm{CO}_{2}$, (pH 7.46, SD 0.07, $\mathrm{n}=10)$.

In order to asses the mechanisms involved in the response of the chicken DA to hypercarbic and normocarbic acidosis, some experiments were performed in the presence of the following pharmacological tools: the NO synthase (NOS) inhibitor N (G)-nitro-L- arginine methyl ester (L-NAME; $0.1 \mathrm{mM}$ ), the soluble guanylate cyclase (sGC) inhibitor $1 \mathrm{H}$ $[1,2,4]$ oxadiazolo[4,3-a]quinoxalin-1-one (ODQ, $10 \mu \mathrm{M})$, the sarco-endoplasmatic reticulum $\mathrm{Ca}^{2+}$-ATPase (SERCA) inhibitor thapsigargin $(2 \mu \mathrm{M})$, non selective $\mathrm{K}^{+}$channel inhibitor tetraethylammonium $(5 \mathrm{mM})$, the voltage-gated $\mathrm{K}^{+}$channel $\left(\mathrm{K}_{\mathrm{V}}\right)$ inhibitor 4-aminopyridine (4AP, $10 \mathrm{mM})$, the ATP-sensitive $\mathrm{K}^{+}$channel $\left(\mathrm{K}_{\mathrm{ATP}}\right)$ inhibitor glibenclamide $(10 \mu \mathrm{M})$, the largeconductance $\mathrm{Ca}^{2+}$-activated $\mathrm{K}^{+}$channel $\left(\mathrm{BK}_{\mathrm{Ca}}\right)$ inhibitor iberiotoxin $(100 \mathrm{nM})$, the intermediateconductance $\mathrm{K}_{\mathrm{Ca}}\left(\mathrm{IK}_{\mathrm{Ca}}\right)$ channel inhibitor TRAM-34 $(1 \mu \mathrm{M})$, and the small-conductance $\mathrm{K}_{\mathrm{Ca}}$ $\left(\mathrm{SK}_{\mathrm{Ca}}\right)$ channel inhibitor apamin $(50 \mathrm{nM})$.

In order to evaluate the effects of prolonged incubation under normocarbic acidosis on the responsiveness of the chicken DA to contractile and relaxing agonists, DA rings were incubated for $1 \mathrm{~h}$ in control or low bicarbonate $\left(12 \mathrm{mM} \mathrm{NaHCO}_{3}\right) \mathrm{KRB}$ (both solutions aerated with $\left.21 \% \mathrm{O}_{2} / 5 \% \mathrm{CO}_{2}\right)$ and concentration-response curves to $\mathrm{KCl}(31.25 \mathrm{mM}-125 \mathrm{mM}), \mathrm{NE}(1 \mathrm{nM}$ $10 \mu \mathrm{M}$ ), the NO donor sodium nitroprusside (SNP, $10 \mathrm{nM}-0.1 \mathrm{mM}$ ) and the adenylate cyclase activator forskolin $(10 \mathrm{nM}-10 \mu \mathrm{M})$ were constructed. The relaxing effects of SNP and forskolin were evaluated during the contraction induced by $\mathrm{KCl}(62.5 \mathrm{mM})$.

\section{Data analysis}

Results are shown as mean (SD) of measurements in $n$ animals. For clarity, results are shown in the figures as mean \pm SE. Contractions are expressed in terms of active wall tension $(\mathrm{N} / \mathrm{m})$, 
calculated as the force divided by twice the length of the segment, while the relaxant responses are expressed as the percentage of reduction of the contraction induced by $\mathrm{O}_{2}, \mathrm{NE}, \mathrm{KCl}$ or U46619. Differences between mean values were compared by ANOVA for repeated measures or by one-way ANOVA followed by Bonferroni post hoc test. Differences were considered significant at a $P<0.05$. All analyses were performed using a commercially available statistics package (GraphPad InStat version 3.00; GraphPad Software Inc, San Diego, CA, U.S.A.).

\section{Drugs and solutions}

Solutions containing different concentrations of $\mathrm{K}^{+}$were prepared by replacing part of the $\mathrm{NaCl}$ of the KRB buffer by an equimolar amount of $\mathrm{KCl}$. U46619 was obtained from Cayman Chemical (Ann Arbor, MI), and ODQ was from Tocris (Ballwin, MO). All the other drugs were obtained from Sigma (St. Louis, MO). All drugs were dissolved initially in distilled deionized water (except U46619, ODQ, and TRAM-34 that were dissolved in DMSO) to prepare adequate stock solutions and further dilutions were also made in deionized water. The final bath concentration of DMSO did not exceed $0.1 \%$, which we have found elsewhere to have little or no effect on mechanical activity (Agren et al. 2007).

\section{RESULTS}

The mean body-mass of the 19-day chicken embryos was $29.06 \mathrm{~g}$ (SD 2.23, $\mathrm{n}=98$ ). The mean diameter of the DA rings, under passive tension equivalent to $20 \mathrm{mmHg}$ transmural pressure, was $861 \mu \mathrm{m}(\mathrm{SD} 193, \mathrm{n}=94)$ for the pulmonary side and $915 \mu \mathrm{m}$ (SD 111, $\mathrm{n}=24)$ for the aortic side. Mean active wall tensions in response to $21 \% \mathrm{O}_{2}, \mathrm{NE}(10 \mu \mathrm{M}), \mathrm{KCl}(62.5 \mathrm{mM})$, and U46619 $(1 \mu \mathrm{M})$ are summarized in Table 1. 

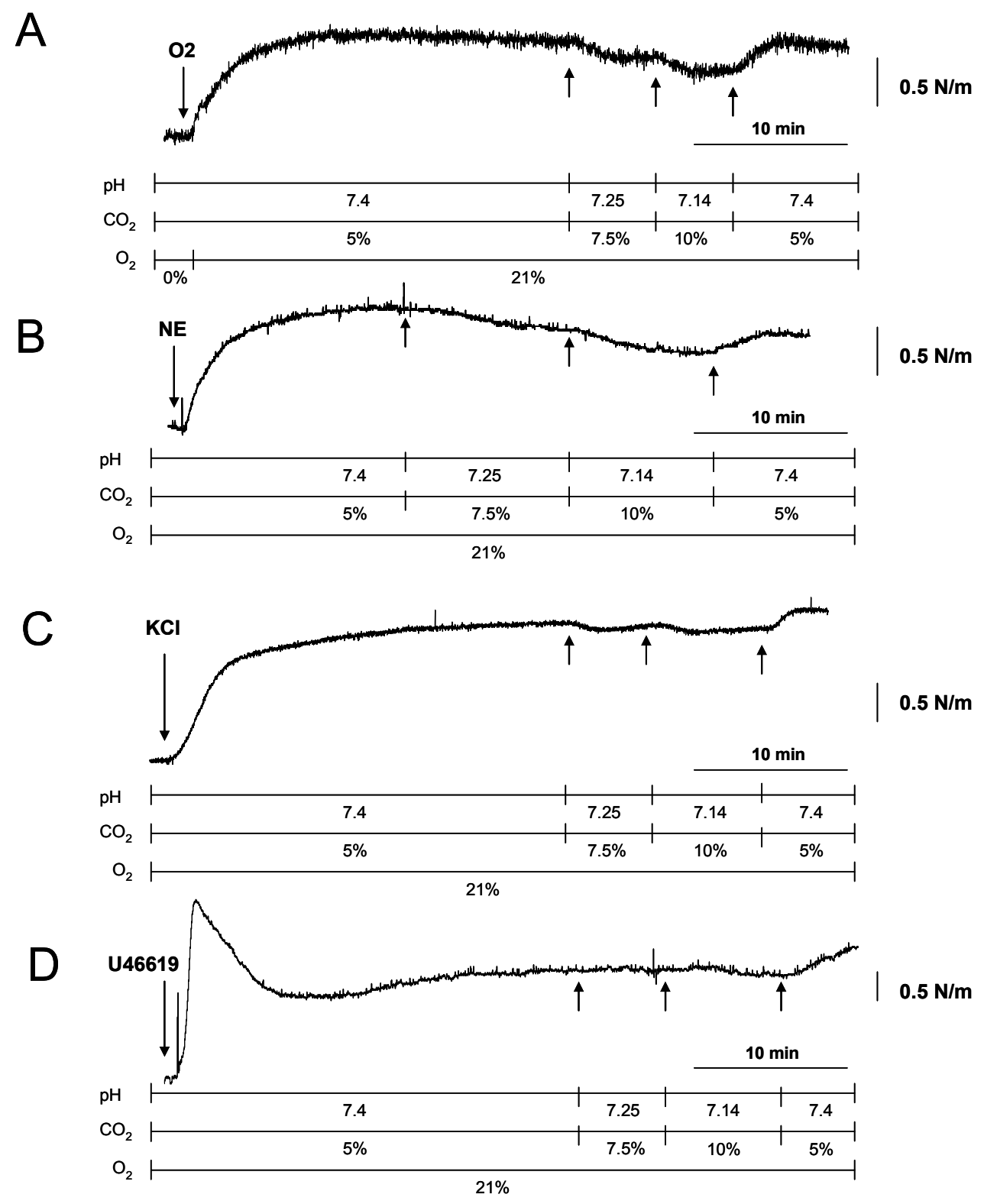

Figure 1. Hypercarbic acidosis-induced relaxation of the chicken DA (pulmonary side). Typical original recordings of tension development over time in DA rings from 19-d chicken fetuses. Vessels were contracted with $\mathrm{O}_{2}$ (A), norepinephrine ( $\left.\mathrm{NE}, 10 \mu \mathrm{M}, \mathrm{B}\right), \mathrm{KCl}(62.5 \mathrm{mM}, \mathrm{C})$, or U46619 (1 $\left.\mu \mathrm{M}, \mathrm{D}\right)$. Downheaded arrows indicate adding contractile agonists and up-headed arrows indicate changes in $\mathrm{CO}_{2} / \mathrm{pH}$ conditions. 
Hypercarbic acidosis relaxed chicken $D A$.

As shown in Figures 1 and 2, increasing the $\mathrm{CO}_{2}$ in the $\mathrm{KRB}$ solution reduced, in a concentration-dependent manner, the tone induced by $\mathrm{O}_{2}, \mathrm{NE}$ and $\mathrm{U} 46619$ in the pulmonary side of the chicken DA. The relaxation induced by hypercarbic acidosis was significantly higher in the DA rings contracted with $\mathrm{O}_{2}\left(7.5 \% \mathrm{CO}_{2}: 26.3 \%\right.$ relaxation, $\mathrm{SD} 15.6 ; 10 \% \mathrm{CO}_{2}: 43.0 \%$ relaxation, $\mathrm{SD} 21.3, \mathrm{n}=23)$ than in the rings contracted with $\mathrm{KCl}\left(7.5 \% \mathrm{CO}_{2}: 9.8 \%, \mathrm{SD} 15.8 ; 10 \% \mathrm{CO}_{2}\right.$ : $10.45 \%$, SD 18.7, $\mathrm{n}=16, p<0.01$ vs. $\mathrm{O}_{2}$-contracted vessels), or $\mathrm{U} 46619\left(7.5 \% \mathrm{CO}_{2}: 4.6 \%\right.$, SD $2.0 ; 10 \% \mathrm{CO}_{2}: 6.8 \%$, SD 12.6, $\mathrm{n}=14, p<0.001$ vs. $\mathrm{O}_{2}$-contracted vessels). In contrast, the relaxation induced by hypercarbic acidosis in NE-contracted DA rings $\left(7.5 \% \mathrm{CO}_{2}: 18.0 \%\right.$, SD $15.9 ; 10 \% \mathrm{CO}_{2}: 28.6 \%$, SD 23.1, $\mathrm{n}=23$ ) was not significantly different than in $\mathrm{O}_{2}$-contracted rings. Hypercarbic acidosis-induced relaxation was fully reversed when $\mathrm{CO}_{2}$ in the bubbling gas mixture was returned to $5 \%$ (Figure 1).

As shown in Figure $2 \mathrm{~B}$ and $\mathrm{C}$, the presence of the NOS inhibitor L-NAME, the sGC inhibitor ODQ, the SERCA inhibitor thapsigargin, the Kv channel inhibitor 4-AP, the $\mathrm{K}_{\mathrm{ATP}}$ channel inhibitor glibenclamide, the $\mathrm{IK}_{\mathrm{Ca}}$ channel inhibitor TRAM-34, and the $\mathrm{SK}_{\mathrm{Ca}}$ channel inhibitor apamin did not affect the relaxation induced by hypercarbic acidosis. In contrast, in the presence of the non selective $\mathrm{K}^{+}$channel inhibitor tetraethylammonium or the $\mathrm{BK}_{\mathrm{Ca}}$ channel inhibitor iberiotoxin the relaxation induced by hypercarbic acidosis was significantly $(p<0.05)$ impaired (Figure $2 \mathrm{C}$ ).

As shown in Figure 3, hypercarbic acidosis also relaxed the aortic side of the chicken DA. These DA rings, responded to $\mathrm{O}_{2}$ with relaxation (Figure $3 \mathrm{~A}$ ), as previously described . Hypercarbic acidosis did not significantly change the tone of $\mathrm{O}_{2}$ relaxed aortic side DA rings but induced significant relaxations when the vessels were pre-contracted with $\mathrm{NE}\left(7.5 \% \mathrm{CO}_{2}: 10.3 \%\right.$ relaxation, SD 11.4; $10 \% \mathrm{CO}_{2}: 18.2 \%$ relaxation, $\left.\mathrm{SD} 7.1, \mathrm{n}=6\right)$ or $\mathrm{U} 46619\left(7.5 \% \mathrm{CO}_{2}: 14.9 \%\right.$ relaxation, $\mathrm{SD} 11.3 ; 10 \% \mathrm{CO}_{2}: 31.2 \%$ relaxation, $\left.\mathrm{SD} 19.3, \mathrm{n}=7\right)$. In contrast, hypercarbic acidosis did not induce a significant relaxation of the aortic side rings pre-contracted with $\mathrm{KCl}$ (Figure 3 C). 

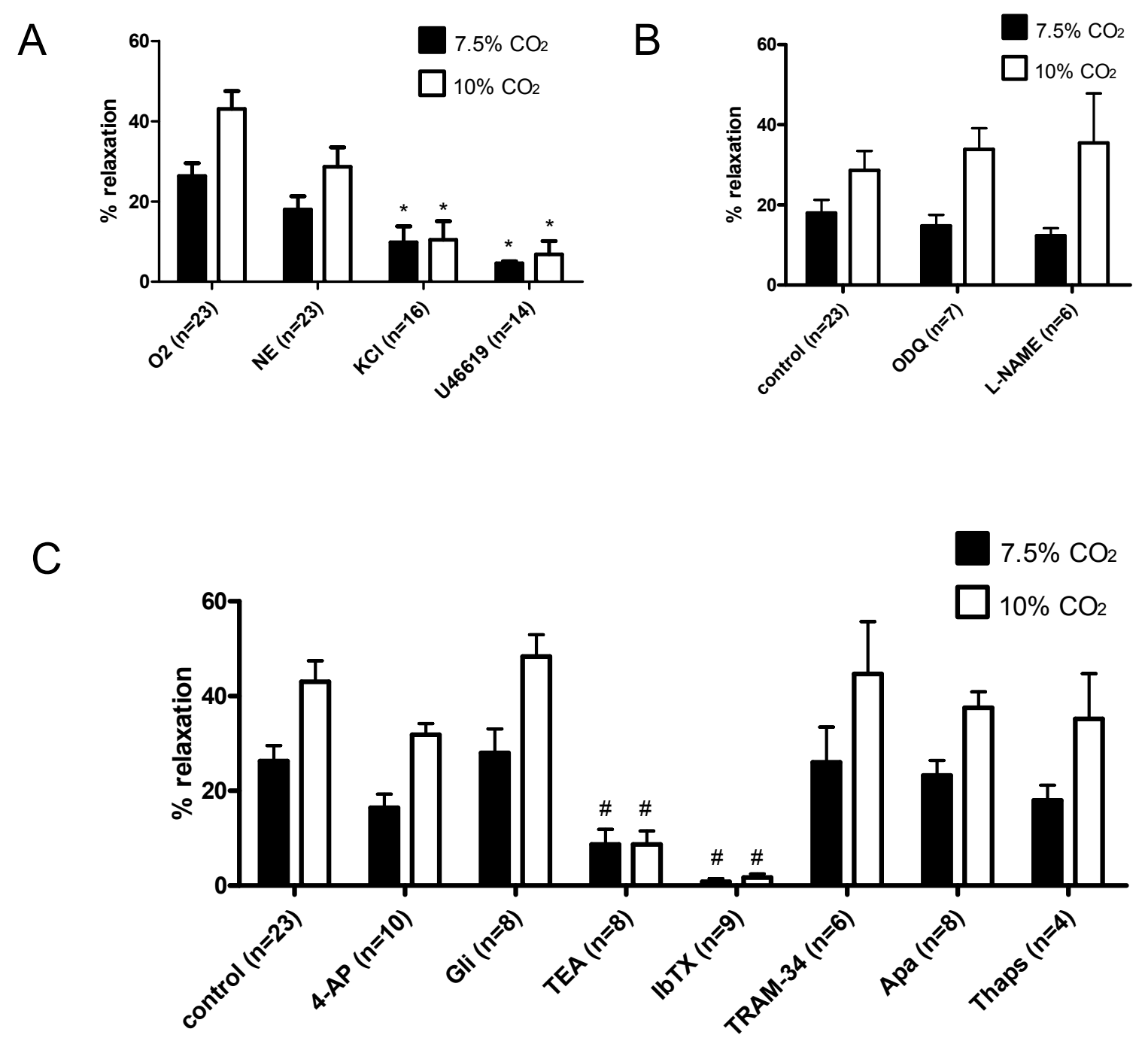

Figure 2. Mechanisms involved in hypercarbic acidosis-induced relaxation of the chicken DA (pulmonary side). A: Summary (mean $+\mathrm{SE})$ of the effects of $7.5 \% \mathrm{CO}_{2}\left(\mathrm{pH} 7.25\right.$, black columns) and $10 \% \mathrm{CO}_{2}(\mathrm{pH}$ 7.14, white columns) on the contraction induced by $\mathrm{O}_{2}, \mathrm{KCl}, \mathrm{NE}$, and $\mathrm{U} 46619$. * $p<0.05$ for difference from $\mathrm{O}_{2}$-contracted DA. B and C: Effects of L-NAME, ODQ, 4-AP, glibenclamide (Gli), tetraethylammonium (TEA), iberiotoxin (IbTX), TRAM-34, apamin (Apa), and thapsigargin (Thaps) on the relaxation induced by hypercarbic acidosis in DA rings contracted with $\mathrm{NE}(\mathrm{B})$, or $\mathrm{O}_{2}(\mathrm{C})$. \# $p<0.05$ for difference with the relaxation induced by a similar $\mathrm{CO}_{2}$ concentration in the control group. 


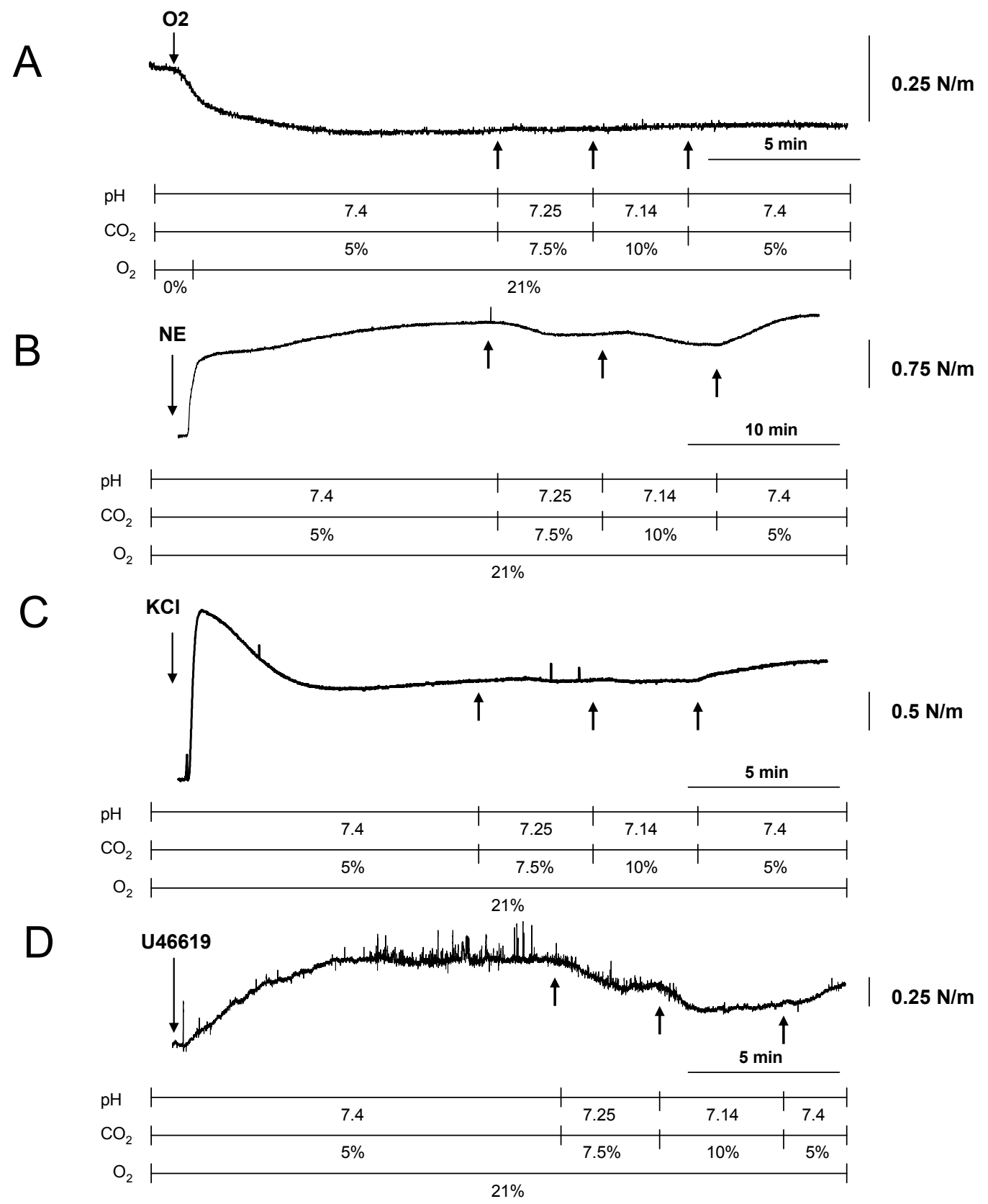

Figure 3. Hypercarbic acidosis-induced relaxation of the chicken DA (aortic side). Typical original recordings of tension development over time in DA rings from 19-d chicken fetuses. Vessels were stimulated with $\mathrm{O}_{2}(\mathrm{~A})$, norepinephrine (NE, $\left.10 \mu \mathrm{M}, \mathrm{B}\right), \mathrm{KCl}(62.5 \mathrm{mM}, \mathrm{C})$, or U46619 (1 $\left.\mu \mathrm{M}, \mathrm{D}\right)$. Downheaded arrows indicate adding contractile agonists and up-headed arrows indicate changes in $\mathrm{CO}_{2} / \mathrm{pH}$ conditions. 
Normocarbic acidosis induced transient relaxation of the chicken $D A$.

Normocarbic acidosis $\left(\mathrm{CO}_{2} 5 \%, \mathrm{NaHCO}_{3} 12 \mathrm{mmol} \mathrm{L}{ }^{-1}, \mathrm{pH} 7.13\right)$ induced relaxation of chicken DA rings (pulmonary side) contracted by $\mathrm{O}_{2}$ (Figure $4 \mathrm{~A}$ ) or NE (Figure $4 \mathrm{~B}$, and $\mathrm{C}$ )). When the $\mathrm{CO}_{2}$ concentration was reduced to $2.5 \%$ (euhydric hypocarbia, $\mathrm{pH} 7.40$ ) the effect of normocarbic acidosis was reverted (Figure 4 A, and B). However, as shown in Figure 4 C, this return of tone was also observed when the conditions of normocarbic acidosis were maintained, indicating the transient nature of the relaxation induced by this type of acidosis. The peak of this transient relaxation (Figure $4 \mathrm{E}$ ) was significantly lower in the DA rings contracted with $\mathrm{KCl}$ $(22.9 \%$ SD $11.8, n=9)$ than in rings contracted with $\mathrm{O}_{2}(61.1 \%$ SD $15.9, \mathrm{n}=9)$ or $\mathrm{NE}(53.9 .1 \%$, SD 25.1, $\mathrm{n}=9$ ). The transient relaxation induced by normocarbic acidosis was not affected by the presence of tetraethylammonium, iberiotoxin, TRAM-34, or apamin (data not shown).

\section{Euhydric hypercarbia induced a transient contraction of the chicken DA.}

To analyze whether hypercarbia induced vascular effects in the absence of acidosis, DA rings (pulmonary side) contracted with $\mathrm{O}_{2}$ or $\mathrm{NE}$ were exposed to euhydric hypercarbia $\left(10 \% \mathrm{CO}_{2}\right.$, $\mathrm{NaHCO}_{3} 48 \mathrm{mmol} \mathrm{L}^{-1}, \mathrm{pH}$ 7.46). As shown in Figure 4 D, euhydric hypercarbia induced a transient increase of the previous tone induced by $\mathrm{O}_{2}(59.2 \%$ increase, SD 22.3, $\mathrm{n}=7)$ and NE (8.7\% increase, SD 3.3, n=8, Figure $4 \mathrm{~F}$ ), which returned to the previous level after 3-5 min. Ten minutes after the start of euhydric hypercapnia the tone of the DA rings showed a 1.2\% (SD 12.0, $\mathrm{n}=7)$ and a $6.7 \%(\mathrm{SD} 4.3, \mathrm{n}=8)$ reduction of the previous tone induced by $\mathrm{O}_{2}$ and $\mathrm{NE}$, respectively.

Table 1. Mean active wall tensions. Mean (SD) active wall tensions (N/m) in response to $\mathrm{O}_{2}, \mathrm{NE}$ $(10 \mu \mathrm{M}), \mathrm{KCl}$, and $\mathrm{U} 46619(1 \mu \mathrm{M})$ in the pulmonary and aortic side of the chicken DA. * $p<0.05$ vs. pulmonary side, $\mathrm{NS}=$ not significant.

\begin{tabular}{lccccc}
\hline & Pulmonary side & $\mathbf{n}$ & Aortic side & n & $\boldsymbol{P}$ \\
\hline $21 \% \mathrm{O}_{2}$ & $0.26(0.13)$ & 50 & $-0.09(0.08)$ & 8 & $<0.05$ \\
$\mathrm{NE}(10 \mu \mathrm{M})$ & $0.51(0.26)$ & 56 & $0.29(0.11)$ & 6 & $<0.05$ \\
$\mathrm{KCl}(62.5 \mathrm{mM})$ & $0.41(0.12)$ & 33 & $0.54(0.25)$ & 13 & $\mathrm{NS}$ \\
$\mathrm{U} 46619(1 \mu \mathrm{M})$ & $0.83(0.29)$ & 17 & $0.41(0.43)$ & 7 & $<0.05$ \\
\hline
\end{tabular}




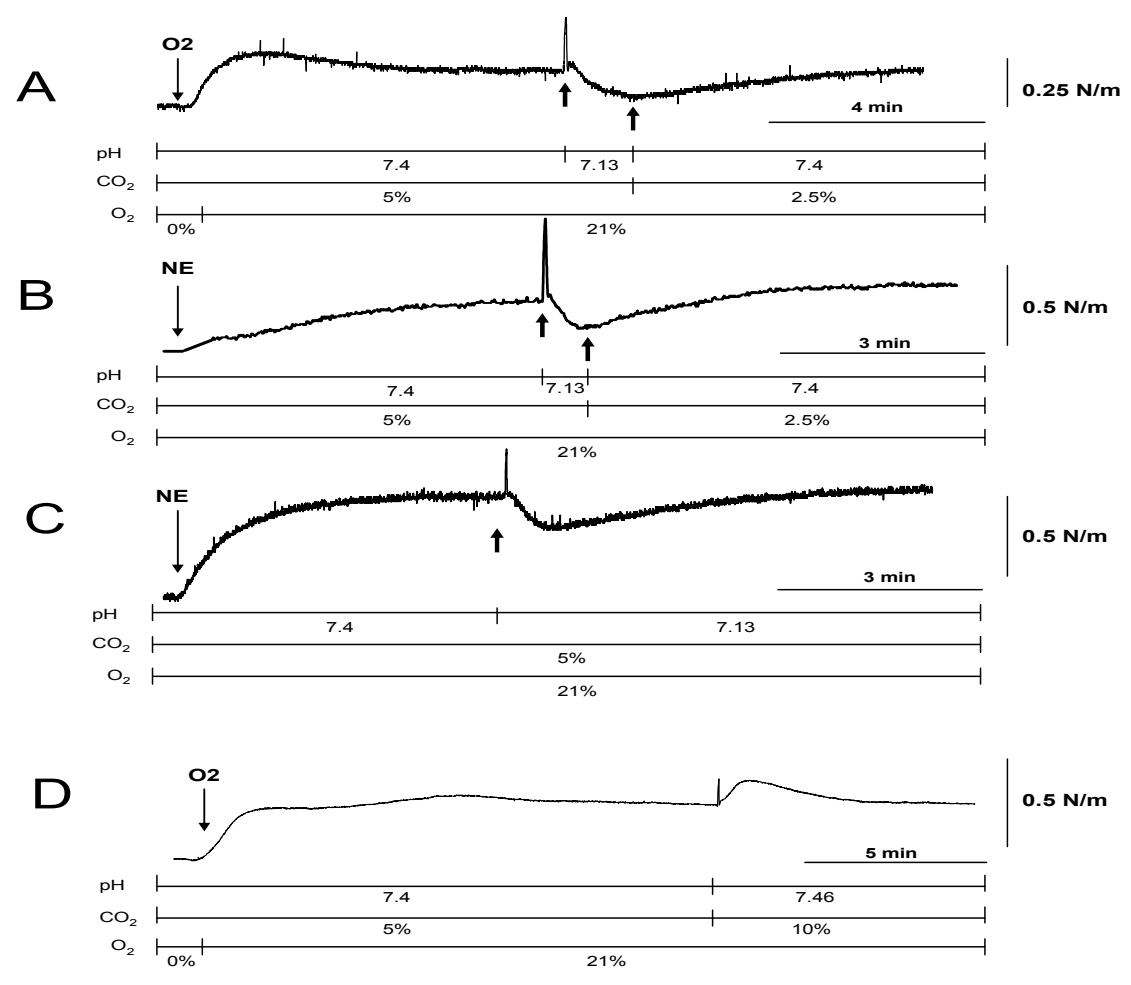

E

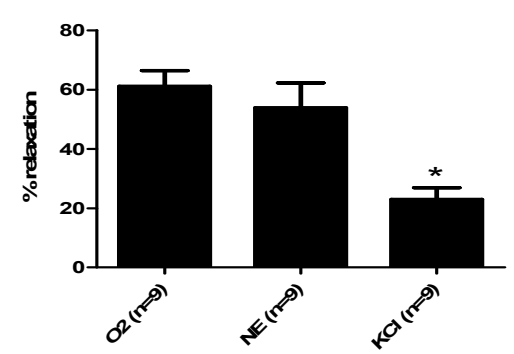

$\mathrm{F}$

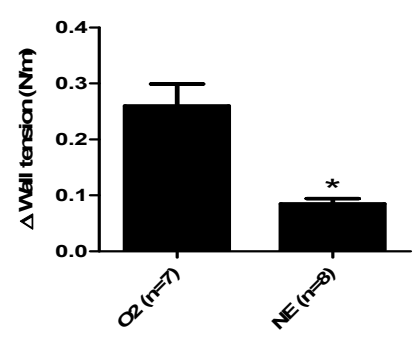

Figure 4. Effects of normocarbic acidosis and euhydric hypercarbia in chicken DA (pulmonary side). AD: Typical original recordings of tension development over time in DA rings from 19-d chicken fetuses. Vessels were contracted with $\mathrm{O}_{2}$ or NE $(10 \mu \mathrm{M})$. Down-headed arrows indicate adding contractile agonists and up-headed arrows indicate changes in $\mathrm{CO}_{2} / \mathrm{pH}$ conditions. The relaxation induced by normocarbic acidosis $\left(\mathrm{CO}_{2} 5 \%, \mathrm{NaHCO}_{3} 12 \mathrm{mmol} \mathrm{L}^{-1}, \mathrm{pH}\right.$ 7.13) was reverted by euhydric hypocarbia (A, B) but also when normocarbic acidosis was maintained (C). Euhydric hypercarbia $\left(10 \% \mathrm{CO}_{2}, \mathrm{NaHCO}_{3} 48\right.$ mmol L ${ }^{-1}, \mathrm{pH}$ 7.46) induced a transient contraction of the pulmonary side of chicken DA (D). E: Summary $($ mean $+\mathrm{SE})$ of the relaxant effects of normocarbic acidosis in the pulmonary side. F: Summary (mean + $\mathrm{SE}$ ) of the contractile effects of euhydric hypercarbia in the pulmonary side. ${ }^{*} p<0.05$ for difference from $\mathrm{O}_{2}$-contracted DA. 

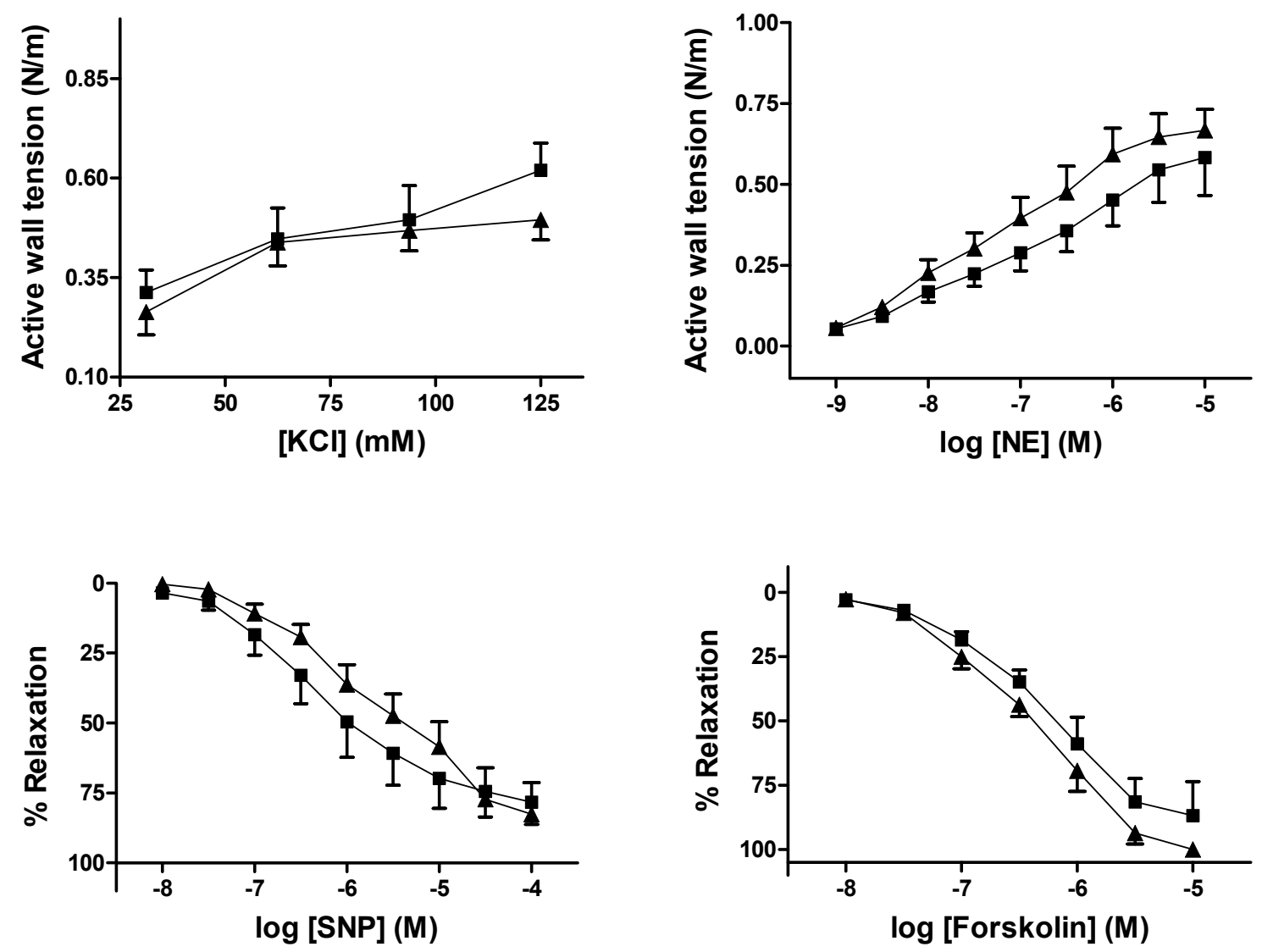

Figure 5. Changes in tension in chicken DA rings (pulmonary side) in response to cumulative concentrations of $\mathrm{KCl}(\mathrm{A})$, norepinephrine (NE, B), sodium nitroprusside (SNP, C) and forskolin (D) in control (squares) and normocarbic acidotic (pH 7.13, triangles) conditions. For the study of SNP- and forskolin-induced relaxation, vessels were pre-contracted with $\mathrm{KCl}(62.5 \mathrm{mM})$. Each point represents the mean \pm SE of 6-8 animals.

Prolonged incubation under normocarbic acidosis did not affect DA responsiveness to agonists. As shown in Figure 5, $1 \mathrm{~h}$ of incubation under normocarbic acidosis $\left(\mathrm{CO}_{2} 5 \%, \mathrm{NaHCO}_{3} 12 \mathrm{mmol}\right.$ $\mathrm{L}^{-1}, \mathrm{pH}$ 7.14) had no effect on either the potency or the efficacy of $\mathrm{KCl}$ and $\mathrm{NE}$ in causing contraction, and of SNP and forskolin in causing relaxation of the chicken DA (pulmonary side).

\section{DISCUSSION}

The effects of acidosis on DA reactivity have been scarcely studied (Kovalcik 1963). In the present work, we observed that in vitro hypercarbic and normocarbic acidosis induced relaxation 
of the chicken DA. This relaxation varied depending on the agonist used to contract the vessel but, interestingly, it was maximal when DA contraction was induced by $\mathrm{O}_{2}$. Moreover, a marked reduction in DA tone was achieved at clinically significant levels of acidosis (i.e. pH 7.25). When the mechanisms putatively involved in acidosis-induced ductal relaxation were analyzed, we observed that the presence of the non selective $\mathrm{K}^{+}$channel blocker tetraethylammonium or the selective $\mathrm{BK}_{\mathrm{Ca}}$ channel inhibitor iberiotoxin abolished the relaxation evoked by hypercarbic acidosis but not by normocarbic acidosis. Therefore, our data suggest that stimulation of $\mathrm{BK}_{\mathrm{Ca}}$ channels may account for the relaxing effects of hypercarbic acidosis in the chicken DA.

The chicken fetus appears as an interesting model for the study of DA developmental biology. Recently, an extensive characterization of the pharmacology of the chicken DA has been performed by our group and other investigators. The chicken DA is sensitive to a wide range of vasoactive agonists including $\mathrm{O}_{2}$, prostanoids, potassium channel blockers, $\mathrm{NO}$, catecholamines, and endothelin-1 (Agren et al. 2007; Agren et al. 2008; Belanger et al. 2008; Greyner and Dzialowski 2008; Agren et al. 2009; Cogolludo et al. 2009; Van der Sterren et al. 2009). The main vasoconstrictor of the mammalian DA, the postnatal increase in $\mathrm{O}_{2}$ tension, appears to play also a relevant role in the closure of the chicken DA whereas the main vasodilator of the mammalian $\mathrm{DA}, \mathrm{PGE}_{2}$, is a weak relaxant agent of the chicken DA which even stimulates vasoconstrictive receptors (Agren et al. 2007; Greyner and Dzialowski 2008; Agren et al. 2009; Cogolludo et al. 2009). Another important difference with the mammalian ductus, is the absence of response of the avian DA to cyclooxygenase (COX) inhibitors (Agren et al. 2007). Therefore, and although only a few studies suggest that the vascular effects of acidosis are mediated by COX-associated vasoactive mediators (Wray and Smith 2004), our present findings about the ductal effects of acidosis warrant confirmation in mammalian species.

Numerous studies demonstrated that the response and the specific mechanisms responsible for the vascular effects of acidosis are species, vascular bed, and acidosis type (i.e. metabolic or respiratory) dependent (Wray and Smith 2004). Increase in the endothelial release of NO (Carr et al. 1993; Fukuda et al. 1993; Aalkjaer and Poston 1996), decrease of $\mathrm{Ca}^{2+}$ influx through blockade of L-type channels (Austin and Wray 2000), increase in $\mathrm{Ca}^{2+}$ sequestration through SERCA activation (Loutzenhiser et al. 1990; Elmoselhi et al. 1995; Elmoselhi et al. 1996), and hyperpolarization through activation of $\mathrm{K}_{\mathrm{ATP}}, \mathrm{K}_{\mathrm{V}}$, or $\mathrm{K}_{\mathrm{Ca}}$ channels (Hayabuchi et al. 1998; Lindauer et al. 2003) have been demonstrated to account for the relaxation induced by the 
decrease in extra or intracellular $\mathrm{pH}$ in different blood vessels. By using pharmacological tools, we evaluated the participation of these mechanisms in the ductal effects of acidosis. We observed that the relaxation induced by hypercarbic acidosis was not affected by the blockade of NOS, sGC, SERCA, $\mathrm{K}_{\mathrm{ATP}}, \mathrm{K}_{\mathrm{V}}, \mathrm{SK}_{\mathrm{Ca}}$ or $\mathrm{IK}_{\mathrm{Ca}}$ channels. In contrast, hypercarbic acidosis-induced relaxation was impaired when the DA rings were stimulated with high $\mathrm{K}^{+}$depolarizing solution or by the blockade of $\mathrm{BK}_{\mathrm{Ca}}$ channels. As mentioned above, this suggests that the mechanism responsible for hypercarbic acidosis-induced relaxation involves membrane hyperpolarization due to activation of $\mathrm{BK}_{\mathrm{Ca}}$ channel activity.

Membrane hyperpolarization appeared also to play a role in the transient relaxation evoked by normocarbic acidosis, which was also impaired by high $\mathrm{K}^{+}$solution. However, none of blockers tested affected normocarbic acidosis-induced relaxation. Therefore, the underlying mechanism could not be clarified in this study. The transduction of the extracellular $\mathrm{pH}$ alterations into intracellular $\mathrm{pH}$ changes varies depending on the type of acidosis (Wray and Smith 2004) and this might explain the differences between hypercarbic and normocarbic acidosis. To exclude the possibility that a direct effect of molecular $\mathrm{CO}_{2}$ might be responsible for the ductal relaxation evoked by hypercarbic acidosis, we performed experiments in which $\mathrm{CO}_{2}$ concentration was raised while $\mathrm{pH}$ was maintained (euhydric hypercarbia). Under these conditions only a transient contraction was observed. In other vascular beds, the extracellular $\mathrm{pH}-$ independent action of elevated $\mathrm{CO}_{2}$ has been variously reported as vasodilator, vasoconstrictor, or without effect (Sweeney et al. 1998; Sweeney et al. 1999; Vankova et al. 2005). Euhydric hypercarbia causes intracellular acidosis due to diffusion of $\mathrm{CO}_{2}$ into the cell and, in fact, the difference in degree of intracellular acidosis observed in vascular tissues during hypercarbic acidosis and euhydric hypercarbia was relatively small (Vankova et al. 2005). Therefore, our data suggest that the decrease in the extracellular $\mathrm{pH}$ is the stimulus that relaxes the chicken DA. However, further research is warranted to clarify the differential effects of hypercarbic and normocarbic extracellular acidosis not only on DA reactivity but also on intracellular $\mathrm{pH}$, membrane potential, and $\mathrm{Ca}^{2+}$ influx.

An extremely interesting feature of the chicken DA is the presence of morphological and functional heterogeneity along its path between the pulmonary artery and the aorta. Thus, the pulmonary side shows the structure of a muscular artery and responds to $\mathrm{O}_{2}$ with contraction, whereas the aortic part shows the morphology of an elastic artery and relaxes in response to $\mathrm{O}_{2}$ 
(Agren et al. 2007; Belanger et al. 2008; Copeland and Dzialowski 2009). In addition, the two parts of the DA show marked differences in their responsiveness to contractile and relaxing agonists (Agren et al. 2008; Agren et al. 2009). Bergwerff et al (1996) demonstrated that the distal part of the chicken DA is mesodermal in origin and is the result of the incorporation of dorsal aorta tissue, whereas the muscular pulmonary side was shown to consist almost exclusively of neural crest derived cells. In the present work, we observed that acidosis-induced relaxation was uniformly present in both segments of the chicken DA. Therefore, the $\mathrm{O}_{2}$-sensitive smooth muscle cells of the pulmonary side of the DA did not present a specific response to hypercarbic acidosis.

In several vascular tissues from different species acidosis produces not only direct changes in tone but also has a modulatory effect on other vasoactive systems (Farrukh et al. 1989; Farrukh et al. 1996; Dvoretsky et al. 2000; Modin et al. 2001; Hattori et al. 2002; Yartsev et al. 2002). As the ductal relaxation induced by normocarbic acidosis was transient (Figure 4), we aimed to analyze whether, apart from this direct effect, a more prolonged incubation under normocarbic acidosis altered the DA responsiveness to contractile and relaxant agonists. We observed that this degree of normocarbic acidosis had no effect on either the potency or the efficacy of $\mathrm{KCl}$ and $\mathrm{NE}$ in causing contraction, and of SNP and forskolin in causing relaxation of the chicken DA. Therefore, neither receptor-dependent nor -independent contraction and neither cGMP- nor cAMP-mediated relaxation appear to be affected by prolonged exposure of the DA to acidosis.

Permissive hypercarbia in which higher levels of $\mathrm{PaCO}_{2}$ are tolerated (provided the arterial $\mathrm{pH}$ does not fall below a preset minimal value) is often used in the ventilatory management of extremely premature infants, in an attempt to reduce ventilator-induced lung injury (Mariani et al. 1999; Woodgate and Davies 2001; Thome et al. 2006; Miller and Carlo 2007). The main concerns about the vascular effects of permissive hypercarbia addressed the possibility of alterations in the cerebral and pulmonary circulation (Thome and Carlo 2002). Moreover, the incidence of patent DA does not appear to be augmented in the preterm newborns exposed to permissive hypercarbia (Mariani et al. 1999). On the other side, respiratory acidosis requiring increased ventilator rates and peak airway pressures is frequently observed in infants with patent DA (Bancalari et al. 2005; Bouissou et al. 2008) and it has been reported a correlation between metabolic acidosis and large patent DA (Jadhav et al. 2007). In the present study, we 
demonstrated that the clinically accepted acidosis produces significant relaxation of the DA. Our data, although in vitro and in a non-mammalian species, suggest a role for $\mathrm{pH}$ in the control of ductal tone. 


\section{REFERENCES}

Aalkjaer, C. and L. Poston (1996). "Effects of $\mathrm{pH}$ on vascular tension: which are the important mechanisms?" J Vasc Res 33(5): 347-59.

Agren, P., A. L. Cogolludo, et al. (2007). "Ontogeny of chicken ductus arteriosus response to oxygen and vasoconstrictors." Am J Physiol Regul Integr Comp Physiol 292(1): R485-96.

Agren, P., S. van der Sterren, et al. (2009). "Developmental changes in the effects of prostaglandin E2 in the chicken ductus arteriosus." J Comp Physiol B 179(2): 133-43.

Agren, P., S. van der Sterren, et al. (2008). "Developmental changes in endothelium-dependent relaxation of the chicken ductus arteriosus." J Physiol Pharmacol 59(1): 55-76.

Austin, C. and S. Wray (2000). "Interactions between $\mathrm{Ca}(2+)$ and $\mathrm{H}(+)$ and functional consequences in vascular smooth muscle." Circ Res 86(3): 355-63.

Bancalari, E., N. Claure, et al. (2005). "Patent ductus arteriosus and respiratory outcome in premature infants." Biol Neonate 88(3): 192-201.

Belanger, C., J. Copeland, et al. (2008). "Morphological changes in the chicken ductus arteriosi during closure at hatching." Anat Rec (Hoboken) 291(8): 1007-15.

Bergwerff, M., M. C. DeRuiter, et al. (1996). "Onset of elastogenesis and downregulation of smooth muscle actin as distinguishing phenomena in artery differentiation in the chick embryo." Anat Embryol (Berl) 194(6): 545-57.

Bouissou, A., T. Rakza, et al. (2008). "Hypotension in preterm infants with significant patent ductus arteriosus: effects of dopamine." J Pediatr 153(6): 790-4.

Carr, P., J. E. Graves, et al. (1993). "Carbon dioxide induced vasorelaxation in rat mesenteric small arteries precontracted with noradrenaline is endothelium dependent and mediated by nitric oxide." Pflugers Arch 423(3-4): 343-5.

Cogolludo, A. L., J. Moral-Sanz, et al. (2009). "Maturation of O2 sensing and signalling in the chicken ductus arteriosus." Am J Physiol Lung Cell Mol Physiol.

Copeland, J. and E. M. Dzialowski (2009). "Effects of hypoxic and hyperoxic incubation on the reactivity of the chicken embryo (Gallus gallus) ductus arteriosi in response to catecholamines and oxygen." Exp Physiol 94(1): 152-61.

Dvoretsky, D. P., O. V. Karachentseva, et al. (2000). "Effects of extracellular pH on the response of the isolated rat mesenteric artery to electrical field stimulation." Acta Physiol Hung 87(2): 145-52. 
Elmoselhi, A. B., M. Blennerhassett, et al. (1995). "Properties of the sarcoplasmic reticulum $\mathrm{Ca}(2+)$-pump in coronary artery skinned smooth muscle." Mol Cell Biochem 151(2): 14955.

Elmoselhi, A. B., S. E. Samson, et al. (1996). "SR Ca2+ pump heterogeneity in coronary artery: free radicals and IP3-sensitive and -insensitive pools." Am J Physiol 271(5 Pt 1): C16529.

Fabres, J., W. A. Carlo, et al. (2007). "Both extremes of arterial carbon dioxide pressure and the magnitude of fluctuations in arterial carbon dioxide pressure are associated with severe intraventricular hemorrhage in preterm infants." Pediatrics 119(2): 299-305.

Farrukh, I. S., G. H. Gurtner, et al. (1989). "Effect of pH on pulmonary vascular tone, reactivity, and arachidonate metabolism." J Appl Physiol 67(1): 445-52.

Farrukh, I. S., J. R. Hoidal, et al. (1996). "Effect of intracellular pH on ferret pulmonary arterial smooth muscle cell calcium homeostasis and pressure." J Appl Physiol 80(2): 496-505.

Fukuda, S., M. Morioka, et al. (1993). "Endothelium dependence of effects of high PCO2 on agonist-induced contractility of rat aorta." Am J Physiol 264(2 Pt 2): H512-9.

Greyner, H. and E. M. Dzialowski (2008). "Mechanisms mediating the oxygen-induced vasoreactivity of the ductus arteriosus in the chicken embryo." Am J Physiol Regul Integr Comp Physiol 295(5): R1647-59.

Hattori, K., S. Tsuchida, et al. (2002). "Augmentation of NO-mediated vasodilation in metabolic acidosis." Life Sci 71(12): 1439-47.

Hayabuchi, Y., Y. Nakaya, et al. (1998). "Effect of acidosis on Ca2+-activated K+ channels in cultured porcine coronary artery smooth muscle cells." Pflugers Arch 436(4): 509-14.

Hyvelin, J. M., C. O'Connor, et al. (2004). "Effect of changes in $\mathrm{pH}$ on wall tension in isolated rat pulmonary artery: role of the RhoA/Rho-kinase pathway." Am J Physiol Lung Cell Mol Physiol 287(4): L673-84.

Jadhav, P., P. S. Parimi, et al. (2007). "Parenteral amino acid and metabolic acidosis in premature infants." JPEN J Parenter Enteral Nutr 31(4): 278-83.

Kovalcik, V. (1963). "The Response of the Isolated Ductus Arteriosus to Oxygen and Anoxia." J Physiol 169: 185-97. 
Lindauer, U., J. Vogt, et al. (2003). "Cerebrovascular vasodilation to extraluminal acidosis occurs via combined activation of ATP-sensitive and Ca2+-activated potassium channels." $\underline{\mathrm{J}}$ Cereb Blood Flow Metab 23(10): 1227-38.

Loutzenhiser, R., Y. Matsumoto, et al. (1990). "H(+)-induced vasodilation of rat aorta is mediated by alterations in intracellular calcium sequestration." Circ Res 67(2): 426-39.

Lynch, F., M. Sweeney, et al. (2000). "Hypercapnia-induced contraction in isolated pulmonary arteries is endothelium-dependent." Respir Physiol 121(1): 65-74.

Mariani, G., J. Cifuentes, et al. (1999). "Randomized trial of permissive hypercapnia in preterm infants." Pediatrics 104(5 Pt 1): 1082-8.

Miller, J. D. and W. A. Carlo (2007). "Safety and effectiveness of permissive hypercapnia in the preterm infant." Curr Opin Pediatr 19(2): 142-4.

Modin, A., H. Bjorne, et al. (2001). "Nitrite-derived nitric oxide: a possible mediator of 'acidicmetabolic' vasodilation." Acta Physiol Scand 171(1): 9-16.

Sutendra, G. and E. D. Michelakis (2007). "The chicken embryo as a model for ductus arteriosus developmental biology: cracking into new territory." Am J Physiol Regul Integr Comp Physiol 292(1): R481-4.

Sweeney, M., D. Beddy, et al. (1998). "Effects of changes in pH and CO2 on pulmonary arterial wall tension are not endothelium dependent." J Appl Physiol 85(6): 2040-6.

Sweeney, M., R. G. O'Regan, et al. (1999). "Effects of changes in pH and PCO2 on wall tension in isolated rat intrapulmonary arteries." Exp Physiol 84(3): 529-39.

Thome, U. H. and W. A. Carlo (2002). "Permissive hypercapnia." Semin Neonatol 7(5): 409-19.

Thome, U. H., W. Carroll, et al. (2006). "Outcome of extremely preterm infants randomized at birth to different $\mathrm{PaCO} 2$ targets during the first seven days of life." Biol Neonate 90(4): 218-25.

Van der Sterren, S., P. Agren, et al. (2009). "Morphological and functional alterations of the ductus arteriosus in a chicken model of hypoxia-induced fetal growth retardation." Pediatr Res 65(3): 279-84.

Vankova, M., V. A. Snetkov, et al. (2005). "Euhydric hypercapnia increases vasoreactivity of rat pulmonary arteries via HCO3- transport and depolarisation." Cardiovasc Res 65(2): 50512. 
Woodgate, P. G. and M. W. Davies (2001). "Permissive hypercapnia for the prevention of morbidity and mortality in mechanically ventilated newborn infants." Cochrane Database Syst Rev(2): CD002061.

Wray, S. and R. D. Smith (2004). "Mechanisms of action of pH-induced effects on vascular smooth muscle." Mol Cell Biochem 263(1-2): 163-72.

Yartsev, V. N., O. V. Karachentseva, et al. (2002). "Effect of pH changes on reactivity of rat mesenteric artery segments at different magnitude of stretch." Acta Physiol Scand 174(1): $1-7$.

Authors address: E. Villamor, MD, PhD. Dept of Pediatrics, Maastricht University Medical Center (MUMC+). P. Debyelaan 25. P.O. Box 5800. 6202 AZ Maastricht. The Netherlands. Phone +31 43-3877246, fax +31 43-3875246 e-mail: E.Villamor@mumc.nl 


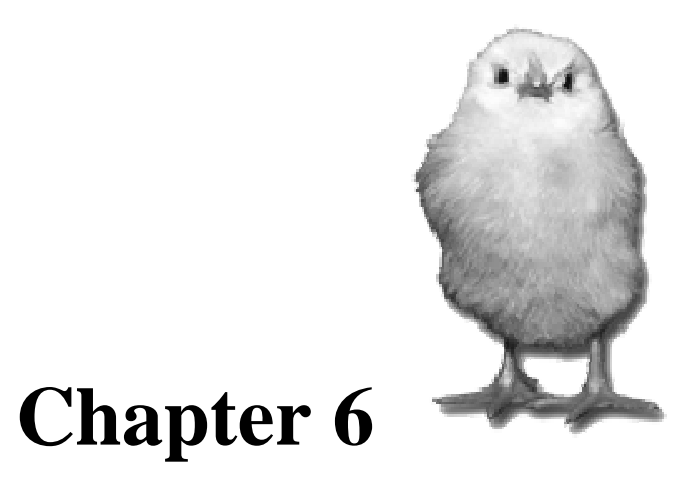

MORPHOLOGICAL AND FUNCTIONAL ALTERATIONS OF THE DUCTUS ARTERIOSUS IN A CHICKEN MODEL OF HYPOXIA-INDUCED FETAL GROWTH RETARDATION

Saskia van der Sterren, Pia Ågren, Bea Zoer, Carolina L. Kessels, Carlos E. Blanco and Eduardo Villamor

Pediatric Res 2009, 65 (3): 279-284 


\title{
Morphological and Functional Alterations of the Ductus Arteriosus in a Chicken Model of Hypoxia-Induced Fetal Growth Retardation
}

\author{
SASKIA VAN DER STERREN, PIA ÅGREN, BEA ZOER, LILIAN KESSELS, CARLOS E. BLANCO, AND EDUARDO VILLAMOR \\ Department of Pediatrics, Maastricht University Medical Centre, GROW School for Oncology and Developmental Biology, 6202 AZ \\ Maastricht, The Netherlands
}

\begin{abstract}
The hypoxic conditions in which children with intrauterine growth retardation (IUGR) develop are hypothesized to alter the development of the ductus arteriosus (DA). We aimed to evaluate the effects of in ovo hypoxia on chicken DA morphometry and reactivity. Hypoxia $\left(15 \% \mathrm{O}_{2}\right.$ from day 6 to 19 of the 21-d incubation period) produced a reduction in the body mass of the 19-d fetuses and a shortening of right and left DAs. However, ductal lumen and media cross-sectional areas were not affected by hypoxia. The ductal contractions induced by oxygen, $\mathrm{KCl}, \mathrm{H}_{2} \mathrm{O}_{2}$, 4-aminopyridine, and endothelin-1 were similar in control and hypoxic fetuses. In contrast, the DAs from the hypoxic fetuses showed increased contractile responses to norepinephrine and phenylephrine and impaired relaxations to acetylcholine, sodium nitroprusside, and isoproterenol. The relaxations induced by 8-Br-cGMP, forskolin, Y-27632, and hydroxyfasudil were not altered by chronic hypoxia. In conclusion, chronic in ovo hypoxia-induced growth retardation in fetal chickens and altered the response of the DA to adrenergic agonists and to endothelium-dependent and -independent relaxing agents. Our observations support the concept that prolonged patency of the DA in infants with IUGR may be partially related with hypoxia-induced changes in local vascular mechanisms. (Pediatr Res 65: 279-284, 2009)
\end{abstract}

$\mathrm{I}^{\mathrm{n}}$ ntrauterine growth retardation (IUGR) is most frequently the consequence of placental insufficiency resulting in decreased availability of nutrients and oxygen (1). Although IUGR is considered as an important cause of pre- and postnatal morbidity, its impact on the several areas of morbidity associated with prematurity remains controversial. Reports vary from higher to similar rates of respiratory distress syndrome, chronic lung disease, necrotizing enterocolitis, retinopathy of prematurity, and patent ductus arteriosus (DA) in preterm infants with and without IUGR $(1,2)$.

The putative alterations produced by hypoxia and other prenatal insults in the normal development of DA are unclear. Histologic evidence of accelerated maturation of the DA was described in the autopsy of preterm infants exposed to chronic intrauterine stress, leading to the hypothesis that this may have resulted clinically in effective postnatal DA closure (3). In contrast, other authors have described in the DA of premature infants with IUGR, histologic changes, such as fragmentation, coagulation, necrosis of the internal elastic lamina, hemorrhage with

Received August 4, 2008; accepted September 25, 2008.

Correspondence: Eduardo Villamor, M.D., Ph.D., Department of Pediatrics, Maastricht University Medical Centre (MUMC+), P. Debyelaan 25, P.O. Box 5800, 6202 AZ Maastricht, The Netherlands; e-mail: E.Villamor@mumc.nl necrosis, and loosening of elastic fibers and muscles in the tunica media that may have produced subsequent patent DA (4).

The chicken fetus is an excellent model for the study of the cardiovascular consequences of prenatal growth retardation (5-7). Recently, we have studied the chicken DA reactivity and demonstrated that the effects of vasoactive mediators on its tone are developmentally regulated with loss of responsiveness to vasodilators and increase of responsiveness to vasoconstrictors with advancing age $(8-10)$.

Hypoxia has profound effects on endothelial and vascular smooth muscle cellular physiology affecting the transcriptionally regulated expression of vasoactive substances, the modulation of receptor populations, the density and activities of ion channels, and the signal transduction pathways involved in modulating vascular tone $(5-7,11-14)$. Postnatal constriction of the full-term DA produces hypoxia of the muscle media, and this stimulus appears as essential for the anatomic remodeling that prevents subsequent ductal reopening (15). In the present study, we hypothesize that prolonged hypoxic exposure alters the development of the DA contractile apparatus that is essential for rapid constriction after birth. Therefore, our aim was to evaluate the effects of in ovo hypoxia on the chicken DA reactivity and morphology.

\section{METHODS}

Incubation and hypoxia protocol. Experiments were performed in accordance with Dutch law for animal experimentation and were approved by the Ethical Committee of the University of Maastricht. Fertile Lohman-selected White Leghorn eggs were incubated at $37.8^{\circ} \mathrm{C}$ and $45 \%$ humidity (Incubator model 25HS, Masalles Comercial, Spain). Control embryos were incubated under normoxic conditions $\left(21 \% \mathrm{O}_{2}, 0.03 \% \mathrm{CO}_{2}\right)$. Experimental embryos were incubated under normoxic conditions until day 6 of incubation when eggs were transferred to a second incubator where hypoxia $(15.0 \pm 0.3 \%$ atmospheric $\mathrm{O}_{2}, 0.03 \% \mathrm{CO}_{2}$ ) was maintained by providing a constant flow of $\mathrm{N}_{2}$ and compressed air with a flow meter. The $\mathrm{O}_{2}$ and $\mathrm{CO}_{2}$ concentrations in the incubator were monitored with a DrDAQ $\mathrm{O}_{2}$ sensor (Pico Technology, United Kingdom) and an infrared $\mathrm{CO}_{2}$ analyzer (Beckman Instruments, Inc., Fullerton, CA).

Morphometric analysis of the DA. On day 19 of incubation, the embryos were taken out and immediately killed by decapitation. With the aid of a dissecting microscope (Mild M8; Leica, Cambridge, United Kingdom), the

\footnotetext{
Abbreviations: 4-AP, 4-aminopyridine; ACh, acetylcholine; cGMP, cyclic GMP; CSA, cross-sectional area; ET-1, endothelin-1; KRB, KrebsRinger bicarbonate; $\mathbf{K}_{\mathbf{V}}$, voltage-gated $\mathrm{K}^{+}$channels; NE, norepinephrine; $\mathbf{p D}_{\mathbf{2}},-\log \mathrm{EC}_{50} ;$ Phe, phenylephrine; sGC, soluble guanylate cyclase; SNP, sodium nitroprusside
} 

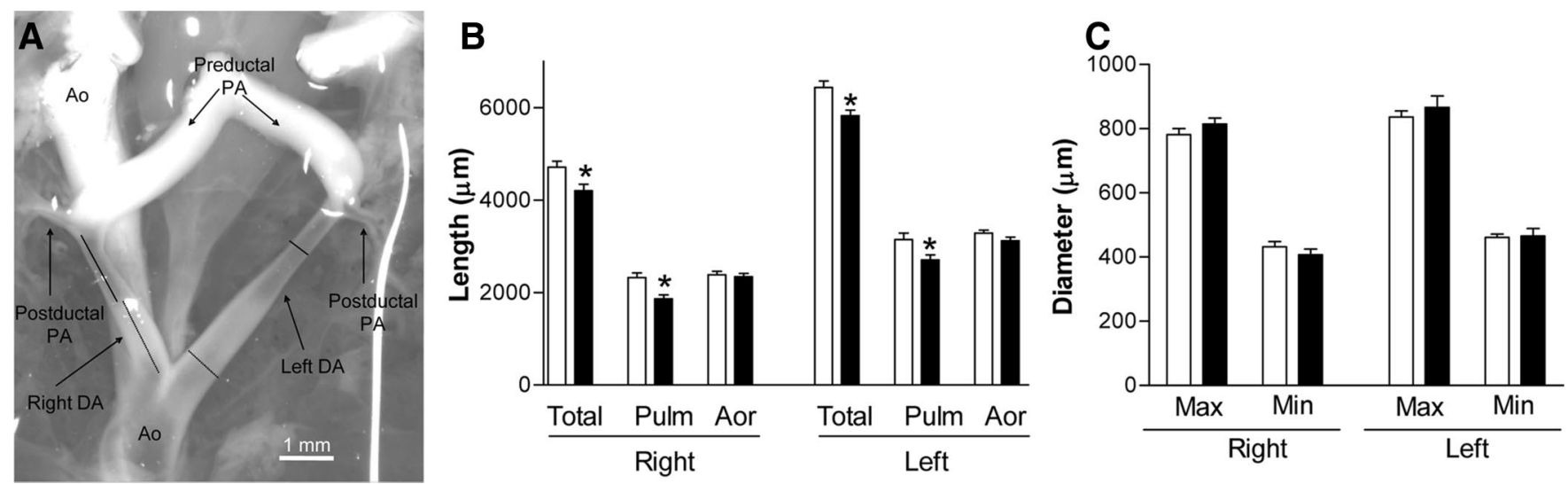

Figure 1. Anatomy of the chicken DA. The method used to determine the length and diameter of the pulmonary (solid line) and the aortic (dashed line) of the DAs is also depicted. Ao, aorta; PA, pulmonary artery. Lengths $(B)$ and diameters $(C)$ of the DAs of 19-d chicken fetuses exposed to hypoxia $(\square)$ or normoxia ( $\square$ ) during incubation. Pulm, pulmonary side; Aor, aortic side. Each bar represents the mean \pm SEM of eight animals. * $p<0.05$ for difference from normoxia.

heart, the esophagus and the crop were removed, the right and the left DA were exposed, and the preparation was photographed (Fig. 1) with a digital camera (Leica DFC 280). Pictures were subsequently analyzed with a computerized morphometric system (Quantimet 570C; Leica,). Analysis was performed by a single observer (P.A.), who was unaware of the experimental conditions. The total length of the DAs, the length of the aortic and the pulmonary segments, and the maximal and minimal diameters were determined. Each measurement was repeated three times and the mean value recorded.

Microscopic morphometric analysis was assessed in DAs fixed in situ with the whole-body freezing technique. Embryos were frozen in $1 \%$ carboxymethylcellulose in liquid nitrogen. Serial, transversal sections ( $8 \mu \mathrm{m}$ thick) through the whole length of the DAs, were obtained on a Leica freezing microtome (CM 3050S) and double staining was performed for elastin (Lawson solution; Klinipath, Duiven, The Netherlands) and a MAb against smooth muscle $\alpha$-actin (Dako, Carpinteria, CA). Microscopic images were analyzed with the Quantimet 570C to determine media layer cross-sectional area (CSA), media wall thickness, and intraluminal CSA. This analysis was only performed in the right DA because its orientation allowed the obtention of transversal sections of the vessel (Fig. 2). From each specimen, 3-5 sections with the morphology of the pulmonary side and 8-10 with the morphology of the aortic side of the DA were analyzed. Sections with a transitional morphology between the two parts were discarded for analysis. Analysis was performed by a single observer (L.K.), who was unaware of the experimental conditions.

\section{Recording of DA reactivity}

Reactivity was analyzed only in the proximal (pulmonary) side of the vessel. Rings from hypoxic and normoxic embryos were studied in parallel. The myograph organ bath was filled with Krebs-Ringer bicarbonate (KRB) buffer maintained at $39^{\circ} \mathrm{C}$ and continuously aerated with one of the following gas mixtures: $95 \% \mathrm{~N}_{2} / 5 \% \mathrm{CO}_{2}\left(\mathrm{Po}_{2}=2.6-3.3 \mathrm{kPa}\right), 5 \% \mathrm{O}_{2} / 90 \% \mathrm{~N}_{2} / 5 \% \mathrm{CO}_{2}$ $\left(\mathrm{Po}_{2}=6.8-7.2 \mathrm{kPa}\right)$, or $21 \% \mathrm{O}_{2} / 74 \% \mathrm{~N}_{2} / 5 \% \mathrm{CO}_{2}\left(\mathrm{Po}_{2}=16-20 \mathrm{kPa}\right)$. The final $\mathrm{pH}$ was $7.38-7.42$ and $\mathrm{PCO}_{2}$ was $4.6-5.6 \mathrm{kPa}$ in all solutions (8). Each DA ring was stretched to its individual optimal lumen diameter, i.e., the diameter at which it developed the strongest contractile response to $62.5 \mathrm{mM}$ $\mathrm{KCl}(8)$. During the first phase of stabilization and determination of optimal diameter, $\mathrm{KRB}$ buffer was aerated with $95 \% \mathrm{~N}_{2} / 5 \% \mathrm{CO}_{2}$. Afterward, and depending on the specific protocol, one of the above-described gas mixtures was used.

To assess the responsiveness of the DA to oxygen, vessels were incubated for 30 min with $95 \% \mathrm{~N}_{2} / 5 \% \mathrm{CO}_{2}$. Then the gas mixture was switched to $21 \%$ $\mathrm{O}_{2} / 74 \% \mathrm{~N}_{2} / 5 \% \mathrm{CO}_{2}$. This gas was maintained for $10 \mathrm{~min}$. In another set of experiments, the organ chamber was bubbled with $5 \% \mathrm{O}_{2} / 90 \% \mathrm{~N}_{2} / 5 \% \mathrm{CO}_{2}$ and concentration-response curves to $\mathrm{KCl}$, the inhibitor of voltage-gated $\left(\mathrm{K}_{\mathrm{V}}\right)$ $\mathrm{K}^{+}$channels 4-aminopyridine (4-AP), $\mathrm{H}_{2} \mathrm{O}_{2}$, endothelin-1 (ET-1), norepinephrine (NE), and phenylephrine (Phe) were constructed. Relaxing agonists were evaluated during contraction induced by $62.5 \mathrm{mM} \mathrm{K}^{+}$. Concentrationresponse curves for acetylcholine (ACh), the nitric oxide (NO) donor sodium nitroprusside (SNP), the cGMP (cGMP) analog 8-Br-cGMP, the $\beta$-adrenoceptor agonist isoproterenol, the adenylyl cyclase activator forskolin, and the Rho-kinase inhibitors Y-27632 and hydroxyfasudil were constructed.
Drugs and solutions. $\mathrm{KRB}$ contained (in $\mathrm{mmol} / \mathrm{L}$ ): $\mathrm{NaCl}, 118.5 ; \mathrm{KCl}$, 4.75; $\mathrm{MgSO}_{4} \cdot 7 \mathrm{H}_{2} \mathrm{O}, 1.2 ; \mathrm{KH}_{2} \mathrm{PO}_{4}, 1.2 ; \mathrm{NaHCO}_{3}, 25.0 ; \mathrm{CaCl}_{2}, 2.5$; glucose, 5.5. Solutions containing different concentrations of $\mathrm{K}^{+}$were prepared by replacing part of the $\mathrm{NaCl}$ by an equimolar amount of $\mathrm{KCl}$. All the drugs were obtained from Sigma Chemical Co (St. Louis, MO) and dissolved initially in distilled deionized water (except forskolin in ethanol).

Data analysis. Results are shown as mean (SD) of measurements in $n$ animals. For clarity, results in the figures are shown as mean \pm SEM. Contractions are expressed in Newton/meter and relaxations as percentage of reduction of the contraction induced by $\mathrm{K}^{+}$. Sensitivity (expressed as $\left.\mathrm{pD}_{2}=-\log \mathrm{EC}_{50}\right)$ and maximal contraction or relaxation $\left(E_{\max }\right)$ to agonists was determined by fitting individual concentration-response data to a nonlinear sigmoidal regression curve. Comparisons were made by an unpaired $t$ test. Differences were considered significant at a $p<0.05$.

\section{RESULTS}

Fetal growth and DA morphometry. Exposure of chicken fetuses to $15 \%$ instead of $21 \% \mathrm{O}_{2}$ from day 6 to day 19 of incubation induced growth retardation (body mass normoxic: $29.9 \mathrm{~g}$, SD 5.6, $n=34$; hypoxic: 25.3 , SD 5.5, $n=32, p<$ 0.01 versus normoxic).

Both the right and the left DAs were shorter in the hypoxic fetuses (Fig. 1B). When the lengths of pulmonary and the aortic sides of the DA were analyzed, it was observed that the ductal shortening induced by hypoxia was due to a shortening of the pulmonary segment (Fig. $1 B$ ). The external diameter of the DA was not significantly different between normoxic and hypoxic fetuses (Fig. 1C).

As shown in Fig. 2, the chicken DAs exhibited two distinct phenotypes along their lengths. The proximal (pulmonary) DA displayed the structure of a muscular artery with a dense $\alpha$-actin-positive media subjacent to the endothelium and few layers of elastic fibers around the muscular layer. The distal (aortic) DA contains many elastic fibers that fill the vascular wall arranged in concentric lamellae with $\alpha$-actin-positive smooth muscle cells embedded between the lamellae. The muscular phenotype was present in $49.4 \%$ (SD 8.7, $n=5$ ) of the length of the right DA from the normoxic animals and in $33.0 \%$ (SD 11.5, $n=5, p<0.05$ versus control) of the vessel length from the hypoxic group. The lumen CSA was significantly greater in the pulmonary than the aortic side of the DA and the media CSA was significantly greater in the aortic than 
A

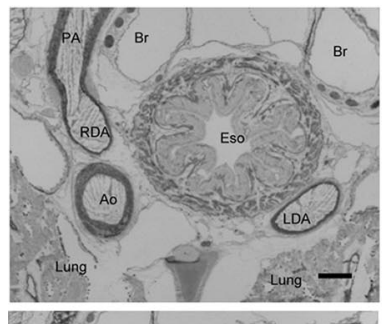

B
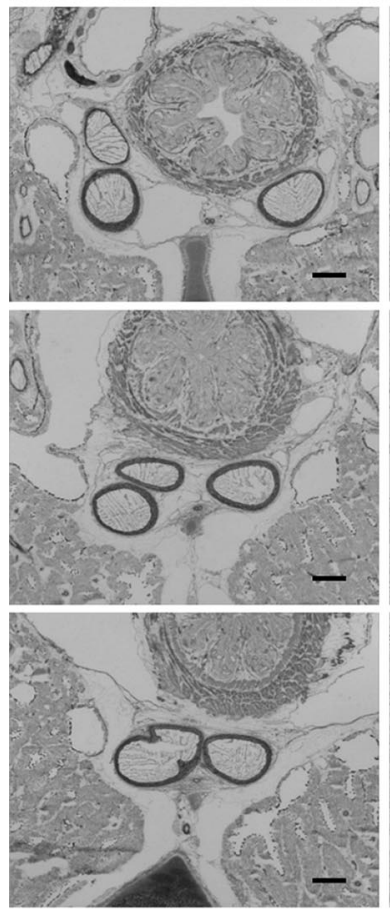

c

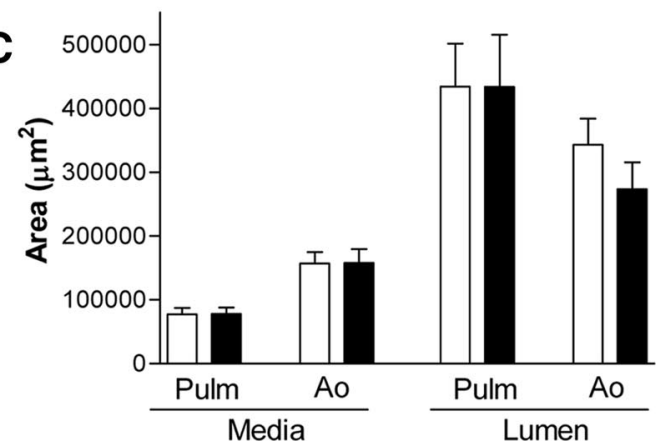

Figure 2. Histology of the chicken DA. Light micrographs showing double staining for elastin and $\alpha$-actin of cross-sections of snap-frozen 19-d chicken fetuses exposed to normoxia $(A)$ or hypoxia $(B)$ during incubation. Bars 200 $\mu \mathrm{M}$. Ao, aorta; PA, pulmonary artery; Eso, esophagus; $\mathrm{Br}$, bronchus; $\mathrm{R}$, right; $\mathrm{L}$, left. $(C)$ The media and lumen cross-sectional areas of the right DA were not significantly different between normoxic $(\square)$ and hypoxic ( $\square$ ) fetuses. Each bar represents the mean \pm SEM of five animals.

in the pulmonary side of the vessel. The media and lumen CSAs of the right DA were not significantly different between normoxic and hypoxic fetuses (Fig. 2C).

DA reactivity. Switching the $\mathrm{O}_{2}$ mixture from 0 to $21 \%$ (3 to $18 \mathrm{kPa}$ ) produced a progressive increase of the $\mathrm{O}_{2}$ concentration in the organ chamber that reached a steady state after $\sim 3 \mathrm{~min}$ (8). This increase in $\mathrm{O}_{2}$ concentration resulted in a contractile response of the DA that was not significantly different between hypoxic and normoxic fetuses (Fig. $3 A$ ). In addition, the contractions induced by 4 -AP (Fig. $3 \mathrm{~A}$ ), $\mathrm{KCl}$ (Fig. $3 B ; \mathrm{pD}_{2}$ normoxic: $1.61, \mathrm{SD} 0.12$; hypoxic: 1.69 , SD $0.14 ; p>0.05$ ), $\mathrm{H}_{2} \mathrm{O}_{2}$ (Fig. 3C), and ET-1 (Fig. 3D) did not vary between the experimental groups. The diameter at which maximal responses to depolarizing high- $\mathrm{K}^{+}$solution were obtained was significantly higher in the DAs from the hypoxic fetuses $(843.1 \mu \mathrm{m}, \mathrm{SD} 92.31, n=32$ versus $775.8 \mu \mathrm{m}$, SD 92.3, $n=32 ; p<0.05)$, but the passive wall stretch induced by this optimal diameter was not significantly different (normoxia: $0.89 \mathrm{~N} / \mathrm{m}$, SD 0.19; hypoxia: $0.92 \mathrm{~N} / \mathrm{m}$, SD 0.24).

The adrenergic agonists NE (Fig. $3 E$ ) and Phe (Fig. $3 F$ ) induced significantly $(p<0.05)$ larger contractions in the DAs from the hypoxic (NE: $0.91 \mathrm{~N} / \mathrm{m}, \mathrm{SD} 0.22, n=11$; Phe:0.87 $\mathrm{N} / \mathrm{m}, \mathrm{SD} 0.20, n=11)$ than in those from the normoxic fetuses (NE: $0.72 \mathrm{~N} / \mathrm{m}, \mathrm{SD} 0.23, n=11$; Phe:0.69 N/m, SD $0.18, n=11$ ). However, the sensitivity $\left(\mathrm{pD}_{2}\right)$ to $\mathrm{NE}$ (normoxic: 6.67, SD 0.22; hypoxic: 6.65 , SD 0.23 ) and Phe (normoxic: 5.42, SD 0.15; hypoxic: 5.45, SD 0.17) did not vary between the experimental groups.

Acetylcholine (Fig. 4A), SNP (Fig. 4B), 8-Br-cGMP (Fig. $4 C$ ), isoproterenol (Fig. 5A), forskolin (Fig. 5B), Y-27632 (Fig. 5C), and hydroxyfasudil (Fig. 5D) relaxed DA rings (precontracted with $62.5 \mathrm{mM} \mathrm{KCl}$ ) in a concentrationdependent manner. The relaxations induced by ACh $\left(E_{\max }\right.$ normoxic: $39.49 \%, \mathrm{SD} 16.2, n=8 ; E_{\max }$ hypoxic: $15.02 \%$, $\mathrm{SD} 10.2, n=8, p<0.05$ versus normoxic), $\mathrm{SNP}\left(E_{\max }\right.$ normoxic: $59.9 \%, \mathrm{SD} 27.7, n=8 ; E_{\max }$ hypoxic: $33.1 \%$, SD $16.4, n=8, p<0.05$ versus normoxic), and isoproterenol $\left(E_{\max }\right.$ normoxic: $168.1 \%, \mathrm{SD} 19.4, n=8 ; E_{\max }$ hypoxic: $112 \%$, SD $16.4, n=8, p<0.05$ versus normoxic) were significantly impaired in the DAs from the fetuses incubated under hypoxic conditions. The sensitivity to SNP was significantly greater in normoxic than in hypoxic fetuses $\left(\mathrm{pD}_{2}\right.$ normoxic: 5.84, SD 0.4; $\mathrm{pD}_{2}$ hypoxic 4.95 , $\mathrm{SD} 0.41, p<0.01$ versus normoxic). The sensitivities to ACh and isoproteronol did not differ significantly between groups. The relaxations induced by 8 -Br-cGMP, forskolin, Y-27632, and hydroxyfasudil were not significantly different when normoxic and hypoxic DAs were compared.

\section{DISCUSSION}

We have characterized the morphologic and functional status of the DA in a chicken model of hypoxia-induced fetal growth retardation (5-7). We did not find significant evidences for an accelerated or delayed anatomical remodeling of the DA in the growth-retarded chicken fetuses. In contrast, the DA of the hypoxic fetuses showed an enhanced contractile response to $\alpha$-adrenergic agonists and an impaired relaxation to the $\beta$-adrenoceptor agonist isoproterenol, the endotheliumdependent vasodilator acetylcholine and the endotheliumindependent vasodilator SNP.

The DA belongs to a specialized system of $\mathrm{O}_{2}$-sensitive organs and tissues in the body that includes, among others, the pulmonary arteries, the carotid body, and the neuroepithelial body, which share striking similarities in the ways they respond to changes in $\mathrm{O}_{2}$ tension $(16,17)$. The mechanism proposed to explain $\mathrm{O}_{2}$-induced ductal contraction includes a 

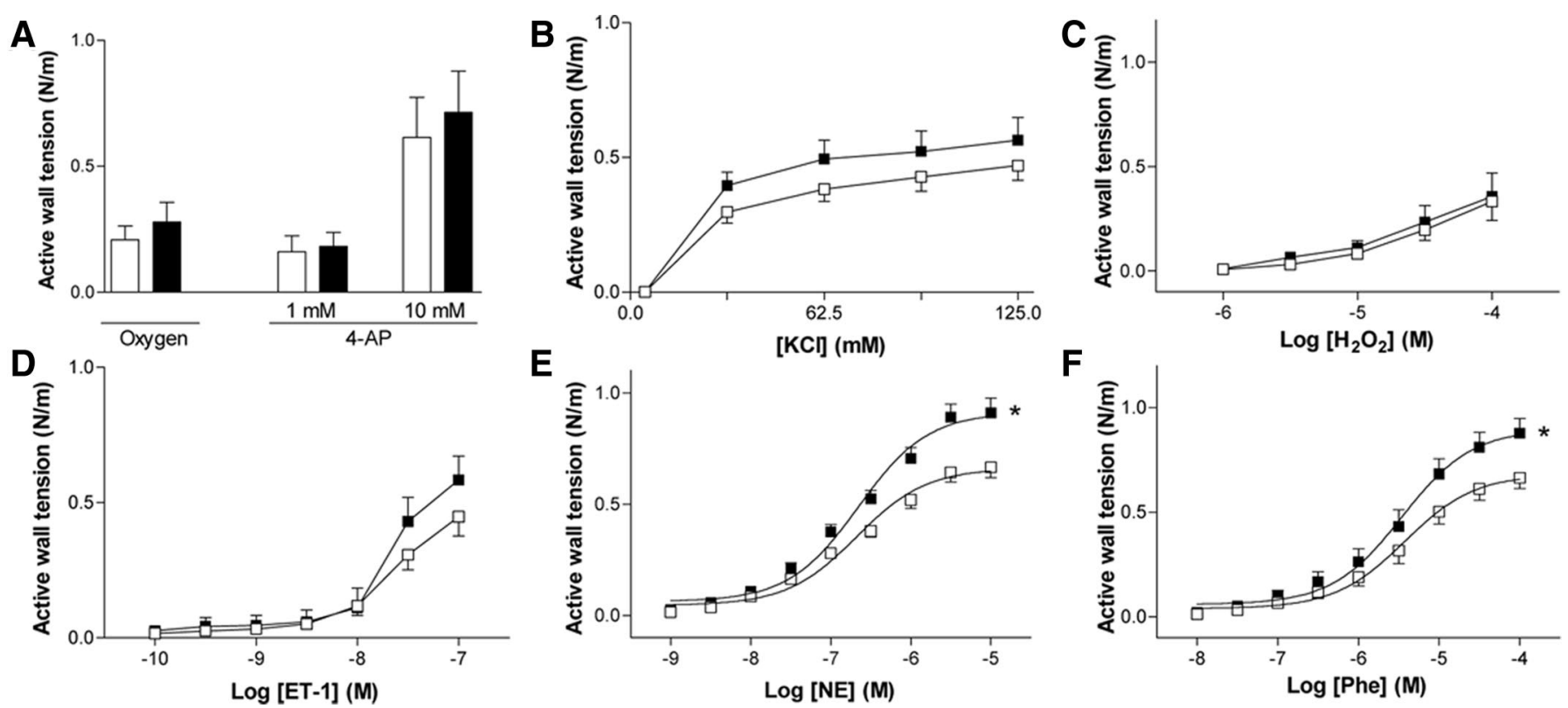

Figure 3. Contractile effects of oxygen, 4-AP, $\mathrm{KCl}, \mathrm{H}_{2} \mathrm{O}_{2}, \mathrm{ET}-1$, norepinephrine, and phenylephrine in DA rings of 19-d chicken fetuses exposed to hypoxia or normoxia $(\square)$ during incubation. Each point (or bar) represents the mean \pm SEM of $8-11$ animals. ${ }^{*} p<0.05$ for difference in $E_{\max }$ from normoxia.
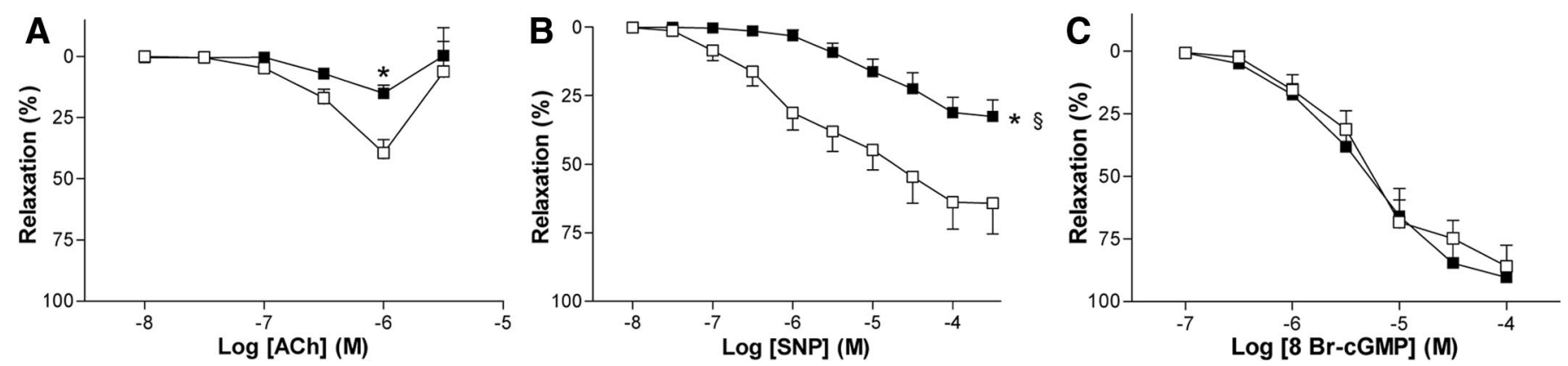

Figure 4. Concentration-dependent relaxant effects of acetylcholine, SNP, and 8-Br cGMP in DA rings of 19-d chicken fetuses incubated under hypoxia ( $\square$ ) or normoxia $(\square)$. Each point represents the mean \pm SEM of 6-11 animals. ${ }^{*} p<0.05$ for difference in $E_{\max }$ from normoxia. $\$ p<0.05$ for difference in $\mathrm{pD} \mathrm{D}_{2}$ from normoxia.

sensor: the electron transport chain of the mitochondria that increases production of reactive oxygen species, particularly $\mathrm{H}_{2} \mathrm{O}_{2}$, in response to changes in $\mathrm{O}_{2}$ levels. $\mathrm{H}_{2} \mathrm{O}_{2}$ can reach the cell membrane and decrease the opening of $\mathrm{K}_{\mathrm{V}}$ channels. This causes DA depolarization, opening of the voltage-gated $\mathrm{Ca}^{2+}$ channels, increase in intracellular $\mathrm{Ca}^{2+}$, and vasoconstriction $(16,17)$. Preliminary results of our laboratory indicate that this "mitochondria- $\mathrm{H}_{2} \mathrm{O}_{2}-\mathrm{K}_{\mathrm{V}}$ channels" axis is also involved in the response of chicken DA to $\mathrm{O}_{2}$ (8, and unpublished results). Although chronic hypoxia could putatively alter each component of the above axis (18), we have not observed any hypoxia-induced alteration of the chicken DA response to oxygen. Moreover, the contractions induced by high- $\mathrm{K}^{+}$depolarizing solution, the $\mathrm{K}_{\mathrm{V}}$ channel blocker 4-AP, and $\mathrm{H}_{2} \mathrm{O}_{2}$ were not significantly affected by chronic hypoxia.

Within the vasculature in general, chronic hypoxia produces a broad spectrum of structural and functional changes that are typically organ specific (18). As reported elsewhere, chronic moderate hypoxia in the chicken fetus led, in the femoral artery, to impairment of endothelium-dependent relaxation $(6,7)$ and increased periarterial sympathetic innervation (5), whereas in the pulmonary arteries led to an impairment of the responsiveness to several vasoconstrictors but did not affect endothelium-dependent or -independent relaxations (7). In the present work, we observed that chronic hypoxia impaired ACh- and SNP-mediated relaxations of the DA. Previously, we demonstrated that ACh induces endothelium-dependent relaxation of the chicken DA and that $\mathrm{NO}$ and endothelium derived hyperpolarizing factor are involved in this response (9). On the other hand, SNP evoked endothelium-independent relaxation of the chicken DA through the activation of soluble guanylate cyclase (sGC) (9). Therefore, the $\mathrm{NO} / \mathrm{sGC} / \mathrm{cGMP}$ axis is active in the chicken DA and our present results indicate that chronic hypoxia induced an impairment of this vasodilatory pathway. It should be noted that, in the present work, we studied the effects of relaxant agonists in DA rings contracted with high- $\mathrm{K}^{+}$depolarizing solution. Thus, the contribution of hyperpolarizing mechanisms to relaxation could not be analyzed in our experiments. In relation to the vascular effects of chronic hypoxia, numerous investigations have examined the involvement of the NO/sGC/cGMP axis in pulmonary and systemic vessels. The majority of these studies report hypoxiainduced endothelial impairment with normal response to $\mathrm{NO}$ donors $(19,20)$. However, other authors report alterations in both endothelium-dependent and -independent relaxation after expo- 

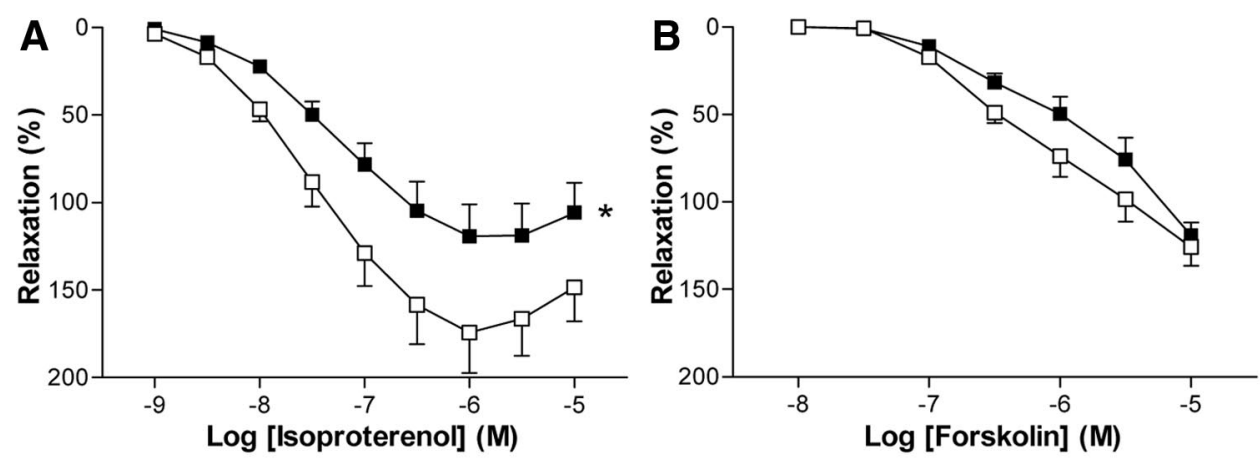

Figure 5. Concentration-dependent relaxant effects of isoproterenol, forskolin, Y-27632, and hydroxyfasudil in DA rings of 19-d chicken fetuses incubated under hypoxia ( $\square$ ) or normoxia $(\square)$. Each point represents the mean \pm SEM of 6-11 animals. ${ }^{*} p<0.05$ for difference in $E_{\max }$ from normoxia.
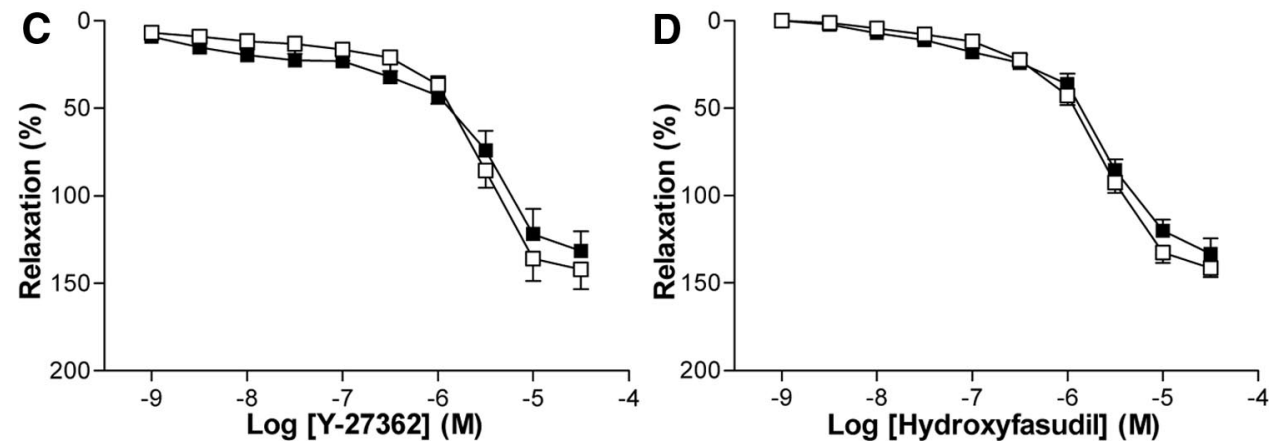

sure to chronic hypoxia (21). In turn, chronic hypoxia has been reported to elevate vascular sGC abundance and activity in some studies (12), but decrease it in others (22). In the present study, we observed that the relaxation induced by the cell-permeable analog of cGMP, 8-Br-cGMP, was similar in the DA from normoxic and hypoxic fetuses, indicating that signaling events coupling cGMP to relaxation were not affected by chronic hypoxia. Taking together, our results suggest that chronic hypoxiainduced impairment of NO-evoked relaxation is due to a reduced sGC activity. However, an additional impairment the endothelial NO synthase or an increase in phosphodiesterase-mediated catalysis of cGMP cannot be discarded.

Our study also reports that adrenergic agonist-induced contractions to norepinephrine and phenylephrine were enhanced in the DA from chicken fetuses exposed to chronic hypoxia during incubation. On the other hand, the DA relaxations induced by the $\beta$-adrenoceptor agonist isoproterenol were impaired in the hypoxic fetuses. Accordingly, other investigators reported that femoral artery constriction in response to adrenergic agonists was significantly enhanced in femoral arteries from rats (23) and lambs (14) gestated under hypoxia. In contrast, chronic hypoxia impaired the contraction evoked by $\alpha$-adrenergic agonists in pulmonary arteries (14). Previously, we demonstrated that norepinephrine and phenylephrine induced a developmentally increased contraction of the chicken DA (8). Interestingly, the relaxation induced by isoproterenol decreased with development (10). Therefore, the changes induced by hypoxia in DA adrenergic responsiveness mimic the changes induced by development, suggesting that the effect of hypoxia might be consequence of a developmental acceleration. In addition, the impairment of ACh- and SNP-mediated relaxation, which is a characteristic feature of the mature chicken DA (9), was also observed in the hypoxic fetuses. However, other features of the mature chicken DA, such as the enhanced responsiveness to $\mathrm{O}_{2}, \mathrm{KCl}, \mathrm{H}_{2} \mathrm{O}_{2}, \mathrm{ET}-1$, or 4 -AP $(8,24)$ were not present in the DA of the hypoxic animals.

Activation of the RhoA/Rho-kinase pathway can induce $\mathrm{Ca}^{2+}$ sensitization, a phenomenon in which sustained vasoconstriction occurs, independent of ongoing increases in cytosolic $\mathrm{Ca}^{2+}$ $(25,26)$. Recently, Rho kinase activation has been implicated in DA constriction in several mammalian species $(25,26)$. Our observation of the Rho-kinase inhibitors Y-27632 and hydroxyfasudil concentration dependently decreasing tone of $\mathrm{KCl}$ precontracted chicken DA suggests that this pathway also plays a role in the regulation of DA contraction in this species. $\mathrm{Nu}$ merous experimental evidences indicate that chronic hypoxia augments Rho kinase-induced vascular smooth muscle $\mathrm{Ca}^{2+}$ sensitization, particularly in the pulmonary vasculature $(13,27)$ McNamara et al. (13) reported that pulmonary vascular RhoA is activated and Rho-kinase activity is increased in rat pups by exposure to hypoxia from birth for $14 \mathrm{~d}$. Moreover, hypoxiainduced RhoA expression in the lung is age dependent and found to be greatest in the fetus (27). In the present study, we observed that the relaxation evoked by Y-27632 and hydroxyfasudil was similar in DAs from normoxic and hypoxic fetuses. This indirectly suggests that Rho-kinase activity in the chicken DA was unaffected by chronic prenatal hypoxia.

The chicken DA presents morphologic and functional heterogeneity along its path between the pulmonary artery and the aorta $(8,24)$. Thus, the pulmonary side shows the structure of a muscular artery and responds to $\mathrm{O}_{2}$ with contraction, whereas the aortic part shows the morphology of an elastic artery and relaxes in response to $\mathrm{O}_{2}(8,24)$. In addition, $\mathrm{ACh}, \mathrm{SNP}$, and the NOindependent stimulator of sGC BAY 41-2272 induced larger relaxations in the aortic side of the vessel (9), whereas isoproterenol, forskolin, and the phosphodiesterase 3 inhibitor milrinone evoked larger relaxations in the pulmonary side (10). The reac- 
tivity studies of the present work were exclusively focused on the pulmonary side, which appears to be the "real" DA in the chicken. Bergwerff et al. (28) demonstrated that the distal elastic part of the chicken DA is mesodermal in origin and is the result of the incorporation of dorsal aorta tissue, whereas the muscular pulmonary side was shown to consist almost exclusively of neural crest derived cells. In the present work, we observed that the proportion of DA with muscular morphology was significantly reduced in the hypoxic animals. In addition, and although the in situ diameter of the DA was not affected by hypoxia, the functional diameter (i.e., the one at which the vessels showed maximal $\mathrm{K}^{+}$-induced contraction) was higher in the hypoxic group. With our present results, we can only speculate about these findings. However, and interestingly, numerous studies demonstrated that exposing animals to chronic hypoxia results in morphologic and functional changes in the neural crest-derived, oxygen-sensing cells of the carotid body (29). The specific effects of chronic hypoxia in the neural crest-derived cells of the DA and in the vascular elastic properties warrant further investigation.

As mentioned in the introduction, there have been reported signs of accelerated (3) or abnormal (4) DA development in preterm infants with IUGR. Recently, Rakza et al. (2) described that the DA is larger in infants with IUGR than in eutrophic preterm infants, as soon as $6 \mathrm{~h}$ after birth. In our chicken model, and with the exception of the above discussed shortening of the pulmonary segment, no other signs of morphologic alterations were found and the CSAs of the DA lumen and wall were comparable between normoxic and hypoxic 19-d fetuses. This suggests that at this stage of development the DA maintains a similar degree of patency in both groups. The 19-d fetuses used in the present study were noninternally pipped. On day 19 of incubation, the fetus internally pips by piercing the air cell inner membrane with its beak and begins lung ventilation. During the internal pipping, the relative blood flow to the chorioallantoic membrane progressively declines, whereas blood flow to the lungs increases (24). However, the presence of the ductal shunt is still necessary during internal pipping. In fact, Belanger et al. (24), reported that internal pipping did not induce significant changes in chicken DA diameter but these changes were observed during external pipping. At this stage, ductal closure was associated with a breakdown of the internal elastic lamina, migration of smooth muscle cells into the neointimal zone, and swelling and detachment of the endothelial layer $(9,24)$. By day 2 posthatching the lumen of the proximal portion of the DA is completely occluded (24). Whether the structural and functional alterations that we described in the present work accelerate or delay this process remains to be investigated.

\section{REFERENCES}

1. Fang S 2005 Management of preterm infants with intrauterine growth restriction. Early Hum Dev 81:889-900

2. Rakza T, Magnenant E, Klosowski S, Tourneux P, Bachiri A, Storme L 2007 Early hemodynamic consequences of patent ductus arteriosus in preterm infants with intrauterine growth restriction. J Pediatr 151:624-628

3. King DT, Emmanouilides GC, Andrews JC, Hirose FM 1980 Morphologic evidence of accelerated closure of the ductus arteriosus in preterm infants. Pediatrics 65:872-880

4. Ibara S, Tokunaga M, Ikenoue T, Murata Y, Hirano T, Asano H, Uemura Y 1994 Histologic observation of the ductus arteriosus in premature infants with intrauterine growth retardation. J Perinatol 14:411-416
5. Ruijtenbeek K, le Noble FA, Janssen GM, Kessels CG, Fazzi GE, Blanco CE, De Mey JG 2000 Chronic hypoxia stimulates periarterial sympathetic nerve development in chicken embryo. Circulation 102:2892-2897

6. Ruijtenbeek K, Kessels LC, De Mey JG, Blanco CE 2003 Chronic moderate hypoxia and protein malnutrition both induce growth retardation, but have distinct effects on arterial endothelium-dependent reactivity in the chicken embryo. Pediatr Res 53:573579

7. Villamor E, Kessels CG, Ruijtenbeek K, van Suylen RJ, Belik J, de Mey JG, Blanco CE 2004 Chronic in ovo hypoxia decreases pulmonary arterial contractile reactivity and induces biventricular cardiac enlargement in the chicken embryo. Am J Physiol Regul Integr Comp Physiol 287:R642-R651

8. Agren P, Cogolludo AL, Kessels CG, Perez-Vizcaino F, De Mey JG, Blanco CE, Villamor E 2007 Ontogeny of chicken ductus arteriosus response to oxygen and vasoconstrictors. Am J Physiol Regul Integr Comp Physiol 292:R485-R496

9. Agren P, van der Sterren S, Cogolludo AL, Frazziano G, de Mey JG, Blanco CE, Villamor E 2008 Developmental changes in endothelium-dependent relaxation of the chicken ductus arteriosus. J Physiol Pharmacol 59:55-76

10. Agren P, van der Sterren S, Cogolludo AL, Blanco CE, Villamor E 2008 Developmental changes in the effects of prostaglandin $\mathrm{E}(2)$ in the chicken ductus arteriosus. J Comp Physiol [B] [Epub ahead of print]

11. Marino M, Beny JL, Peyter AC, Bychkov R, Diaceri G, Tolsa JF 2007 Perinatal hypoxia triggers alterations in $\mathrm{K}+$ channels of adult pulmonary artery smooth muscle cells. Am J Physiol Lung Cell Mol Physiol 293:L1171-L1182

12. Li D, Laubach VE, Johns RA 2001 Upregulation of lung soluble guanylate cyclase during chronic hypoxia is prevented by deletion of eNOS. Am J Physiol Lung Cell Mol Physiol 281:L369-L376

13. McNamara PJ, Murthy P, Kantores C, Teixeira L, Engelberts D, van Vliet T, Kavanagh BP, Jankov RP 2008 Acute vasodilator effects of Rho-kinase inhibitors in neonatal rats with pulmonary hypertension unresponsive to nitric oxide. Am J Physiol Lung Cell Mol Physiol 294:L205-L213

14. Herrera EA, Pulgar VM, Riquelme RA, Sanhueza EM, Reyes RV, Ebensperger G, Parer JT, Valdez EA, Giussani DA, Blanco CE, Hanson MA, Llanos AJ 2007 High-altitude chronic hypoxia during gestation and after birth modifies cardiovascular responses in newborn sheep. Am J Physiol Regul Integr Comp Physiol 292:R2234-R2240

15. Kajino H, Goldbarg S, Roman C, Liu BM, Mauray F, Chen YQ, Takahashi Y, Koch CJ, Clyman RI 2002 Vasa vasorum hypoperfusion is responsible for medial hypoxia and anatomic remodeling in the newborn lamb ductus arteriosus. Pediatr Res 51:228-235

16. Sutendra G, Michelakis ED 2007 The chicken embryo as a model for ductus arteriosus developmental biology: cracking into new territory. Am J Physiol Regul Integr Comp Physiol 292:R481-R484

17. Thebaud B, Wu XC, Kajimoto H, Bonnet S, Hashimoto K, Michelakis ED, Archer SL 2008 Developmental absence of the $\mathrm{O}_{2}$ sensitivity of L-type calcium channels in preterm ductus arteriosus smooth muscle cells impairs $\mathrm{O}_{2}$ constriction contributing to patent ductus arteriosus. Pediatr Res 63:176-181

18. Paffett ML, Walker BR 2007 Vascular adaptations to hypoxia: molecular and cellular mechanisms regulating vascular tone. Essays Biochem 43:105-119

19. Peyter AC, Muehlethaler V, Liaudet L, Marino M, Di Bernardo S, Diaceri G, Tolsa JF 2008 Muscarinic receptor M1 and phosphodiesterase 1 are key determinants in pulmonary vascular dysfunction following perinatal hypoxia in mice. Am J Physiol Lung Cell Mol Physiol 295:L201-L213

20. Phillips SA, Olson EB, Morgan BJ, Lombard JH 2004 Chronic intermittent hypoxia impairs endothelium-dependent dilation in rat cerebral and skeletal muscle resistance arteries. Am J Physiol Heart Circ Physiol 286:H388-H393

21. Xue Q, Ducsay CA, Longo LD, Zhang L 2008 Effect of long-term high-altitude hypoxia on fetal pulmonary vascular contractility. J Appl Physiol 104:1786-1792

22. Hassoun PM, Filippov G, Fogel M, Donaldson C, Kayyali US, Shimoda LA, Bloch KD 2004 Hypoxia decreases expression of soluble guanylate cyclase in cultured rat pulmonary artery smooth muscle cells. Am J Respir Cell Mol Biol 30:908-913

23. Williams SJ, Campbell ME, McMillen IC, Davidge ST 2005 Differential effects of maternal hypoxia or nutrient restriction on carotid and femoral vascular function in neonatal rats. Am J Physiol Regul Integr Comp Physiol 288:R360-R367

24. Belanger C, Copeland J, Muirhead D, Heinz D, Dzialowski EM 2008 Morphological changes in the chicken ductus arteriosi during closure at hatching. Anat Rec (Hoboken) 291:1007-1015

25. Kajimoto H, Hashimoto K, Bonnet SN, Haromy A, Harry G, Moudgil R, Nakanishi T, Rebeyka I, Thebaud B, Michelakis ED, Archer SL 2007 Oxygen activates the Rho/Rho-kinase pathway and induces RhoB and ROCK-1 expression in human and rabbit ductus arteriosus by increasing mitochondria-derived reactive oxygen species: a newly recognized mechanism for sustaining ductal constriction. Circulation 115:1777-1788

26. Clyman RI, Waleh N, Kajino H, Roman C, Mauray F 2007 Calcium-dependent and calcium-sensitizing pathways in the mature and immature ductus arteriosus. Am J Physiol Regul Integr Comp Physiol 293:R1650-R1656

27. Bailly K, Ridley AJ, Hall SM, Haworth SG 2004 RhoA activation by hypoxia in pulmonary arterial smooth muscle cells is age and site specific. Circ Res 94:13831391

28. Bergwerff M, Verberne ME, DeRuiter MC, Poelmann RE, Gittenberger-de Groot AC 1998 Neural crest cell contribution to the developing circulatory system: implications for vascular morphology? Circ Res 82:221-231

29. Wang ZY, Bisgard GE 2005 Postnatal growth of the carotid body. Respir Physiol Neurobiol 149:181-190 

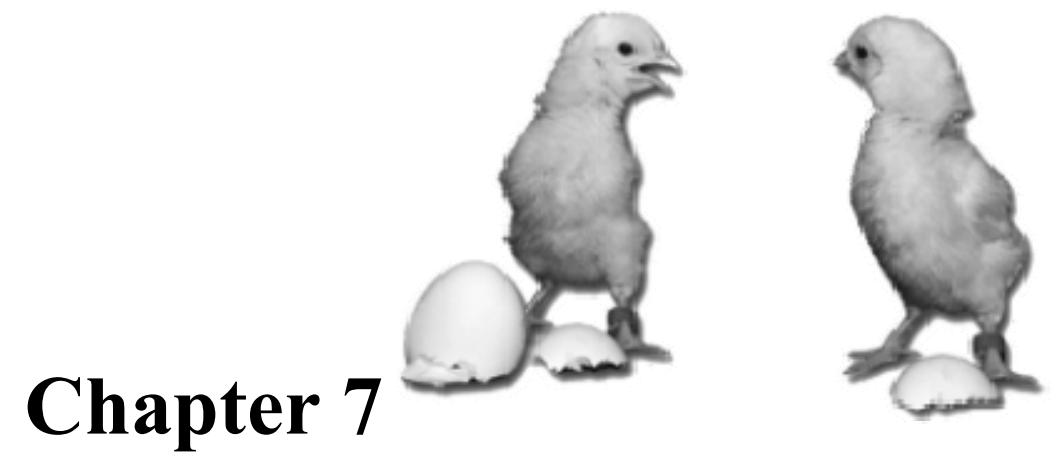

DISCUSSION 


\section{General discussion and future perspectives}

Failure of DA closure after birth is a common complication of premature delivery that is still presenting challenges in terms of diagnosis, assessment and treatment options (Smith 1998; Bancalari et al. 2005; Clyman 2006; Reese 2006). Significant progress in our understanding of the DA physiology and pathophysiology has been achieved with the use of animal models, including the sheep, the rabbit, the mouse, the rat or primates (Sutendra and Michelakis 2007). However, the complexity of the available mammalian models is an important limitation (Sutendra and Michelakis 2007). Effects of external stresses, such as hypoxia or malnutrition (as seen in placental insufficiency) cannot be studied without maternal and placental influences (Ruijtenbeek et al. 2002a; Sutendra and Michelakis 2007). Intervention of the fetal/placental circulation through complex surgery or manipulation of the ambient $\mathrm{O}_{2}$ levels affects both the mother and the fetus (Ruijtenbeek et al. 2002a; Sutendra and Michelakis 2007). Many mammals also have a relatively long gestation period, thereby resulting in time consuming and expensive studies (Ruijtenbeek et al. 2002a). A new model dealing with these difficulties needs to be developed.

During the last years, our group has analyzed the developmental changes in the reactivity of chicken embryo systemic and PAs and the influence of prenatal insults, such as chronic hypoxia or malnutrition, on chicken cardiovascular development (van Golde et al. 1996; Mulder et al. 1997; van Golde et al. 1997; Mulder et al. 1998; van Golde et al. 1999; le Noble et al. 2000; Mulder et al. 2000; Ruijtenbeek et al. 2000; Carlo et al. 2001; Mulder et al. 2001; Mulder et al. 2002; Ruijtenbeek et al. 2002a; Ruijtenbeek et al. 2002b; Villamor et al. 2002; Ruijtenbeek et al. 2003a; Ruijtenbeek et al. 2003b; Villamor et al. 2004; Villamor et al. 2005). However, and although probably more is known about the descriptive embryology, teratology, and experimental embryology of the chicken embryo than of any other model organism, developmental changes in the reactivity of the chicken DA had not been studied. In the present Thesis we have completed an extensive characterization of the developmental pharmacology of the chicken DA and demonstrated its sensitivity to a wide range of vasoactive agonists including $\mathrm{O}_{2}$, prostanoids, $\mathrm{K}^{+}$ channel blockers, $\mathrm{NO}, \mathrm{CO}_{2}$, catecholamines, ET-1, AC activators, GC activators, PDE inhibitors, and ROK blockers. At the same time, the group of Dzialowski (University of North Texas) confirmed some of our results and added crucial new information for 
the understanding of chicken DA developmental vascular biology (Belanger et al. 2008; Greyner and Dzialowski 2008; Copeland and Dzialowski 2009). The main findings of the present Thesis can be summarized as follows:

1. The main vasoconstrictor of the mammalian DA, the postnatal increase in $\mathrm{O}_{2}$ tension, appears also to play a relevant role in the closure of the chicken DA (Chapter 2). $\mathrm{O}_{2}$ also has a profound modulatory effect on other vasoactive systems favoring the action of vasoconstrictors (Chapter 2) and decreasing the action of vasodilators (Chapters 3 and 4)

2. The main vasodilator of the mammalian $\mathrm{DA}, \mathrm{PGE}_{2}$, is a weak relaxant agent of the chicken DA which even stimulates vasoconstrictive receptors (Chapter 4).

3. The chicken DA undergoes a developmental increase in its contractile responsiveness (Chapter 2) and a developmental decrease in its responsiveness to several relaxant agonists (Chapters 3 and 4).

4. The chicken DA presents morphological and functional heterogeneity along its path between the PA and the aorta. Thus, the pulmonary side shows the structure of a muscular artery and responds to $\mathrm{O}_{2}$ with contraction, whereas the aortic part shows the morphology of an elastic artery and relaxes in response to $\mathrm{O}_{2}$ (Chapter 2). Apart from $\mathrm{O}_{2}$, there is a marked difference between the pulmonary and the aortic side in the responsiveness to contractile (Chapter 2) and relaxant agonists (Chapters 3 and 4).

5. Moderate changes in extracellular $\mathrm{pH}$ have profound effects on chicken DA tone. Hypercarbic and normocarbic acidosis induced ductal relaxation (Chapter 5).

6. Chronic hypoxia in ovo did not induce significant remodeling of chicken DA but altered ductal reactivity (Chapter 6).

\section{Developmental changes in chicken DA responsiveness to oxygen and other vasoconstrictors}

The fetal circulation is designed to meet the requirements of a rapidly growing organism existing at a low $\mathrm{PO}_{2}$ relative to postnatal life. Therefore, the assembly of a blood vessel into a well-organized and functional structure is essential for organ growth and development. In mature animals, VSM and endothelial cells, both highly specialized cells, have the principal function of regulating blood vessel tone, blood pressure, and blood flow distribution (Owens et al. 2004; Rzucidlo et al. 2007). 
During development, however, endothelial and VSM cells play a key role in blood vessel morphogenesis. These cells exhibit high rates of proliferation, migration, and production of extracellular matrix components that make up a major portion of the vessel wall. These processes occur while the new forming vessels are simultaneously acquiring the capacity to regulate vascular tone (Owens et al. 2004; Rzucidlo et al. 2007).

To ensure proper constriction after birth, the DA acquires vasoactive competence early in the development and changes in responsiveness with advancing gestational age (Smith 1998; Bergwerff et al. 1999; Clyman 2006). In Chapter 2, we show that a significant contraction to high- $\mathrm{K}^{+}$depolarizing solution is present in the 15-day DA (0.7 incubation), indicating that at this developmental stage DASMCs are already equipped with contractile proteins and a mature excitation-contraction coupling. The relative small increase in the response to depolarization between 15 and 19 days (2-fold), compared to the increase in carotid and femoral arteries (5-7 fold, le Noble et al. 2000), implies an early maturation of the SM in the DA.

As presented in Chapter 2, the 15-day DA did not respond to $\mathrm{O}_{2}$ or $\alpha$ adrenoceptor agonists, but the presence of responses to the TxA $\mathrm{A}_{2}$ mimetic U46619 and ET-1, in the 15-day DA, indicates that pharmacomechanical coupling is also developed rather early in this vessel. Accordingly, several studies in mammals indicate that the SMCs in the DA are more differentiated than those in other fetal arteries (Kim et al. 1993; Colbert et al. 1996; Sakurai et al. 1996).

As mentioned above, the immature (15-day) chicken DA was unresponsive to $\mathrm{O}_{2}$ and $\alpha$-adrenoceptor agonists. Interestingly, the time course of catecholamines in the plasma of chicken embryos is characterized by a maximum of epinephrine and NE at day 19, shortly before lung ventilation (i.e. internal pipping) is initiated (Wittmann and Prechtl 1991; Mulder et al. 2000). This process of internal pipping is also accompanied by an increase in $\mathrm{O}_{2}$ concentration. We have observed that the efficacy (but not the potency) of NE increased when 19-day DA was bubbled with high $\mathrm{O}_{2}$ concentrations. In addition, when 21-day DA was precontracted with $\mathrm{NE}$, the $\mathrm{O}_{2}$ evoked response was larger than under basal conditions. Therefore, regarding our results, one might speculate that the presence of higher $\mathrm{O}_{2}$ tension, higher catecholamine concentrations, the positive interactions between $\mathrm{O}_{2}$ - and NE-induced contractions, and a developmental increase in the sensitivity of the DA to these 
vasoactive mediators are critical factors involved in the closure of the chicken DA during transition to ex ovo life.

\section{Developmental changes in chicken DA responsiveness to relaxant agonists}

\subsection{Prostaglandins}

$\mathrm{PGE}_{2}$ plays a major role in prenatal patency and postnatal closure of the mammalian DA, namely during fetal life by exerting a potent relaxant effect (Smith 1998; Clyman 2006), and after birth by abruptly withdrawing its action. In the mammalian ductus, inhibition of PGs production by COX inhibitors induces a tonic contraction of the vessel (Smith et al. 1994; Smith and McGrath 1995; Nguyen et al. 1997; Smith 1998; Bhattacharya et al. 1999; Bouayad et al. 2001; Leonhardt et al. 2003; Kajino et al. 2004; Waleh et al. 2004). Most of the physiological functions that prostanoids exhibit in mammals seem to be present in avian and other non-mammalian vertebrates (Rowley 1991). Prostanoids are produced in chicken blood vessels and participate in the regulation of vascular tone (Chand and Eyre 1976; Claeys et al. 1981; Wideman et al. 1999). However, we observed that in the chicken DA COX inhibitors did not produce significant contractile effects (Chapter 2) and did not affect the responsiveness to other agonists (Chapter 3 ). This suggests that locally produced PGs are not important mediators in the control of chicken ductal tone. Accordingly, Dzialowski and Greyner (2008) demonstrated that COX inhibition did not produce any change in the basal tension of DA of another avian species, the emu.

When we analyzed the direct effects of $\mathrm{PGE}_{2}$ in chicken DA tone (Chapter 4), we observed that $\mathrm{PGE}_{2}$ is indeed a vasodilator but its relaxant response is masked by its ability to activate TP receptors. We found that TP receptor occupancy either by an agonist (U46619) or an antagonist (SQ29,548) results in the appearance or the increase of the relaxant response to $\mathrm{PGE}_{2}$. This is consistent with a stimulatory action of $\mathrm{PGE}_{2}$ on TP receptors. Nevertheless, the relaxant potency and efficacy of $\mathrm{PGE}_{2}$ in the chicken DA, even after blocking its effect on the TP receptor, was very low. Very recently, Greyner \& Dzialowski (2008) confirmed the contractile effects of $\mathrm{PGE}_{2}$, $\mathrm{PGD}_{2}$, and $\mathrm{PGF}_{2 \alpha}$ in the chicken DA. 


\subsection{Endothelium-dependent relaxation}

Stimulation of muscarinic receptors by ACh evokes an endothelium-dependent relaxation in systemic (aorta, femoral, carotid, mesenteric) and PAs of the chicken fetus (le Noble et al. 2000; Rouwet et al. 2000; Villamor et al. 2002; Martinez-Lemus et al. 2003; Nishimura et al. 2003). Endothelium-derived NO appears as the main mediator of this relaxation but EDHF might also be involved (le Noble et al. 2000; Villamor et al. 2002). Inhibition of the production of PGs (i.e. COX blockade) does not affect ACh-evoked relaxation of systemic or PAs (le Noble et al. 2000; Villamor et al. 2002). Although technical limitations have restricted the studies of endotheliumdependent relaxation to vessels from more mature fetal chickens, NO appears as a critical regulator of fetal circulation during earlier stages of development as well (Ungureanu-Longrois et al. 1997; Takahashi et al. 2001; Dunn et al. 2005; Groenendijk et al. 2005). In several mammalian species endothelium-dependent relaxation, particularly in the pulmonary circulation, is reduced during fetal life and transiently compromised immediately after birth (Abman et al. 1991; Boels et al. 1999; Villamor et al. 2003). Paradoxically, increased release of endogenous NO seems to be necessary for a smooth transition of the pulmonary circulation at birth (Abman et al. 1990; Abman 1999). In the chicken, endothelium-dependent relaxation of pulmonary and systemic arteries remain unchanged during the last phase of incubation which includes the gradual transition to postnatal life (i.e. during the processes of internal and external pipping, le Noble et al. 2000; Villamor et al. 2002). Therefore, the transient impairment of pulmonary endothelial function described in mammalian neonates is absent in the chicken.

The endothelium is also an important modulator of the vascular tone of the chicken DA during in ovo life and during its closure at hatching (Chapter 3). ACh induces a concentration-dependent response in DA in fetal chickens. Low concentrations induce endothelium-dependent relaxation of the chicken DA mediated via NO and EDHF. High concentrations induce an endothelium-dependent contraction. $\mathrm{O}_{2}$-induced contraction of the DA is also modulated by the endothelium: increases with inhibition of NOS or sGC and decreases in the presence of ET-1 receptor blockers. Endothelial damage is common to numerous vascular diseases but, interestingly, occurs as a normal developmental process in the DA. When examined by scanning electron microscopy, the endothelium of the DA from the fetus prior to internal pipping shows a smooth and continuous surface. In contrast, the intimal 
surface of DAs harvested from externally-pipped embryos has an irregular endothelial lining with protrusion and detachment of endothelial cells, leaving large areas of exposed subendothelial tissue. This process of endothelial detachment has been recently confirmed by other investigators (Belanger et al. 2008) and is accompanied by a marked impairment in NO production and endothelium-mediated relaxation (Chapter 3).

\subsection{Cyclic GMP-mediated relaxation}

As mentioned above, ACh-induced relaxation and NO production were markedly decreased in the DA of the externally-pipped 21-day chicken. In contrast, the relaxation induced by the cell-permeable analog of cGMP 8-Br-cGMP was not affected by age, suggesting that the mechanisms mediating cGMP-induced relaxation are preserved in the VSM of the closing DA (Chapter 3). We also observed that the response to the NO donor SNP was impaired by age, which might suggest that transition to ex ovo life is accompanied by a reduction in sGC activity. However, the response to the NO-independent $\mathrm{SGC}$ activator BAY 41-2272 remained unchanged in the 21-day DA. To explain the differences between SNP and BAY 41-2272, it should be taken into account that the release of NO from SNP is coupled to a process of bioactivation in the vascular tissue (Feelisch 1998) and this process might be altered by age in the DA.

\subsection{Cyclic AMP-mediated relaxation}

In Chapter 4 we show that the DA from 15-day chicken fetuses is more sensitive to $\mathrm{PGE}_{2}$ than the DA from 19-day fetuses. However, in the presence of a TP antagonist the relaxant responses to $\mathrm{PGE}_{2}$ are similar in 15 and 19 days, a result that indicate that the contribution of TP receptor activation in the response to $\mathrm{PGE}_{2}$ increases during maturation. In addition, from 19- to 21-day there is an additional reduction in the relaxant responses to $\mathrm{PGE}_{2}$ when $\mathrm{SQ} 29,548$ is present (i.e., independent of TP receptor activation). The relaxant response by the $\beta$-adrenoceptor agonist isoproterenol, but not those elicited by the AC activator forskolin or the PDE3 inhibitor milrinone, decreased with maturation. $\mathrm{PGE}_{2}$ and isoproterenol induce relaxation, at least partially, through the AC/cAMP pathway. Our results, therefore, suggest a developmental decrease in the relaxant efficacy of the AC/cAMP pathway during the transition to ex ovo life. Nevertheless, direct activation of AC with 
forskolin induced a similar relaxation at all stages of incubation. Thus, the developmental differences in the responses to $\mathrm{PGE}_{2}$ and isoproterenol from 19- to 21day seem to be due to changes in the coupling between their receptors and AC.

\section{The two sides of the chicken DA}

The chicken DA is the result of the fusion of two vessels with different embryological origin, morphology and functionality (Chapters 2, 3, 4, 5, 6 and Bergwerff et al. 1996; Bergwerff et al. 1999; Belanger et al. 2008; Greyner and Dzialowski 2008). The pulmonary side shows the structure of a muscular artery and responds to $\mathrm{O}_{2}$ with contraction, whereas the aortic part shows the morphology of an elastic artery and relaxes in response to $\mathrm{O}_{2}$ (Chapter 2). A markedly higher contractile efficacy of $\mathrm{NE}$ and U46619 was observed in the pulmonary side of the chicken DA (Chapter 2 and 4), while ACh, SNP and the NO-independent stimulator of sGC BAY 41-2272 induced larger relaxations in the aortic side of the vessel (Chapter 3). In addition, we show in Chapter 4 that isoproterenol, forskolin, and milrinone evoked significantly larger relaxations in the pulmonary side. This might indicate that the pulmonary side of the vessel is more sensitive to the vasodilators acting through cAMP-mediated pathway, whereas the aortic side would be more sensitive to cGMP-mediated relaxation. However, and surprisingly, the relaxation evoked by $\mathrm{PGE}_{2}$ was similar in both regions of the DA.

The pulmonary side appears to be the "real" DA in the chicken. Bergwerff et al $(1996 ; 1998 ; 1999)$ demonstrated that the distal elastic part of the chicken DA is of mesodermal origin and is the result of the incorporation of dorsal aorta tissue, whereas the muscular pulmonary side was shown to consist almost exclusively of neural crest derived cells. In the majority of mammals, normal DA closure takes place from the pulmonary to the aortic end (Gittenberger-de Groot et al. 1985; Giuriato et al. 1993), but the presence of areas with so marked differences in reactivity have not previously been described. The heterogeneity of the chicken DA makes the vessel particularly attractive for the study of its developmental vascular biology but also poses a methodological problem. As mentioned in Chapter 2, the maximal length of the rings allowed in the myographs that we used is $2 \mathrm{~mm}$, whereas the length of the chicken DA is $\sim 4-6 \mathrm{~mm}$. Although the pulmonary and the aortic side of the ductus can be clearly differentiated during the dissection, when mounting the central portion of the DA it is difficult to control for the exact amount of tissue of each part that is finally 
present in the myograph. In addition, putative developmental changes in the proportion between the two parts of the DA might influence developmental changes in the responsiveness to the different agonists.

\section{Changes in $\mathrm{pH}$ and $\mathrm{DA}$ reactivity}

Respiratory and metabolic acidosis are frequent events in the clinical course of very preterm infants (Woodgate and Davies 2001; Bancalari et al. 2005; Fabres et al. 2007; Miller and Carlo 2007). Moreover, permissive hypercarbia in which higher levels of $\mathrm{PaCO}_{2}$ are tolerated (provided the arterial $\mathrm{pH}$ does not fall below a preset minimal value) is often used in the ventilatory management of extremely premature infants, in an attempt to reduce ventilator-induced lung injury (Mariani et al. 1999; Woodgate and Davies 2001; Miller and Carlo 2007). Changes in pH can have profound influence on pulmonary and systemic vascular resistance and on the reactivity of the vessels to agonists (Sweeney et al. 1998; Sweeney et al. 1999; Lynch et al. 2000; Hyvelin et al. 2004; Wray and Smith 2004). Surprisingly, the effects of pH on the reactivity of DA had not been previously studied.

We have observed (Chapter 5) that in vitro hypercarbic and normocarbic acidosis induced relaxation of the chicken DA. This relaxation varied depending on the agonist used to contract the vessel but, interestingly, it was maximal when DA contraction was induced by $\mathrm{O}_{2}$. Moreover, a marked reduction in DA tone was achieved at clinically significant levels of acidosis (i.e. $\mathrm{pH}$ 7.25). When the mechanisms putatively involved in acidosis-induced ductal relaxation were analyzed, we observed that the presence of the non selective $\mathrm{K}^{+}$channel blocker TEA or the selective $\mathrm{BK}_{\mathrm{Ca}}$ channels inhibitor iberiotoxin abolished the relaxation evoked by hypercarbic acidosis but not by normocarbic acidosis. Therefore, our data suggest that stimulation of $\mathrm{BK}_{\mathrm{Ca}}$ channels may account for the relaxing effects of hypercarbic acidosis in the chicken DA. Our data, although in vitro and in a non-mammalian species, suggest a role for $\mathrm{pH}$ in the control of ductal tone and warrant confirmation in the mammalian DA.

\section{Chronic prenatal hypoxia and DA morphology and function}

An adverse intrauterine environment is most frequently the consequence of placental insufficiency resulting in decreased availability of nutrients and $\mathrm{O}_{2}$. Chronic exposure to hypoxia or undernutrition or a combination of both these stressors during prenatal 
life may interfere with fetal growth, which may result in changes in arterial function and structure. The chicken embryo is an excellent model for the study of the consequences of hypoxia-induced prenatal growth retardation (Ruijtenbeek et al. 2000; Ruijtenbeek et al. 2002a; Ruijtenbeek et al. 2003a; Ruijtenbeek et al. 2003b; Villamor et al. 2004). In Chapter 6 we analyzed the effects of in ovo hypoxia $\left(15 \% \mathrm{O}_{2}\right.$ from day 6 to 19 of the 21-day incubation period) on chicken DA morphometry and reactivity. We did not find significant evidences for an accelerated or delayed anatomical remodeling of the DA in the growth-retarded chicken fetuses. However, the proportion of DA with muscular morphology was significantly reduced in the hypoxic animals and the vessels showed an enhanced contractile response to $\alpha$ adrenergic agonists and an impaired relaxation to the $\beta$-adrenoceptor agonist isoproterenol, the endothelium-dependent vasodilator ACh and the endotheliumindependent vasodilator SNP. Our observations support the concept that prolonged patency of the DA in infants with IUGR may be partially related with hypoxiainduced changes in local vascular mechanisms.

In contrast to our results, Copeland \& Dzialowski (2009) reported that $15 \% \mathrm{O}_{2}$ from day 0 of incubation induced a delayed response to catecholamines and $\mathrm{O}_{2}$. Critical time windows exist during development and if environmental changes are experienced in the window of vulnerability, then the trajectory of development of the responding organ may be changed in ways that result in transient or persistent alterations (Nathanielsz 2006). The difference between our results and the ones of Copeland \& Dzialowski (2009), suggest that exposure of the chicken embryo to hypoxia during very early development is critical for the development of an impaired contractile ability of the DA.

\section{Future Perspectives}

6.1 Further characterization of the maturation of $\mathrm{O}_{2}$ sensing and signalling in the DA Although modulated by the endothelium, the DA constriction in response to $\mathrm{O}_{2}$ persists in vitro and after endothelial denudation, indicating that the core mechanism resides within the SMCs (Tristani-Firouzi et al. 1996). In the DA from rabbit (Tristani-Firouzi et al. 1996) and human term fetuses (Michelakis et al. 2000), $\mathrm{O}_{2}$ induced constriction is thought to be mediated by the inhibition of $K_{V}$ channels, resulting in membrane depolarization, and $\mathrm{Ca}^{2+}$ entry through voltage operated $\mathrm{Ca}^{2+}$ channels. Michelakis et al. (2000) proposed a model in which a rise in $\mathrm{O}_{2}$ modulates 
the function of the mitochondrial ETC (the sensor), leading to an increased production of $\mathrm{H}_{2} \mathrm{O}_{2}$ (the mediator) which causes the inhibition of $\mathrm{K}_{\mathrm{V}}$ channels (the effector). Very recently, $\mathrm{Ca}^{2+}$ entry through SOCs (Hong et al. 2006; Clyman et al. 2007; Greyner and Dzialowski 2008) or its release from intracellular stores (Keck et al. 2005), and ROK-mediated $\mathrm{Ca}^{2+}$-sensitization (Hong et al. 2006; Clyman et al. 2007; Kajimoto et al. 2007) have been identified as other downstream effectors of the $\mathrm{O}_{2}$-sensing system in the DA of several species including the chicken (Greyner and Dzialowski 2008).

The mechanisms underlying the failure of the preterm DA to constrict and close after birth are not completely elucidated. For numerous investigators a key issue is a better understanding of the response to $\mathrm{O}_{2}$ with advancing gestation and the mechanisms involved in this developmental process (Michelakis et al. 2000; Michelakis et al. 2002; Thebaud et al. 2004; Clyman 2006; Thebaud et al. 2008). The reduced response to $\mathrm{O}_{2}$ in preterm DA may reflect a deficiency in the sensor(s), the mediator(s), the effector(s) or a combination of these. As mentioned above, we found that responsiveness of chicken DA to $\mathrm{O}_{2}$ was very weak or absent at day 15 but present at day 19 of incubation and that the pulmonary side of the vessel responds to $\mathrm{O}_{2}$ with contraction, i.e. similar to the mammalian DA, whereas the aortic part relaxes in response to $\mathrm{O}_{2}$ (Bergwerff et al. 1999; Agren et al. 2007; Greyner and Dzialowski 2008). Therefore, by comparing the portion of the vessel that responds to $\mathrm{O}_{2}$ with contraction (i.e. the pulmonary side of the 19-20 d DA) with the one that responds with relaxation (i.e. the aortic side of the 19-20 d DA) and the one unresponsive to $\mathrm{O}_{2}$ (i.e. the pulmonary side of the $15 \mathrm{~d}$ DA), the chicken DA offers a unique model to obtain information about the maturation of the mechanisms involved in $\mathrm{O}_{2}$ responsiveness. Further investigations are warranted to analyze the involvement of the mitochondrial ETC as sensor, $\mathrm{H}_{2} \mathrm{O}_{2}$ and other ROS as mediators, and $\mathrm{K}_{\mathrm{V}}$ channels, voltage and SOCs, intracellular $\mathrm{Ca}^{2+}$ stores, and ROK as effectors of $\mathrm{O}_{2}$-induced contraction in the DA of developing fetal chickens.

\subsection{The chicken fetus as model for the study of $\mathrm{O}_{2}$ sensing/signalling in other vascular} beds.

The DA belongs to a specialized system of $\mathrm{O}_{2}$-sensitive organs and tissues in the body that includes the PAs, the carotid body and the neuroepithelial body among others. These tissues share striking similarities in the their response to changes in $\mathrm{O}_{2}$ tension (Weir et al. 2002; Weir et al. 2005; Aaronson et al. 2006; Sutendra and Michelakis 
2007; Weir et al. 2008). However, if the mechanisms responsible for SM contraction in hypoxic pulmonary vasoconstricition and normoxic contraction of the DA are virtually the same, why is the response to a change in $\mathrm{O}_{2}$ diametrically opposite? Numerous investigators agree that a change in the redox status of the SMCs in the PA and DA initiates the change in vascular tone (Weir et al. 2002; Weir et al. 2005; Aaronson et al. 2006; Sutendra and Michelakis 2007; Weir et al. 2008). Exactly what the redox signal may be and the subsequent signalling sequence remains to be determined. The hypoxic vasoconstriction of pulmonary vessels is a highly conserved adaptive physiological mechanism that optimizes $\mathrm{O}_{2}$ saturation of pulmonary venous blood by increasing pulmonary vascular resistance in poorly aerated lung regions (Villamor et al. 1997; Michelakis et al. 2004; Moudgil et al. 2005; Weir et al. 2005; Aaronson et al. 2006; Russell et al. 2008). In contrast, the systemic vasculature frequently responds to hypoxia with vasodilation in an effort to maintain adequate tissue oxygenation (Russell et al. 2008). In fetal chickens, the DA (pulmonary side) and the femoral arteries respond to hypoxia with relaxation (Ruijtenbeek et al. 2002b) and the aortic side of the DA, the intrapulmonary arteries (Zoer et al. 2009) and the chorioallantoic arteries (Lindgren et al. 2009) with contraction. The mechanisms that initiate, differentiate and regulate this variety of vascular responses to $\mathrm{O}_{2}$ need to be elucidated. In addition, the $\mathrm{O}_{2}$ - sensitive vessels of the chicken fetus offer a unique model for the analysis of new mediators, such as sphingomyelinase (Cogolludo et al. 2009) or hydrogen sulfide (Olson et al. 2006), which have been suggested to participate in the process of vascular $\mathrm{O}_{2}$ sensing/signalling.

\subsection{Effects of prenatal hormonal environment on the development of the DA}

Among prematurely born infants, females have an advantage compared to males, with a significantly greater chance of surviving, and a better outcome with less morbidity than male infants with similar birth weights and gestational ages (Ingemarsson 2003; Elsmen et al. 2004; Vatten and Skjaerven 2004). The biological mechanisms contributing to the male disadvantage or female advantage have not been elucidated. However, speculations involve estrogen and androgens. The fetus is supplied from the placenta with estrogen in increasing amounts during the gestation and premature cessation has been shown to contribute to perinatal morbidity, an effect that may be higher in males since they have no own production of estrogen (Trotter et al. 1999; Derzbach et al. 2005). 
One of the neonatal complications that is more common in preterm males than females is PDA (Stevenson et al. 2000). Differences in vascular reactivity depending on gender have been shown in many vascular responses in both systemic and PAs (Polderman et al. 1993; Hayashi et al. 1995; Earley and Resta 2002; Sader and Celermajer 2002). Both endothelium-dependent and -independent responses differ between males and females. Sex hormones seem to play a role in regulating the vascular response, both in long term and short term (Schwertz and Penckofer 2001; Sader and Celermajer 2002; Khalil 2005). Estrogens have been shown to regulate the gene expression of $\mathrm{K}^{+}$and $\mathrm{Ca}^{2+}$ channels and to play a role in regulation of $\mathrm{Ca}^{2+}$ handling (Orshal and Khalil 2004; Tsang et al. 2004).

Sexual differentiation occurs in opposite ways in birds and mammals. In mammals, the phenotype of homogametic sex (female) develops in the (relative) absence of steroids and in the heterogametic sex (male) the presence of testosterone and other testicular hormones is a preliminary condition for development of male characteristics (Biau et al. 2006). In the absence of testicular hormones development takes the feminine course. In contrast, birds develop masculine characteristics in the absence of estrogens, while in females (the heterogametic sex), extensive expression of the aromatase gene (around day 5-6 of incubation) leads to estrogen synthesis (Bruggeman et al. 2002; Biau et al. 2006). Already at 7.5 day of incubation, plasma levels of steroids differ between males and females (Bruggeman et al. 2002).

Another hormone with a possible role regulating DA development is thyroid hormone. Several plasma-membrane ion transporters including, $\mathrm{K}_{\mathrm{V}}$ channels, are regulated at both the transcriptional and post-transcriptional levels by thyroid hormone (Ishikawa et al. 1989; Ojamaa et al. 2000; Owen et al. 2007) and an association between PDA and hypothyroidism, in term as well as in preterm infants, has also been found (Nakagawa 1993; Allegaert et al. 2004; Guarnieri et al. 2008; van Wassenaer and Kok 2008).

Manipulation of the hormonal environment of the chicken embryo can be easily performed by injection, into the albumen of fertilized eggs, of aromatase inhibitors (which blocks the synthesis of estrogen from testosterone, Bruggeman et al. 2002) or anti-thyroid drugs (Liu et al. 2003; Liu and Porter 2004). Therefore the chicken offers a unique model to obtain information about the influence of hormones in the maturation of the DA. Also the direct effect of the hormones in DA reactivity remains to be studied. 


\subsection{Responsiveness of chicken DA to isoprostanes}

Isoprostanes are PG isomers that are produced in vivo primarily by a free radicalcatalyzed peroxidation of polyunsaturated fatty acids (Janssen et al. 2005; Janssen 2008). Initially, isoprostanes were recognized as being valuable markers of oxidative stress and numerous pathological conditions have been shown to be associated with increases in urinary, plasma, and tissue levels of isoprostanes. Moreover, few members of the isoprostane family are biologically active and could contribute to the functional consequences of oxidant injury and mediate many of the features of the disease states for which they are used as indicators (Janssen et al. 2005; Janssen 2008).

Newborns and particularly preterm infants are very susceptible to oxidative stress. A large growing body of literature is addressing the possible role of isoprostanes in the pathophysiology of several neonatal conditions, such as asphyxia, intraventricular hemorrhage, periventricular leukomalacia, bronchopulmonary dysplasia, pulmonary hypertension and retinopathy of prematurity (Hardy et al. 2000; Ahola et al. 2004; Weinberger et al. 2006; Yi et al. 2006). However, the possible contribution of isoprostanes to the normal transition to extra-uterine life remains largely unknown. There is increasing evidence that isoprostanes exert a wide variety of actions on VSM and endothelial cells. Many have described contractile responses to isoprostanes in a wide variety of vascular tissues, generally via stimulation of TP receptors (Oliveira et al. 2000; Gonzalez-Luis et al. 2005; Janssen et al. 2005; Janssen 2008; Mueed et al. 2008).

In addition, and depending on the compound and the vascular bed vasodilatory actions of isoprostanes have been also identified (Jourdan et al. 1997; Zhang et al. 2003; Gonzalez-Luis et al. 2005; Zhang et al. 2005). These actions were frequently masked by the vasoconstrictive effects of isoprostanes on TP receptors and were only observed when these receptors were blocked by antagonists (such as SQ 29,548 or ICI 192605), or saturated by an agonist (such as U46619, Jourdan et al. 1997; Zhang et al. 2003; Zhang et al. 2005). However, the effects of isoprostanes have not been studied in the DA of any species. Our preliminary results suggest that the isoprostanes 8-iso$\mathrm{PGE}_{2}$ and 8-iso-PGF ${ }_{2 \alpha}$ induce TP-mediated contraction of the chicken DA. Similarly to $\mathrm{PGE}_{2}, 8$-iso- $\mathrm{PGE}_{2}$ induced ductal relaxation when the TP receptor was blocked or 
saturated. The developmental changes in the DA responsiveness to isoprostanes warrant future investigation.

\subsection{Responsiveness of chicken DA to CO}

Another mediator that plays a relevant role in the control of the mammalian DA tone and whose study is warranted in the non-mammalian DA is CO (Smith 1998; Baragatti et al. 2007). CO is produced by the degradation of heme by intracellular HO. Different research groups have provided evidence of the ability of CO to relax vascular tone similar to that of NO (i.e. through activation of sGC, Wang et al. 1997; Werkstrom et al. 1997; Villamor et al. 2000; Komuro et al. 2001; Leo et al. 2008). The expression and activity of $\mathrm{HO}$ as well as the developmental changes in the responsiveness of the chicken DA to $\mathrm{CO}$ are currently under investigation in our laboratory.

\subsection{Effects of prenatal/perinatal insults on DA development.}

As mentioned elsewhere, the egg-chicken model offers the possibility of manipulating the environment of development without interferences of maternal hormonal, metabolic, or hemodynamic alterations. In the present Thesis we analyzed the effects of chronic prenatal hypoxia on chicken DA development. Very recently, Copeland \& Dzialowski (2009) demonstrated that incubation in hyperoxia accelerates chicken DA development. Preliminary results of our laboratory also indicate that premature exposure to hyperoxia induces significant alterations in the developmental trajectory of the chicken DA. Other prenatal insults that we demonstrated to induce alterations in chicken perinatal vascular homeostasis are malnutrition (Ruijtenbeek et al. 2003b), exposure to cigarette smoke extract (Carlo et al. 2001) or inhibition of NOS (Villamor et al. 2005). Injection of drugs (Carlo et al. 2001; Villamor et al. 2005) or gene transfer (Williams et al. 2006) during incubation open a new territory for the investigation of the pathways involved in the developmental vascular biology of the DA. 
Aaronson, P. I., T. P. Robertson, et al. (2006). "Hypoxic pulmonary vasoconstriction: mechanisms and controversies." J Physiol 570(Pt 1): 53-8.

Abman, S. H. (1999). "Abnormal vasoreactivity in the pathophysiology of persistent pulmonary hypertension of the newborn." Pediatr Rev 20(11): e103-9.

Abman, S. H., B. A. Chatfield, et al. (1990). "Role of endothelium-derived relaxing factor during transition of pulmonary circulation at birth." Am J Physiol 259(6 Pt 2): H1921-7.

Abman, S. H., B. A. Chatfield, et al. (1991). "Maturational changes in endotheliumderived relaxing factor activity of ovine pulmonary arteries in vitro." $\underline{\mathrm{Am} \mathrm{J}}$ Physiol 260(4 Pt 1): L280-5.

Agren, P., A. L. Cogolludo, et al. (2007). "Ontogeny of chicken ductus arteriosus response to oxygen and vasoconstrictors." Am J Physiol Regul Integr Comp Physiol 292(1): R485-96.

Ahola, T., V. Fellman, et al. (2004). "Plasma 8-isoprostane is increased in preterm infants who develop bronchopulmonary dysplasia or periventricular leukomalacia." Pediatr Res 56(1): 88-93.

Allegaert, K., C. Vanhole, et al. (2004). "Association of patent ductus arteriosus and severe hypothyroidism in term newborns: coincidence or causal?" J Matern Fetal Neonatal Med 16(6): 339-41.

Altimiras, J. and D. A. Crossley, 2nd (2000). "Control of blood pressure mediated by baroreflex changes of heart rate in the chicken embryo (Gallus gallus)." Am J Physiol Regul Integr Comp Physiol 278(4): R980-6.

Alzamora-Castro, V., G. Battilana, et al. (1960). "Patent ductus arteriosus and high altitude." Am J Cardiol 5: 761-3.

Archer, S. and E. Michelakis (2002). "The mechanism(s) of hypoxic pulmonary vasoconstriction: potassium channels, redox $\mathrm{O}(2)$ sensors, and controversies." News Physiol Sci 17: 131-7.

Archer, S. L., J. Huang, et al. (1993). "A redox-based O2 sensor in rat pulmonary vasculature." Circ Res 73(6): 1100-12.

Archer, S. L., E. K. Weir, et al. (2000). "Molecular identification of O2 sensors and O2-sensitive potassium channels in the pulmonary circulation." Adv Exp Med Biol 475: 219-40.

Arishima, K., T. Takizawa, et al. (1995). "Propranolol inhibits the spontaneous closure of the ductus arteriosus in newborn rats." J Vet Med Sci 57(5): 943-4.

Arnal, J. F., A. T. Dinh-Xuan, et al. (1999). "Endothelium-derived nitric oxide and vascular physiology and pathology." Cell Mol Life Sci 55(8-9): 1078-87.

Aronson, S., G. Gennser, et al. (1970). "Innervation and contractile response of the human ductus arteriosus." Eur J Pharmacol 11(2): 178-86.

Bancalari, E., N. Claure, et al. (2005). "Patent ductus arteriosus and respiratory outcome in premature infants." Biol Neonate 88(3): 192-201.

Baragatti, B., F. Brizzi, et al. (2003). "Cyclooxygenase-1 and cyclooxygenase- 2 in the mouse ductus arteriosus: individual activity and functional coupling with nitric oxide synthase." Br J Pharmacol 139(8): 1505-15.

Baragatti, B., F. Brizzi, et al. (2007). "Interactions between NO, CO and an endothelium-derived hyperpolarizing factor (EDHF) in maintaining patency of the ductus arteriosus in the mouse." Br J Pharmacol 151(1): 54-62.

Bateson, E. A., R. Schulz, et al. (1999). "Response of fetal rabbit ductus arteriosus to bradykinin: role of nitric oxide, prostaglandins, and bradykinin receptors." Pediatr Res 45(4 Pt 1): 568-74. 
Belanger, C., J. Copeland, et al. (2008). "Morphological changes in the chicken ductus arteriosi during closure at hatching." Anat Rec (Hoboken) 291(8): 1007-15.

Bellaris, A. and M. Osmond (1998). The atlas of chick development, Academic Press.

Benson, L. N. and K. N. Cowan (2002). The arterial duct: its persistence and its patency. Paediatric Cardiology. R. H. Anderson, E. J. Baker, F. J. Macartney, M. L. Rigby, E. A. Shinebourne and M. Tynan, Churchill Livingstone: 14051459.

Bergwerff, M., M. C. DeRuiter, et al. (1999). "Comparative anatomy and ontogeny of the ductus arteriosus, a vascular outsider." Anat Embryol (Berl) 200(6): 55971.

Bergwerff, M., M. C. DeRuiter, et al. (1996). "Onset of elastogenesis and downregulation of smooth muscle actin as distinguishing phenomena in artery differentiation in the chick embryo." Anat Embryol (Berl) 194(6): 545-57.

Bergwerff, M., M. E. Verberne, et al. (1998). "Neural crest cell contribution to the developing circulatory system: implications for vascular morphology?" $\underline{\text { Circ }}$ Res 82(2): 221-31.

Bhattacharya, M., P. Asselin, et al. (1999). "Developmental changes in prostaglandin $\mathrm{E}(2)$ receptor subtypes in porcine ductus arteriosus. Possible contribution in altered responsiveness to prostaglandin E(2)." Circulation 100(16): 1751-6.

Biau, S., S. Bayle, et al. (2006). "The chick embryo: an animal model for detection of the effects of hormonal compounds." Anal Bioanal Chem.

Blackburn, S. T. (2003). Maternal, fetal, and neonatal physiology : A clinical perspective, Saunders, Elsevier Science.

Bodach, E., F. Coceani, et al. (1980). "The response of the isolated ductus arteriosus to transmural stimulation and drugs." Br J Pharmacol 71(2): 419-27.

Boels, P. J., J. Deutsch, et al. (1999). "Maturation of the response to bradykinin in resistance and conduit pulmonary arteries." Cardiovasc Res 44(2): 416-28.

Bolotina, V. M., S. Najibi, et al. (1994). "Nitric oxide directly activates calciumdependent potassium channels in vascular smooth muscle." Nature 368(6474): 850-3.

Boreus, L. O., T. Malmfors, et al. (1969). "Demonstration of adrenergic receptor function and innervation in the ductus arteriosus of the human fetus." Acta Physiol Scand 77(3): 316-21.

Born, G. V., G. S. Dawes, et al. (1956). "The constriction of the ductus arteriosus caused by oxygen and by asphyxia in newborn lambs." J Physiol 132(2): 30442.

Bos, C. L., D. J. Richel, et al. (2004). "Prostanoids and prostanoid receptors in signal transduction." Int J Biochem Cell Biol 36(7): 1187-205.

Bouayad, A., X. Hou, et al. (2002). "Cyclooxygenase isoforms and prostaglandin E2 receptors in the ductus arteriosus." Current Therapeutic Research 63(10): 669681.

Bouayad, A., H. Kajino, et al. (2001). "Characterization of PGE2 receptors in fetal and newborn lamb ductus arteriosus." Am J Physiol Heart Circ Physiol 280(5): H2342-9.

Bruggeman, V., P. Van As, et al. (2002). "Developmental endocrinology of the reproductive axis in the chicken embryo." Comp Biochem Physiol A Mol Integr Physiol 131(4): 839-46.

Burton, F. G., J. M. Stevensson, et al. (1989). "The relationship between eggshell porosity and air space in gas tension measured before and during the 
parafoetal period and their effects on the hatching process in the domestic fowl." Respir. Physiology 77: 89-100.

Bustamante, S. A., Y. Pang, et al. (1996). "Inducible nitric oxide synthase and the regulation of central vessel caliber in the fetal rat." Circulation 94(8): 1948-53.

Carlo, W. F., E. Villamor, et al. (2001). "Chronic exposure to cigarette smoke extract impairs endothelium-dependent relaxation of chicken embryo pulmonary arteries." Biol Neonate 80(3): 247-50.

Carvajal, J. A., A. M. Germain, et al. (2000). "Molecular mechanism of cGMPmediated smooth muscle relaxation." J Cell Physiol 184(3): 409-20.

Chand, N. and P. Eyre (1976). "Effects of prostaglandins E1, E2 and F2 alpha and polyphloretin phosphate of domestic fowl." Arch Int Pharmacodyn Ther 221(2): 261-65.

Claeys, M., E. Wechsung, et al. (1981). "Prostaglandin E2 is the prevalent metabolite of arachidonic acid formed by aortic tissue of the chicken." Arch Int Pharmacodyn Ther 249(2): 312-5.

Clarke, J. A. (1965). "An X-ray microscopic study of the vasa vasorum of the human ductus arteriosus." J Anat 99(Pt 3): 527-37.

Clyman, R. I. (2006). "Mechanisms regulating the ductus arteriosus." Biology of the Neonate 89(4): 330-335.

Clyman, R. I., C. Y. Chan, et al. (1999a). "Permanent anatomic closure of the ductus arteriosus in newborn baboons: the roles of postnatal constriction, hypoxia, and gestation." Pediatr Res 45(1): 19-29.

Clyman, R. I., Y. Q. Chen, et al. (2001). "In utero remodeling of the fetal lamb ductus arteriosus: the role of antenatal indomethacin and avascular zone thickness on vasa vasorum proliferation, neointima formation, and cell death." Circulation 103(13): 1806-12.

Clyman, R. I., P. Hardy, et al. (1999b). "Cyclooxygenase-2 plays a significant role in regulating the tone of the fetal lamb ductus arteriosus." Am J Physiol 276(3 Pt 2): R913-21.

Clyman, R. I., F. Mauray, et al. (1989). "Influence of increased pulmonary vascular pressures on the closure of the ductus arteriosus in newborn lambs." Pediatr Res 25(2): 136-42.

Clyman, R. I., F. Mauray, et al. (1983). "Factors determining the loss of ductus arteriosus responsiveness to prostaglandin E." Circulation 68(2): 433-6.

Clyman, R. I., F. Mauray, et al. (1980). "Age-dependent sensitivity of the lamb ductus arteriosus to indomethacin and prostaglandins." J Pediatr 96(1): 94-8.

Clyman, R. I., S. R. Seidner, et al. (2002). "VEGF regulates remodeling during permanent anatomic closure of the ductus arteriosus." Am J Physiol Regul Integr Comp Physiol 282(1): R199-206.

Clyman, R. I., N. Waleh, et al. (1998). "Regulation of ductus arteriosus patency by nitric oxide in fetal lambs: the role of gestation, oxygen tension, and vasa vasorum." Pediatr Res 43(5): 633-44.

Clyman, R. I., N. Waleh, et al. (2007). "Calcium-dependent and calcium-sensitizing pathways in the mature and immature ductus arteriosus." Am J Physiol Regul Integr Comp Physiol 293(4): R1650-6.

Coceani, F., C. Ackerley, et al. (2001). "Function of cyclo-oxygenase-1 and cyclooxygenase- 2 in the ductus arteriosus from foetal lamb: differential development and change by oxygen and endotoxin." Br J Pharmacol 132(1): 241-51. 
Coceani, F., S. Barogi, et al. (2005). "Cyclooxygenase isoenzymes and patency of ductus arteriosus." Prostaglandins Leukot Essent Fatty Acids 72(2): 71-7.

Coceani, F. and L. Kelsey (1991). "Endothelin-1 release from lamb ductus arteriosus: relevance to postnatal closure of the vessel." Can J Physiol Pharmacol 69(2): 218-21.

Coceani, F. and L. Kelsey (2000). "Endothelin-1 release from the lamb ductus arteriosus: are carbon monoxide and nitric oxide regulatory agents?" Life Sci 66(26): 2613-23.

Coceani, F., L. Kelsey, et al. (1992). "Evidence for an effector role of endothelin in closure of the ductus arteriosus at birth." Can J Physiol Pharmacol 70(7): 1061-4.

Coceani, F., L. Kelsey, et al. (1994). "Occurrence of endothelium-derived relaxing factor--nitric oxide in the lamb ductus arteriosus." Can J Physiol Pharmacol 72(1): 82-8.

Coceani, F., L. Kelsey, et al. (2002). "The response of the lamb ductus arteriosus to endothelin: developmental changes and influence of light." Life Sci 71(10): 1209-17.

Coceani, F., L. Kelsey, et al. (1997). "Carbon monoxide formation in the ductus arteriosus in the lamb: implications for the regulation of muscle tone." $\mathrm{Br} \mathrm{J}$ Pharmacol 120(4): 599-608.

Coceani, F., Y. Liu, et al. (1999). "Endothelin A receptor is necessary for O(2) constriction but not closure of ductus arteriosus." Am J Physiol 277(4 Pt 2): H1521-31.

Coceani, F., Y. A. Liu, et al. (2000). "Deletion of the endothelin-A-receptor suppresses oxygen-induced constriction but not postnatal closure of the ductus arteriosus." J Cardiovasc Pharmacol 36(5 Suppl 1): S75-7.

Coceani, F. and P. M. Olley (1973). "The response of the ductus arteriosus to prostaglandins." Can J Physiol Pharmacol 51(3): 220-5.

Cogolludo, A., L. Moreno, et al. (2009). "Activation of neutral sphingomyelinase is involved in acute hypoxic pulmonary vasoconstriction." Cardiovasc Res 82(2): 296-302.

Colbert, M. C., M. L. Kirby, et al. (1996). "Endogenous retinoic acid signaling colocalizes with advanced expression of the adult smooth muscle myosin heavy chain isoform during development of the ductus arteriosus." $\underline{\text { Circ Res }}$ 78(5): 790-8.

Coleman, H. A., M. Tare, et al. (2004). "Endothelial potassium channels, endothelium-dependent hyperpolarization and the regulation of vascular tone in health and disease." Clin Exp Pharmacol Physiol 31(9): 641-9.

Copeland, J. and E. M. Dzialowski (2009). "Effects of hypoxic and hyperoxic incubation on the reactivity of the chicken embryo (Gallus gallus) ductus arteriosi in response to catecholamines and oxygen." Exp Physiol 94(1): 15261.

Corbet, A. J. (1998). Medical Manipulation of the Ductus Arteriosus. The Science and Practice of Pediatric Cardiology. A. Garson, J. T. Bricker, D. J. Fisher and S. R. Neish. Baltimore, Maryland, Williams \& Wilkins. II.

Cotton, R. B., M. T. Stahlman, et al. (1978). "Medical management of small preterm infants with symptomatic patent ductus arteriosus." J Pediatr 92(3): 467-73.

de Ruiter, M. C., A. C. Gittenberger-de Groot, et al. (1989). "The special status of the pulmonary arch artery in the branchial arch system of the rat." Anat Embryol (Berl) 179(4): 319-25. 
Derzbach, L., A. Treszl, et al. (2005). "Gender dependent association between perinatal morbidity and estrogen receptor-alpha Pvull polymorphism." J Perinat Med 33(5): 461-2.

Doyle, L. W. (2001). "Outcome at 5 years of age of children 23 to 27 weeks' gestation: refining the prognosis." Pediatrics 108(1): 134-41.

Duchen, M. R. (1999). "Contributions of mitochondria to animal physiology: from homeostatic sensor to calcium signalling and cell death." J Physiol 516 ( Pt 1): $1-17$.

Dunn, L. K., S. K. Gruenloh, et al. (2005). "Chick chorioallantoic membrane as an in vivo model to study vasoreactivity: characterization of developmentdependent hyperemia induced by epoxyeicosatrienoic acids (EETs)." Anat Rec A Discov Mol Cell Evol Biol 285(2): 771-80.

Earley, S. and T. C. Resta (2002). "Estradiol attenuates hypoxia-induced pulmonary endothelin-1 gene expression." Am J Physiol Lung Cell Mol Physiol 283(1): L86-93.

Eldridge, F. L., H. N. Hultgren, et al. (1954). "The physiologic closure of the ductus arteriosus in newborn infants: a preliminary report." Science 119(3099): 7312.

Eliot, R. J., R. Lam, et al. (1980). "Plasma catecholamine concentrations in infants at birth and during the first 48 hours of life." J Pediatr 96(2): 311-5.

Elsmen, E., I. Hansen Pupp, et al. (2004). "Preterm male infants need more initial respiratory and circulatory support than female infants.[see comment]." Acta Paediatrica 93(4): 529-33.

Fabres, J., W. A. Carlo, et al. (2007). "Both extremes of arterial carbon dioxide pressure and the magnitude of fluctuations in arterial carbon dioxide pressure are associated with severe intraventricular hemorrhage in preterm infants." Pediatrics 119(2): 299-305.

Fay, F. S. (1971). "Guinea pig ductus arteriosus. I. Cellular and metabolic basis for oxygen sensitivity." Am J Physiol 221(2): 470-9.

Fay, F. S. and F. F. Jobsis (1972). "Guinea pig ductus arteriosus. 3. Light absorption changes during response to O 2." Am J Physiol 223(3): 588-95.

Fineman, J. R., Y. Takahashi, et al. (1998). "Endothelin-receptor blockade does not alter closure of the ductus arteriosus." Am J Physiol 275(5 Pt 2): H1620-6.

Friedman, W. F., K. M. Fitzpatrick, et al. (1978). "The patent ductus arteriosus." Clin Perinatol 5(2): 411-36.

Friedman, W. F., M. P. Printz, et al. (1983). "The vasoactivity of the fetal lamb ductus arteriosus studied in utero." Pediatr Res 17(5): 331-7.

Furchgott, R. F. and P. M. Vanhoutte (1989). "Endothelium-derived relaxing and contracting factors." Faseb J 3(9): 2007-18.

Gersony, W. M., G. J. Peckham, et al. (1983). "Effects of indomethacin in premature infants with patent ductus arteriosus: results of a national collaborative study." J Pediatr 102(6): 895-906.

Gilbert, E. F., H. J. Bruyere, Jr., et al. (1977). "The effect of practolol and butoxamine on aortic arch malformation in beta adrenoreceptor stimulated chick embryos." Teratology 15(3): 317-23.

Gittenberger-de Groot, A. C., J. L. Strengers, et al. (1985). "Histologic studies on normal and persistent ductus arteriosus in the dog." J Am Coll Cardiol 6(2): 394-404. 
Giuriato, L., M. Scatena, et al. (1993). "Rabbit ductus arteriosus during development: anatomical structure and smooth muscle cell composition." Anat Rec 235(1): 95-110.

Goldbarg, S. H., Y. Takahashi, et al. (2002). "In utero indomethacin alters O2 delivery to the fetal ductus arteriosus: implications for postnatal patency." Am J Physiol Regul Integr Comp Physiol 282(1): R184-90.

Gonzalez-Luis, G., F. Perez-Vizcaino, et al. (2005). "Age-related differences in vasoconstrictor responses to isoprostanes in piglet pulmonary and mesenteric vascular smooth muscle." Pediatr Res 57(6): 845-52.

Greyner, H. and E. M. Dzialowski (2008). "Mechanisms mediating the oxygeninduced vasoreactivity of the ductus arteriosus in the chicken embryo." Am J Physiol Regul Integr Comp Physiol 295(5): R1647-59.

Groenendijk, B. C., B. P. Hierck, et al. (2005). "Changes in shear stress-related gene expression after experimentally altered venous return in the chicken embryo." Circ Res 96(12): 1291-8.

Guarnieri, G. F., N. Laforgia, et al. (2008). "Delayed closure of ductus arteriosus in term newborns with congenital hypothyroidism: effect of L-thyroxine therapy." Pediatr Cardiol 29(2): 455-6.

Guimaraes, S. and D. Moura (2001). "Vascular adrenoceptors: an update." Pharmacol Rev 53(2): 319-56.

Hammerman, C. (1995). "Patent ductus arteriosus. Clinical relevance of prostaglandins and prostaglandin inhibitors in PDA pathophysiology and treatment." Clin Perinatol 22(2): 457-79.

Hardy, P., I. Dumont, et al. (2000). "Oxidants, nitric oxide and prostanoids in the developing ocular vasculature: a basis for ischemic retinopathy." Cardiovasc Res 47(3): 489-509.

Harms, D. (1967). "[On the occlusion of the ductus arteriosus of Gallus domesticus]." Z Zellforsch Mikrosk Anat 81(3): 433-44.

Hayashi, T., K. Yamada, et al. (1995). "Estrogen increases endothelial nitric oxide by a receptor-mediated system." Biochem Biophys Res Commun 214(3): 847-55.

Herrera, C., J. Holberton, et al. (2004). "Prolonged versus short course of indomethacin for the treatment of patent ductus arteriosus in preterm infants." Cochrane Database Syst Rev(1): CD003480.

Hodach, R. J., A. E. Hodach, et al. (1975). "The role of beta-adrenergic activity in the production of cardiac and aortic arch anomalies in chick embryos." Teratology 12(1): 33-45.

Hong, Z., F. Hong, et al. (2006). "Role of store-operated calcium channels and calcium sensitization in normoxic contraction of the ductus arteriosus." Circulation 114(13): 1372-9.

Hughes, A. F. W. (1943). "The histogenesis of the arteries of the chick embryo." $\underline{J}$ Anat 77: 266-287.

Hyvelin, J. M., C. O'Connor, et al. (2004). "Effect of changes in $\mathrm{pH}$ on wall tension in isolated rat pulmonary artery: role of the RhoA/Rho-kinase pathway." Am J Physiol Lung Cell Mol Physiol 287(4): L673-84.

Ikeda, M., R. R. Sonnenschein, et al. (1972). "Catecholamine content and uptake of the ductus arteriosus of the fetal lamb." Experientia 28(8): 914-5.

Ingemarsson, I. (2003). "Gender aspects of preterm birth." Bjog 110 Suppl 20: 34-8.

Ishikawa, T., T. Chijiwa, et al. (1989). "Thyroid hormones directly interact with vascular smooth muscle strips." Mol Pharmacol 35(6): 760-5. 
Janssen, L. J. (2008). "Isoprostanes and lung vascular pathology." Am J Respir Cell Mol Biol 39(4): 383-9.

Janssen, L. J., A. Catalli, et al. (2005). "The pulmonary biology of isoprostanes." Antioxid Redox Signal 7(1-2): 244-55.

Jourdan, K. B., T. W. Evans, et al. (1997). "Evidence for a dilator function of 8-iso prostaglandin F2 alpha in rat pulmonary artery." Br J Pharmacol 120(7): 12805.

Jurrus, E. R. and H. S. Weiss (1977). "In vitro tissue oxygen tensions in the rabbit aortic arch." Atherosclerosis 28(3): 223-32.

Kajimoto, H., K. Hashimoto, et al. (2007). "Oxygen activates the Rho/Rho-kinase pathway and induces RhoB and ROCK-1 expression in human and rabbit ductus arteriosus by increasing mitochondria-derived reactive oxygen species: a newly recognized mechanism for sustaining ductal constriction." Circulation 115(13): 1777-88.

Kajino, H., Y. Q. Chen, et al. (2000). "Tissue hypoxia inhibits prostaglandin and nitric oxide production and prevents ductus arteriosus reopening." Am J Physiol Regul Integr Comp Physiol 279(1): R278-86.

Kajino, H., Y. Q. Chen, et al. (2001). "Factors that increase the contractile tone of the ductus arteriosus also regulate its anatomic remodeling." Am J Physiol Regul Integr Comp Physiol 281(1): R291-301.

Kajino, H., S. Goldbarg, et al. (2002). "Vasa vasorum hypoperfusion is responsible for medial hypoxia and anatomic remodeling in the newborn lamb ductus arteriosus." Pediatr Res 51(2): 228-35.

Kajino, H., T. Taniguchi, et al. (2004). "An EP4 receptor agonist prevents indomethacin-induced closure of rat ductus arteriosus in vivo." Pediatr Res 56(4): 586-90.

Kamper, A. M., L. C. Paul, et al. (2002). "Prostaglandins are involved in acetylcholine- and 5-hydroxytryptamine-induced, nitric oxide-mediated vasodilatation in human forearm." J Cardiovasc Pharmacol 40(6): 922-9.

Karadas, B., T. Kaya, et al. (2004). "Comparison of effects of cyclooxygenase inhibitors on myometrial contraction and constriction of ductus arteriosus in rats." Eur J Pharmacol 485(1-3): 289-98.

Katzung, B. G. (1995). Basic and clinical pharmacology. Norwalk, Connecticut, Paramount Publishing Buiseness and Professional Group.

Keck, M., E. Resnik, et al. (2005). "Oxygen increases ductus arteriosus smooth muscle cytosolic calcium via release of calcium from inositol triphosphatesensitive stores." Am J Physiol Lung Cell Mol Physiol 288(5): L917-23.

Kempf, H., C. Linares, et al. (1998). "Pharmacological inactivation of the endothelin type A receptor in the early chick embryo: a model of mispatterning of the branchial arch derivatives." Development 125(24): 4931-41.

Khalil, R. A. (2005). "Sex hormones as potential modulators of vascular function in hypertension." Hypertension 46(2): 249-54.

Kim, H. S., M. Aikawa, et al. (1993). "Ductus arteriosus. Advanced differentiation of smooth muscle cells demonstrated by myosin heavy chain isoform expression in rabbits." Circulation 88(4 Pt 1): 1804-10.

Kiserud, T. (2005). "Physiology of the fetal circulation." Semin Fetal Neonatal Med 10(6): 493-503.

Kitazawa, T., A. N. Polzin, et al. (2004). "CPI-17-deficient smooth muscle of chicken." J Physiol 557(Pt 2): 515-28. 
Kluckow, M., N. Evans, et al. (1999). "Prostacyclin concentrations and transitional circulation in preterm infants requiring mechanical ventilation." Arch Dis Child Fetal Neonatal Ed 80(1): F34-7.

Knight, D. B. (2001). "The treatment of patent ductus arteriosus in preterm infants. A review and overview of randomized trials." Semin Neonatol 6: 63-73.

Knight, D. H., D. F. Patterson, et al. (1973). "Constriction of the fetal ductus arteriosus induced by oxygen, acteylcholine, and norepinephrine in normal dogs and those genetically predisposed to persistent patency." Circulation 47(1): 127-32.

Koch, J., G. Hensley, et al. (2006). "Prevalence of spontaneous closure of the ductus arteriosus in neonates at a birth weight of 1000 grams or less." Pediatrics 117(4): 1113-21.

Komuro, T., M. K. Borsody, et al. (2001). "The vasorelaxation of cerebral arteries by carbon monoxide." Exp Biol Med (Maywood) 226(9): 860-5.

Kovalcik, V. (1963). "The Response of the Isolated Ductus Arteriosus to Oxygen and Anoxia." J Physiol 169: 185-97.

le Noble, F. A., K. Ruijtenbeek, et al. (2000). "Contractile and relaxing reactivity in carotid and femoral arteries of chicken embryos." Am J Physiol Heart Circ Physiol 278(4): H1261-8.

Leo, M. D., Y. K. Siddegowda, et al. (2008). "Role of nitric oxide and carbon monoxide in N(omega)-Nitro-L-arginine methyl ester-resistant acetylcholineinduced relaxation in chicken carotid artery." Eur J Pharmacol 596(1-3): 1117.

Leonhardt, A., A. Glaser, et al. (2003). "Expression of prostanoid receptors in human ductus arteriosus." Br J Pharmacol 138(4): 655-9.

Levin, M., S. Goldbarg, et al. (2005). "ATP depletion and cell death in the neonatal lamb ductus arteriosus." Pediatr Res 57(6): 801-5.

Levin, M., D. McCurnin, et al. (2006). "Postnatal constriction, ATP depletion, and cell death in the mature and immature ductus arteriosus." Am J Physiol Regul Integr Comp Physiol 290(2): R359-64.

Lindgren, I., B. Zoer, et al. (2009). "Chronic hypoxia and incubation age affects Badrenoceptor -mediated relaxation in systemic but not chorioallantoic arteries of the broiler chicken fetus." Abstract, Book of the 35th Annual Meeting of FNPS. Page 135.

Liu, L., C. E. Dean, et al. (2003). "Thyroid hormones interact with glucocorticoids to affect somatotroph abundance in chicken embryonic pituitary cells in vitro." Endocrinology 144(9): 3836-41.

Liu, L. and T. E. Porter (2004). "Endogenous thyroid hormones modulate pituitary somatotroph differentiation during chicken embryonic development." $\underline{\mathrm{J}}$ Endocrinol 180(1): 45-53.

Lynch, F., M. Sweeney, et al. (2000). "Hypercapnia-induced contraction in isolated pulmonary arteries is endothelium-dependent." Respir Physiol 121(1): 65-74.

Macrez-Lepretre, N., F. Kalkbrenner, et al. (1997). "Distinct functions of Gq and G11 proteins in coupling alpha1-adrenoreceptors to $\mathrm{Ca} 2+$ release and $\mathrm{Ca} 2+$ entry in rat portal vein myocytes." J Biol Chem 272(8): 5261-8.

Malviya, M., A. Ohlsson, et al. (2008). "Surgical versus medical treatment with cyclooxygenase inhibitors for symptomatic patent ductus arteriosus in preterm infants." Cochrane Database Syst Rev(1): CD003951.

Mariani, G., J. Cifuentes, et al. (1999). "Randomized trial of permissive hypercapnia in preterm infants." Pediatrics 104(5 Pt 1): 1082-8. 
Martinez-Lemus, L. A., R. K. Hester, et al. (2003). "Pulmonary artery vasoactivity in broiler and Leghorn chickens: an age profile." Poult Sci 82(12): 1957-64.

Matsumoto, T., T. Kobayashi, et al. (2003). "Phosphodiesterases in the vascular system." J Smooth Muscle Res 39(4): 67-86.

Maurice, D. H., D. Palmer, et al. (2003). "Cyclic nucleotide phosphodiesterase activity, expression, and targeting in cells of the cardiovascular system." $\underline{\mathrm{Mol}}$ Pharmacol 64(3): 533-46.

McMurphy, D. M., M. A. Heymann, et al. (1972). "Developmental changes in constriction of the ductus arteriosus: responses to oxygen and vasoactive agents in the isolated ductus arteriosus of the fetal lamb." Pediatr Res 6(4): 231-8.

Metcalfe, J. and M. K. Stock (1993). "Current topic: oxygen exchange in the chorioallantoic membrane, avian homologue of the mammalian placenta." Placenta 14(6): 605-13.

Michelakis, E., I. Rebeyka, et al. (2000). "Voltage-gated potassium channels in human ductus arteriosus." Lancet 356(9224): 134-7.

Michelakis, E. D., I. Rebeyka, et al. (2002). "O2 sensing in the human ductus arteriosus: regulation of voltage-gated $\mathrm{K}+$ channels in smooth muscle cells by a mitochondrial redox sensor." Circ Res 91(6): 478-86.

Michelakis, E. D., B. Thebaud, et al. (2004). "Hypoxic pulmonary vasoconstriction: redox regulation of $\mathrm{O} 2$-sensitive $\mathrm{K}+$ channels by a mitochondrial $\mathrm{O} 2$-sensor in resistance artery smooth muscle cells." J Mol Cell Cardiol 37(6): 1119-36.

Miller, J. D. and W. A. Carlo (2007). "Safety and effectiveness of permissive hypercapnia in the preterm infant." Curr Opin Pediatr 19(2): 142-4.

Momma, K., T. Nakanishi, et al. (2003). "Inhibition of in vivo constriction of fetal ductus arteriosus by endothelin receptor blockade in rats." Pediatr Res 53(3): 479-85.

Momma, K. and M. Toyono (1999). "The role of nitric oxide in dilating the fetal ductus arteriosus in rats." Pediatr Res 46(3): 311-5.

Momma, K., M. Toyono, et al. (1998). "Accelerated maturation of fetal ductus arteriosus by maternally administered vitamin A in rats." Pediatr Res 43(5): 629-32.

Momma, K., K. Toyoshima, et al. (2005). "In vivo dilation of fetal and neonatal ductus arteriosus by inhibition of phosphodiesterase-5 in rats." Pediatr Res 58(1): 42-5.

Mosalli, R. and K. Alfaleh (2008). "Prophylactic surgical ligation of patent ductus arteriosus for prevention of mortality and morbidity in extremely low birth weight infants." Cochrane Database Syst Rev(1): CD006181.

Moudgil, R., E. D. Michelakis, et al. (2005). "Hypoxic pulmonary vasoconstriction." J Appl Physiol 98(1): 390-403.

Mueed, I., T. Tazzeo, et al. (2008). "Isoprostanes constrict human radial artery by stimulation of thromboxane receptors, $\mathrm{Ca} 2+$ release, and RhoA activation." $\underline{\mathrm{J}}$ Thorac Cardiovasc Surg 135(1): 131-8.

Mulder, A. L., J. M. Golde, et al. (2000). "Developmental changes in plasma catecholamine concentrations during normoxia and acute hypoxia in the chick embryo." J Physiol 527 Pt 3: 593-9.

Mulder, A. L., A. Miedema, et al. (2002). "Sympathetic control of the cardiovascular response to acute hypoxemia in the chick embryo." Am J Physiol Regul Integr Comp Physiol 282(4): R1156-63. 
Mulder, A. L., J. C. van Golde, et al. (1998). "Cardiac output distribution in response to hypoxia in the chick embryo in the second half of the incubation time." $\mathrm{J}$ Physiol 508 ( Pt 1): 281-7.

Mulder, A. L., C. A. van Goor, et al. (2001). "Alpha-adrenergic contribution to the cardiovascular response to acute hypoxemia in the chick embryo." Am J Physiol Regul Integr Comp Physiol 281(6): R2004-10.

Mulder, T. L., J. C. van Golde, et al. (1997). "Cardiac output distribution in the chick embryo from stage 36 to 45." Cardiovasc Res 34(3): 525-8.

Nakagawa, T. (1993). "Delayed closure of ductus arteriosus in premature infants with transient hypothyroidism." Lancet 341(8848): 839.

Nakanishi, T., H. Gu, et al. (1993). "Mechanisms of oxygen-induced contraction of ductus arteriosus isolated from the fetal rabbit." Circ Res 72(6): 1218-28.

Nathanielsz, P. W. (2006). "Animal models that elucidate basic principles of the developmental origins of adult diseases." Ilar J 47(1): 73-82.

Nguyen, M., T. Camenisch, et al. (1997). "The prostaglandin receptor EP4 triggers remodelling of the cardiovascular system at birth." Nature 390(6655): 78-81.

Nishimura, H., Y. Yang, et al. (2003). "Maturation-dependent changes of angiotensin receptor expression in fowl." Am J Physiol Regul Integr Comp Physiol 285(1): R231-42.

Noel, S. and S. Cassin (1976). "Maturation of contractile response of ductus arteriosus to oxygen and drugs." American journal of physiology 231(1): 240-243.

Oberhansli-Weiss, I., M. A. Heymann, et al. (1972). "The pattern and mechanisms of response to oxygen by the ductus arteriosus and umbilical artery." Pediatr Res 6(9): 693-700.

Ojamaa, K., A. Kenessey, et al. (2000). "Thyroid hormone metabolism and cardiac gene expression after acute myocardial infarction in the rat." Am J Physiol Endocrinol Metab 279(6): E1319-24.

Oliveira, L., N. A. Stallwood, et al. (2000). "Effects of some isoprostanes on the human umbilical artery in vitro." Br J Pharmacol 129(3): 509-14.

Olschewski, A., Z. Hong, et al. (2004). "Opposite effects of redox status on membrane potential, cytosolic calcium, and tone in pulmonary arteries and ductus arteriosus." Am J Physiol Lung Cell Mol Physiol 286(1): L15-22.

Olson, K. R., R. A. Dombkowski, et al. (2006). "Hydrogen sulfide as an oxygen sensor/transducer in vertebrate hypoxic vasoconstriction and hypoxic vasodilation." J Exp Biol 209(Pt 20): 4011-23.

Orshal, J. M. and R. A. Khalil (2004). "Gender, sex hormones, and vascular tone." Am J Physiol Regul Integr Comp Physiol 286(2): R233-49.

Owen, P. J., R. Sabit, et al. (2007). "Thyroid disease and vascular function." Thyroid 17(6): 519-24.

Owens, G. K., M. S. Kumar, et al. (2004). "Molecular regulation of vascular smooth muscle cell differentiation in development and disease." Physiol Rev 84(3): 767-801.

Polderman, K. H., C. D. Stehouwer, et al. (1993). "Influence of sex hormones on plasma endothelin levels." Ann Intern Med 118(6): 429-32.

Rahn, H., S. Matalon, et al. (1985). Circulatory changes and oxygen delivery in the chick embryo prior to hatching. Cardiovascular shunts. Alfred Benzon Symposium 21. K. Johansen and W. W. Burggren. Copenhagen, Munksgaard: 199-215.

Rahn, H., C. V. Paganelli, et al. (1974). "The avian egg: air-cell gas tension, metabolism and incubation time." Respir Physiol 22(3): 297-309. 
Rairigh, R. L., L. Storme, et al. (2000). "Role of neuronal nitric oxide synthase in regulation of vascular and ductus arteriosus tone in the ovine fetus." $\underline{\mathrm{Am} \mathrm{J}}$ Physiol Lung Cell Mol Physiol 278(1): L105-10.

Randall, D., W. Burggren, et al. (2001). Eckert Animal Physiology - Mechanisms and Adaptations. New York, W. H. Freeman and Company.

Rang, H. P., M. Dale, et al. (1995). Pharmacology. New York, Churchill Livingstone.

Ratz, P. H., K. M. Berg, et al. (2005). "Regulation of smooth muscle calcium sensitivity: $\mathrm{KCl}$ as a calcium-sensitizing stimulus." Am J Physiol Cell Physiol 288(4): C769-83.

Reese, J. (2006). "Death, dying, and exhaustion in the ductus arteriosus: prerequisites for permanent closure." Am J Physiol Regul Integr Comp Physiol 290(2): R357-8.

Reese, J., B. C. Paria, et al. (2000). "Coordinated regulation of fetal and maternal prostaglandins directs successful birth and postnatal adaptation in the mouse." PNAS 97(17): 9759-9764.

Reeve, H. L., S. L. Archer, et al. (1997). "Ion channels in the pulmonary vasculature." Pulm Pharmacol Ther 10(5-6): 243-52.

Reeve, H. L., S. Tolarova, et al. (2001). "Redox control of oxygen sensing in the rabbit ductus arteriosus." J Physiol 533(Pt 1): 253-61.

Reynolds, S. R. M. (1953). "Circulatory adaptations to birth." The scientific monthly(October).

Richard, C., J. Gao, et al. (2004). "Patency of the preterm fetal ductus arteriosus is regulated by endothelial nitric oxide synthase and is independent of vasa vasorum in the mouse." Am J Physiol Regul Integr Comp Physiol 287(3): R652-60.

Rojas, M. A., A. Gonzalez, et al. (1995). "Changing trends in the epidemiology and pathogenesis of neonatal chronic lung disease." J Pediatr 126(4): 605-10.

Roulet, M. J. and R. F. Coburn (1981). "Oxygen-induced contraction in the guinea pig neonatal ductus arteriosus." Circ Res 49(4): 997-1002.

Rouwet, E. V., J. G. De Mey, et al. (2000). "Development of vasomotor responses in fetal mesenteric arteries." Am J Physiol Heart Circ Physiol 279(3): H1097105.

Rowley, A. (1991). Eicosanoids: aspects of their structure, function, and evolution. The Phylogenesis of Immune Functions. G. Warr and N. Cohen, CRC Press, Boca Ration: 269-294.

Rubanyi, G. M. and L. H. Botelho (1991). "Endothelins." Faseb J 5(12): 2713-20.

Ruijtenbeek, K., J. G. De Mey, et al. (2002a). "The chicken embryo in developmental physiology of the cardiovascular system: a traditional model with new possibilities." Am J Physiol Regul Integr Comp Physiol 283(2): R549-50; author reply R550-1.

Ruijtenbeek, K., C. G. Kessels, et al. (2003a). "Chronic moderate hypoxia during in ovo development alters arterial reactivity in chickens." Pflugers Arch 447(2): 158-67.

Ruijtenbeek, K., C. G. Kessels, et al. (2002b). "Direct effects of acute hypoxia on the reactivity of peripheral arteries of the chicken embryo." Am J Physiol Regul Integr Comp Physiol 283(2): R331-8.

Ruijtenbeek, K., L. C. Kessels, et al. (2003b). "Chronic moderate hypoxia and protein malnutrition both induce growth retardation, but have distinct effects on arterial endothelium-dependent reactivity in the chicken embryo." Pediatr Res 53(4): 573-9. 
Ruijtenbeek, K., F. A. le Noble, et al. (2000). "Chronic hypoxia stimulates periarterial sympathetic nerve development in chicken embryo." Circulation 102(23): 2892-7.

Russell, M. J., R. A. Dombkowski, et al. (2008). "Effects of hypoxia on vertebrate blood vessels." J Exp Zool Part A Ecol Genet Physiol 309(2): 55-63.

Rybalkin, S. D., C. Yan, et al. (2003). "Cyclic GMP phosphodiesterases and regulation of smooth muscle function." Circ Res 93(4): 280-91.

Rzucidlo, E. M., K. A. Martin, et al. (2007). "Regulation of vascular smooth muscle cell differentiation." J Vasc Surg 45 Suppl A: A25-32.

Sader, M. A. and D. S. Celermajer (2002). "Endothelial function, vascular reactivity and gender differences in the cardiovascular system." Cardiovasc Res 53(3): 597-604.

Sakurai, H., R. Matsuoka, et al. (1996). "Expression of four myosin heavy chain genes in developing blood vessels and other smooth muscle organs in rabbits." Eur J Cell Biol 69(2): 166-72.

Salomonsson, M. and W. J. Arendshorst (2001). "Norepinephrine-induced calcium signaling pathways in afferent arterioles of genetically hypertensive rats." Am J Physiol Renal Physiol 281(2): F264-72.

Salter, K. J. and R. Z. Kozlowski (1998). "Differential electrophysiological actions of endothelin-1 on $\mathrm{Cl}$ - and $\mathrm{K}+$ currents in myocytes isolated from aorta, basilar and pulmonary artery." J Pharmacol Exp Ther 284(3): 1122-31.

Salter, K. J., C. M. Wilson, et al. (1998). "Endothelin-1, delayed rectifier K channels, and pulmonary arterial smooth muscle." J Cardiovasc Pharmacol 31 Suppl 1: S81-3.

Schneider, D. J. and J. W. Moore (2006). "Patent ductus arteriosus." Circulation 114(17): 1873-82.

Schwertz, D. W. and S. Penckofer (2001). "Sex differences and the effects of sex hormones on hemostasis and vascular reactivity." Heart Lung 30(6): 401-26; quiz 427-8.

Scotland, R. S., M. Madhani, et al. (2005). "Investigation of vascular responses in endothelial nitric oxide synthase/cyclooxygenase-1 double-knockout mice: key role for endothelium-derived hyperpolarizing factor in the regulation of blood pressure in vivo." Circulation 111(6): 796-803.

Seidner, S. R., Y. Q. Chen, et al. (2001). "Combined prostaglandin and nitric oxide inhibition produces anatomic remodeling and closure of the ductus arteriosus in the premature newborn baboon." Pediatr Res 50(3): 365-73.

Sendao Oliveira, A. P. and L. M. Bendhack (2004). "Relaxation induced by acetylcholine involves endothelium-derived hyperpolarizing factor in 2-kidney 1-clip hypertensive rat carotid arteries." Pharmacology 72(4): 231-9.

Shen, J., T. Nakanishi, et al. (2002). "The role of endothelin in oxygen-induced contraction of the ductus arteriosus in rabbit and rat fetuses." Heart Vessels 16(5): 181-8.

Shimoda, L. A., J. T. Sylvester, et al. (1998). "Inhibition of voltage-gated K+ current in rat intrapulmonary arterial myocytes by endothelin-1." Am J Physiol 274(5 Pt 1): L842-53.

Silver, M. M., R. M. Freedom, et al. (1981). "The morphology of the human newborn ductus arteriosus: a reappraisal of its structure and closure with special reference to prostaglandin E1 therapy." Hum Pathol 12(12): 1123-36.

Smith, G. C. (1998). "The pharmacology of the ductus arteriosus." Pharmacol Rev 50(1): 35-58. 
Smith, G. C., R. A. Coleman, et al. (1994). "Characterization of dilator prostanoid receptors in the fetal rabbit ductus arteriosus." J Pharmacol Exp Ther 271(1): 390-6.

Smith, G. C. and J. C. McGrath (1988). "Indomethacin, but not oxygen tension, affects the sensitivity of isolated neonatal rabbit ductus arteriosus, but not aorta, to noradrenaline." Cardiovasc Res 22(12): 910-5.

Smith, G. C. and J. C. McGrath (1993). "Characterisation of the effect of oxygen tension on response of fetal rabbit ductus arteriosus to vasodilators." Cardiovasc Res 27(12): 2205-11.

Smith, G. C. and J. C. McGrath (1995). "Contractile effects of prostanoids on fetal rabbit ductus arteriosus." J Cardiovasc Pharmacol 25(1): 113-8.

Somlyo, A. P. and A. V. Somlyo (2003). "Ca2+ sensitivity of smooth muscle and nonmuscle myosin II: modulated by $\mathrm{G}$ proteins, kinases, and myosin phosphatase." Physiol Rev 83(4): 1325-58.

Starling, M. B. and R. B. Elliott (1974). "The effects of prostaglandins, prostaglandin inhibitors, and oxygen on the closure of the ductus arteriosus, pulmonary arteries and umbilical vessels in vitro." Prostaglandins 8(3): 187-203.

Stevenson, D. K., J. Verter, et al. (2000). "Sex differences in outcomes of very low birthweight infants: the newborn male disadvantage." Arch Dis Child Fetal Neonatal Ed 83(3): F182-5.

Sutendra, G. and E. D. Michelakis (2007). "The chicken embryo as a model for ductus arteriosus developmental biology: cracking into new territory." Am J Physiol Regul Integr Comp Physiol 292(1): R481-4.

Sweeney, M., D. Beddy, et al. (1998). "Effects of changes in pH and CO2 on pulmonary arterial wall tension are not endothelium dependent." J Appl Physiol 85(6): 2040-6.

Sweeney, M., R. G. O'Regan, et al. (1999). "Effects of changes in pH and PCO2 on wall tension in isolated rat intrapulmonary arteries." Exp Physiol 84(3): 52939.

Takahashi, T., Y. Sugishita, et al. (2001). "Ets-1 is involved in transcriptional regulation of the chick inducible nitric oxide synthase gene in embryonic ventricular myocytes." Mol Cell Biochem 226(1-2): 57-65.

Takahashi, Y., C. Roman, et al. (2000). "Cyclooxygenase-2 inhibitors constrict the fetal lamb ductus arteriosus both in vitro and in vivo." Am J Physiol Regul Integr Comp Physiol 278(6): R1496-505.

Takizawa, T., E. Horikoshi, et al. (1999). "Role of the nitric oxide-cGMP system in the regulation of ductus arteriosus patency in fetal rats." J Vet Med Sci 61(12): 1277-80.

Takizawa, T., E. Horikoshi, et al. (2000a). "Biphasic response of the ductus arteriosus to combined administration of indomethacin and L-NAME in fetal rats." Biol Neonate 78(4): 300-3.

Takizawa, T., T. Kihara, et al. (2000b). "Role of nitric oxide in regulating the ductus arteriosus caliber in fetal rats." J Vet Med Sci 62(7): 707-10.

Taniguchi, T., H. Azuma, et al. (2001). "Endothelin-1-endothelin receptor type A mediates closure of rat ductus arteriosus at birth." J Physiol 537(Pt 2): 579-85.

Tare, M., H. C. Parkington, et al. (2000). "EDHF, NO and a prostanoid: hyperpolarization-dependent and -independent relaxation in guinea-pig arteries." Br J Pharmacol 130(3): 605-18.

Teitel, D. F. and S. C. Cassidy (2001). Fetal and postnatal circulations: Systemic. Moss and Adams' Heart Disease in Infants, Children and Adolescents: 
Including the Fetus and Young Adult. H. D. Allen, H. P. Gutgesell, E. B. Clark and D. J. Driscoll. Philadelphia, Lippincott Williams \& Wilkins. 1.

Thebaud, B., E. Michelakis, et al. (2002). "Sildenafil reverses O2 constriction of the rabbit ductus arteriosus by inhibiting type 5 phosphodiesterase and activating $\mathrm{BK}(\mathrm{Ca})$ channels." Pediatr Res 52(1): 19-24.

Thebaud, B., E. D. Michelakis, et al. (2004). "Oxygen-sensitive Kv channel gene transfer confers oxygen responsiveness to preterm rabbit and remodeled human ductus arteriosus: implications for infants with patent ductus arteriosus." Circulation 110(11): 1372-9.

Thebaud, B., X. C. Wu, et al. (2008). "Developmental absence of the O2 sensitivity of L-type calcium channels in preterm ductus arteriosus smooth muscle cells impairs $\mathrm{O} 2$ constriction contributing to patent ductus arteriosus." Pediatr Res 63(2): 176-81.

Tomita, H., S. Fuse, et al. (1996). "Catecholamine-induced ductus arteriosus constriction in children." Am J Cardiol 77(15): 1372-5.

Tristani-Firouzi, M., H. L. Reeve, et al. (1996). "Oxygen-induced constriction of rabbit ductus arteriosus occurs via inhibition of a 4-aminopyridine-, voltagesensitive potassium channel." J Clin Invest 98(9): 1959-65.

Trotter, A., L. Maier, et al. (1999). "Effects of postnatal estradiol and progesterone replacement in extremely preterm infants." J Clin Endocrinol Metab 84(12): 4531-5.

Tsang, S. Y., X. Yao, et al. (2004). "Differential regulation of $\mathrm{K}+$ and $\mathrm{Ca} 2+$ channel gene expression by chronic treatment with estrogen and tamoxifen in rat aorta." Eur J Pharmacol 483(2-3): 155-62.

Ungureanu-Longrois, D., Y. Bezie, et al. (1997). "Effects of exogenous and endogenous nitric oxide on the contractile function of cultured chick embryo ventricular myocytes." J Mol Cell Cardiol 29(2): 677-87.

Waleh, N., H. Kajino, et al. (2004). "Prostaglandin E2--mediated relaxation of the ductus arteriosus: effects of gestational age on g protein-coupled receptor expression, signaling, and vasomotor control." Circulation 110(16): 2326-32.

Waleh, N., S. Seidner, et al. (2005). "The role of monocyte-derived cells and inflammation in baboon ductus arteriosus remodeling." Pediatr Res 57(2): 254-62.

Wall, M. E., J. E. Faber, et al. (2004). "Norepinephrine-induced calcium signaling and expression of adrenoceptors in avian tendon cells." Am J Physiol Cell Physiol 287(4): C912-8.

Walsh, R. S. and R. M. Mentzer, Jr. (1987). "Role of cyclic nucleotides in relaxation of fetal lamb ductus arteriosus." Surgery 102(2): 313-8.

van Golde, J., T. Mulder, et al. (1997). "Changes in mean chorioallantoic artery blood flow and heart rate produced by hypoxia in the developing chick embryo." Pediatr Res 42(3): 293-8.

van Golde, J., T. Mulder, et al. (1996). "The chorioallantoic artery blood flow of the chick embryo from stage 34 to 43." Pediatr Res 40(6): 867-71.

van Golde, J. M., T. A. Mulder, et al. (1999). "Hyperoxia and local organ blood flow in the developing chick embryo." J Physiol 515 ( Pt 1): 243-8.

Van Overmeire, B. and S. Chemtob (2005). "The pharmacologic closure of the patent ductus arteriosus." Semin Fetal Neonatal Med 10(2): 177-84.

van Wassenaer, A. G. and J. H. Kok (2008). "Trials with thyroid hormone in preterm infants: clinical and neurodevelopmental effects." Semin Perinatol 32(6): 42330. 
Wang, R., Z. Wang, et al. (1997). "Carbon monoxide-induced vasorelaxation and the underlying mechanisms." Br J Pharmacol 121(5): 927-34.

Vatten, L. J. and R. Skjaerven (2004). "Offspring sex and pregnancy outcome by length of gestation." Early Hum Dev 76(1): 47-54.

Waypa, G. B. and P. T. Schumacker (2005). "Hypoxic pulmonary vasoconstriction: redox events in oxygen sensing." J Appl Physiol 98(1): 404-14.

Weinberger, B., S. Nisar, et al. (2006). "Lipid peroxidation in cord blood and neonatal outcome." Pediatr Int 48(5): 479-83.

Weir, E. K., Z. Hong, et al. (2002). "Redox signaling in oxygen sensing by vessels." Respir Physiol Neurobiol 132(1): 121-30.

Weir, E. K., J. Lopez-Barneo, et al. (2005). "Acute oxygen-sensing mechanisms." N Engl J Med 353(19): 2042-55.

Weir, E. K., M. Obreztchikova, et al. (2008). "Mechanisms of oxygen sensing: a key to therapy of pulmonary hypertension and patent ductus arteriosus." $\underline{\mathrm{Br} \mathrm{J}}$ Pharmacol 155(3): 300-7.

Werkstrom, V., L. Ny, et al. (1997). "Carbon monoxide-induced relaxation and distribution of haem oxygenase isoenzymes in the pig urethra and lower oesophagogastric junction." Br J Pharmacol 120(2): 312-8.

White, P. T. (1974). "Experimental studies on the circulatory system of the late chick embryo." J Exp Biol 61(3): 571-92.

Wideman, R. F., Jr., P. Maynard, et al. (1999). "Thromboxane mimics the pulmonary but not systemic vascular responses to bolus $\mathrm{HCl}$ injections in broiler chickens." Poult Sci 78(5): 714-21.

Villamor, E., C. G. Kessels, et al. (2003). "Role of superoxide anion on basal and stimulated nitric oxide activity in neonatal piglet pulmonary vessels." $\underline{\text { Pediatr }}$ Res 54(3): 372-81.

Villamor, E., C. G. Kessels, et al. (2004). "Chronic in ovo hypoxia decreases pulmonary arterial contractile reactivity and induces biventricular cardiac enlargement in the chicken embryo." Am J Physiol Regul Integr Comp Physiol 287(3): R642-51.

Villamor, E., C. G. Kessels, et al. (2005). "Cardiopulmonary effects of chronic administration of the NO synthase inhibitor L-NAME in the chick embryo." Biol Neonate 88(3): 156-63.

Villamor, E., F. Perez-Vizcaino, et al. (2000). "Relaxant effects of carbon monoxide compared with nitric oxide in pulmonary and systemic vessels of newborn piglets." Pediatr Res 48(4): 546-53.

Villamor, E., K. Ruijtenbeek, et al. (2002). "Vascular reactivity in intrapulmonary arteries of chicken embryos during transition to ex ovo life." Am J Physiol Regul Integr Comp Physiol 282(3): R917-27.

Villamor, E., T. Ruiz, et al. (1997). "Endothelium-derived nitric oxide-dependent response to hypoxia in piglet intrapulmonary arteries." Biol Neonate 72(1): 62-70.

Williams, M. L., J. E. Coleman, et al. (2006). "Lentiviral expression of retinal guanylate cyclase-1 (RetGC1) restores vision in an avian model of childhood blindness." PLoS Med 3(6): e201.

Wilson, D. P., M. Susnjar, et al. (2005). "Thromboxane A2-induced contraction of rat caudal arterial smooth muscle involves activation of $\mathrm{Ca} 2+$ entry and $\mathrm{Ca} 2+$ sensitization: Rho-associated kinase-mediated phosphorylation of MYPT1 at Thr-855, but not Thr-697." Biochem J 389(Pt 3): 763-74. 
Wittmann, J. and J. Prechtl (1991). "Respiratory function of catecholamines during the late period of avian development." Respir Physiol 83(3): 375-86.

Wolinsky, H. and S. Glagov (1967). "Nature of species differences in the medial distribution of aortic vasa vasorum in mammals." Circ Res 20(4): 409-21.

Wolpert, L., R. Beddington, et al. (2002). Principles of Development, Oxford University Press.

Woodgate, P. G. and M. W. Davies (2001). "Permissive hypercapnia for the prevention of morbidity and mortality in mechanically ventilated newborn infants." Cochrane Database Syst Rev(2): CD002061.

Wray, S. and R. D. Smith (2004). "Mechanisms of action of $\mathrm{pH}$-induced effects on vascular smooth muscle." Mol Cell Biochem 263(1-2): 163-72.

Wright, D. H., D. Abran, et al. (2001). "Prostanoid receptors: ontogeny and implications in vascular physiology." Am J Physiol Regul Integr Comp Physiol 281(5): R1343-60.

Wu, G. R., S. Jing, et al. (2001). "The effect of vitamin A on contraction of the ductus arteriosus in fetal rat." Pediatr Res 49(6): 747-54.

Yi, S. L., C. Kantores, et al. (2006). "8-Isoprostane-induced endothelin-1 production by infant rat pulmonary artery smooth muscle cells is mediated by Rhokinase." Free Radic Biol Med 41(6): 942-9.

Yoshida, M., A. Suzuki, et al. (1994). "Mechanisms of vasoconstriction induced by endothelin-1 in smooth muscle of rabbit mesenteric artery." J Physiol 477 ( Pt 2): 253-65.

Zhang, Y., E. Pertens, et al. (2005). "8-isoprostaglandin E(2) activates $\mathrm{Ca}(2+)$ dependent $\mathrm{K}(+)$ current via cyclic AMP signaling pathway in murine renal artery." Eur J Pharmacol 520(1-3): 22-8.

Zhang, Y., T. Tazzeo, et al. (2003). "Vasodilatory and electrophysiological actions of 8-iso-prostaglandin E2 in porcine coronary artery." J Pharmacol Exp Ther 305(3): 1054-60.

Zoer, B., L. Kessels, et al. (2009). "Effects of prenatal hypoxia on pulmonary vascular reactivity in chickens prone to pulmonary hypertension." J Physiol Pharmacol 60(1): 119-30. 


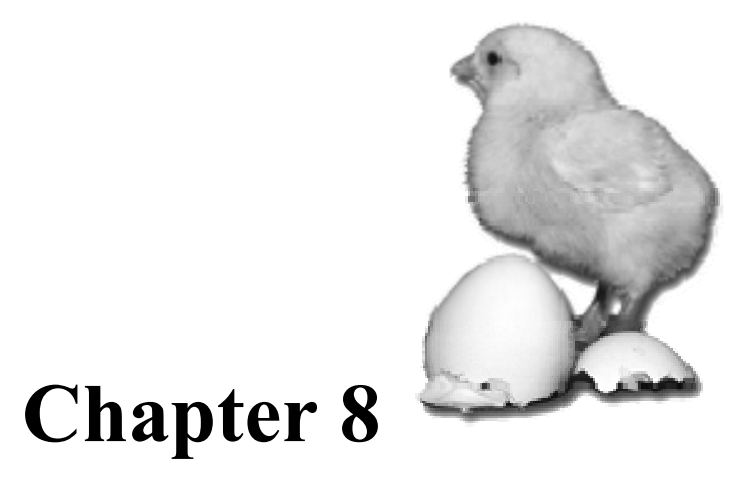

\author{
SAMENVATTING \\ SUMMARY \\ ACKNOWLEDGEMENTS \\ CURRICULUM VITAE
}




\section{Samenvatting}

Het persisteren van de ductus arteriosus (DA) bij prematuren na de geboorte is nog steeds een uitdaging wat betreft diagnose, benadering en behandelingsmogelijkheden. Er is een significante vooruitgang in de kennis over fysiologie en pathosfysiologie van de DA geboekt door het gebruik van diermodellen, zoals schapen, konijnen, muizen, raten en primaten. Echter de complexiteit van de beschikbare diermodellen is een belangrijke limiterende factor. Effecten van externe factoren als hypoxie en malnutritie (zoals gezien wordt bij placentaire insufficiëntie) kunnen niet bestudeerd worden zonder te worden beïnvloedt door maternale en placentaire factoren. Interventies van de foetale en placentaire circulatie door middel van complexe chirurgie of manipulatie van het zuurstofgehalte in de omgeving zullen zowel effecten hebben op de moeder als de foetus. Veel zoogdieren kennen daarnaast een relatief lange zwangerschapsperiode, resulterend in langdurige en kostbare experimenten. Er is noodzaak aan een nieuw model die deze beperkingen niet kent.

Nog meer dan in andere diermodellen is bij het kippenembryo de beschrijvende embryologie, teratologie en experimentele embryologie bestudeerd. Echter veranderingen in DA reactiviteit bij het kippenembryo gedurende de foetale ontwikkeling waren nog niet bestudeerd. Met deze thesis vervolledigen we een uitgebreide beschrijving van farmacologie tijdens de foetale ontwikkeling van de DA bij het kippenembryo en beschrijven we de gevoeligheid van de DA aan verschillende vasoactieve agonisten. De belangrijkste bevindingen van deze thesis kunnen als volgt worden samengevat:

1. De postnatale stijging in zuurstofspanning, de belangrijkste vasoconstictor van de DA bij zoogdieren, blijkt ook een relevante rol te spelen in het sluiten van de DA in de kip (hoofdstuk 2). Zuurstof heeft ingrijpende modulerende effecten op andere vasoactieve systemen zoals bevordering van de effecten van vasoconstrictoren (hoofdstuk 2) en vermindering van de effecten van vasodilatoren (hoofdstuk 3 en 4).

2. De belangrijkste vasodilator van de DA bij zoogdieren, $\mathrm{PGE}_{2}$, heeft slechts een zwak relaxerend effect op de DA bij de kip en stimuleert zelfs receptoren betrokken bij de vasoconstrictie (hoofdstuk 4). 
3. Er is een toename in contractiele responsiviteit (hoofdstuk 2) en een afname van responsiviteit voor verschillende relaxerende agonisten (hoofdstuk 3 en 4) gedurende de foetale ontwikkeling van de DA bij de kip.

4. Er is een duidelijke morfologische en functionele heterogeniciteit van de DA bij de kip. De pulmonale kant heeft de structuur van een musculeuze arterie en contraheert als reactie op zuurstof. De aortale kant heeft de structuur van een elastische arterie die relaxeert als reactie op zuurstof (hoofdstuk II). Daarnaast is er ook een duidelijk verschil in responsiviteit voor vasocontrictoren (hoofdstuk 2) en vasodilatoren (hoofdstuk 3 en 4).

5. Veranderingen in extracellulaire $\mathrm{pH}$ hebben ingrijpende effceten op de tonus van de DA bij de kip. Hypercapnische en normocapnische acidose veroorzaakt relaxatie van de DA (hoofdstuk 5).

6. Chronisch hypoxische incubatie van de kippeneieren veroorzaakte geen significante remodelling van de DA bij de kip maar veranderde wel de reactiviteit van de DA (hoofdstuk 6). 


\section{Summary}

Failure of ductus arteriosus (DA) closure after birth is a common complication of premature delivery that is still presenting challenges in terms of diagnosis, assessment and treatment options. Significant progress in our understanding of the DA physiology and pathophysiology has been achieved with the use of animal models including sheep, rabbits, mice, rats or primates. However, the complexity of available models is an important limitation. The effects of external stress, such as hypoxia and malnutrition (as seen in placental insufficiency) can not be studied without interference from the mother as well as the placenta. Complex surgery to interfere with foetal or placental circulation, as well as modifications of ambient oxygen level, will influence both the mother and the foetus. Many mammals also have a long gestation, leading to long and expensive experiments. There is a need to develop a new model, without these limitations.

However, and even though probably more is known about the descriptive embryology, teratology, and experimental embryology of the chicken embryo than of any other model organism, developmental changes in the reactivity of the chicken DA had not previously been studied. With this Thesis we present a complete extensive characterization of the developmental pharmacology of the chicken DA. The main findings of the present Thesis can be summarized as follows:

1. The main vasoconstrictor of the mammalian DA, the postnatal increase in oxygen tension, appears to play also a relevant role in the closure of the chicken DA (chapter 2). $\mathrm{O}_{2}$ has also a profound modulatory effect on other vasoactive systems favoring the action of vasoconstrictors (chapter 2) and decreasing the action of vasodilators (chapter 3 and 4)

2. The main vasodilator of the mammalian $\mathrm{DA}, \mathrm{PGE}_{2}$, is a weak relaxant agent of the chicken DA which even stimulates vasoconstrictive receptors (Chapter 4).

3. The chicken DA undergoes a developmental increase in its contractile responsiveness (chapter 2) and a developmental decrease in its responsiveness to several relaxant agonists (chapters 3 and 4).

4. The chicken DA presents morphological and functional heterogeneity along its path between the pulmonary artery and the aorta. Thus, the pulmonary side shows the structure of a muscular artery and responds to $\mathrm{O}_{2}$ with contraction, 
whereas the aortic part shows the morphology of an elastic artery and relaxes in response to $\mathrm{O}_{2}$ (chapter 2). Apart from $\mathrm{O}_{2}$, there is a marked difference between the pulmonary and the aortic side in the responsiveness to contractile (chapter 2) and relaxant agonists (chapters 3 and 4).

5. Moderate changes in extracellular $\mathrm{pH}$ have profound effects on chicken DA tone. Hypercarbic and normocarbic acidosis induced ductal relaxation (chapter $5)$.

6. Chronic hypoxia in ovo did not induce significant remodeling of chicken DA but altered ductal reactivity (chapter 6). 


\section{Acknowledgements}

So I have reached the end of the project, and also the end of this book. I would like to take this opportunity to thank some people that have helped me with the progress of the Thesis and during my stay in the Netherlands.

My supervisors:

Eduardo, my main supervisor for this Thesis. We have had our discussions and arguments about things, but in the end we did a good job and we finished the project. Thank you for all the time and energy that you have put into the project. Also thank you for mending Björn's leg when he was bitten by that dog on our biking excursion around Maastricht. Carlos for your comments and ideas and Luc for supporting the chicken ductus project. Angel, you joined the lab during a time when a lot of things were going on. It was lovely to have you around to discuss problems and finding solutions. You taught me a lot about pharmacology and I deeply appreciate your help with the development of my Thesis.

The department of Pharmacology:

Jo de Mey, your door was always open, for discussion and advice. You always took the time and I really enjoyed our discussions. I want to thank you for your commitment and energy and for creating a positive and creative sphere in the myograph lab.

I would like to thank my colleagues Fazzi and Ger for sharing their room with me. You guys are just lovely, frequently putting a smile on my face, arguing with each other like a married couple. Both of you were always there to help and assist me, answer questions and to keep me company. A special thank you to Fazzi for being such a good guy, and for providing me with all the chicken pictures. Our room had a tendency to turn into a meeting point, with Marijke and Paul quite often coming in for a chat. Marijke, we shared some great laughs in the lab, and to be honest quite often on the cost of others. You are the myograph expert in the lab, and anytime I had a question you were there to help me. 
The chicken group:

It was an interesting experience working with the chicken group (Lilian, Bea, Trudie, Saskia and Rob). I think we learned a lot from each other. Lilian has performed a lot of the histological work for my Thesis. Saskia, you came in as a talented student and worked hard with the experiments. It resulted in more than one article and the first one, on hypoxia, became my $6^{\text {th }}$ chapter. Trudie was only with our group for a short period of time. You were a good friend. I remember when we got together to bake Swedish ginger thins shortly before Christmas. That was really fun. Rob also joined the group, and performed experiments on the ductus. You also worked hard and it resulted in an article that became my $5^{\text {th }}$ chapter in this Thesis. Thank you also for writing the Dutch summary for my Thesis. Thanks to all of you.

I also want to mention Natascha and Tamara, who took care of a lot of the bureaucratic steps for my thesis. Thank you for all your help. Thanks to "Fundación de Investigación Médica Mutua Madrileña” for the financial support.

My Family:

Björn, my best friend, my companion that moved with me to Maastricht. For always being there to support me, and help me through difficult times. Thank you for all the good times that we already have had and for the ones that I'm sure we will have in the future. During our stay in Maastricht, we took the opportunity to visit some special places, among them Luxemburg. In the winter we visited Vianden, with a great castle overlooking the small town. Everything was lit up, and the snow was lying thick. We just had a great time there. In the summer we went to Bourscheid. We spent the days hiking around in the surrounding mountains. With millions of ticks (not so great), and great views. I really hope we will go back there some day.

Nike, you always greeted me with your wagging tail. Just to take you out on a walk, even if I were in a bad mood you lifted my spirit, just by running around being a bit crazy. Our Sunday excursions into the walking area between Maastricht and Cadier en Keer always gave me new energy. We usually started early in the morning, bringing breakfast with us. Even though it wasn't allowed you did get to run around a bit. I miss you like crazy, but I know you have it better now. 
My current distractions, Vessla (our hovawart) and Panda (our really furry cat). Even if you probably didn't help me that much with my Thesis, at least you have distracted me from it.

Thanks to my parents, that even learned how to Skype, to be able to stay in contact with us during our stay in the Netherlands. You have always supported me in my choices.

And Friends:

A very special occasion during our stay in Maastricht was my boyfriends (now husband) 30th birthday, when our friends (Karin, Ola, their daughter Emma, Björn, Jenny, Micke, Karin, Annelie and Fredrik) visited us from Sweden. It was just lovely to have our friends around us, but there is one thing I remember more than anything else. We had just come back from picking them up at the airport and Annelie and Fredrik started unpacking their bags. As they know how it is to be stuck in another country, longing home, they brought us some special gifts, several bags with CHEEZ DOODLES, CHEEZ BALLZ and special Swedish candy. That was just so special. We also had a lovely dinner together all of us, and we got to visit the Casemates (Maastricht's underground maze).

Last but no least, of course, I must thank IKEA. That is a friend you can always trust. It reminds you of Sweden, with Swedish books in the bookshelves, and Swedish food and candy. We used to go there for a visit every now and then, just to feel a bit like home.

During this time I have learned a lot and also realized some things about myself. Among other things I have realized that I really enjoy my home country. 


\title{
C URR I C U L UM VITAE
}

\author{
NAME \\ Pia Anna Elisabet Ågren \\ DATE OF BIRTH August 8, 1979 \\ PLACE OF BIRTH Gårdsby, Sweden
}

EDUCATION

1998-2003 Master in Biology, Linköping University, Sweden Thesis: A descriptive study of behavioural repertoire and frequency of a European lynx family (Lynx lynx) in Zoo.

2003-2005 Master in Applied Biology, Linköping University, Sweden Thesis: Ontogeny of the Vascular Reactivity of the Ductus Arteriosus in the Chicken Embryo.

\section{RESEARCH}

2004-2010 PhD Pharmacology/Vascular biology, Department of Pediatrics, Maastricht University Medical Center (MUMC+), Research Institute Growth and Development (GROW), University of Maastricht, Maastricht, The Netherlands

Title: The Chicken Embryo as a Model for Ductus Arteriosus Developmental Biology

2009-2010 Trainee, Wallenberg Laboratory for Cardiovascular Research, Sahlgrenska Akademy, Göteborg University, Sweden

\section{LIST OF PUBLICATIONS}

Ontogeny of chicken ductus arteriosus response to oxygen and vasoconstrictors. Pia Ågren, Angel L. Cogolludo, Carolina G. A. Kessels, Francisco Pérez-Viscaíno, Jo G. R. De Mey, Carlos E. Blanco and Eduardo Villamor, Am J Physiol Regul Integr Comp Physiol. 2007; 292:485-496.

Developmental changes in endothelium-dependent relaxation of the chicken ductus arteriosus. Pia Ågren, Saskia van der Sterren, Angel L. Cogolludo, Giovanna Frazziano, Jo G. R. De Mey, Carlos E. Blanco and Eduardo Villamor, Journal of Physiology and Pharmacology. 2008; 59(1):55-76.

Developmental changes in the effects of prostaglandin $E_{2}$ in the chicken ductus arteriosus. Pia Ågren, Saskia van der Sterren, Angel 
L. Cogolludo, Carlos E. Blanco and Eduardo Villamor, Journal of Comparative Physiology. 2009 Feb; 179(2):133-43.

Morphological and functional alterations of the ductus arteriosus in a chicken model of hypoxia-induced fetal growth retardation. Saskia van der Sterren, Pia Ågren, Bea Zoer, Carolina L. Kessels, Carlos E. Blanco and Eduardo Villamor, Pediatric Research. 2009 Mar; 65(3):279-84.

Response of chicken ductus arteriosus to hypercarbic and normocarbic acidosis. Rob M. Moonen, Pia Ågren, Angel L. Cogolludo, Francisco Peréz-Viscaíno and Eduardo Villamor, Neonatology. 2009 Dec 10; 98(1):47-56 